\title{
Design and Simulation of a Microturbine Trigeneration System Incorporating Hydraulic Storage and an Inverse Brayton Cycle
}

\author{
Written By \\ Matthew Blieske, B.Eng \\ Carleton University \\ Ottawa, Canada \\ A thesis submitted to the Faculty of Graduate Studies and Research in partial \\ fulfilment of the requirements for the degree of \\ Master of Applied Science \\ Ottawa-Carleton Institute of Mechanical and Aeronautical Engineering \\ Carleton University \\ Ottawa, Canada \\ January 2008
}

(C) Matthew Blieske 2008 


$\begin{array}{ll}\begin{array}{l}\text { Library and } \\ \text { Archives Canada }\end{array} & \begin{array}{l}\text { Bibliothèque et } \\ \text { Archives Canada }\end{array} \\ \begin{array}{l}\text { Published Heritage } \\ \text { Branch }\end{array} & \begin{array}{l}\text { Direction du } \\ \text { Patrimoine de l'édition }\end{array} \\ \begin{array}{l}\text { 395 Wellington Street } \\ \text { Ottawa ON K1A 0N4 } \\ \text { Canada }\end{array} & \begin{array}{l}\text { 395, rue Wellington } \\ \text { Ottawa ON K1A 0N4 } \\ \text { Canada }\end{array}\end{array}$

Your file Votre référence ISBN: 978-0-494-44031-5 Our file Notre référence ISBN: 978-0-494-44031-5

NOTICE:

The author has granted a nonexclusive license allowing Library and Archives Canada to reproduce, publish, archive, preserve, conserve, communicate to the public by telecommunication or on the Internet, loan, distribute and sell theses worldwide, for commercial or noncommercial purposes, in microform, paper, electronic and/or any other formats.

The author retains copyright ownership and moral rights in this thesis. Neither the thesis nor substantial extracts from it may be printed or otherwise reproduced without the author's permission.
AVIS:

L'auteur a accordé une licence non exclusive permettant à la Bibliothèque et Archives Canada de reproduire, publier, archiver, sauvegarder, conserver, transmettre au public par télécommunication ou par l'Internet, prêter, distribuer et vendre des thèses partout dans le monde, à des fins commerciales ou autres, sur support microforme, papier, électronique et/ou autres formats.

L'auteur conserve la propriété du droit d'auteur et des droits moraux qui protège cette thèse. $\mathrm{Ni}$ la thèse ni des extraits substantiels de celle-ci ne doivent être imprimés ou autrement reproduits sans son autorisation.
In compliance with the Canadian Privacy Act some supporting forms may have been removed from this thesis.

While these forms may be included in the document page count, their removal does not represent any loss of content from the thesis.
Conformément à la loi canadienne sur la protection de la vie privée, quelques formulaires secondaires ont été enlevés de cette thèse.

Bien que ces formulaires aient inclus dans la pagination, il n'y aura aucun contenu manquant.

\section{Canada}




\section{Abstract}

Integrated micro-power systems that can provide electricity, heating and cooling (i.e. trigeneration) have the potential to provide greater overall efficiencies than traditional micro-cogeneration power systems with separate cooling devices. With rising grid power rates, small-scale trigeneration has the potential to be economically attractive. The majority of trigeneration systems under development and in use utilize expensive components such as absorption chillers suitable for medium to large-scale trigeneration, which are not economically suitable for small-scale applications.

To bring the economic benefit of trigeneration to small-scale users without incorporating expensive components, an inverted Brayton cycle (IBC) is employed which makes use of the expander section already present in a microturbine. A hydraulic accumulator, indirectly charged by a microturbine, provides pressurized air, which is passed through the expander section of the microturbine and cooled due to expansion; simultaneously providing power and cooling flow. As the microturbine is indirectly fired, the flow passing through the engine or IBC can be directly vented into the household, eliminating the need for additional heat exchangers. 
A study was conducted to assess the thermodynamic and economic performance of the proposed system compared to systems currently used, such as individual generation provided by an air conditioner, high efficiency natural gas furnace, and grid power. Simulations were run for a full year based on actual external temperature, electrical, and thermal loads for a single family detached dwelling located in Winnipeg, Canada. The output of the microturbine studied is $10 \mathrm{kWe}$, suitable for a domestic household, however the system is easily scaled for larger commercial applications. The majority of the components in the system studied are off-the-shelf products. Performance data was generated using MATLAB ${ }^{\text {TM }}$ while economic performance was determined with time-based simulations conducted using SIMULINK ${ }^{\mathrm{m}}$. The system allows energy islanding by providing for all household energy needs throughout the year, however integration with a power grid is optional. It was found that the operating costs for the proposed trigeneration system in an energy islanding mode of operation were equivalent to or less than individual generation (air conditioning unit, natural gas furnace, grid power) during heating modes of operation, and more expensive for cooling modes of operation. The yearly energy cost for the trigeneration system exceeded the total cost of running individual systems by 30 to 48 percent, however there remains much room for improvement to the trigeneration concept. All economic data was based upon fair market energy prices found in central Canada. 


\section{Acknowledgments}

Writing this thesis has been the highlight of my academic career, and has been the most challenging, exciting, and rewarding experience of my life. I could not have achieved the results I did without the guidance and tutelage of my cosupervisors Dr. Donald Gauthier and Dr. Xiao Huang. My gratitude to you both for helping to improve me as an engineer, researcher, and writer.

Special thanks to Marianne Manning of the National Research Council Canadian Centre for Housing Technology in Ottawa, Ontario for providing access to measured thermal and electrical load data. Gratitude is expressed towards Dr. Ian Beausoleil-Morrison, Associate Professor and Canada Research Chair at Carleton University for providing access to ESP-r source code. Financial support was graciously provided by Dr. John Rogers of Innovative Materials Technology (IMT).

Finally, I must thank my wife who selflessly shelved her life in Winnipeg to set up shop in a strange and new land to allow me to pursue my dreams. Any struggles overcome while completing this work were far surpassed by the trials she was forced to endure moving away from family and a career. I couldn't have done this without you. 


\section{Table of Contents}

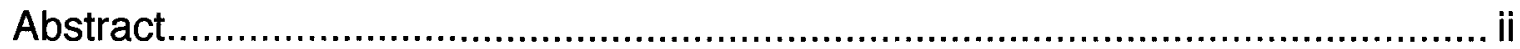

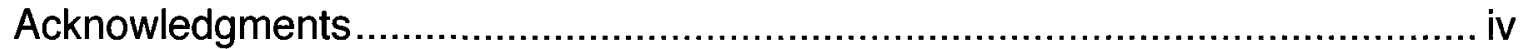

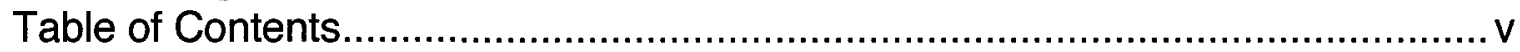

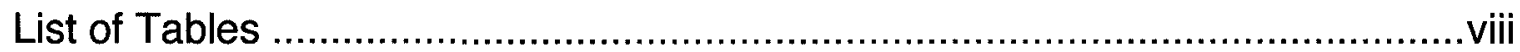

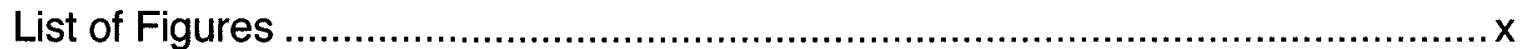

Nomenclature

Acronyms and abbreviations............................................................ $\mathrm{xx}$

Chapter 1 Introduction .....................................................................................1

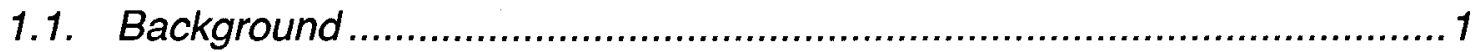

1.2. DG, CHP, and CHCP market outlook ............................................ 4

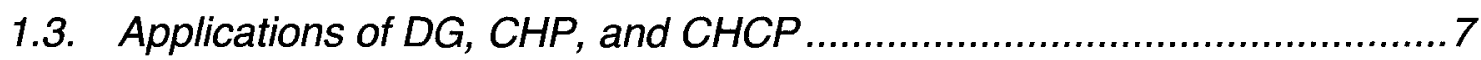

1.3.1. Emergency power.................................................................. 7

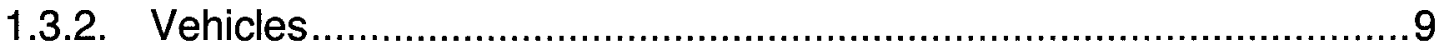

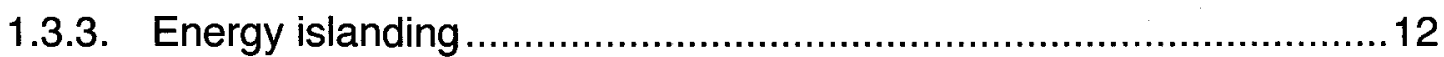

1.3.4. Peak shaving ................................................................... 14

1.3.5. Process heat and cooling ....................................................... 15

1.4. Small-scale CHP and CHCP technology ........................................ 16

1.4.1. Reciprocating engines ...................................................... 16

1.4.2. Stirling engines ................................................................. 19

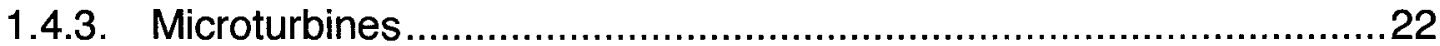

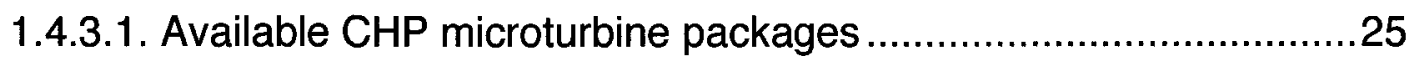

1.4.3.2. High-speed generators......................................................26

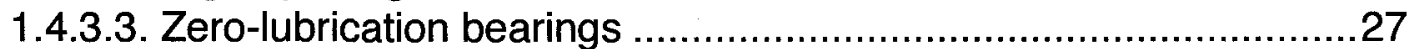

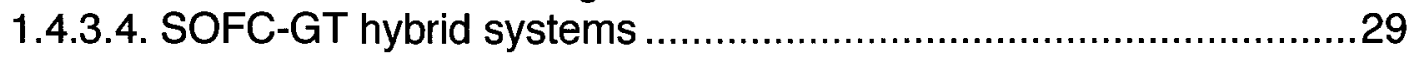

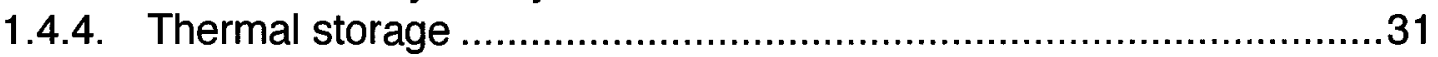

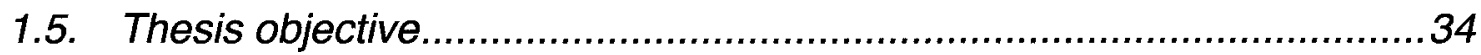

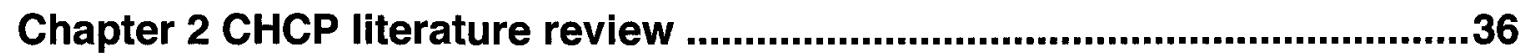

2.1. The motivation behind developing CHCP ...................................36

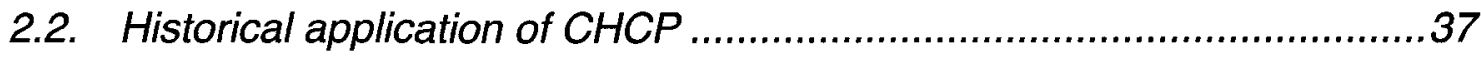

2.2.1. Typical cycle profile of current commercial CHCP ........................ 38

2.2.1.1. Suitability of VCR and ACR refrigeration for small-scale CHCP...40

2.2.2. Production CHCP packages .......................................... 45

2.3. Experimental small-scale CHCP systems .....................................45

2.4. Simulated small-scale CHCP systems .........................................48 
2.5. Hydraulic storage and the inverse Brayton cycle.

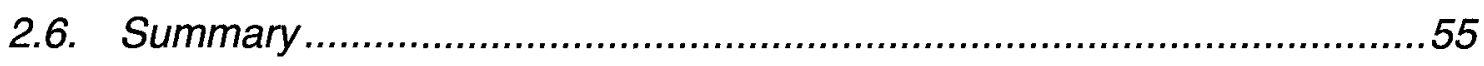

Chapter 3 Description of Model and Simulation .......................................57

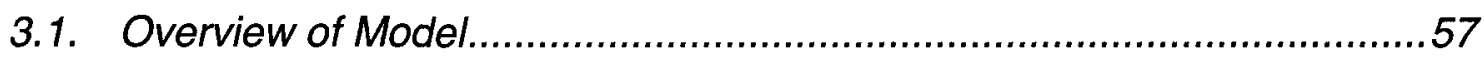

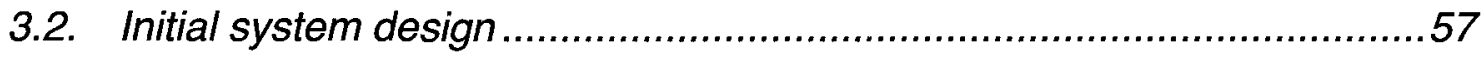

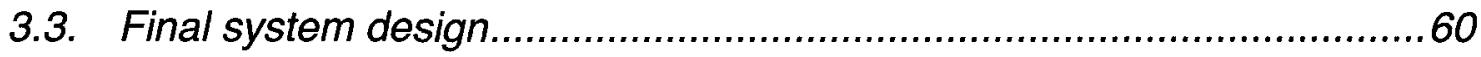

3.3.1. Heat exchanger network (HEN) ...............................................67

3.3.1.1. On-design operation (maximum \#2 $\mathrm{Hx}$ temperature operation) ....67

3.3.1.2. Off-design operation (EIT specified) .........................................73

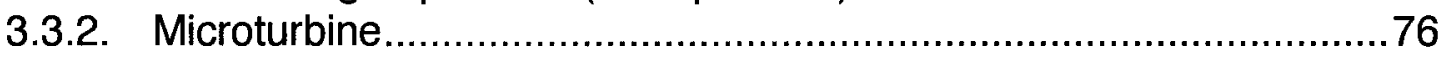

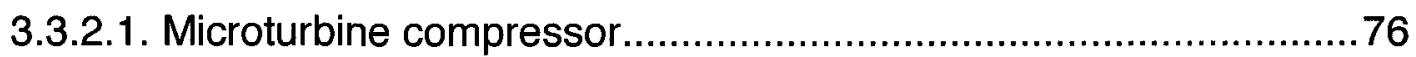

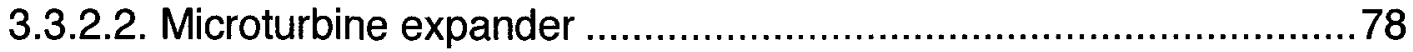

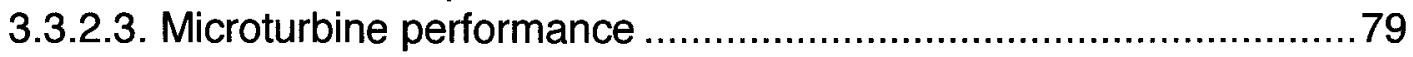

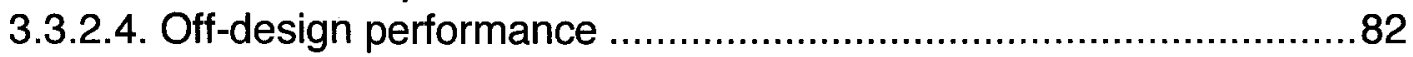

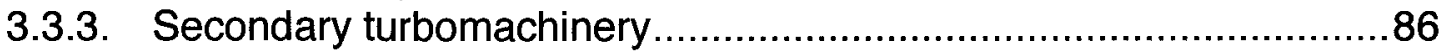

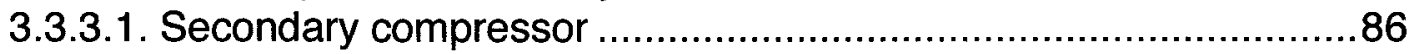

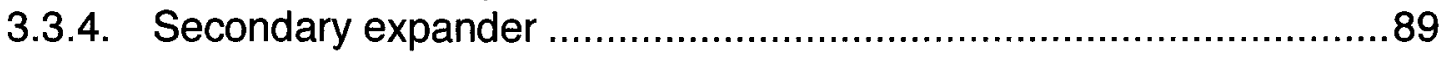

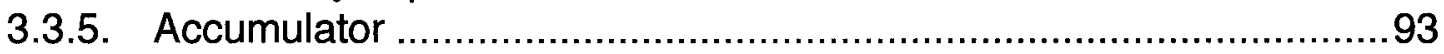

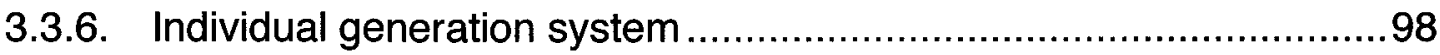

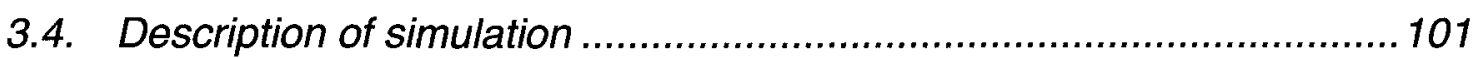

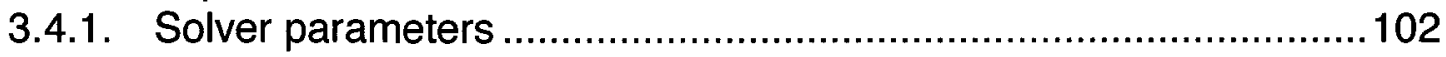

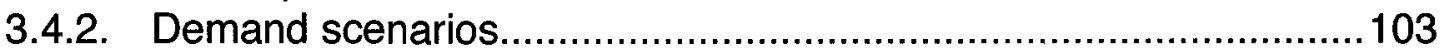

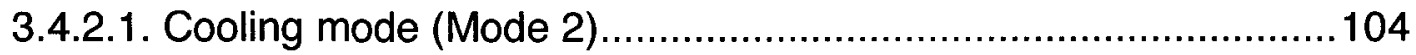

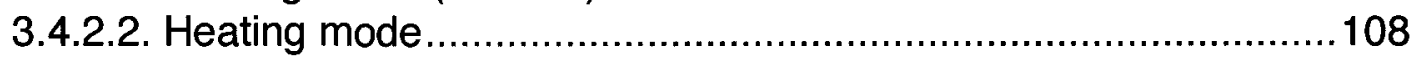

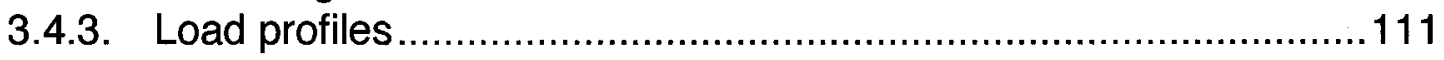

Chapter 4 Simulation Results and Sensitivity Studies...............................115

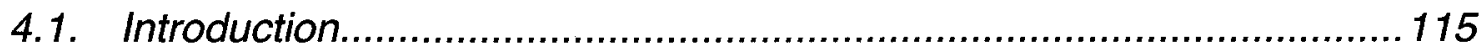

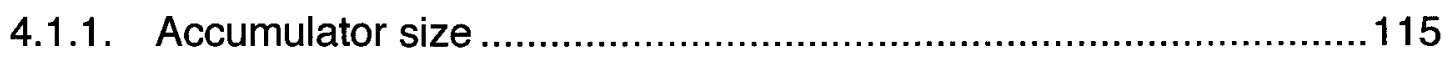

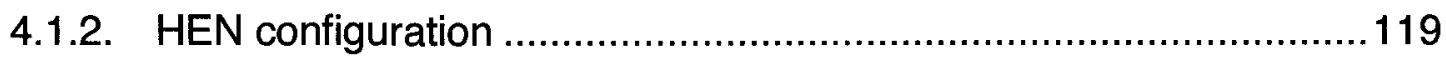

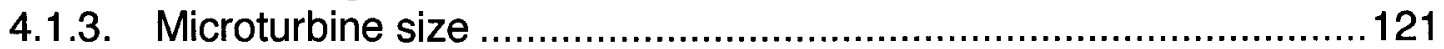

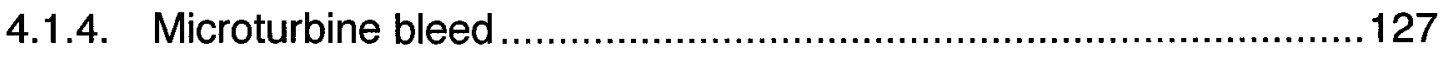

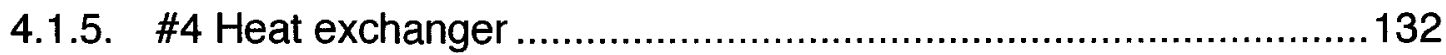

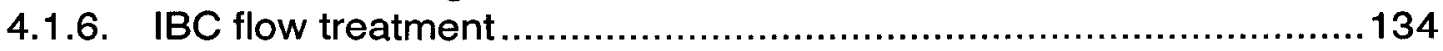

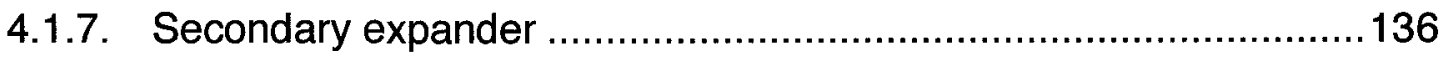

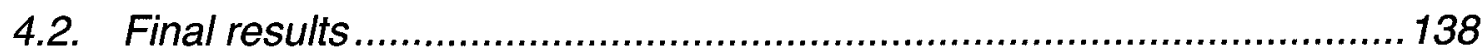

4.2.1. Market variation study ....................................................... 144

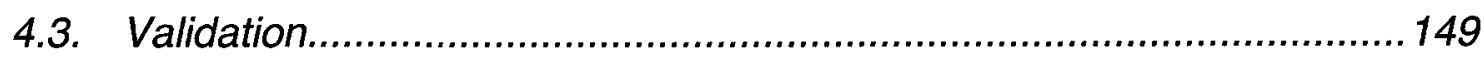


Chapter 5 Component Selection and Conceptual Design 150

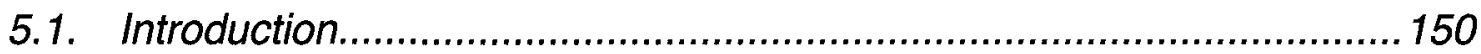

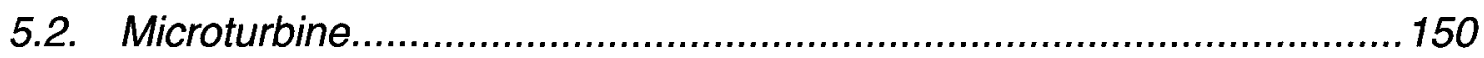

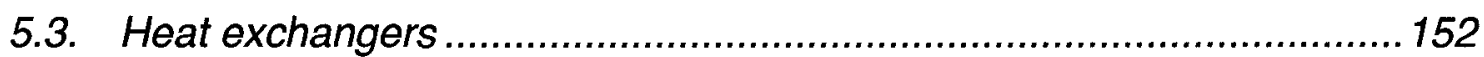

5.3.1. High-temperature heat exchanger $(\# 2 \mathrm{Hx})$................................152

5.3.2. Low-temperature heat exchangers (\#1 and \#3 Hxs)......................154

5.3.2.1. Brazed plate heat exchanger ...............................................156

5.3.2.2. Shell and tube heat exchanger.............................................157

5.3.2.3. Plate fin heat exchanger ...................................................... 161

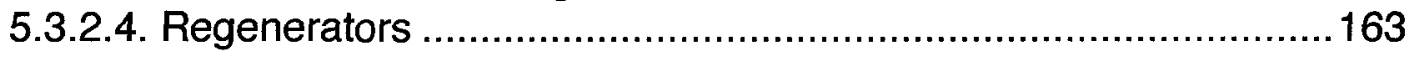

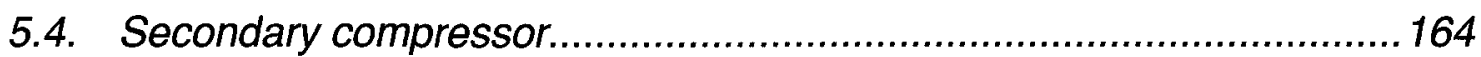

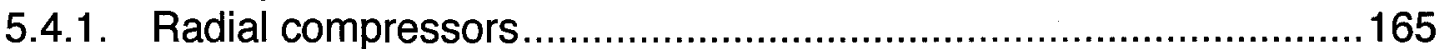

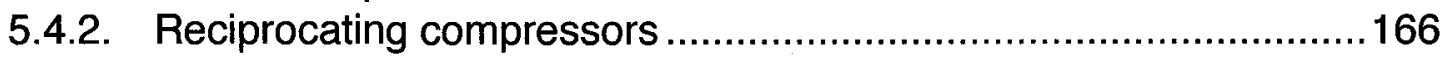

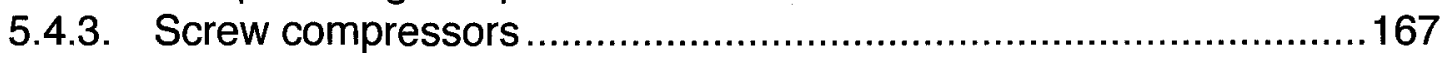

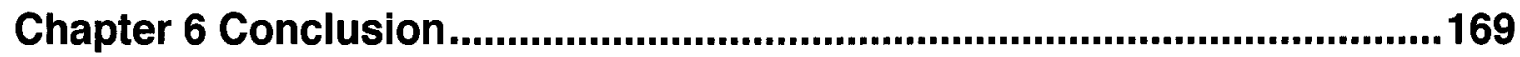

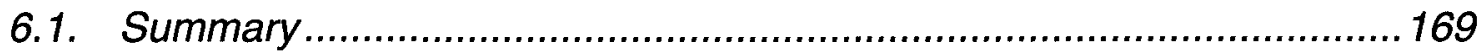

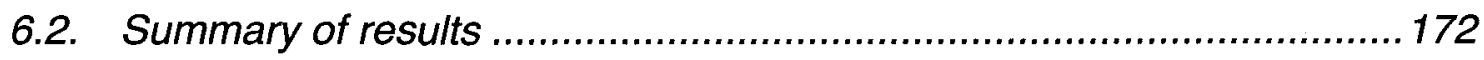

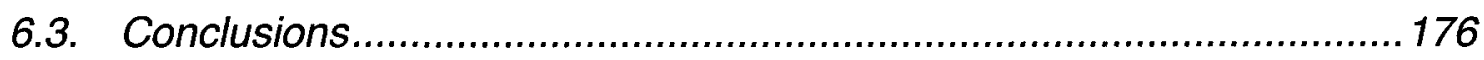

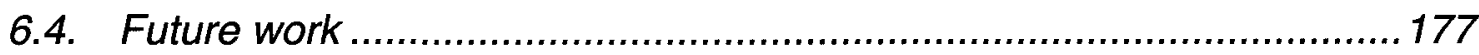

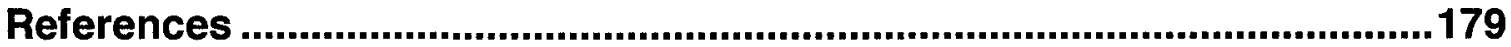

Appendix A Experimental small-scale CHCP apparatuses...........................189

Appendix B ESP-r profiles....................................................................191

Appendix C Garrett GT22 performance maps ........................................195

Appendix D Capstone microturbine standard maintenance schedule ............197

Appendix E Component Performance Validation .......................................198

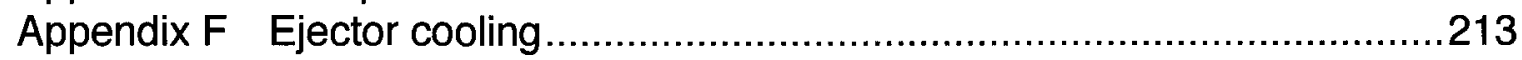




\section{List of Tables}

\section{Chapter 1}

Table 1-1: Comparison of existing CHP to potential CHP supplied in the United States. 7

Table 1-2: Average downtime costs for selected industries 8

Table 1-3:Canadian space heating energy consumption statistics, presented in petaJoules

Table 1-4: Typical maintenance costs for prime mover CHP and CHCP technologies

Table 1-5: Quantitative comparison of potential small-scale DG/CHP/CHCP powerplants (less than $50 \mathrm{~kW}$ ).

\section{Chapter 2}

Table 2-1: Performance data for several experimental small-scale CHCP systems at ISO conditions 46

Table 2-2: Performance data for simulated small-scale CHCP systems .49

\section{Chapter 4}

Table 4-1: Effect of increasing maximum \#2 $\mathrm{Hx}$ temperature $\left(\mathrm{T}_{23}\right)$ on microturbine electrical efficiency in Mode 2.

Table 4-2: Projected economic performance of the trigeneration and independent generation systems

Table 4-3: Yearly economic performance of the trigeneration and independent generation systems for international markets.

\section{Chapter 5}

Table 5-1: Summary of specifications for commercially available microturbines

Table 5-2: Heat exchanger operating temperatures for an OAT of $288 \mathrm{~K}$ 155 


\section{Appendix $E$}

Table E-1: Comparison of design point performance of Mode 1 at standard atmospheric conditions for several similar microturbine IFGT cycles..........206

Table E-2: Comparison of design point performance of Mode 2 at standard atmospheric conditions for several similar microturbine IFGT cycles..........207 


\section{List of Figures}

\section{Chapter 1}

Figure 1-1: Cycle diagram for typical industrial CHCP based on a gas turbine and an absorption chiller cycle... 2

Figure 1-2: Cycle diagram for a typical industrial CHCP based on a gas turbine and a vapour compression refrigeration system. 2

Figure 1-3: Specific capital costs of medium to large cogeneration systems ........5

Figure 1-4: Capacity of commercial CHP by application in the United States (2000) 6

Figure 1-5: IHI Dynajet 2.6 microturbine powered portable generator...................9

Figure 1-6: Honeywell APU installed in a B737...............................................10

Figure 1-7: Existing reciprocating engine CHP in the United States (2002).......18

Figure 1-8: Stirling engine produced by STM power ......................................20

Figure 1-9: Cutaway view of a microturbine ...................................................23

Figure 1-10: High speed generator permanent magnet rotor shaft ...................27

Figure 1-11: Schematic of a magnetic bearing............................................28

Figure 1-12: Schematic of a SOFC-GT hybrid system ...................................30

Figure 1-13: Example of using below ground thermal storage ..........................32

Figure 1-14: Example of integrated thermal storage ......................................33

\section{Chapter 2}

Figure 2-1: Typical layout for commercial CHCP utilizing diesel or GT powerplants. 39

Figure 2-2: Schematic of a double-effect $\mathrm{LiBr}$ absorption chiller adapted from ...41

Figure 2-3: Specific capital costs for absorption chillers with curve fits for large

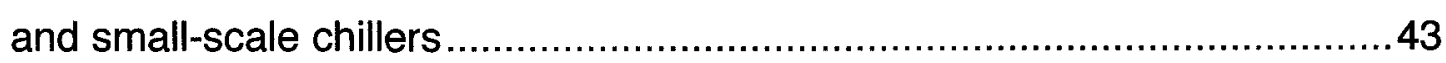

Figure 2-4: Specific maintenance costs for absorption chillers .......................44 
Figure 2-5: Schematic of an IBC refrigeration system designed for use in road

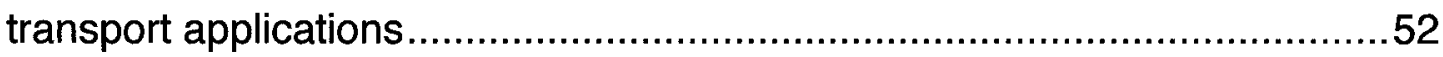

Figure 2-6: IBC applied to building heating and cooling ...............................54

\section{Chapter 3}

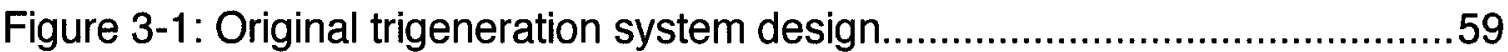

Figure 3-2: Schematic of trigeneration system in heating mode (Mode 1) .........63

Figure 3-3: Schematic of trigeneration system in cooling mode (Mode 2)..........64

Figure 3-4: T-s diagram for the IBC in heating mode .....................................65

Figure 3-5: T-s diagram for the IBC in cooling mode ....................................66

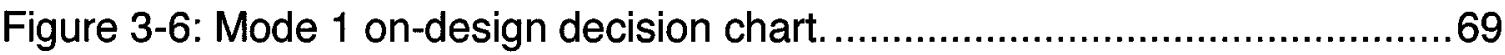

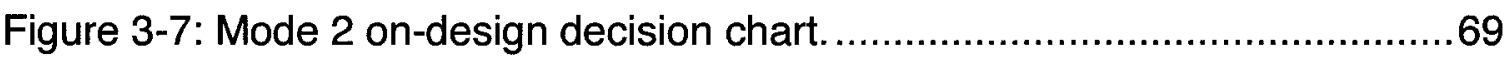

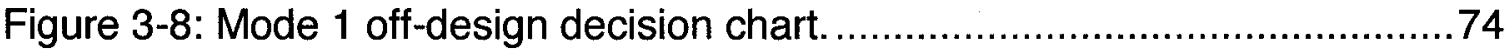

Figure 3-9: Mode 2 off-design decision chart.............................................. 74

Figure 3-10: Microturbine compressor decision chart. ....................................77

Figure 3-11: Microturbine expander decision chart.........................................79

Figure 3-12: Microturbine performance decision chart...................................81

Figure 3-13: Microturbine off-design decision chart. ......................................83

Figure 3-14: Off-design performance of the microturbine compressor and expander normalized by design point values .............................................84

Figure 3-15: Secondary compressor decision chart......................................87

Figure 3-16: Isentropic efficiency as a function of power input for the secondary

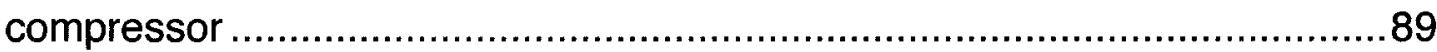

Figure 3-17: Secondary expander decision chart........................................91

Figure 3-18: Secondary expander load following decision tree .........................92

Figure 3-19: Off-design operating line for secondary expander. ........................93

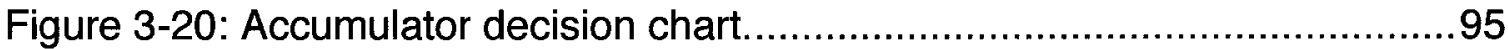

Figure 3-21: Independent generation decision chart......................................100

Figure 3-22: Process logic chart for cooling control ......................................106 
Figure 3-23: Flow chart for heating control logic

Figure 3-24: Geometry used in ESP-r to model thermal loads.

Figure 3-25: Sample of loads estimated using ESP-r.

\section{Chapter 4}

Figure 4-1: Accumulator behaviour in Mode 1 for low load conditions 116

Figure 4-2: Accumulator behaviour in Mode 1 for high-load conditions.

Figure 4-3: Accumulator behaviour in Mode 2 for low-load conditions.

Figure 4-4: Accumulator behaviour in Mode 2 for high-load conditions.

Figure 4-5: Comparison of thermal efficiency and SFC performance from full power to synchronous idle for HEN Mode 1 and Mode 2 configurations at standard ambient conditions of $101.325 \mathrm{kPa}$ and $288 \mathrm{~K}$

Figure 4-6: Effect of microturbine size on system behaviour. Operating costs, accumulator temperature, and pressure compared for three different microturbine sizes while satisfying a heating load (Mode 1).

Figure 4-7: Household temperature response for three different microturbine sizes while satisfying a heating load (Mode 1).

Figure 4-8: Effect of microturbine size on system behaviour. Operational costs including accumulator temperature and pressure are compared for three different microturbine sizes while satisfying a cooling load (Mode 2). 125

Figure 4-9: Household temperature response for three different microturbine sizes while satisfying a cooling load (Mode 2). 126

Figure 4-10: Fuel costs for Mode 1 (heating load), comparison is made between microturbine operation with compressor bleed versus using a secondary compressor. 128

Figure 4-11: Household setpoint deviation using microturbine bleed flow to charge the accumulator while satisfying a cooling load. 129

Figure 4-12: Variation in accumulator charging flows with household electrical load for various ambient temperatures 
Figure 4-13: Fuel and purchased grid power costs for trigeneration operation with and without \#4 $\mathrm{Hx}$ in Mode 1 and Mode 2 modes of operation.

Figure 4-14: Trigeneration system economic performance with and without increasing EIT

Figure 4-15: Ratio of electrical to thermal output of the IBC expander at maximum

HEN firing temperature $T_{23}=1200 \mathrm{~K}(\mathrm{EIT}=1163 \mathrm{~K})$.

Figure 4-16: Yearly consumption of electricity and natural gas for the

trigeneration and independent generation systems. 140

Figure 4-17: Monthly operating cost comparison between the trigeneration and independent generation systems. 141

Figure 4-18: Yearly cost comparison between the trigeneration and independent generation systems 145

Figure 4-19: Historical and projected household natural gas and electricity prices 146

\section{Chapter 5}

Figure 5-1: Special design for microturbine powertrain 152

Figure 5-2: Directly fired heat exchanger fabricated by Selas Fluid for the oil and

gas industry. 154

Figure 5-3: Illustration of alternating fluid pattern for a three fluid BPHE. 156

Figure 5-4: Graphical summary of TEMA fabrication specifications 159

Figure 5-5: Cross section cutaway of a straight tube and U-tube STHE.... 160

Figure 5-6: Cutaway view of a PFHE in cross-flow and counter-flow 162

Figure 5-7: A rotating matrix regenerator 164

Figure 5-8: Radial compressor (foreground) and axial turbine from a compression ignition turbocharger 165

Figure 5-9: Cutaway view of a screw compressor used in a high-performance supercharger 168 


\section{Appendices}

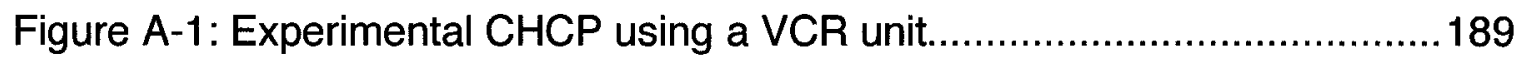

Figure A-2: Experimental CHCP using an ACR unit....................................190

Figure A-3: Experimental CHCP using an ACR unit.....................................190

Figure B-4: Typical Canadian ground temperature profile imposed on exterior of

ground surface of 1 st floor

Figure B-5: Occupant driven gains for 1st floor of ESP-r model......................192

Figure B-6: Occupant driven gains for 2nd floor of ESP-r model .....................192

Figure B-7: Lighting gains for 1st floor of ESP-r model ..................................193

Figure B-8: Lighting gains for 2nd floor of ESP-r model ...............................193

Figure B-9: Equipment gains for 1st floor of ESP-r model..............................194

Figure B-10: Lighting gains for 2nd floor of ESP-r model ............................. 194

Figure C-11: Compressor map for the Garrett GT22 series turbocharger..........195

Figure C-12: Expander map for the Garrett GT22 series turbocharger ............196

Figure D-1: Excerpt from Capstone Turbines scheduled maintenance work

instructions for the $60 \mathrm{kWe} \mathrm{C60} \mathrm{and} \mathrm{C65} \mathrm{models} \mathrm{......................................197}$

Figure E-1: Experimental accumulator apparatus .......................................198

Figure E-2: Comparison of modelled accumulator $(n=1.2)$ and experimental

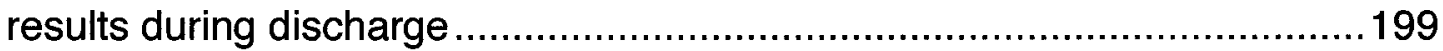

Figure E-3: Comparison of modelled accumulator $(n=1)$ and experimental results

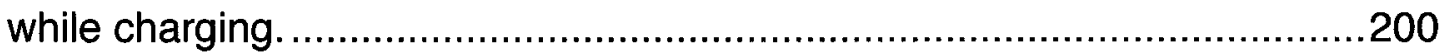

Figure E-4: The effect of heat transfer on modelled accumulator behaviour with zero flow. 201

Figure E-5: Schematic of the bio-IFGT system fuelled by low heating value bio-

fuels 204

Figure E-6: Schematic of the IFGT-Rec-Rec system 208

Figure E-7: Comparison of output from GASTURB ${ }^{\text {TM }}$ and the in-house model for

Mode 1 for various ambient temperatures. 209 
Figure E-8: Comparison of output from GASTURB ${ }^{\mathrm{TM}}$ and the in-house model in Mode 2 for various ambient temperatures..............................................210 Figure E-9: Power as a function of RPM for the VMXa037R screw compressor at ISO standard atmosphere, digitized from sample maps [E.4] ...................211

Figure E-10: Flow rate as a function of RPM for the VMXa037R screw compressor at ISO standard atmosphere, digitized from sample maps......212 Figure E-11: Isentropic efficiency curves for lines of constant pressure rise for the VMXa037R compressor ....................................................................212

Figure F-1: Schematic of an ejector cooling cycle as part of a CHCP system ..213 Figure F-2: Cross-section of an ejector. 214 


\section{Nomenclature}
$A_{c y l}$
surface area of cylindrical portion of accumulator
$A_{s p}$
surface area of spherical portion of accumulator
COP
Coefficient of Performance
$C O P_{n o m} \quad$ Coefficient of Performance at ARI test conditions
$C_{p a}$
specific heat of air
$\bar{h}$
accumulator total free convective heat transfer coefficient
$h_{C, \text { in }}$
heat exchanger cold stream in
$h_{C, \text { out }}$
heat exchanger cold stream out
$\bar{h}_{c y l}$
heat transfer coefficient for cylindrical portion of accumulator
$h_{h}$
household ambient enthalpy
$h_{H, i n}$
heat exchanger hot stream in
$h_{H, \text { out }} \quad$ heat exchanger cold stream out
$h_{\text {in }} \quad$ accumulator inlet enthalpy
$h_{\text {out }}$
accumulator outlet enthalpy
$\bar{h}_{s p}$
heat transfer coefficient for spherical portion of accumulator
$\dot{m}$
microturbine mass flow 


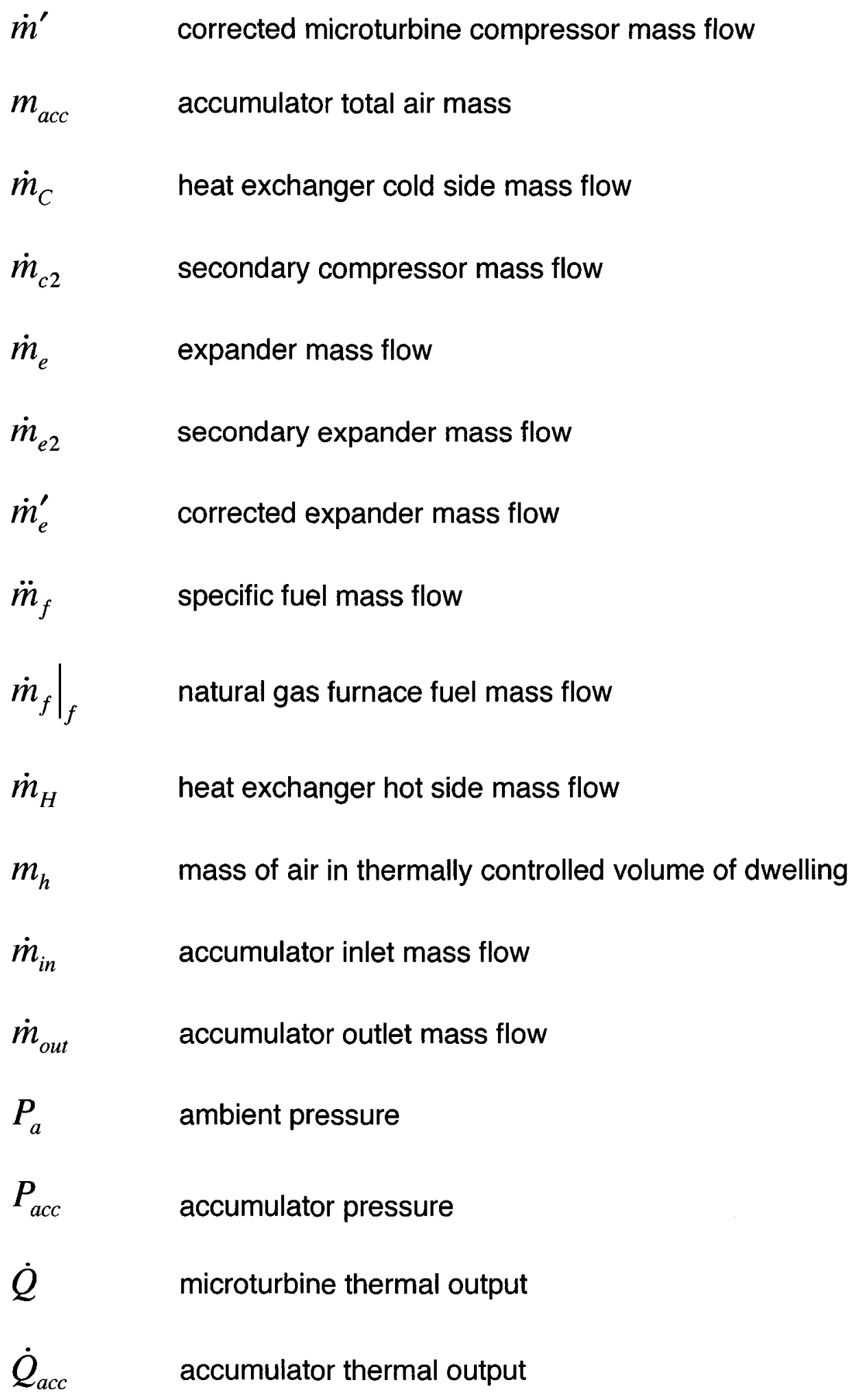


$\dot{Q}_{e 2} \quad$ secondary expander thermal output

$\dot{Q}_{h} \quad$ household thermal load

$\dot{Q}_{a c c}^{\prime} \quad$ accumulator heat loss

$R \quad$ universal gas constant

$T_{a} \quad$ outside air temperature

$T_{a c c} \quad$ accumulator bulk fluid temperature

$T_{\text {ground }} \quad$ ground temperature

$T_{\text {in }} \quad$ \#4 Hx inlet temperature

$T_{\max } \quad$ maximum \#2 $\mathrm{Hx}$ operating temperature

$T_{\text {nom }} \quad$ ambient temperature at ARI test conditions

$T_{\text {out }} \quad$ \#4 Hx exit temperature

$T_{s} \quad$ accumulator external surface temperature

$T_{\infty} \quad$ household ambient temperature

$u_{1} \quad$ control volume internal energy at previous timestep

$u_{2} \quad$ control volume internal energy at current timestep

$V \quad$ accumulator volume

$\dot{V} \quad$ secondary compressor volumetric flow rate

$\dot{W} \quad$ microturbine electrical output 


$\begin{array}{ll}\dot{W}_{a c} & \text { air conditioner work input } \\ \dot{W}_{c 2} & \text { secondary compressor electrical input } \\ \dot{W}_{e 2} & \text { secondary expander electrical output } \\ \dot{W}_{h} & \text { household electrical load } \\ \Delta P_{h x} & \text { heat exchanger pressure loss } \\ \varepsilon & \text { HEN heat exchanger effectiveness } \\ \varepsilon_{4} & \text { \#4 Hx effectiveness } \\ \eta_{c} & \text { compressor isentropic efficiency } \\ \eta_{c 2} & \text { secondary compressor isentropic efficiency } \\ \eta_{c o m b} & \text { combustion efficiency } \\ \eta_{f} & \text { natural gas furnace efficiency } \\ \eta_{m} & \text { mechanical efficiency } \\ \eta_{e} & \text { expander isentropic efficiency } \\ \eta_{e 2} & \text { expander isentropic efficiency }\end{array}$




\section{Acronyms and abbreviations}

ACR

APU

ARI

BPHE

CAD

CAES

$\mathrm{CHCP}$

CHP

Cogen

COP

CPR

DG

EPR

FOD

GHG

GT

HEN

HRSG

$\mathrm{Hx}$

IBC
Absorption Chiller Refrigeration

Auxiliary Power Unit

Air-Conditioning and Refrigeration Institute

Brazed Plate Heat Exchanger

Canadian funds

Compressed Air Energy Storage

Combined Heat Cooling and Power

Combined Heat and Power

Cogeneration

Coefficient of Performance

Compressor Pressure Ratio

Distributed Generation

Expander Pressure Ratio

Foreign Object Damage

Greenhouse gases

Gas Turbine

Heat Exchanger Network

Heat Recovery Steam Generator

Heat exchanger

Inverse Brayton Cycle

$\mathbf{X X}$ 
Internal Combustion Engine

Indirectly Fired Gas Turbine

ISO

International Standards Organization

kWe

kilowatts electrical power output

$\mathrm{kWt}$

kilowatts thermal output

LHV

Lower Heating Value

$\mathrm{LiBr}$

lithium bromide

MCFC

Molten Carbonate Fuel Cell

MWe

megawatt electrical power output

PFHE

Plate fin Heat Exchanger

PR

Pressure ratio

RSI

R-value Système International

SMMT

Setpoint Min-to-Max Time

SOFC

Solid Oxide Fuel Cell

SOFC-GT

Solid Oxide Fuel Cell - Gas Turbine

STHE

Shell and Tube Heat Exchanger

STP

Standard Temperature and Pressure

TELR

Thermal-to-Electrical Load Ratio

TIT

Turbine (Expander) Inlet Temperature

Trigen

Trigeneration

UPS

Uninterruptible Power Supply 
VCR

Vapour Compression Refrigerator

xxii 


\section{Chapter 1}

\section{Introduction}

\subsection{Background}

Often interesting and useful technologies are never fully explored due to unfavourable market conditions. This was especially true for energy conversion innovation, as the cost of improvements to cycle efficiencies had to compete with long payback periods due to low energy prices. This has changed with recent increases in fuel prices and projected shortages of natural gas in the near future. Value-added technologies such as cogeneration that offer multiple energy products have received greater attention and acceptance through validation and operation in industrial environments. Improvements to energy conversion efficiencies were initially the concern of large businesses, however these concepts have drawn the interest of small-scale users as well. There is an interesting opportunity to bring value-added energy solutions to the general consumer, one such technology that shows promise is trigeneration (also known as trigen or combined heat, cooling, and power (CHCP)). Typical trigeneration systems currently found in industry use either a vapour compression cycle or an absorption chiller (ACR) [1.1][1.22][1.45], as illustrated in Figure 1-1 and Figure 1-2. As such systems require installation of a refrigeration unit in addition to a heat recovery steam generator (HRSG), the specific capital cost requirements 
cannot be justified for small-scale generation.

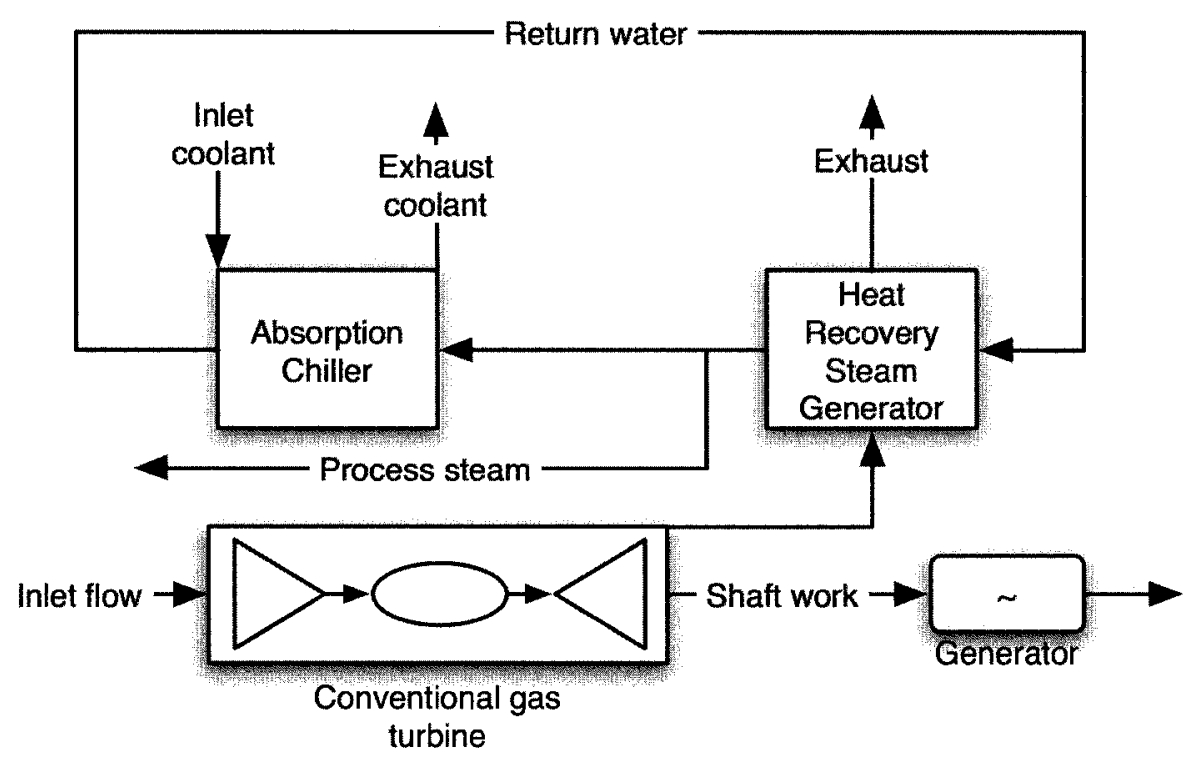

Figure 1-1: Cycle diagram for typical industrial CHCP based on a gas turbine and an absorption chiller cycle

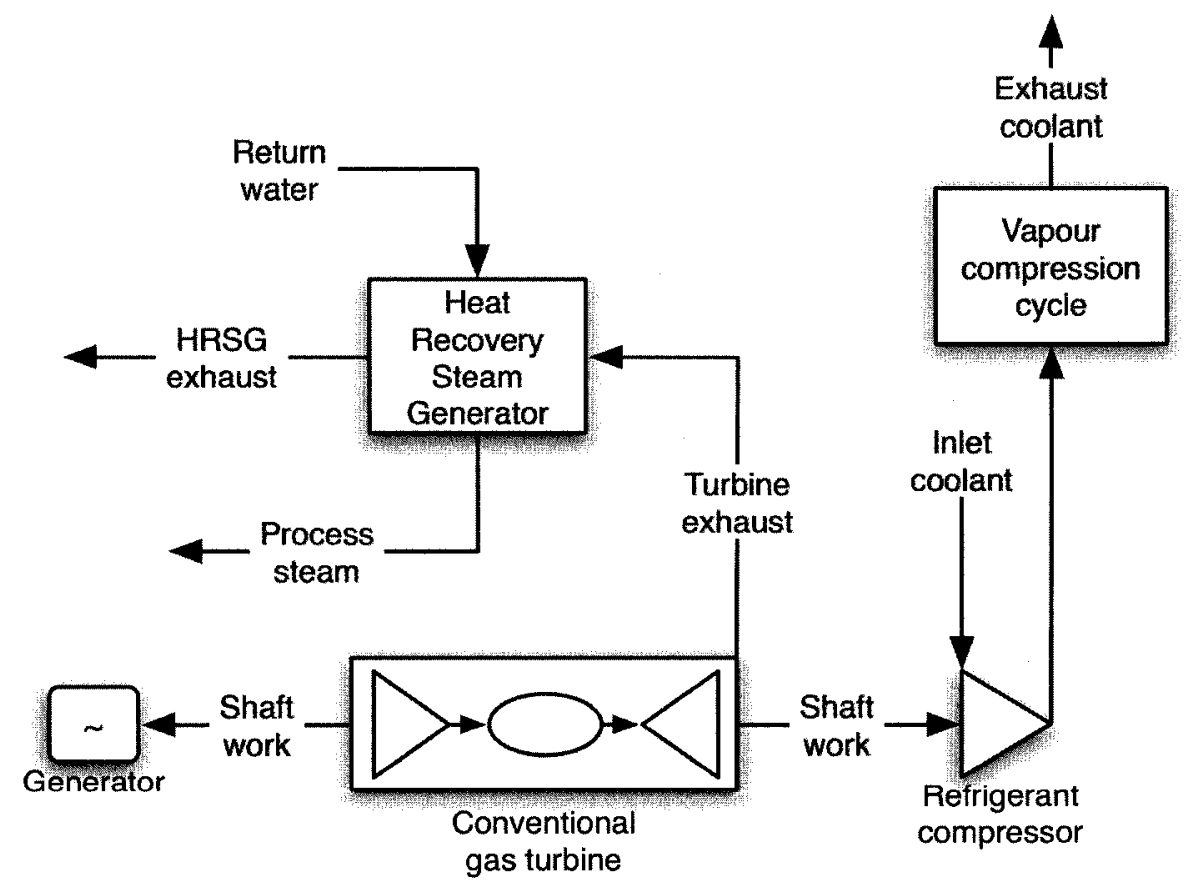

Figure 1-2: Cycle diagram for a typical industrial CHCP based on a gas turbine and a vapour compression refrigeration system. 
To introduce trigeneration to the small-scale consumer, a cycle that eliminates the need for expensive subsystems is required. Another key factor contributing to an increasing interest in distributed generation (DG), cogeneration and trigeneration ( $\mathrm{CHP}$ and $\mathrm{CHCP}$ ) for the small-scale consumer is the unreliable nature of many power grid systems. As power utilities in major urban centres such as Southern California and the Eastern United States seaboard continue to operate close to grid capacity, brownouts and blackouts will most likely become more frequent. A number of companies with sensitive financial and identity data such as CitiBank and JP Morgan have already installed emergency backup power systems [1.30]. However for a small-scale consumer, the overhead involved in purchasing and operating a backup power system is often too high. Combining power generation with cooling and/or heating load production is most likely the only way such a system can be economically attractive to small-scale customers.

Increasing demand for legislation focused on reducing greenhouse gases has resulted in favourable environments for $\mathrm{DG}$ and $\mathrm{CHP}$ in many regions nations around the world. California, Texas and most European countries have created cash incentives for cogen systems that demonstrate a reduction in controlled emissions over conventional energy systems, and meet target thermal efficiencies [1.4]. By rewarding efficient cogen systems with cash incentives, 
small-scale DG becomes more economically attractive. While legislation does not cover trigeneration systems at present, it is anticipated this will change as trigen market penetration increases.

\subsection{DG, CHP, and CHCP market outlook}

In North America, power is provided by a few utilities that, in many cases, enjoy regional monopolies. This proves to be a significant deterrent for distributed power, as electric utilities have traditionally made it hard or impossible for excess DG power to be sold back to the grid. Looming shortfalls in grid power supply in major urban centres along the North American coasts motivated local governments to put pressure on major utilities to begin creating favourable environment for distributed power generation [1.31]. In addition to reducing load on the main grid, it has been suggested that DG has the potential to not only provide stability via decentralization, but to improve power quality and transmission efficiency [1.5]. With regulatory roadblocks falling away, and current micro-generation technology sufficiently developed for commercial and industrial implementation, it is anticipated small-scale DG, CHP, and CHCP will achieve greater market penetration.

The key to achieving small-scale DG, CHP, or CHCP penetration is in driving capital investment costs down. As the major focus of generation efforts has been 
in the megawatt (MW) scale, specific capital costs rise as the output decreases; shown in Figure 1-3. Achieving a small-scale DG, CHP, or CHCP system that has reasonable specific capital costs cannot be accomplished by simply scaling down large engine technology. A technically and economically successful system will be designed from the ground up, specifically targeting the less than $50 \mathrm{kWe}$ range. Distributed $\mathrm{CHP}$ plants in this range have received commercial acceptance in California and Japan; evident by the existence of significant contributors to the microturbine CHP market such as Capstone Turbines in Chatsworth, CA and Ebara Corp. in Japan. However, rising fuel costs compared to minor electric rate increases have prevented significant penetration of CHP and $\mathrm{CHCP}$ technologies into the less than $50 \mathrm{~kW}$ market.

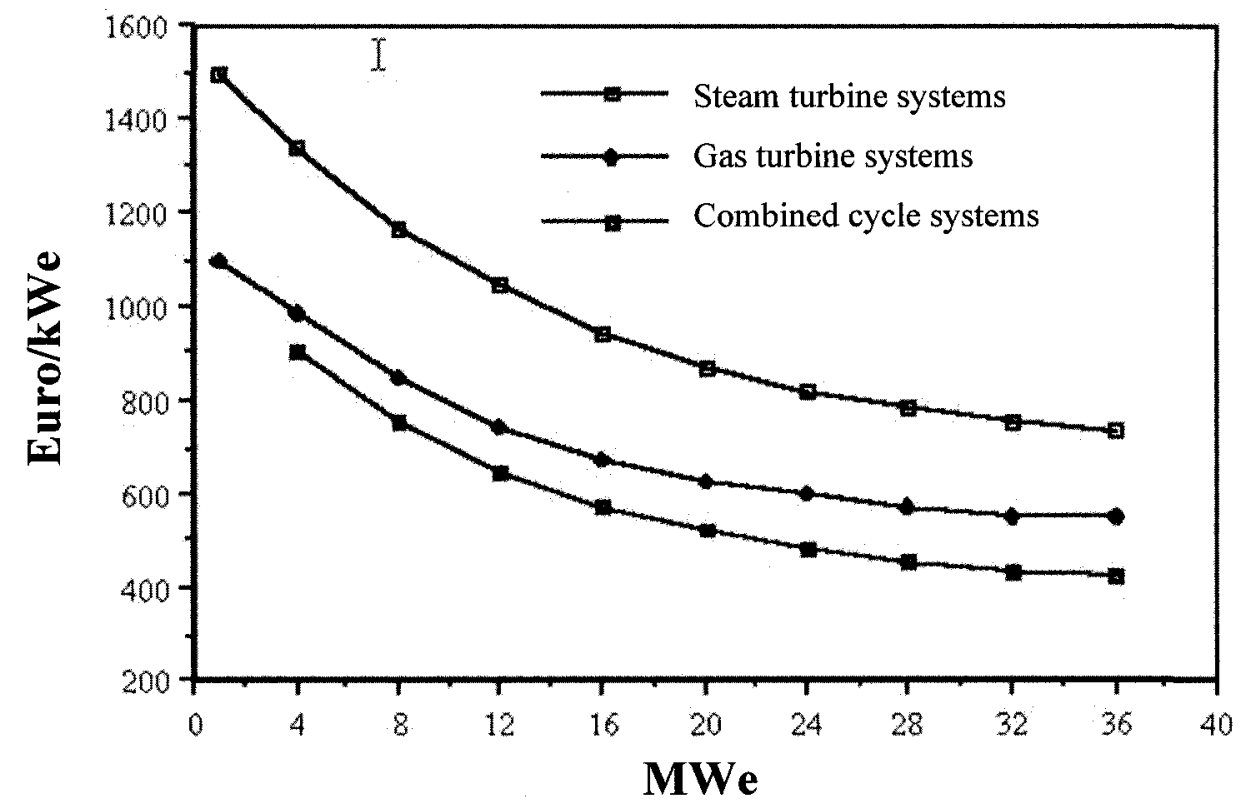

Figure 1-3: Specific capital costs of medium to large cogeneration systems [1.7] 


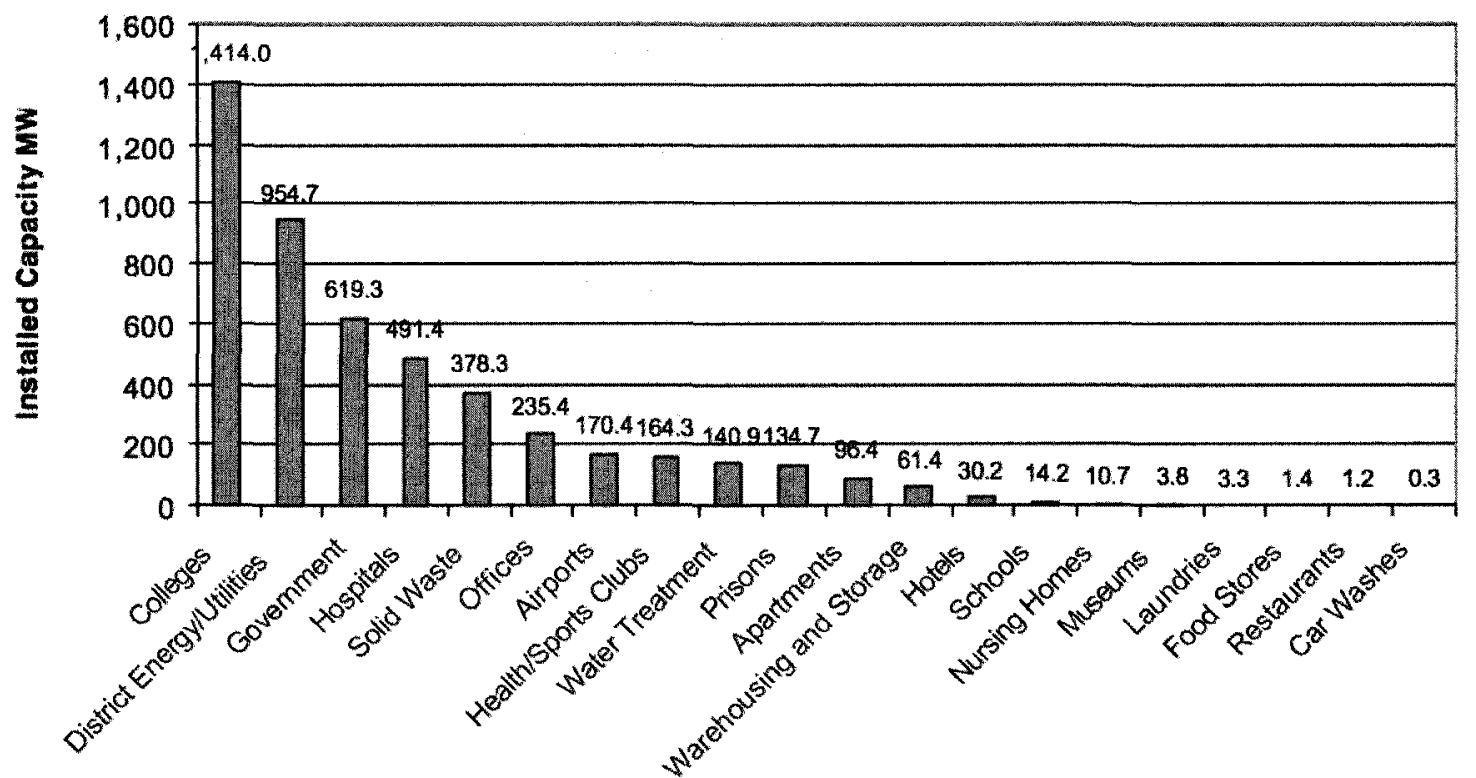

Figure 1-4: Capacity of commercial CHP by application in the United States (2000) [1.39]

As mentioned previously, the power distribution regulatory environment is becoming less hostile and, in fact, favourable towards small-scale distributed CHP. Despite this, current small-scale CHP technologies less than $50 \mathrm{~kW}$ face severe economic challenges. Figure 1-4 illustrates this fact as small-scale facilities such as restaurants and food stores account for only 0.13 percent of total commercial CHP production in the United States [1.39]. With reference to Table 1-1, small commercial users such as restaurants, golf clubs, spas, car washes, and laundromats represent a CHP potential of $9748 \mathrm{MW}$ [1.39]; this data does not include potential from the residential sector, making potential smallscale CHP estimates strongly conservative. This is a large market that has very little incentive to switch to a CHP or CHCP system given the products currently 
on the market. Consumers are becoming more eco-aware when making purchase decisions. The ecological benefits of trigeneration combined with the lack of small-scale systems available make the market potential enormous for a trigen system that can perform well ecologically and economically.

Table 1-1: Comparison of existing CHP to potential CHP supplied in the United States [1.39]

\begin{tabular}{|c|c|c|c|}
\hline Application & $\begin{array}{c}\text { Total Potential } \\
\text { (MW) }\end{array}$ & $\begin{array}{l}\text { Installed CHP } \\
\text { (MW) }\end{array}$ & $\begin{array}{l}\text { Remaining Potential } \\
\text { (MW) }\end{array}$ \\
\hline Hotels/Motels & 6,703 & 30 & 6,673 \\
\hline Nursing Homes & 7,993 & 11 & 7,982 \\
\hline Hospitals & 8,878 & 491 & 8,387 \\
\hline Schools & 14,884 & 14 & 14,870 \\
\hline Colleges/Universities & 4,250 & 1,414 & 2,836 \\
\hline Commercial Laundries & 485 & 3 & 482 \\
\hline Car Washes & 281 & 0 & 281 \\
\hline Health Clubs/Spas & 3,552 & 164 & 3,388 \\
\hline Golf Clubs & 2,208 & 0 & 2,208 \\
\hline Museums & 398 & 4 & 394 \\
\hline Correctional Facilities & 2,721 & 135 & 2,586 \\
\hline Water Treatment/Sanitary & 949 & 141 & 808 \\
\hline Extended Service Restaurants & 3,390 & 1 & 3,389 \\
\hline Supermarkets & 1,184 & 1 & 1,183 \\
\hline Refrigerated Warehouses & 792 & 0 & 792 \\
\hline Office Buildings & 18,614 & 235 & 18,379 \\
\hline Other & N/A & 2,282 & N/A \\
\hline Total & 77,282 & 4,926 & 74,638 \\
\hline
\end{tabular}

\subsection{Applications of DG, CHP, and CHCP}

\subsubsection{Emergency power}

A very limited use for a DG system is for backup or emergency power. Such 
systems have been sold on both large and small scales for decades; typically small-scale units have been restricted to spark ignition or compression ignition engines while larger units have made use of gas turbine generator sets. IHI corp. located in Japan has drawn on Japanese microturbine expertise to produce a mobile $2.6 \mathrm{~kW}$ microturbine emergency generator seen in Figure 1-5.

Many industries cannot afford to stop services or production due to power failures. Often the high cost of installing a backup power system, outweighs the cost of just one power failure. Table 1-2 shows the motivation behind installing emergency power systems, despite the significant capital required for what seems like a minimal return. When generating emergency power, cycle efficiencies and fuel consumption are not the primary concern since the system operates several hours a year, as opposed to 24-7 operation as in a baseload mission.

Table 1-2: Average downtime costs for selected industries [1.12]

\begin{tabular}{|c|c|}
\hline \multicolumn{1}{|c|}{ Industry } & Average downtime costs (USD/hr) \\
\hline Cellular Communications & 41,000 \\
\hline Telephone ticket sales & 72,000 \\
\hline Airline reservations & 90,000 \\
\hline Credit card operations & $2,580,000$ \\
\hline Brokerage operations & $6,480,000$ \\
\hline
\end{tabular}

$\mathrm{CHP}$ and $\mathrm{CHCP}$ systems are not designed for emergency power systems, as the 
increased specific capital cost required to install them cannot be recovered if the system operates only during emergencies. Small-scale users typically do not purchase emergency power systems, as the cost of losing power is usually negligible. An economically successful small-scale trigeneration system cannot be incorporated as part of existing backup power technology, as a trigeneration system must operate for a significant portion of the year to be economically competitive.

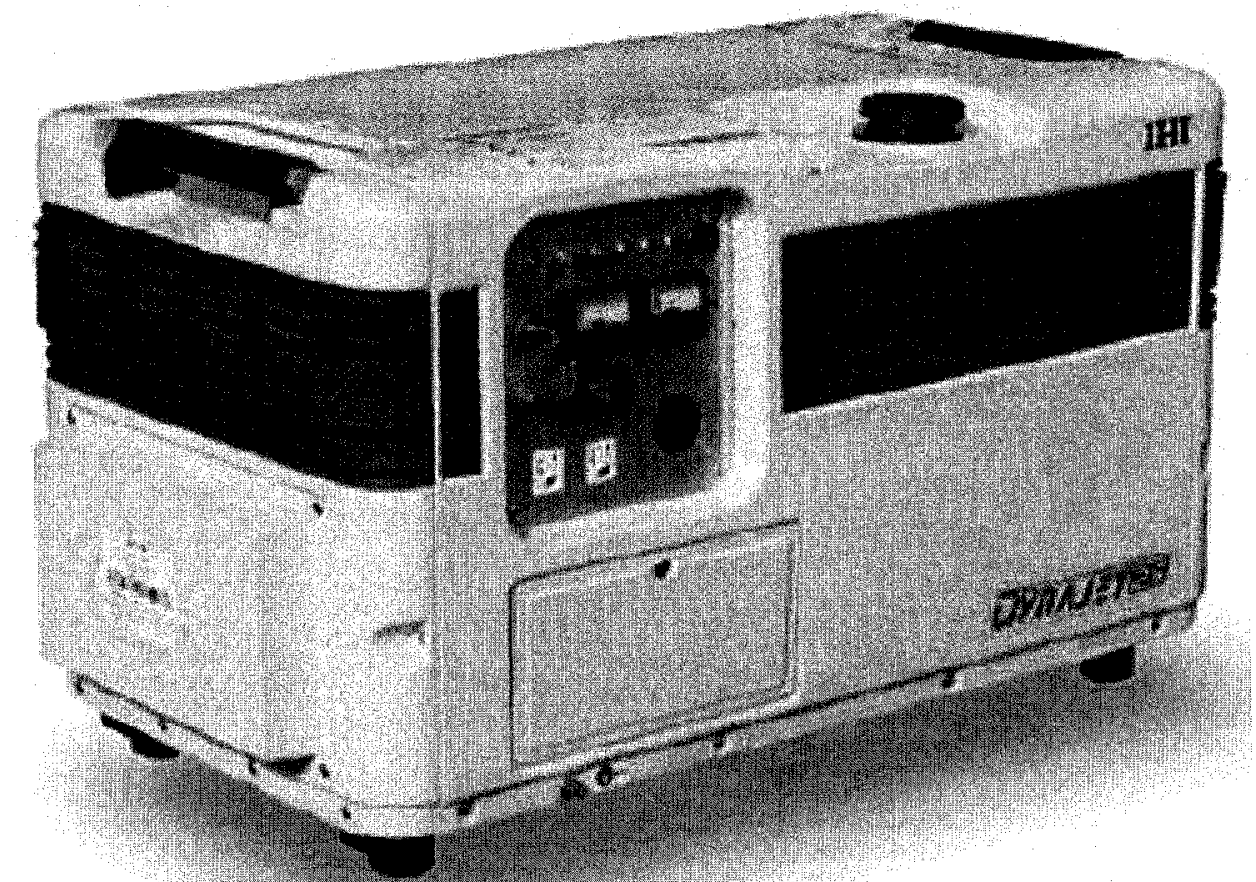

Figure 1-5: IHI Dynajet 2.6 microturbine powered portable generator [1.15]

\subsubsection{Vehicles}

In addition to requiring propulsion, many vehicles require high electrical and 
thermal loads. If the vehicle is large enough, these loads are often satisfied with a secondary powerplant. For example, auxiliary power units (APU) are installed on medium to large aircraft as shown in Figure 1-6.

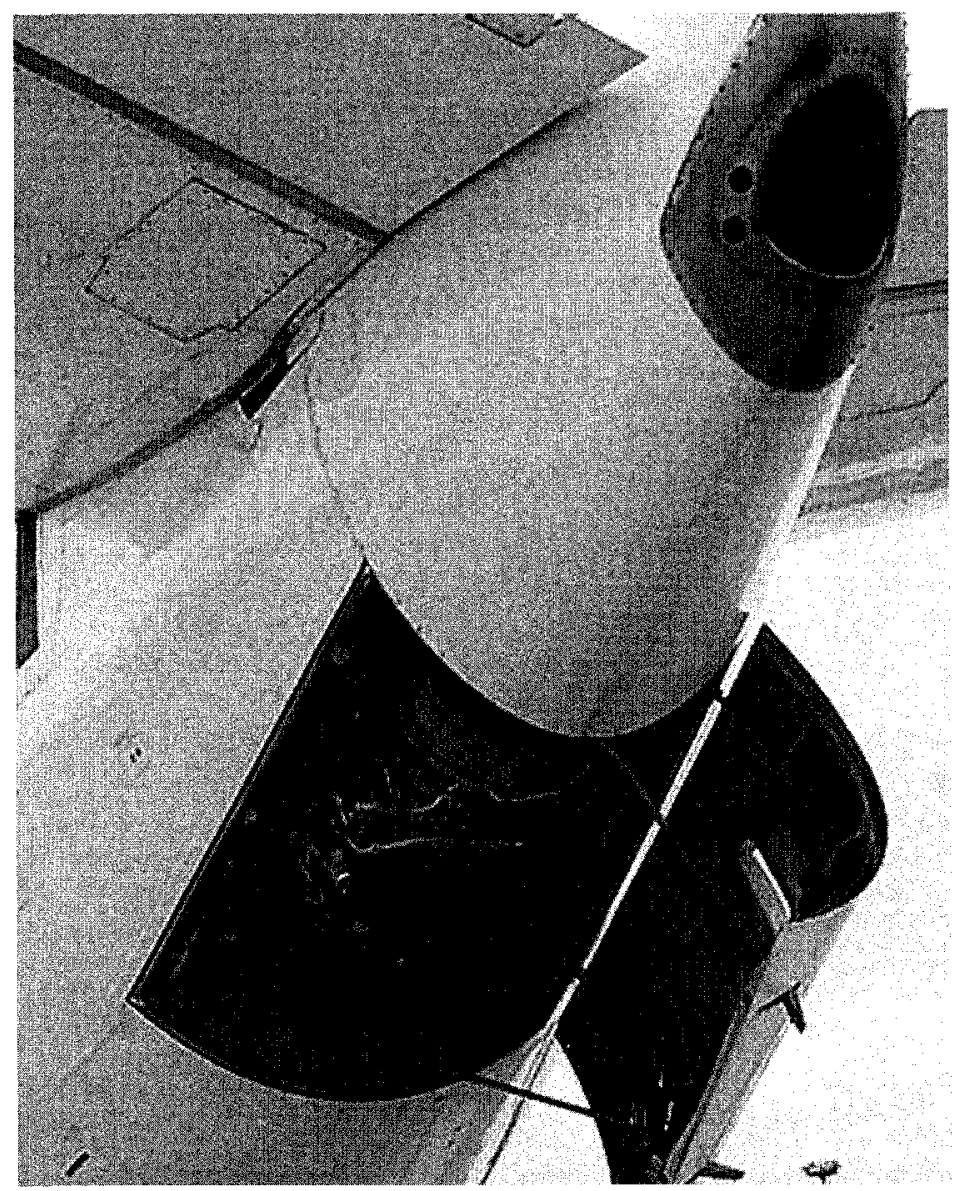

Figure 1-6: Honeywell APU installed in a B737 [1.29]

These small turboshaft gas turbines satisfy thermal and electrical loads while on the apron or during taxi. Unfortunately the overall thermal efficiency of APU trigeneration is very poor. This is partially due to the fact that the thermal load 
provided by the APU is always in excess of what is required by the aircraft; the excess is dumped overboard. There is little motivation to improve this process as the APU is in operation for a small fraction of aircraft operating hours and represents an even smaller fraction of fuel consumption when compared to the consumption of the main engines. While there is much to be learned from APUbased trigeneration, it is clear that terrestrial small-scale users require a different trigeneration system to be economically successful.

An interesting parallel can be made between large ocean vessels employing a CHP system, and a small-scale user. An ocean vessel requires much the same services as a residential customer or a small business: food preparation, laundry, lighting, environmental heating, and process heat, to name a few. Often these loads are satisfied with either a separate dedicated system, or are supplied by the main powerplant; creating a hybrid CHP system. Traditionally such loads were satisfied using a main boiler. Many vessels still use one, however marine cogen has been used in new construction as early as the late 1970s [1.24]. As reducing specific fuel consumption is of primary concern on a marine vessel, the technology developed for marine use should be of particular interest for landbased CHP users; key lessons and cycle innovations developed to save fuel, and system size can help to make a small-scale DG system more attractive to consumers. A significantly different system is required for small-scale land-based 
consumers as marine systems are not capable of trigeneration at the present time. In addition, the specific capital cost of marine cogen systems is too high for small-scale users. A new trigen system that does not use boilers, absorption chillers, or other components oriented towards the large-scale user is required.

\subsubsection{Energy islanding}

For applications where grid power is either inconsistent or non-existent, efficient cost effective energy islanding is required. Northern Canadian communities are often powered by spark ignition or compression ignition engines and heat is provided using electric baseboards or a wood stove. Portable reciprocating engine generators are prone to maintenance issues, and do not make use of exhaust heat. The emissions from these generators, particularly from compression ignition engines, have high concentrations of unburnt hydrocarbons (UHC) and soot. Such communities are prime candidates for a power generation and heating system that can be provided with a small-scale trigen package.

It is not only remote communities that can take advantage of such solutions; industries with mobile applications such as the oil and gas industry, military organizations, can benefit from the mobile high power density offered by microturbines. With respect to a military application, recuperated microturbines are an attractive DG solution in a combat role; low exhaust temperature and 
noise signatures help reduce the chance of detection from infrared seeking equipment and munitions.

Energy islanding has the potential to be attractive for small-scale users with grid power access as well. For customers where power service is routinely disrupted due to inclement weather or due to a weak grid, and for customers where natural gas service is not available, DG systems are an attractive solution to eliminating service disruption and high heating costs. Table 1-3 shows the total energy consumption for Canadian households for the purpose of space heating for 2000 to 2004. Note that while the majority of Canadians use natural gas for space heating, 45.4 percent of the total energy used for space heating did not come from natural gas, presumably due to lack of access and the use of older heating technology. It is also interesting to note that electricity use increased from 2000 to 2004 while natural gas use did not change. This suggests that more people are living in areas without natural gas access, where space heating can only be accomplished with expensive alternatives such as electric heat, oil furnaces, or wood stoves. These statistics indicate that total or partial energy islanding has the potential to become increasingly attractive to small-scale users, however an economically viable small-scale CHP/CHCP package is not available on the market. 
Table 1-3:Canadian space heating energy consumption statistics, presented in petaJoules [1.27]

\begin{tabular}{|c|c|c|c|c|c|}
\hline Year & Electricity & $\begin{array}{c}\text { Natural } \\
\text { Gas }\end{array}$ & $\begin{array}{c}\text { Heating } \\
\text { Oil }\end{array}$ & Other & Wood \\
\hline 2000 & 140.6 & 445.0 & 115.4 & 11.9 & 101.2 \\
\hline 2001 & 134.0 & 404.8 & 104.4 & 11.9 & 94.7 \\
\hline 2002 & 142.0 & 437.6 & 100.9 & 11.5 & 100.1 \\
\hline 2003 & 153.6 & 460.2 & 106.7 & 11.5 & 104.7 \\
\hline 2004 & 157.2 & 442.9 & 92.7 & 11.6 & 106.8 \\
\hline $\begin{array}{c}\text { percent change } \\
2000-2004\end{array}$ & 10.6 & -0.5 & -19.7 & 2.5 & 5.2 \\
\hline
\end{tabular}

\subsubsection{Peak shaving}

To encourage customers to distribute power consumption throughout the day, and to recover costs associated with operating 'peaking' plants, many utilities charge peak rates during high consumption periods. This has resulted in the use of $D G$ as a cost-reduction strategy. As many DG systems are too costly to run when competing with off-peak electricity prices, optimization strategies often include operating a DG system only once a minimum electrical tariff is exceeded [1.2][1.16][1.20]. Most DG systems installed for the purpose of peak shaving do not include CHP or CHCP cycles, as the extra cost associated with such systems cannot be recovered if the system operates for only a portion of the day. Peak shaving had become so popular by the turn of the century that gas turbine gensets in the 3 to $65 \mathrm{MW}$ range are in short supply [1.33]. This trend in grid decentralization can only be expected to continue if electricity peak tariffs continue to climb. For a small-scale user who typically consumes 5 to $8 \mathrm{~kW}$ at 
peak load (for a single family detached household) [1.11], peak shaving DG systems do not make economical sense.

\subsubsection{Process heat and cooling}

Many industrial processes require large amounts of heating and/or cooling load. This load is traditionally generated using boilers (heat load) or chiller technology fired by natural gas or powered with electricity (cooling load). As energy contained in high-temperature exhaust is not utilized, traditional generation of process energy has a lower thermal efficiency compared to cogen or trigen systems.

California DG and CHP standards are seen as the model for the rest of North America who typically follow suit. The California Energy Commission's Distributed Generation and Cogeneration Policy Roadmap outlines a strategy currently being implemented through 2020 to increase DG and CHP market penetration in California to 25 percent of total peak demand [1.31]. To do this, the commission indicates that among other incentives and regulatory requirements, a continued effort to "remove institutional barriers" is essential for DG and CHP success. This is described as making permits easier to obtain, and to provide assistance for integrating DG into the main grid efficiently. With such a favourable regulatory climate, generating process heat and cooling load is much 
more attractive for large-scale industrial users and small-scale users alike. Historically it was very difficult to sell overproduction of electrical power from CHP and $\mathrm{CHCP}$ back to the grid, and still remains so in some areas of North America. This overproduction represented a 'virtual penalty' on overall efficiency, as any energy not used on site was 'dumped overboard'. By being able to generate an income from overproduction, the overall efficiency of a CHP or CHCP system is increased, and an additional income source is generated to offset fuel costs. It can only be anticipated that as peak loads become more of a concern around North America and the world, the DG and CHP framework being established by California will serve as a model for encouraging the growth and economic viability of trigeneration systems.

\subsection{Small-scale CHP and CHCP technology}

There are several technologies to choose from when designing a small-scale CHP or CHCP system. As there are pros and cons to all of them, the following will give a brief overview of which system is best suited for small-scale CHP or CHCP.

\subsubsection{Reciprocating engines}

Commonly referred to as diesel or gasoline engines, these reciprocating prime movers are often seen in an emergency/backup DG role. Diesel generators have 
been used in peaking plants and other non-baseload environments as well, however gasoline engines have not seen the same use outside of small-scale emergency power generation and CHP. Some have experimented with smallscale (less than $15 \mathrm{~kW}$ ) $\mathrm{CHCP}$ and CHP systems involving diesel or gasoline prime movers [1.20][1.22][1.25]. Thermodynamically speaking these systems are good performers with overall efficiencies of 70 to 80 percent, however these studies do not take into consideration maintenance and reliability issues. The biggest weakness of the reciprocating engine is high maintenance costs. Table 1-4 is a high-level comparison of typical maintenance and overhaul costs for four key powerplant CHP and CHCP systems in the 5 to $100 \mathrm{~kW}$ electrical output range. This may come as a surprise as most relate to reciprocating engines via experience gained from operation of cars or trucks, which require routine maintenance roughly once a year. In this context, reciprocating engines can last 10 to 15 or more years before major overhaul.

Table 1-4: Typical maintenance costs for prime mover CHP and CHCP technologies [1.19]

\begin{tabular}{|c|c|c|c|c|}
\hline & Stirling & $\begin{array}{c}\text { Reciprocating } \\
\text { [1.8] }\end{array}$ & $\begin{array}{l}\text { Microturbine } \\
\text { [1.9] }\end{array}$ & $\begin{array}{c}\text { SOFC-GT } \\
{[1.10]}\end{array}$ \\
\hline $\begin{array}{c}\text { Typical } \\
\text { maintenance } \\
\text { costs (USD/kWh) }\end{array}$ & $\begin{array}{c}0.008- \\
0.015\end{array}$ & $0.007-0.018$ & $0.002-0.010$ & 0.023 \\
\hline
\end{tabular}

However the duty cycle during this time is different when compared to a CHP or 
CHCP environment: operation of a vehicle 2 to 3 hours a day for 10 years results in 7300 to 11000 hours of operation. A generator, $\mathrm{CHP}$, or CHCP prime mover will typically operate the majority of the day resulting in 6500 to 7000 hours of operation per year or 6 to 10 times longer over a 10 year period, when compared to a reciprocating engine operating in a vehicle powerplant mission.

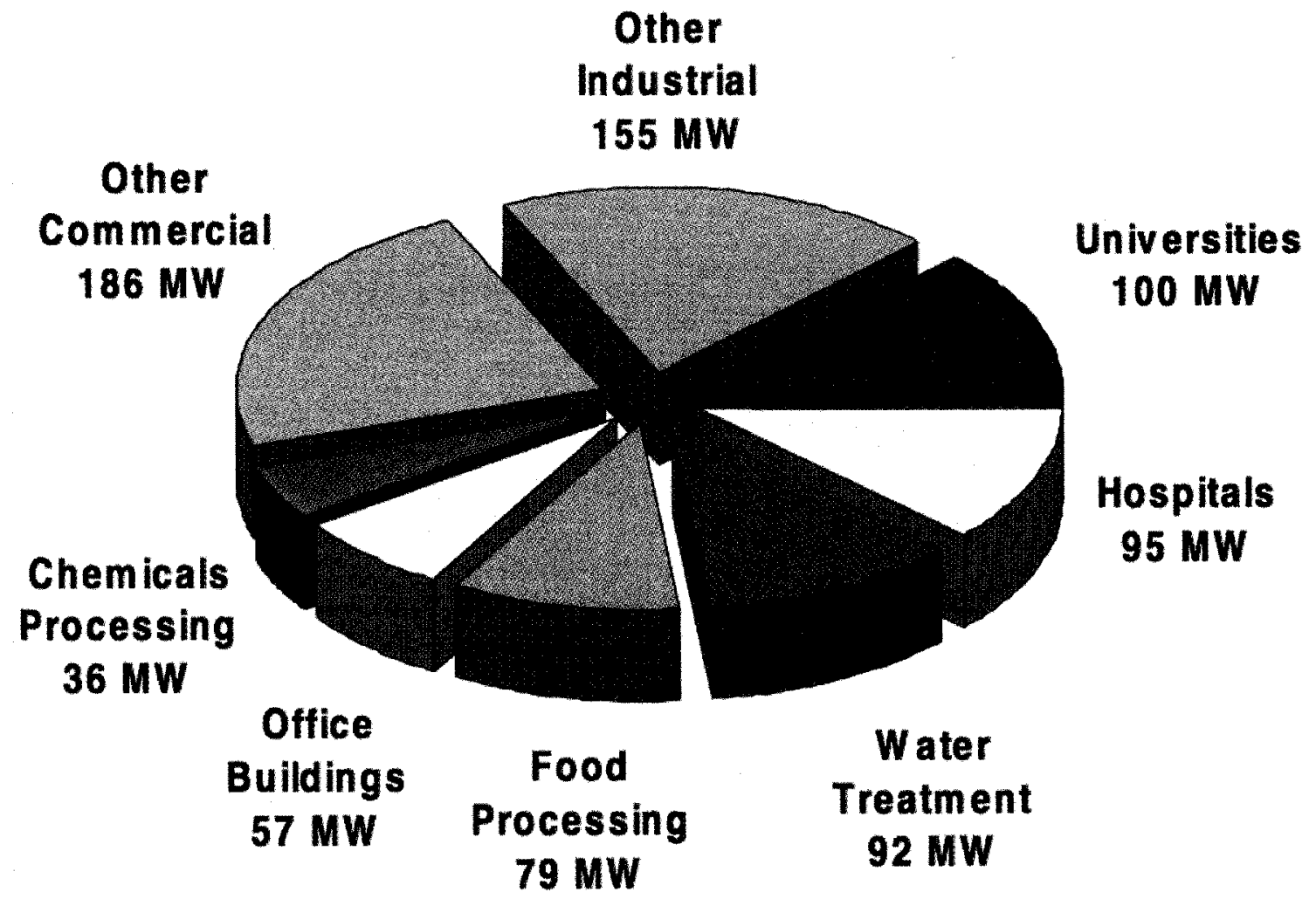

Figure 1-7: Existing reciprocating engine CHP in the United States (2002) [1.8]

A typical small-scale user is not interested in keeping a rigid maintenance schedule and does not employ maintenance personnel to montor the health of 
system components. When gasoline and diesel engines are employed in a largescale DG, CHP, or CHCP environment, the user will most likely employ a power engineer or equivalent to monitor the health and maintain reliability of reciprocating equipment; this is not an option for small-scale users with few employees. As can be seen from Figure 1-7, customers who make use of a reciprocating engine for CHP purposes typically do not have operations in the MW scale.

In addition to maintenance scheduling and cost issues for the small user, noise is also a problem. Reciprocating engines demonstrate steady state operation noise levels in excess of $100 \mathrm{dBA}$ [1.19]. At this level, the Canadian Centre for Occupational Health and Safety recommends unprotected exposure not to exceed 15 to 30 minutes a day [1.3]. While such noise levels may be acceptable for a facility that can segregate the engine from occupied areas, small users cannot afford the luxury of unusable noise polluted space.

\subsubsection{Stirling engines}

Despite being first patented in 1816 [1.46], engines using the Stirling cycle have not received the same fame as its younger counterpart the Otto cycle (patented in 1887) 0 . While the ideal Stirling cycle is closer to Carnot cycle efficiencies, in 
reality it is on par with Brayton and Otto cycles due to problems with piston sealing and regenerator effectivities of less than unity. The Stirling engine uses a closed cycle with a constant temperature heat addition and removal joined by constant volume processes. In an alpha type Stirling engine, two pistons are joined to a crankshaft. One cylinder is heated and the other is cooled. As the fluid in the hot cylinder expands during constant temperature heat addition, the cold cylinder is driven upwards. This forces cold fluid into the hot cylinder, which then draws the hot piston upwards due to contraction of the cooled fluid. Figure 1-8 gives a diagrammatic representation of a production $50 \mathrm{~kW}$ Stirling engine produced by STM Power based in the United States.

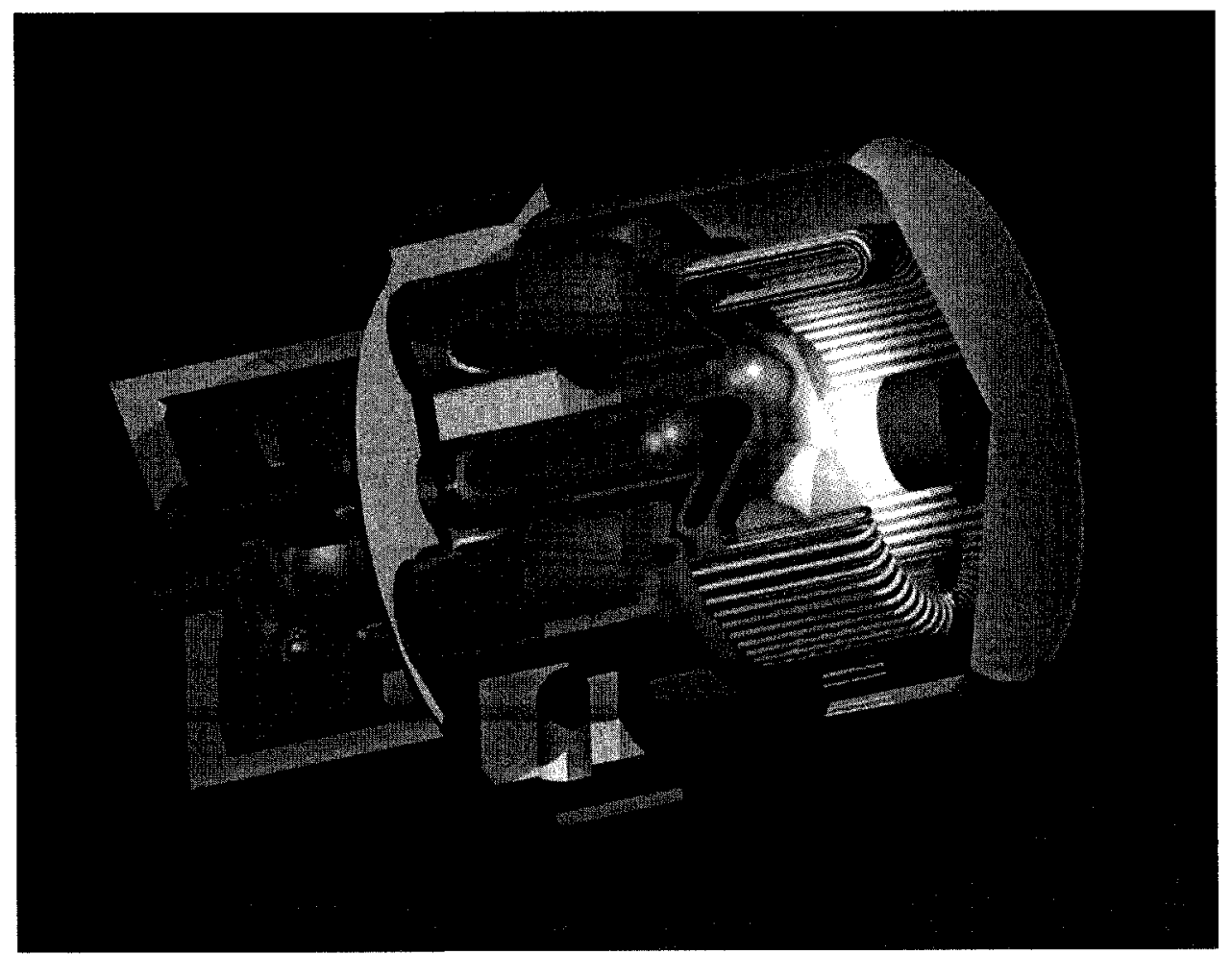

Figure 1-8: Stirling engine produced by STM power [1.36] 
The Stirling engine demonstrates unproven potential to penetrate the less than $15 \mathrm{~kW}$ small-scale CHP market. The combination of low noise signature and small package are attractive to consumers looking for either energy islanding or a supplement to the grid. WhisperGen ${ }^{\mathrm{TM}}$, a company in New Zealand, will be introducing a stirling engine to the European market in 2009 capable of providing $1 \mathrm{~kW}$ of electrical output and upto $12 \mathrm{~kW}$ thermal output (in the form of hot water) [1.42].

Purchase price and maintenance costs are still unavailable with which to make an economic comparison with other $\mathrm{CHP}$ and $\mathrm{CHCP}$ technologies. Historical data on Stirling engines suggest maintenance costs are slightly better than reciprocating engines but still above microturbines (see Table 1-4). Several companies have developed Stirling engines for use in packaged CHP applications including: SOLO in Germany, WhisperGen ${ }^{\top M}$ in New Zealand, and STM Power from the United States. With the exception of WhisperGen ${ }^{\mathrm{TM}}$, all other commercial Stirling CHP packages are targeted for $50 \mathrm{kWe}$ or greater industrial use. Perhaps this is due to the high specific capital cost $(\$ / k W)$ Stirling engine packages have demonstrated. Very conservative estimates place the procurement price of a Stirling CHP package at 3400 USD/kW . A typical North American household requires about $5 \mathrm{kWe}$ at peak demand [1.23], resulting in an estimated 17,000 USD price tag (not including installation) for a small-scale 
residential Stirling CHP unit. Considering a high-efficiency furnace can be purchased for 3,000 to 4,000 USD [1.6], Stirling powered small-scale cogen has some significant economic hurdles to overcome in order to achieve market success.

\subsubsection{Microturbines}

Perhaps the most promising powerplant technology currently available for smallscale trigeneration are microturbines. Having benefited from significant government research and development funding in the United States, microturbines are evolving from being classified as experimental to now being widely accepted as an established technology. The Advanced Microturbine System [1.40] and Microturbine Materials Technology [1.44] programs run by the US Department of Energy have stated objectives to increase the thermal efficiency of microturbines to 40 percent, making it possible for microturbine systems to surpass the efficiencies of small-scale reciprocating engine systems while maintaining reliability. The microturbine is a particularly robust system as there is only one moving part: the main rotor as seen in Figure 1-9. The result is a technology similar to household furnaces; the consumer is aware it is operating, but is not required to carry out any maintenance. As DG microturbine systems have been in operation since the early 90 s, maintenance periods and service life claims have moved from estimates to being supported with field data. 
For example, Appendix $D$ contains actual maintenance intervals for the Capstone Turbines $60 \mathrm{kWe}$ C60 and C65 DG microturbine.

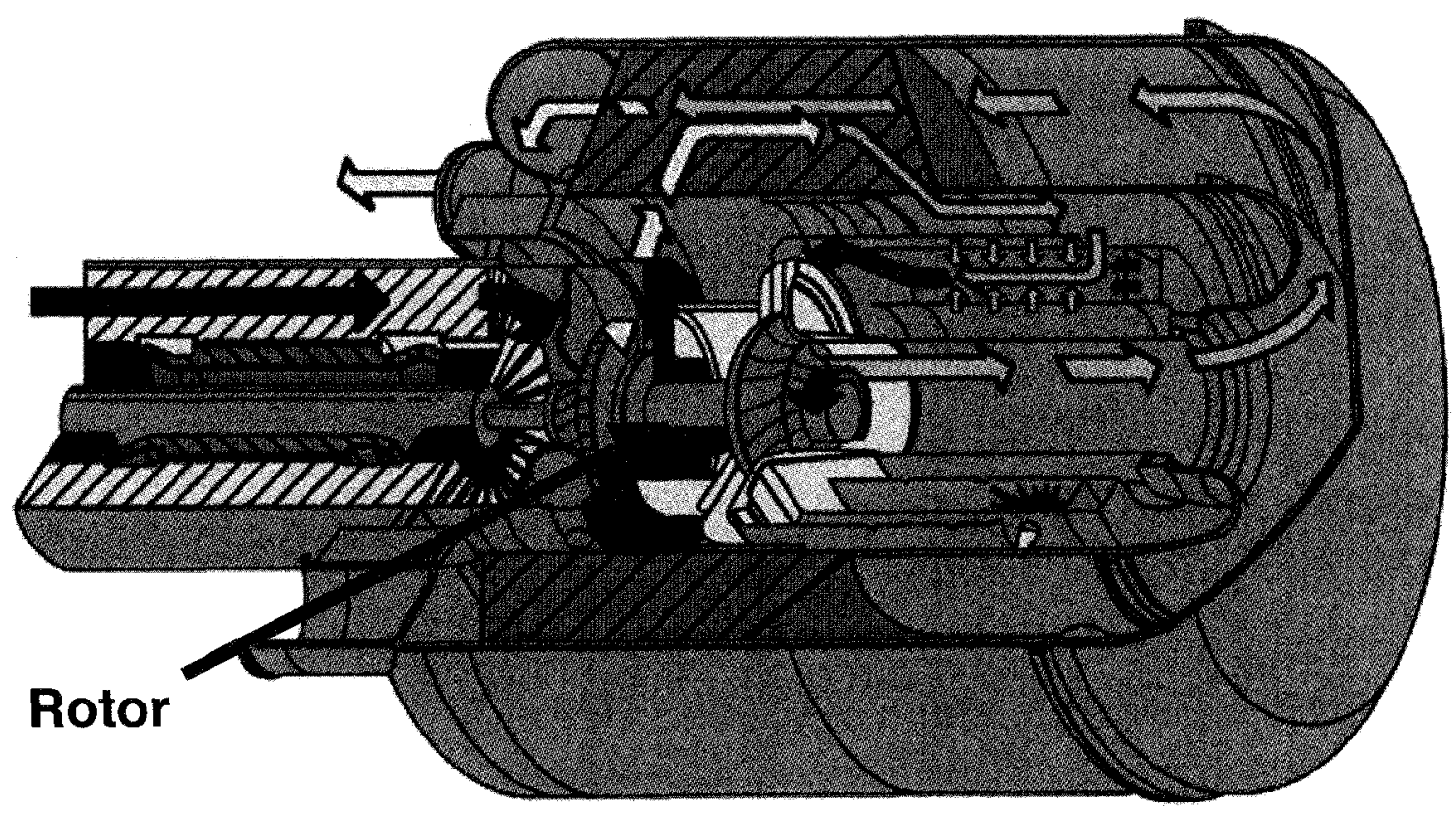

Figure 1-9: Cutaway view of a microturbine[1.42]

Compare this with reciprocating engines, which require the cylinder head and head gasket to be overhauled at 10,000 hour intervals, and demonstrate a useful life of 30,000 hours [1.8]. Stirling engines with an output of less than $15 \mathrm{~kW}$ designed for use in CHP are new to the market and have not accumulated data on reliability and maintenance as of yet. Based upon historical and current experimental data, Stirling CHP systems would most likely require significant routine maintenance at 4,000 to 6,000 hours of operation [1.19]; roughly one 
quarter of the demonstrated 20,000 hour interval for a microturbine (see Appendix D). Estimates for useful life vary wildly for Stirling engines due to a lack of historical data to draw from, therefore it is prudent to leave the useful life of a Stirling powered DG or CHP system as unknown at this point.

Table 1-5: Quantitative comparison of potential small-scale DG/CHP/CHCP powerplants (less than $50 \mathrm{~kW}$ ). This data represents a conservative average from the following sources: [1.8] [1.9] [1.10] [1.19] [1.32] [1.39] [1.40] [1.41]

\begin{tabular}{|c|c|c|c|c|}
\hline $\begin{array}{c}\text { Electrical } \\
\text { efficiency } \\
\text { (percent) }\end{array}$ & $25-30$ & $20-35$ & $30-35$ & $60+$ \\
\hline $\begin{array}{c}\text { CHP Thermal } \\
\text { efficiency } \\
\text { (percent) }\end{array}$ & $71-86$ & $80-89$ & $\sim 80$ & N/A \\
\hline $\begin{array}{c}\text { Specific Captial } \\
\text { Cost (USD/kW) }\end{array}$ & $500-650$ & $3400+$ & $550-700$ & $2850++$ \\
\hline $\begin{array}{c}\text { Maintenance } \\
\text { Cost (USD/kWh) }\end{array}$ & $0.002-0.010$ & $\begin{array}{c}0.008- \\
0.015\end{array}$ & $0.007-0.018$ & 0.023 \\
\hline $\begin{array}{c}\text { Operating noise } \\
\text { (dBA) @ 3ft }\end{array}$ & $57-82$ & $50-75$ & $100+$ & $60(@ 10 \mathrm{~m})$ \\
\hline $\begin{array}{c}\text { Maintenance } \\
\text { intervals (khr) }\end{array}$ & $\sim 11$ & $4-6$ & $8-10$ & $2-4$ \\
\hline $\begin{array}{c}\text { Major Overhaul } \\
\text { (khr) }\end{array}$ & $45+$ & $?$ & $<30$ & 24 \\
\hline
\end{tabular}

As microturbine machinery is very simple with only one moving part, maintenance costs are very low. Mechanical simplicity also results in low specific capital costs. With reference to Table $1-5$, it can be seen that the microturbine 
offers the lowest operational and startup cost of the three options discussed thus far (SOFC-GT systems will be discussed in Section 1.4.3.4). In the case of CHCP, a successful system has to compete with highly efficient individual generation provided by a vapour compression air conditioner, natural gas furnace, and grid power. To do so, low specific capital and maintenance costs are vital. The same can be applied to small-scale DG and CHP systems as consumers requiring less than $50 \mathrm{~kW}$ of electrical power cannot afford the capital required for a Stirling system, nor the maintenance costs of a reciprocating system.

As discussed in Section 1.4.1, a successful DG, CHP, or CHCP system targeted for the small-scale user must demonstrate low operational noise. Table 1-5 compares operating noise levels of competing small-scale powerplants; it can be seen that the microturbine operates within an acceptable noise range. For comparison, the average clothes dryer operates at 60-75 dBA [1.17]. This combination of minimal maintenance, high reliability, and low operating noise ensures that a microturbine trigeneration system is 'out of sight and out of mind'.

\subsubsection{Available CHP microturbine packages}

There has been substantial research and development effort made in the 50 to $150 \mathrm{~kW}$ range for microturbine-powered CHP. As a result, there are several 
commercial products currently available for purchase, Table 1-6 summarizes performance data for the more prominent systems. Despite the selection available in the 50 to $150 \mathrm{~kW}$ range, there are no microturbine CHP products available below $50 \mathrm{~kW}$. On a cold winter day, a typical Canadian single family detached dwelling will require roughly 10 to $15 \mathrm{~kW}$ of heat load with anywhere from $50 \mathrm{~W}$ to $8 \mathrm{~kW}$ of electrical load [1.11]. CHP systems on the market are not sized to meet such a low demand.

Table 1-6: Market survey for microturbine CHP systems (50 to $150 \mathrm{~kW}$ )

\begin{tabular}{|c|c|c|c|c|c|}
\hline Manufacturer & $\begin{array}{c}\text { Product } \\
\text { Name }\end{array}$ & \multicolumn{1}{c}{$\begin{array}{c}\text { Electrical } \\
\text { Output } \\
\text { (kW) }\end{array}$} & \multicolumn{1}{c|}{$\begin{array}{c}\text { Thermal } \\
\text { Output } \\
\text { (kW) }\end{array}$} & \multicolumn{2}{c|}{$\begin{array}{c}\text { Heat } \\
\text { Delivery } \\
\text { System }\end{array} \begin{array}{c}\text { Overall } \\
\text { Efficiency } \\
\text { (percent) }\end{array}$} \\
\hline Capstone & $\begin{array}{c}\text { C6XiCHP } \\
{[1.34]}\end{array}$ & 65 & 120 & Water & $71-82$ \\
\hline Ebara/Elliot & TA100[1.18] & 95 & 172 & Water & 74 \\
\hline Turbec/ABB & T100[1.37] & 100 & 155 & Water & 77 \\
\hline
\end{tabular}

\subsubsection{High-speed generators}

A key enabling technology for small-scale microturbine DG, CHP, and $\mathrm{CHCP}$ systems is the development of high-speed generators. A high-speed generator uses a permanent magnet mounted directly on the rotor shaft, as seen in Figure $1-10$, which allows the generator to operate at speeds of greater than 450,000 RPM. By incorporating the generator as an intrinsic part of the rotor, a gearbox is not required. This eliminates generator-related maintenance, increases the life of the system, and improves efficiency due to negligible mechanical losses in the 
high-speed generator as opposed to significant losses in a gearbox. Another benefit of incorporating high-speed generators into microturbines is the reduction in cost that comes with eliminating a gearbox and bulky conventional generator. High-speed generators help to contribute to the autonomous operation of microturbines; no gearbox inspections or gearbox fluid changes translates to less system maintenance, an essential requirement for the unskilled small-scale user.

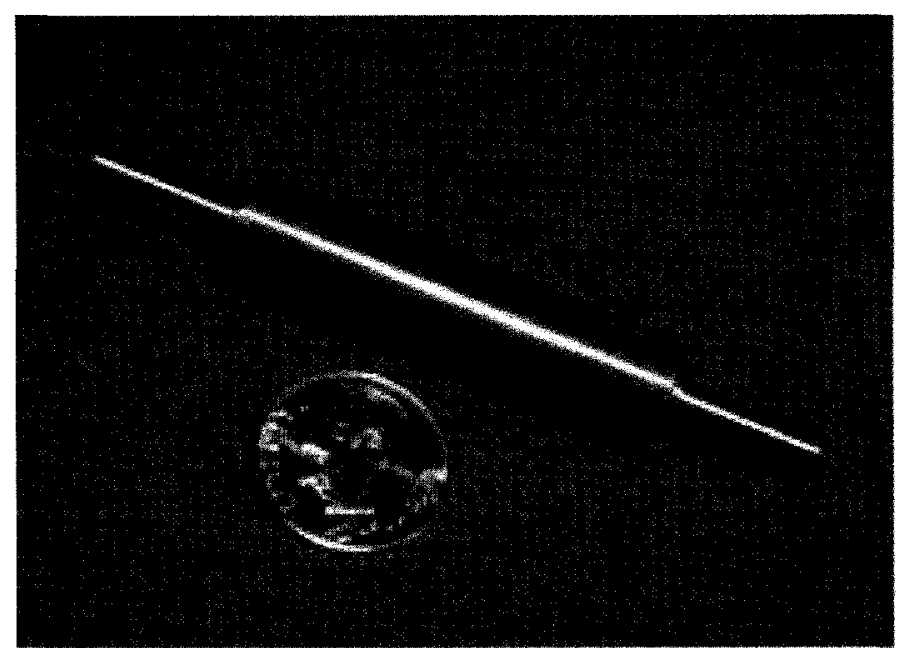

Figure 1-10: High speed generator permanent magnet rotor shaft [1.37]

\subsubsection{Zero-Iubrication bearings}

Bearings have a large effect on turbomachinery life and reliability. Oil degradation, metal flakes, and lubrication coverage issues are some of the major sources of flaking, fatigue, and spalling in lubrication based bearing systems. An oil cooler, reservoir, and pump must be installed as well which only adds to the 
complexity and cost of the system; hence it is highly desirable to eliminate the need for a lubrication system.

Air bearings have significant potential for microturbines in that they eliminate the need for an oil distribution system, and improve component life. The air bearing system along with high-speed generators are enabling technologies for microturbines that contribute to the minimal maintenance and long service life demonstrated. An air bearing uses pressurized air forced through very small gaps between stationary and rotating components, effectively 'floating' the rotating component without any physical contact.

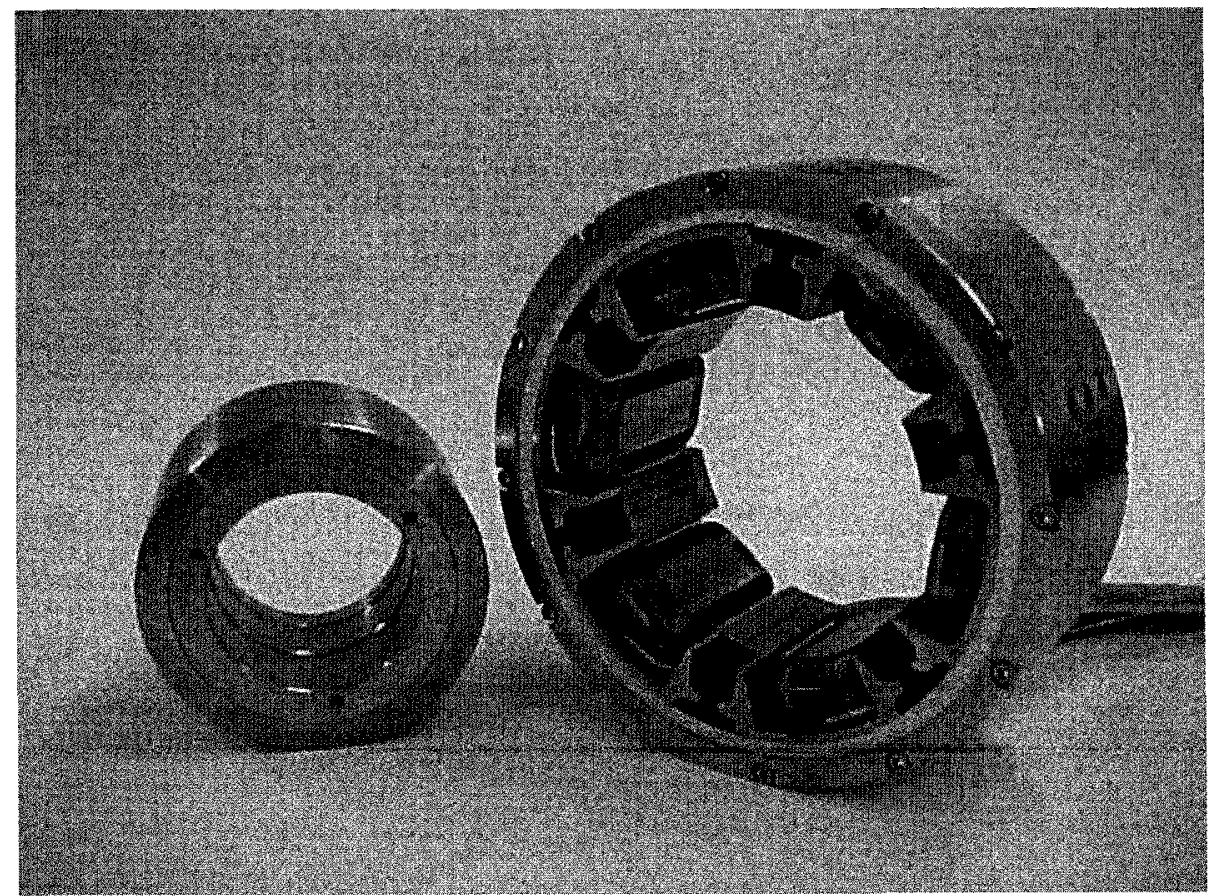

Figure 1-11: Schematic of a magnetic bearing [1.37] 
Magnetic bearings are a more recent addition to the field of non-contact bearing systems. Figure 1-11 shows one particular design by Synchrony, a leader in incorporating magnetic bearings into turbomachinery systems. It can be seen that the rotating shaft floats between the inner magnets and outer magnets, preventing wear due to contact from occurring.

\subsubsection{SOFC-GT hybrid systems}

An interesting addition to the list of potential trigeneration powerplants is the combination of fuel cell technologies with microturbines. The most popular fuel cells used for such an application are the solid oxide fuel cell (SOFC) and the molten carbonate fuel cell (MCFC), as the exhaust from such cells can be as high as $700^{\circ} \mathrm{C}$ [1.13]. While this temperature may seem low for microturbine applications (a typical microturbine TIT is between 800 and $900^{\circ} \mathrm{C}$ ), the microturbine is only used as a bottoming cycle; any electrical load generated by the microturbine contributes to the efficiency of the system as no extra fuel is injected into the SOFC exhaust. Both the SOFC and microturbine produce electrical load with fuel being added to the SOFC alone. Figure 1-12 illustrates one version of the SOFC-GT being developed by the National Fuel Cell Research Centre in California (NFCRC). These systems show great promise with demonstrated overall electrical efficiencies of 60 percent, and projections of 80 percent in the near future [1.32]. 


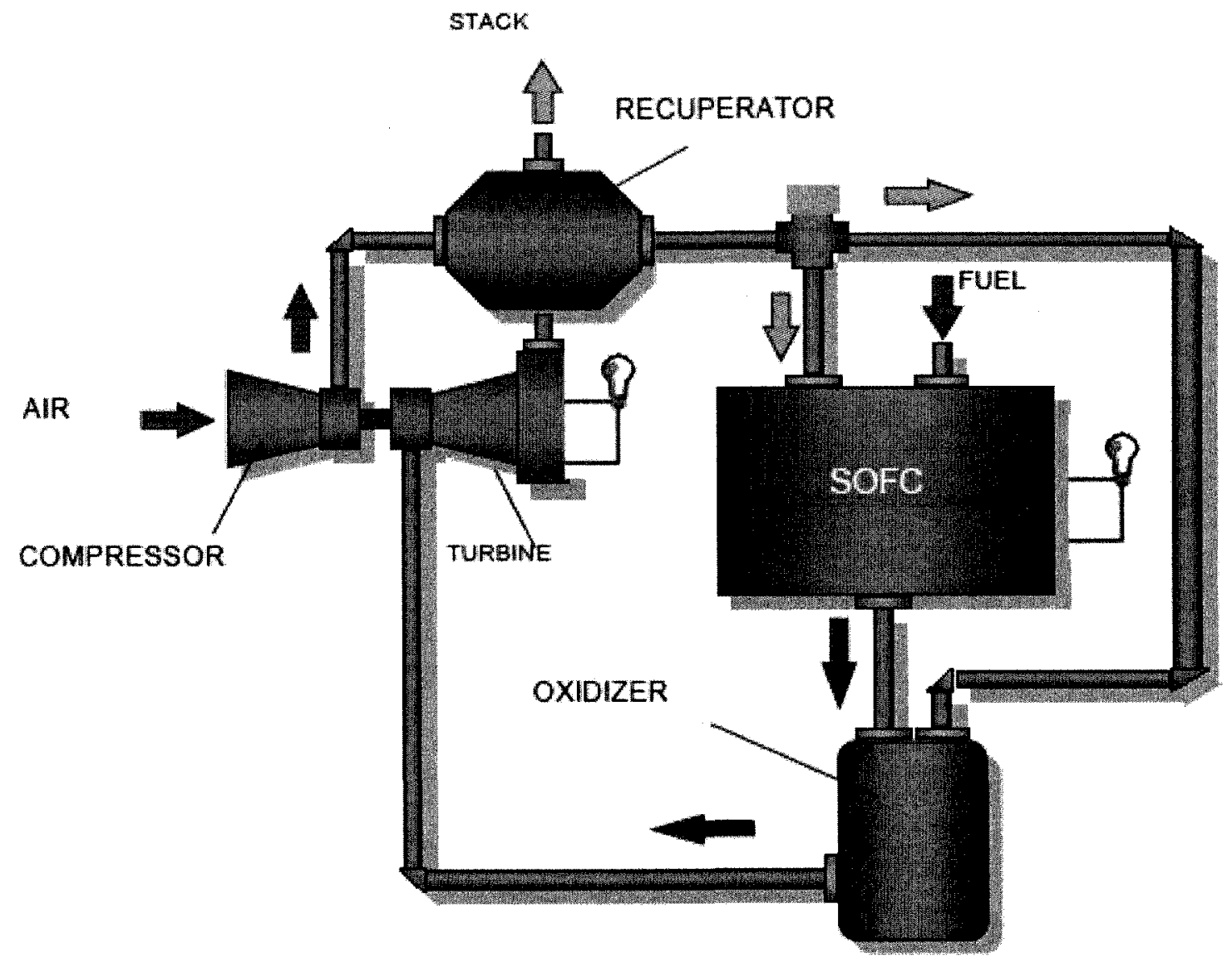

Figure 1-12: Schematic of a SOFC-GT hybrid system [1.32]

Despite demonstrating very high thermal efficiencies, and exhibiting great potential for emissions reduction, the extremely high specific capital (2850 USD/kW) and maintenance costs (0.023 USD/kWh) make SOFC-GT systems unrealistic for small-scale trigeneration [1.10]. Another limiting factor for SOFCGT systems is poor transient response time. Fuel cells require warm-up times and cannot be rapidly throttled. For a small-scale load pattern that typically demonstrates rapid variation in load, the SOFC-GT would not be able to operate 
in a load following manner. No commercial SOFC-GT units are in operation currently as this technology is still under development, however with the results obtained so far by NFCRC and Siemens (formerly Westinghouse) shows great promise for medium to large-scale DG or CHP applications.

SOFC-GT systems have very low thermal-to-electric load ratios (TELR). This is inverse to what is required in a typical small-scale application that demonstrates TELR values of 4 to 5 [1.23]. To meet a small-scale thermal load, significant overproduction of electrical load is required. Unless this load can be sold back to the grid, this overproduction represents a penalty on overall efficiency no matter how efficiently it was produced.

\subsubsection{Thermal storage}

Thermal loads for both small- and large-scale applications typically have periods of peak consumption, and periods of low consumption. Sizing a system based on peak consumption can result in poor performance during off-peak hours. Thermal storage offers a way to overproduce thermal load during off-peak hours, and store it for use during peak consumption. Implementations of thermal storage within the context of DG, CHP, and $\mathrm{CHCP}$ are quite diverse. Thermal storage cannot produce electrical or thermal load without integration of a suitable powerplant, therefore it is not directly comparable with other systems discussed 
in Section 1.4. Thermal storage is a proven option for providing cooling or heating load, and for augmenting the performance of DG, CHP, and CHCP powerplants; it will be briefly discussed as such systems are in use around the world as part of distributed thermal systems. Some implementations of thermal storage include below ground reservoirs (Figure 1-13), integrated reservoirs (Figure 1-14), and two-phase storage [1.14]. There are two main strategies used when implementing thermal storage.

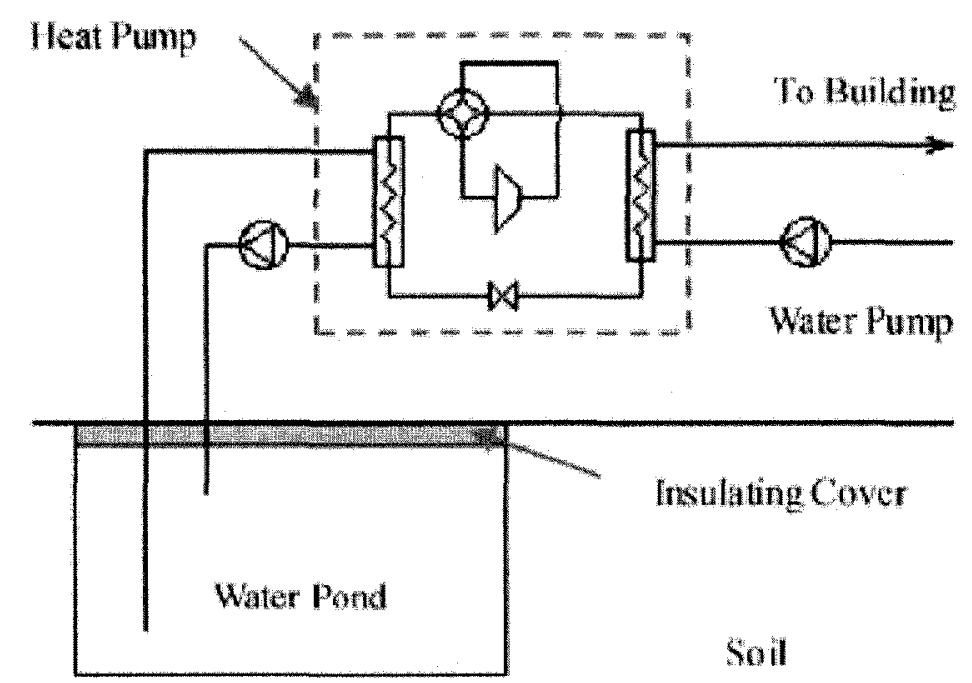

Figure 1-13: Example of using below ground thermal storage [1.45]

One takes advantage of the large heat capacity, and relatively constant temperature of large underground water reservoirs to provide heating and cooling. It typically takes advantage of a heat pump to extract or reject heat from the reservoir. This method can only be used where large underground reservoirs 
of water exist, severely limiting the regions in which such a system can be implemented. Such systems consume electrical power instead of producing it; therefore can only be considered in competition with CHP and CHCP systems when combined with grid power. Two-phase storage is similar to underground storage in that it makes use of the large heat capacity contained in a reservoir of water and ice; the use of two-phase storage increases the specific cooling capacity of underground storage. Large reservoir systems are often used as peaking cycles to reduce electricity consumption during peak hours.

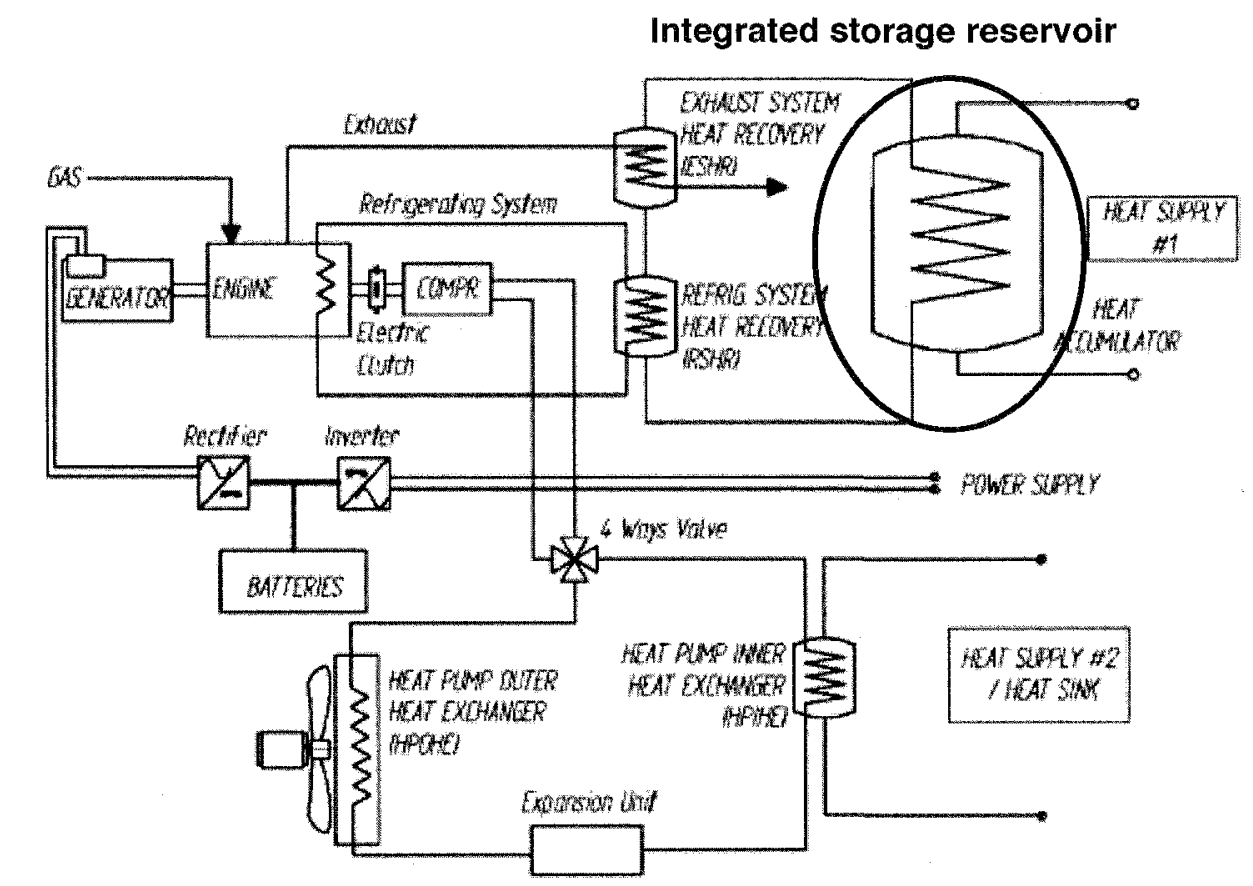

Figure 1-14: Example of integrated thermal storage [1.25][1.26]

Another interesting implementation of thermal storage comes in the form of inlet cooling for gas turbines. The thermal storage system itself can take the form of 
integrated, underground, or two-phase design. However, the cooling product is used to increase specific work output and thermal efficiency of a gas turbine instead of producing cooling load. Estimates place the cost of such a system at 160 USD/kWt of cooling [1.21]. Inlet cooling would benefit a small-scale microturbine-powered trigeneration system, however as a microturbine package can be produced for only 500 to $600 \mathrm{USD} / \mathrm{kWe}$ (see Table 1-5), any reduction in specific fuel consumption would have to be weighed against increased specific capital and maintenance costs.

\subsection{Thesis objective}

The goal of this thesis is to design a trigeneration system targeted for the residential, small business, and institution sectors. This system will be able to be connected to the grid or function as a total energy-islanding device. The system is designed to be in direct economic competition with individual generation from an air conditioning system, natural gas furnace, and grid power. The final design will satisfy the following requirements:

- Be comprised of components that make use of existing technology

- Operation of the system requires no special training, nor should the system require special monitoring.

- Will make use of hydraulic storage combined with an inverse Brayton cycle powered by a microturbine. These technologies will be discussed further in the following section. 
- Be sized to provide for all electrical, cooling, and heating loads for a typical detached single family Canadian household.

- The system must not introduce operational health hazards.

- No storage batteries are to be used in the design.

The work contained in this thesis represents the first phase in the design and manufacture of a small-scale trigeneration system. A proof of concept will be built at a later time, as the scope of this thesis is limited to simulation and modelling. Keeping capital costs low will be a priority. Significant emphasis will be placed on maintaining system simplicity, and using low cost components. 


\section{Chapter 2}

\section{CHCP literature review}

\subsection{The motivation behind developing $\mathrm{CHCP}$}

Technology used in modern CHCP has been available for many years; current efforts are focused on building cycles with proven technology in a fashion that makes economic and thermodynamic sense. The threat of energy shortages, real or imagined, in many places around the world have led many consumers and energy providers alike to look for ways to stretch resources. Trigeneration is seen as one tool to help the new reality facing consumers and energy providers alike.

A key motivation behind trigeneration is to add value to distributed energy systems. Many studies and simulations have shown lower specific capital costs for trigeneration systems over individual generation, in addition to lower specific fuel consumption [2.13]. In some applications where CHP does not make economic sense, the added value of an additional energy product to a CHP system may be more economically viable. By providing cooling output, a trigeneration system enables a building or plant to become completely selfsufficient. This may not be an issue for most, however for total or partial energy islanding, trigeneration packages are very attractive. 


\subsection{Historical application of $\mathrm{CHCP}$}

Historically $\mathrm{CHCP}$ has been primarily targeted for use in large institutions and commercial space [2.36]. There are examples of successful CHCP implementation in industry [2.5], however the number of industrial processes that require significant cooling and heating loads are far fewer than those which require one or the other. $\mathrm{CHCP}$ has been employed primarily in institutions and commercial buildings due to the agreeable match between building energy product requirements and $\mathrm{CHCP}$ energy outputs. Commercial $\mathrm{CHCP}$ is a new technology, as the oldest installations are only 8 to 10 years old [2.21] with the majority being only 3 to 4 years old [2.3][2.27][2.31][2.2][2.1]. Over the past decade CHCP systems have achieved economic success while installed in applications such as airports [2.1], shopping centres [2.2], supermarkets [2.21], hospitals [2.36], and industrial plants [2.5][2.3]. The success of existing CHCP plants around the world have motivated Saudi Arabia to form the National Trigeneration CHP Company (NTCC), a government-backed company charged with the development and installation of trigeneration packages throughout the country. With social and environmental responsibility taking a more prominent role around the world, the attractive combination of reductions in energy consumption and carbon emissions is giving trigeneration systems some much needed momentum [2.31]. This momentum is anticipated to give current experimental CHCP systems the opportunity to compete commercially, and to 
improve trigeneration technology as a whole via increased competition.

\subsubsection{Typical cycle profile of current commercial CHCP}

Cycle design for CHCP systems was briefly described in Section 1.1. The following is a more in-depth summary of $\mathrm{CHCP}$ systems currently in operation around the world. The most popular choice for trigeneration powerplants are either diesel or gas turbine engines, gasoline internal combustion engines are used on a smaller scale. A typical unit will be in the 3 to $10 \mathrm{MWe}$ output range, which coincides with requirements consistent with large institutions, airports, and hospitals.

Figure 2-1 illustrates three common layouts used for large (3 to $10 \mathrm{MWe}$ ) trigeneration systems that incorporate ACR units. Layouts $A$ and $B$ incorporate an internal combustion engine (diesel or gasoline), while layout $\mathrm{C}$ uses a gas turbine. The main difference between diesels and gas turbines is the way heat is extracted, When using an internal combustion engine, a significant portion of the waste heat from is in the form of liquid coolant. Layout A provides for one ACR unit by re-circulating the coolant through the exhaust stack, while layout B provides for two ACR units by incorporating exhaust heat into one cycle and coolant flow into the other. Layout B is particularly advantageous for applications that require different temperatures of cooling flow; two ACR units can produce cooling load at two different temperatures. In layout $\mathrm{C}$ exhaust circulates directly 
through the ACR unit rather than producing steam. This is done to reduce capital and maintenance costs, however an increased pressure drop penalty is paid through the ACR unit.
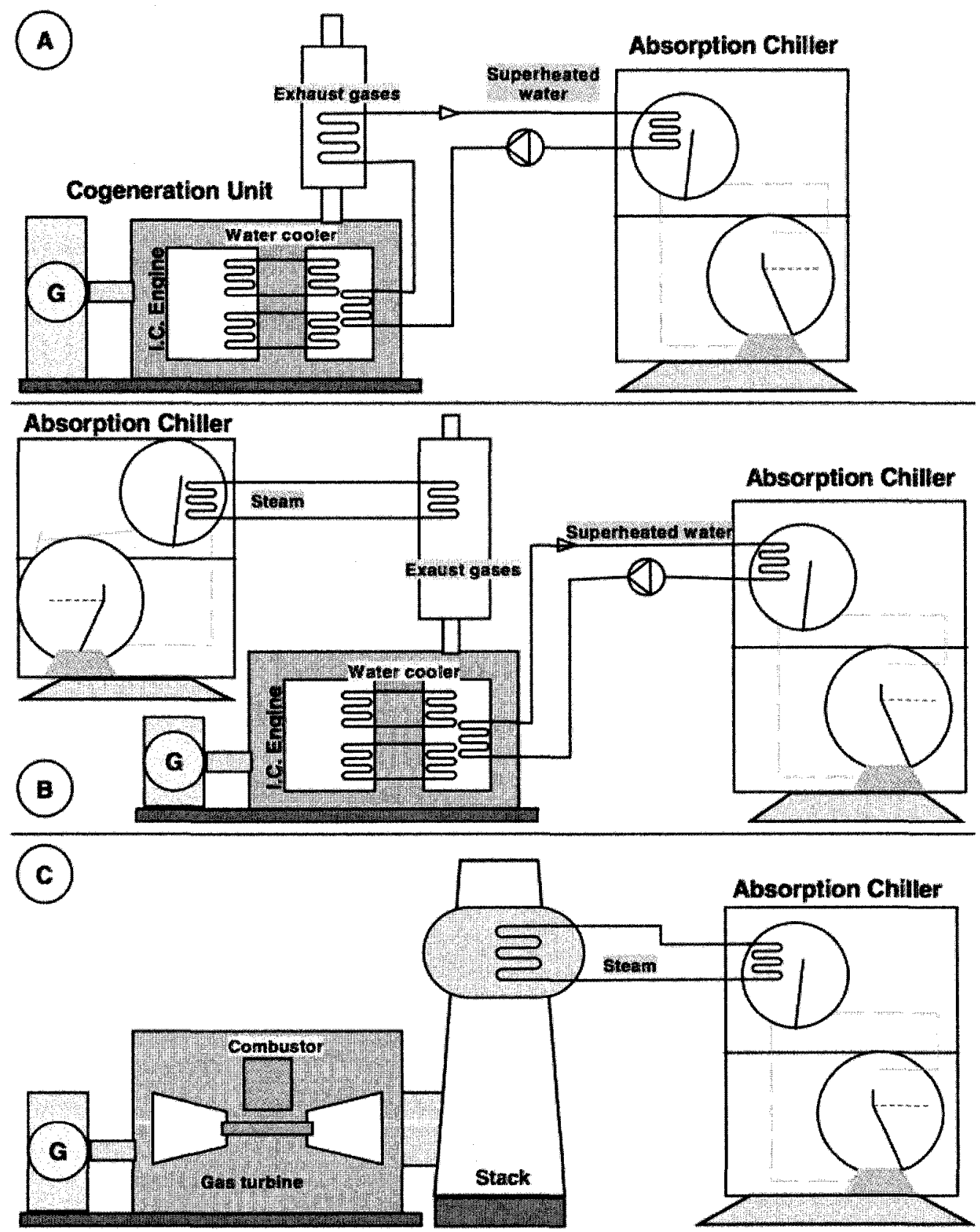

Figure 2-1: Typical layout for commercial CHCP utilizing diesel or GT powerplants [2.8] 
For commercial systems that make use of vapour compression refrigeration units (VCR), there are two primary configurations used: direct drive and indirect drive. The most significant difference between them is how the compressor of the VCR unit is driven. In a direct configuration, a clutched shaft connects the prime mover and the VCR compressor. The VCR unit is engaged by disengaging the clutch, thereby providing direct shaft power to the refrigerant compressor. Conversely, an indirect configuration does not have a direct shaft connection between the prime mover and the VCR compressor. Electrical load is supplied by the generator (which is connected to the prime mover via a shaft), which is used to power the refrigerant compressor.

\subsubsection{Suitability of VCR and ACR refrigeration for small-scale CHCP}

Figure 2-2 is a schematic of an ACR chiller. The chilling effect is produced from energy provided to the generator by high-temperature powerplant exhaust. This system is well suited for CHCP systems as when a heating load is no longer needed or is throttled, exhaust can be re-directed into the ACR rather than dumped overboard, while a VCR CHCP system (see Figure 1-2) does not make use of exhaust heat when producing a cooling load. If heating and cooling loads are required simultaneously (as in the case of a supermarket or food processing plant [2.21]), the VCR-based CHCP system may be a viable option. Since VCR units do not use waste exhaust to provide a cooling effect, they can only remain 
competitive with ACR CHCP if exhaust is used for another application such as process heat. Commercial or residential applications have thermal load profiles that are different than typical industrial demands, as heating and cooling loads are not required simultaneously. Despite high coefficient of performance (COP) values for VCR systems (high-performance VCR residential air conditioners demonstrate COP values of about 3 or more [2.16]), VCR CHCP systems can only economically operate with applications that require simultaneous cooling and heating loads. This is due to the fact that exhaust heat is not utilized in summer months when only cooling and electrical loads are required.

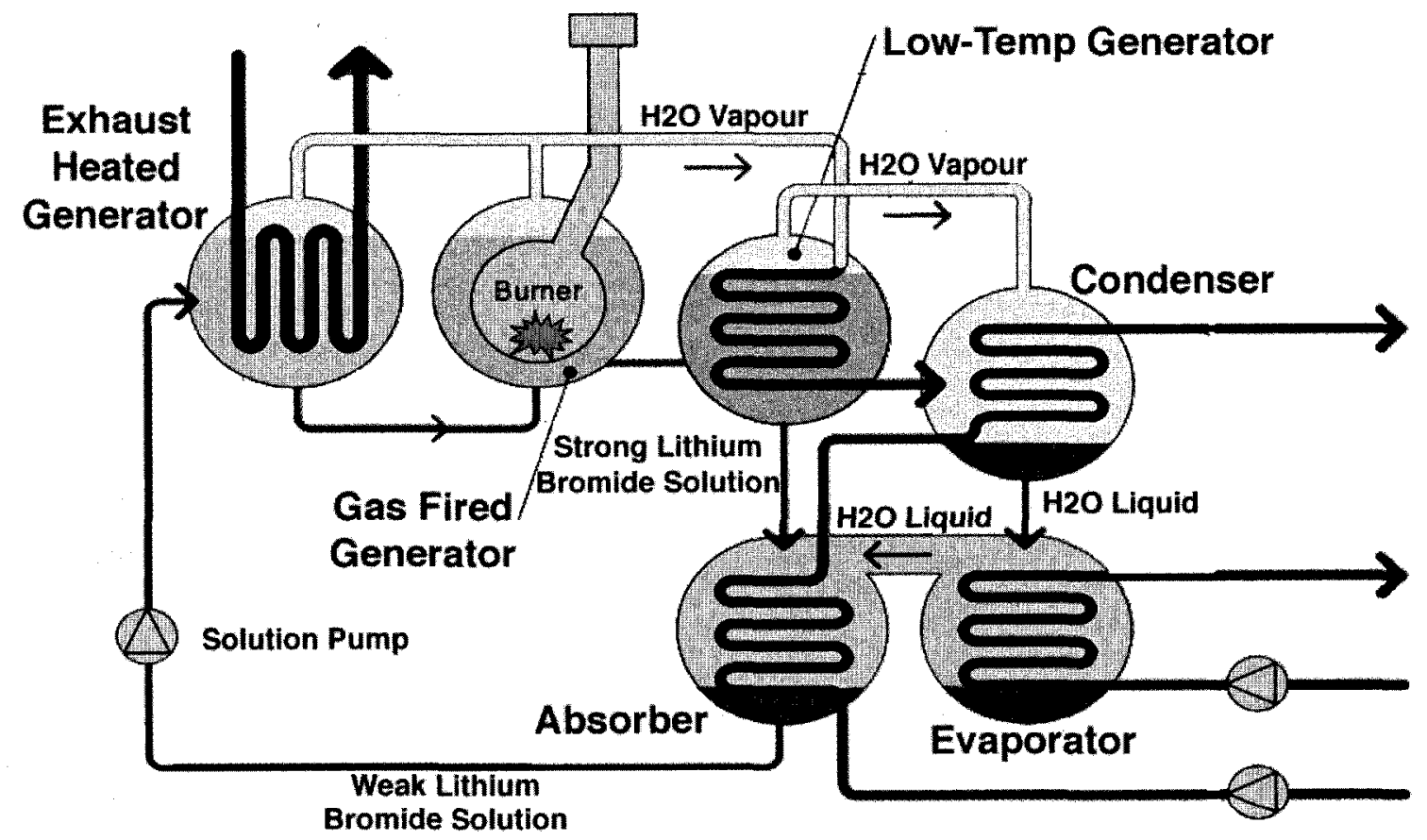

Figure 2-2: Schematic of a double-effect $\mathrm{LiBr}$ absorption chiller adapted from [2.9] 
To maintain high overall efficiency without having to produce both cooling and heating loads simultaneously, ACR refrigeration based CHCP is a more suitable choice. Another factor leading to the domination of ACR over VCR in the trigeneration market is the fact that electrical load is more economically valuable than thermal output. Electrical load can either be used to satisfy electrical loads that would have been purchased, or can be sold back to the grid to generate income. Unlike electrical load waste heat cannot be exported for profit, and is cheaper to produce; hence using electrical load to power a VCR as part of CHCP system unit is not often an economical choice. There are two predominant ACR configurations used in CHCP systems today: single-effect and double-effect ACR. The single-effect ACR uses only exhaust heat to evaporate the working fluid, while the double-effect includes an additional fired generator seen in Figure 2-2. Double-effect ACR can double the COP of single-effect ACR, but also has 20 to 70 percent higher specific capital and maintenance costs [2.23]. As is shown in Figure 2-2, an ACR unit is complex requiring many expensive components in addition to a cooling tower not shown in the diagram. The capital cost for ACR units rises dramatically for smaller units and becomes prohibitively expensive for units sized for a typical household (about 10 to $11 \mathrm{kWt}$ ).

Figure 2-3 contains ACR specific capital costs from several suppliers, and provides a curve fit for small and large-scale chillers. Using the curve fit for small 
chillers (Equation (2-1)) [2.11], an ACR unit sized for a single family detached household would cost about 6400 USD to purchase and install; this cost does not include purchase and installation of a cooling tower; add to this yearly maintenance costs of about 250 USD (see Figure 2-4) for the ACR unit alone.

$$
U S D / k W t=-81.552 \ln (k W t)+778.95
$$

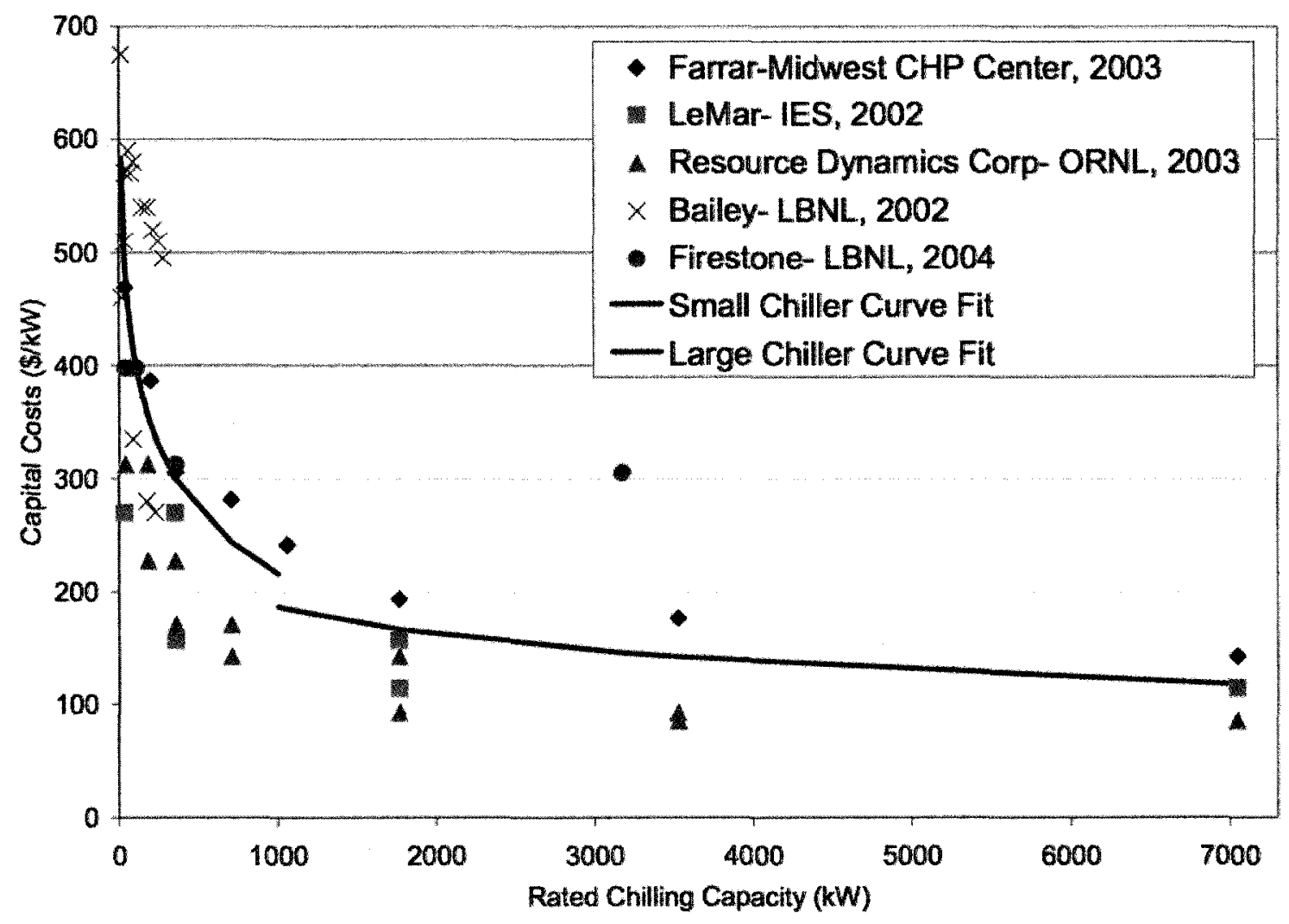

Figure 2-3: Specific capital costs for absorption chillers with curve fits for large and small-scale chillers [2.11]

These costs prevent ACR technology from being considered for small-scale 
trigeneration as in addition to an expensive chiller and cooling tower, a trigeneration system requires the purchase of at least a powerplant in addition to other auxiliary systems. It is clear that an economically successful small-scale CHCP system cannot use ACR or VCR chilling units in order to compete with individual generation system (natural gas furnace, VCR chiller, and grid power) as is common for many North American residential or small-scale commercial applications.

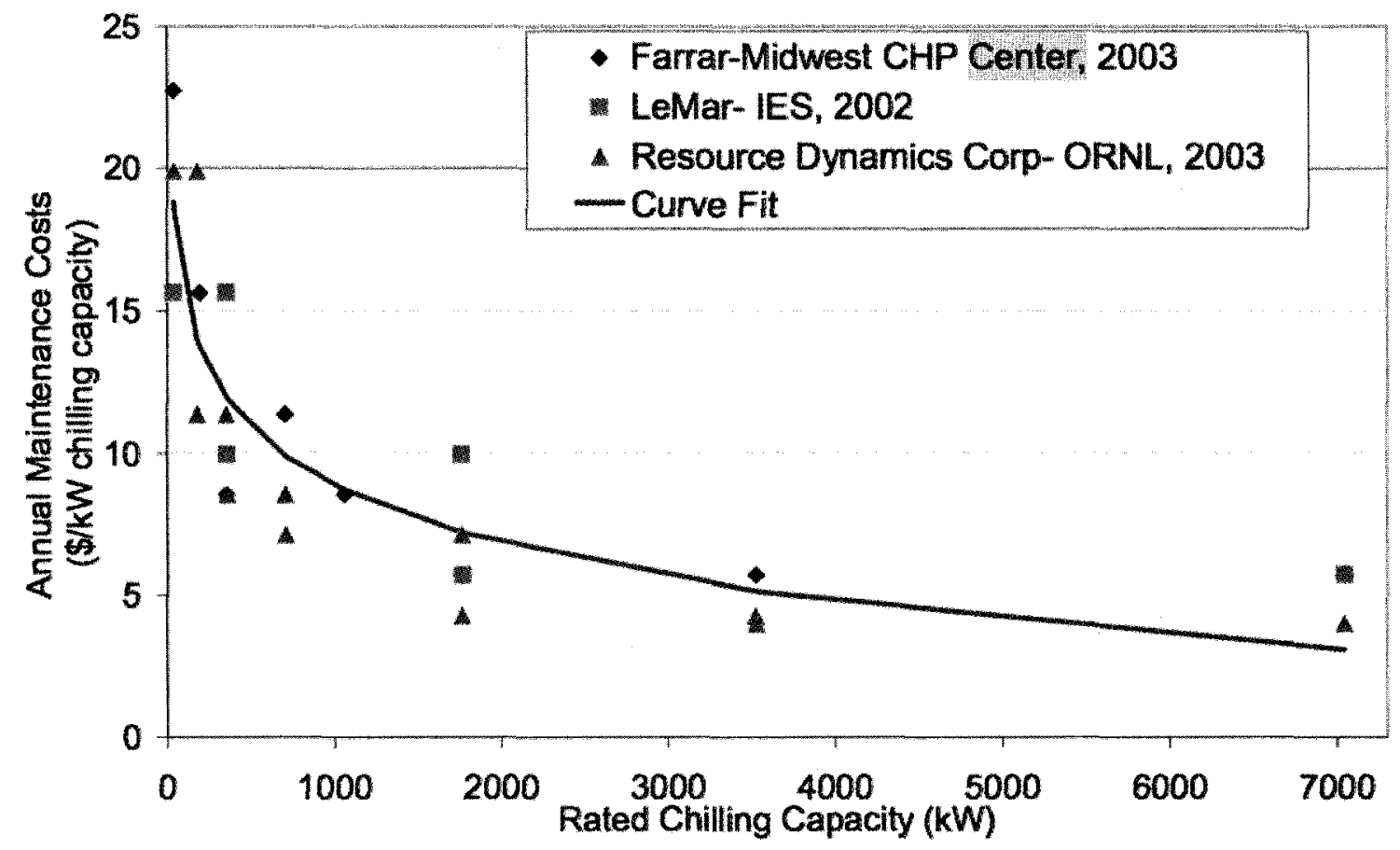

Figure 2-4: Specific maintenance costs for absorption chillers [2.11] 


\subsubsection{Production CHCP packages}

Current $\mathrm{CHCP}$ packages are most commonly designed using off-the-shelf individual components that are matched together in an ad hoc genset package. There are many companies making attempts at proving CHCP technologies in conjunction with the US Department of Energy, however these $\mathrm{CHCP}$ installations are not packaged units [2.10]. They are highly experimental and custom built, involving a high degree of design overhead.

At this time, UTC Power is the only company breaking this tradition by offering the first packaged trigeneration system on the market. This package uses four Capstone microturbines and a $\mathrm{LiBr}$ absorption chiller to provide: $227 \mathrm{kWe}, 500$ kWt cooling load, and $70 \mathrm{kWt}$ heating load at 91 percent overall efficiency when operating in cooling mode. The system can also provide $227 \mathrm{kWe}$ and $322.3 \mathrm{kWt}$ at 68 percent overall efficiency in heating mode [2.28]. UTC Power boasts a 46 percent reduction in $\mathrm{CO}_{2}$ emissions over coal-fired grid power and an average cost savings of 10,000 USD monthly. The system is currently installed in hotels, supermarkets, and shopping centres around the United States.

\subsection{Experimental small-scale CHCP systems}

The main focus of experimental CHCP research is centred on small-scale applications. Perhaps this is due to the fact that large-scale CHCP systems are 
more established, and have demonstrated success in the marketplace while small-scale systems have not. Experimental small-scale CHCP systems published in open literature typically use an internal combustion engine (ICE) as the cycle powerplant as seen in Table 2-1. Examples of the experimental apparatuses can be found in Appendix A. Variation in size of the systems described in Table 2-1 illustrates the scalable nature of small-scale CHCP. The above systems were subjected to loading schemes consistent with an average household and analysed in terms of thermodynamics and economics. All three systems offered improvements in primary energy use when compared to individual generation; experimental data indicates a conservative value of 23 percent is realistically obtainable in practice [2.17].

Table 2-1: Performance data for several experimental small-scale CHCP systems at ISO conditions

\begin{tabular}{|c|c|c|c|c|c|}
\hline $\begin{array}{l}\text { Prime } \\
\text { Mover }\end{array}$ & $\begin{array}{l}\text { Refrigeration } \\
\text { method }\end{array}$ & $\begin{array}{l}\text { Total } \\
\text { Efficiency }\end{array}$ & $\begin{array}{c}\text { Electrical } \\
\text { Output } \\
\text { (kW) }\end{array}$ & $\begin{array}{c}\text { Heating } \\
\text { Output } \\
\text { (kW) }\end{array}$ & $\begin{array}{c}\text { Cooling } \\
\text { Output } \\
\text { (kW) }\end{array}$ \\
\hline $\begin{array}{l}\text { Gasoline } \\
\text { ICE [2.15] }\end{array}$ & ACR & 70 & 12 & 27 & 9 \\
\hline $\begin{array}{c}\text { Gasoline ICE } \\
{[2.24][2.25]}\end{array}$ & VCR & $58-65^{*}$ & 1.5 & 19.6 & 9.1 \\
\hline $\begin{array}{l}\text { Natural gas } \\
\text { ICE [2.12] }\end{array}$ & Ejector $^{\star *}$ & 50 & 5.34 & 5 & 1 \\
\hline
\end{tabular}

${ }^{\text {* }}$ values for ISO standard atmosphere not given, data taken for cooling production during summer months ** a brief description of the ejector cooling cycle can be found in Appendix $F$

These systems are comprised completely from off-the-shelf components, however there is substantial variation in performance data. Overall thermal 
efficiency varies from 70 to 90 percent when producing cooling load, and primary energy reduction over individual generation varies between 23 to 66 percent. The largest differences between the apparatuses in question can be found in the cooling subsystems used. Due to the low COP of ACR units (0.6 to 1.2) [2.8][2.15][2.28], the efficiency of CHCP systems typically is larger during a heating or power mode. For the system using an ACR unit in Table 2-1, the overall efficiency varies between 70 to 75 percent when switching from cooling to heating modes. This variation may seem substantial, but is minor when compared to the reduction in overall efficiency experienced by $\mathrm{CHCP}$ systems utilizing VCR units during cooling only modes of operation.

The efficiencies quoted in Table 2-1 were obtained assuming all the energy products are utilized. For example, the ICE-ACR system produces adequate levels of cooling and heating load to meet a typical household demand of 1 to 4 kWt and 6 to $14 \mathrm{kWt}$ respectively (see Section 3.4.3), but overproduces electrical load. Unless this load can be sold back to the grid, overproduction is a penalty on efficiency. Even if this load can be sold back to the grid, power utilities often charge connection fees and purchase power at a significantly reduced rate that may not compensate adequately for the actual cost of production. Conversely, the ICE-ejector system produces an adequate level of electrical load but severely under produces thermal loads. Within the context of a small-scale non-industrial 
process where loads vary widely, experimental small-scale CHCP systems currently discussed in open literature require additional components to buffer loads. This can take the form of a battery system to deal with over- or underproduction of electrical load, or a backup boiler or furnace to deal with peak thermal loads. The systems shown in Table 2-1 are insufficient to replace individual generation systems while maintaining or improving economic performance.

All three systems were compared to individual generation of electrical and thermal loads on site. System economic performance was not compared against purchasing grid power, electric load was satisfied on site with a generator. This is not a fair economic comparison, as most consumers regardless of size or classification (commercial, industrial, residential) do not generate power on site. Designing CHCP systems that are economically superior to grid power is much more difficult to accomplish, as grid power is usually significantly cheaper to purchase than it is to produce using a genset; the system described in Chapter 3 is designed to compete with grid power.

\subsection{Simulated small-scale CHCP systems}

In addition to experimental small-scale CHCP systems discussed in open literature, there are several simulated systems that warrant comment. Two 
systems in the sub $100 \mathrm{kWe}$ range were found, summarized in Table 2-2.

Table 2-2: Performance data for simulated small-scale CHCP systems

\begin{tabular}{|c|c|c|c|c|c|}
\hline Prime Mover & $\begin{array}{l}\text { Cooling } \\
\text { method }\end{array}$ & $\begin{array}{c}\text { Overall } \\
\text { Efficiency }\end{array}$ & $\begin{array}{c}\text { Electrical } \\
\text { Output } \\
\text { (kW) }\end{array}$ & $\begin{array}{c}\text { Heating } \\
\text { Output } \\
\text { (kW) }\end{array}$ & $\begin{array}{c}\text { Cooling } \\
\text { Output } \\
\text { (kW) }\end{array}$ \\
\hline $\begin{array}{c}\text { Microturbine } \\
{[2.17]}\end{array}$ & $\begin{array}{c}\text { ACR and } \\
\text { VCR }\end{array}$ & 70 & 100 & 117.6 & 75.8 \\
\hline Stirling [2.14] & ACR & 89 & 50 & 76 & 70 \\
\hline
\end{tabular}

The microturbine powered $\mathrm{CHCP}$ simulation ran two iterations which differed in the method by which thermal load was provided; one used an ACR unit, while the other used a heat exchanger and VCR unit. A load profile based upon a commercial retail space was used, the dimensions of the space was scaled according to the thermal output of the CHCP system. As was expected, the ACR unit was superior to the VCR unit economically based upon a full year simulation; capital costs were not taken into account in the simulation. Similar to the experimental systems, both simulated systems made the key assumption that all energy products were used on site in overall efficiency and economic calculations, which is most likely not the case. 


\subsection{Hydraulic storage and the inverse Brayton cycle}

Hydraulic storage has been used for a variety of purposes; this includes providing power for shop tools and industrial machinery, providing pneumatic power for assembly line automation, and for providing propulsion via hydraulically powered motors as early as 1879 [2.4] [2.19]. The idea of using compressed air storage as energy storage (CAES) for power generation was first investigated by the General Electric Company and the Brown Boveri Company (later renamed ABB) in the mid 1970s [2.33] [2.35]. Compressed air was stored in an underground cavern during off-peak hours. During peak hours when load exceeds nominal generation capacity, the high-pressure cavern air is passed through a combustion chamber and then into an expander to provide electrical load. Several independent studies have compared the capital and operational costs of the cavern-CAES system to a gas turbine plant of equal electrical output, and have concluded the cavern-CAES system demonstrates lower operational costs without significantly higher capital investment costs [2.33][2.26][2.30][2.29]. The cavern-style system is tailored for large MW scale power producers, the economic success of which has motivated smaller spin-off technologies.

Active Power, a company based in Austin, Texas has used compressed air storage with an expansion turbine to provide short-term backup power [2.30]. This system is designed to replace battery based UPS systems for servers and 
other sensitive equipment and is capable of providing $20 \mathrm{kWe}$ of continuous power for 15 minutes. Some key advantages of the system include a long service life of 20 years, a higher power density than lead acid batteries, and modular construction. There is no danger of power discharge during storage, ensuring 100 percent readiness at all times. This system demonstrates the environmental benefits of using CAES. Eliminating space consuming, environmentally harmful batteries, which require frequent replacement not only improves system life, but is also more suited to a growing population of consumers who wish to reduce their environmental impact.

Others have seen the potential for small-scale hydraulic storage power systems and have attempted to improve on the idea. A team from Lausanne, Switzerland has modelled and built an experimental prototype of a hydraulic-pneumatic storage hybrid system that promises greater efficiency and energy density over a strictly pneumatic system [2.29]. The system uses a motor/generator to pump hydraulic fluid into an accumulator already pressurized with air. When emergency power is required, high-pressure hydraulic fluid is discharged through a hydraulic motor, producing 1 to $4 \mathrm{kWe}$ via the motor/generator. This system has the advantage of extracting work from the hydraulic fluid at higher efficiencies than a turbo-expander can from air; using a liquid as the working fluid allows much higher specific work output as well. The end result is a significantly higher power 
density when compared to the compressed air UPS system. Both of the described systems are useful for their intended purposes, but are strictly limited to very short periods of discharge. In an effort to extend the concept of the IBC to a continuous flow process, several alternative applications have been developed.

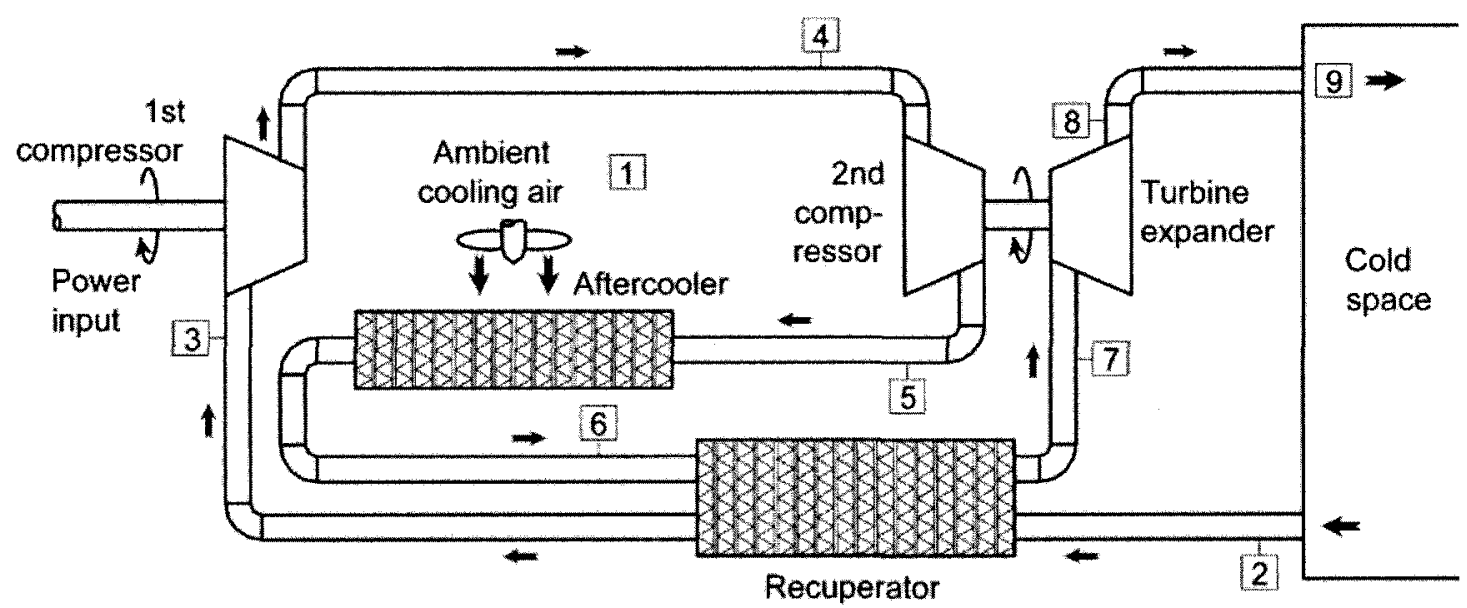

Figure 2-5: Schematic of an IBC refrigeration system designed for use in road transport applications [2.32]

IBC refrigeration is popular with transportation industries such as aviation and rail for space cooling [2.7]. Since IBC refrigeration uses air as the working fluid, the need for liquid refrigerants, associated storage tanks, high-pressure lines, and compressors are eliminated. It has even been suggested that IBC refrigeration could be useful for road transport as well, seen in Figure 2-5 [2.32]. In a world of increasingly tighter environmental requirements, a refrigeration system that does not require controlled substances such as a refrigerant is very appealing. 
In general, IBC refrigeration cycles demonstrate COP values half that of VCR units if generic components are used. However IBC refrigeration COP approaching or exceeding that of VCR units has been demonstrated for optimized systems built using specifically designed turbomachinery and heat exchanging equipment [2.7][2.32]; this emphasises the importance of careful design of an IBC system. Inefficient designs could result in unnecessary abandonment due to poor performance results.

IBC technologies can be applied to gensets as well. Gas turbines experience significant reductions in specific power output and thermal efficiency in hightemperature environments. Systems have been proposed to reduce inlet temperatures including thermal storage [2.20], evaporative cooling [2.6], and IBC refrigeration [2.34]. Gas turbines have very high mass flow rates when compared to reciprocating engines, and therefore require high-capacity inlet cooling refrigeration equipment; IBC refrigeration systems have similar mass flow rates to gas turbines, making them ideal for increasing performance of gas turbine gensets in hot weather conditions. 


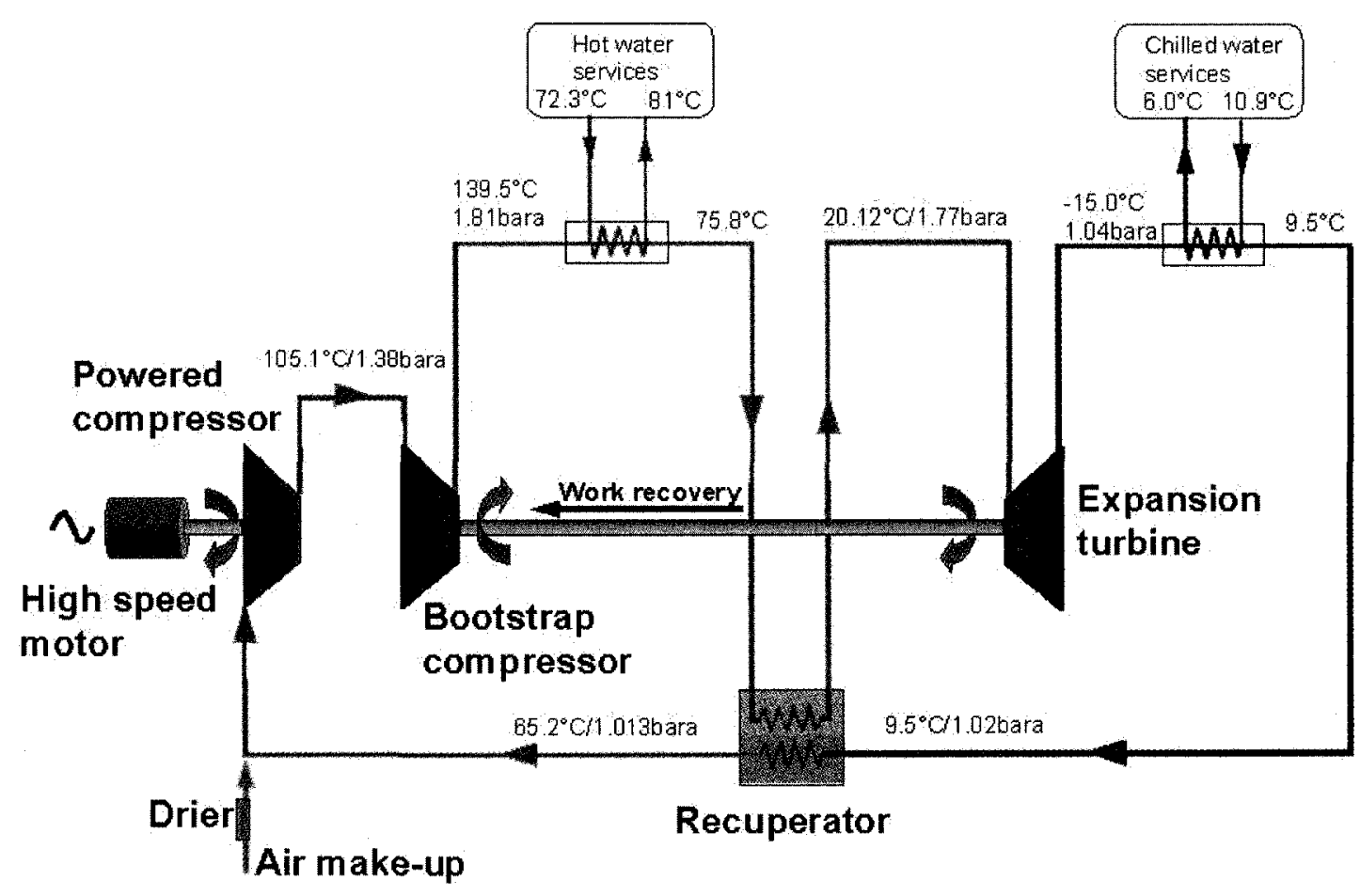

Theoretical building air cycle system

Figure 2-6: IBC applied to building heating and cooling [2.7]

A research consortium headed by Building Research Consultants (BRC) based in the UK is investigating the feasibility of the IBC concept for building heating and cooling [2.7]. The simulated system is designed to provide a simultaneous 80 kWt cool water load and $20 \mathrm{kWt}$ hot water load. The refrigeration side demonstrated COP values of about 0.6 , which is equivilent with single-effect absorption chillers [2.9] while the heating side demonstrated COP values of 1.5. Despite having low refrigeration COP values when compared to modern VCR units, performance was found to be invariant with respect to outside air 
temperature. It is anticipated that over a full year the IBC system can remain competitive with heat pumps and VCR units, which will be investigated with experimentation.

\subsection{Summary}

CHCP systems are relatively new, having been used in commercial and industrial installations only within the past 10 to 15 years. Historically, CHCP systems have been targeted for large industrial or commercial processes where electrical and thermal loads are relatively constant. This permits a CHCP system to be sized such that at full capacity there is no over-production of thermal or electrical loads; small-scale applications of CHCP technology require more flexibility as load profiles are highly variable.

While there is evidence of research and development in the area of small-scale CHCP technology, the majority of commercial development is in the greater than $100 \mathrm{kWe}$ range. This can be attributed to increasing specific capital costs as $\mathrm{CHCP}$ systems are decreased in size; primarily due to the high cost of absorption chillers, the most popular method of providing a thermal load in a CHCP system.

CHCP systems are still only available commercially as custom-built packages from a select few companies; currently United Technologies is the only company offering a standardized CHCP package. Experimental and simulated systems are 
discussed in open literature, however they are often sized for medium to large applications (greater than $50 \mathrm{kWe}$ ). There is no system currently discussed in open literature, or available on the market, that provides an energy islanding CHCP solution for residential or small-scale commercial users at an economical specific capital and maintenance cost.

While CHCP systems may be relatively new, the use of accumulators in combination with the IBC is not. The two concepts have been combined to produce emergency power, but have not been applied to a continuous flow power cycle for small-scale application before. The IBC has been used for mobile refrigeration applications, and more recently is being applied to building heating and cooling. Despite the wide variety of simulated, tested, and commercially applied IBC systems, there exists no IBC system applied to a trigeneration cycle for small-scale applications. This thesis will investigate the feasibility of such a system and report on simulated thermodynamic and economic performance. The simulated trigeneration system will be compared against individual generation using an air conditioning system, natural gas furnace, and grid power. 


\section{Chapter 3}

\section{Description of Model and Simulation}

\subsection{Overview of Model}

This section describes the design and simulation of an indirectly fired trigeneration system with hydraulic accumulation as shown in Figure 3-2 and Figure 3-3. The system is composed of a conventional microturbine, with a network of heat exchangers in lieu of a conventional burner section. By using an indirectly fired process, combustion gases never mix with microturbine flow, allowing microturbine exhaust to be used for household heating or cooling. An air accumulator is used as an energy storage device when the microturbine overproduces electrical load. The compressed air stored in the accumulator is used to generate power and thermal loads when the microturbine is turned off. Two different heat exchanger configurations are used, Mode 1 for heating loads, and Mode 2 for cooling loads as shown in Figure 3-2 and Figure 3-3 respectively.

\subsection{Initial system design}

The initial concept for the trigeneration system had one configuration for cooling and heating modes as shown in Figure 3-1. Key differences between the initial concept and the final system shown in Figure 3-2 and Figure 3-3 are summarized here:

- Initial system design called for the accumulator to be charged with bleed air 
from the microturbine compressor instead of using a separate compressor

- Same HEN configuration was used for both cooling and heating modes

- No secondary expander

- No in-ground \#4 Hx

- Accumulator flow was not cycled through the HEN in heating mode

Once initial simulations were run, it was immediately apparent that the initial configuration had operational difficulties that would prevent it from satisfying a highly variable thermal and electrical load. The following sections describe the modifications made to the base system in an effort to increase thermodynamic and economic performance, and the related effect on system response. 


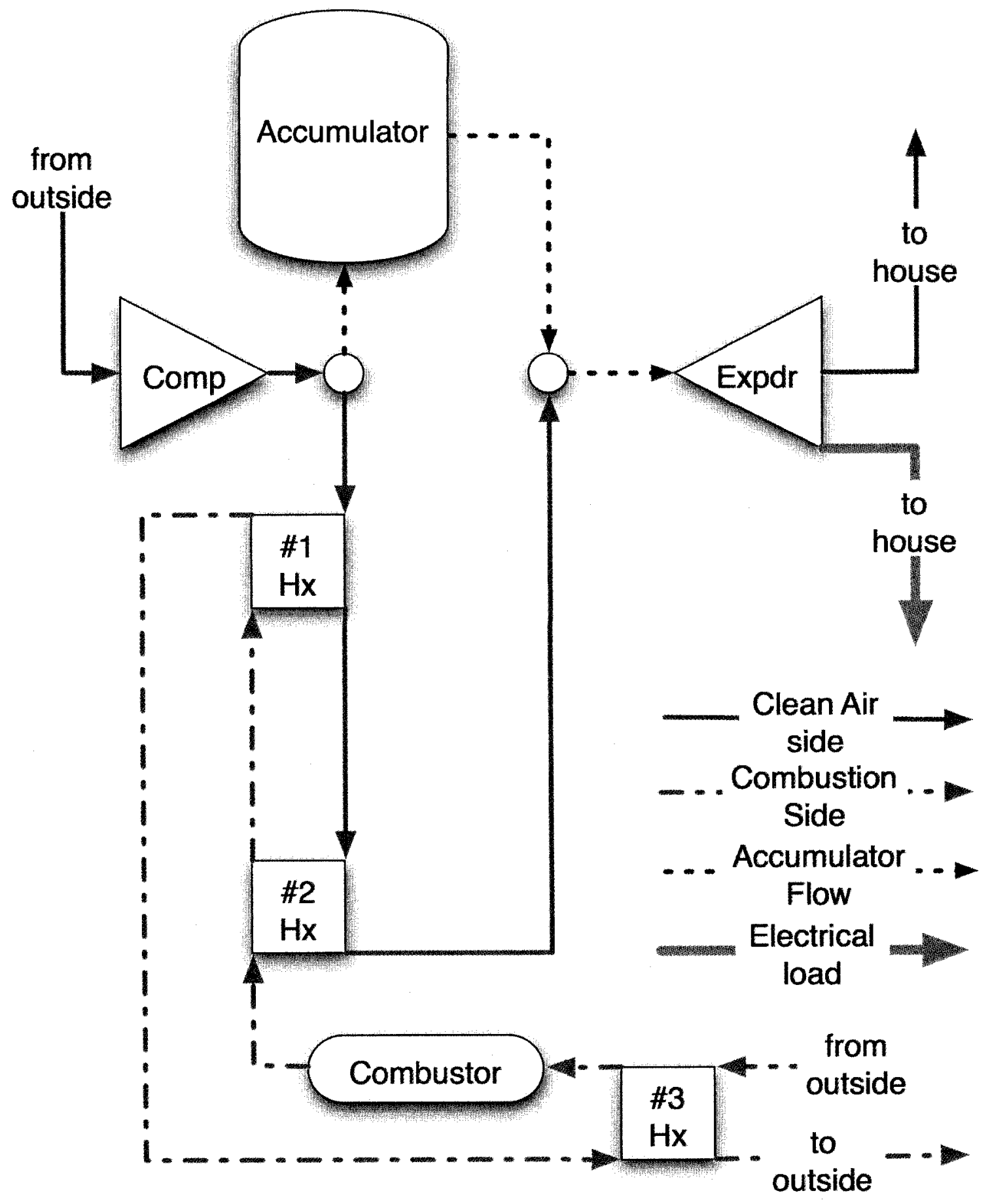

Figure 3-1: Original trigeneration system design 


\subsection{Final system design}

The following is a description of the final configuration and method of operation used in the final simulation.

\section{MICROTURBINE OPERATION:}

In this system, the microturbine is used to:

1) Meet household electrical load demands.

2) Provide a heat load when operating in Mode 1.

3) Charge the accumulator.

As the microturbine almost always produces an electrical output in excess of household demand, the excess is fed to a secondary compressor which charges the accumulator.

INVERSE BRAYTON CYCLE (IBC):

The IBC is used to:

1) Provide household electrical load when the microturbine is not running.

2) Provide a heating load in Mode 1 when the microturbine is not running. While the microturbine produces a thermal load in excess of household demand, the IBC produces less than household demand.

3) Meet household cooling load in Mode 2. The IBC consists of the secondary compressor, \#4 $\mathrm{Hx}$, accumulator, and secondary expander. 
GENERAL ASSUMPTIONS AND CONSTANTS:

The following are a set of assumptions and constants that are applied to all components and throughout the simulation:

- Air was treated as a perfect gas with a composition of 21 percent $\mathrm{O}_{2}, 79$ percent $\mathrm{N}_{2}$, and zero moisture

- No transient behaviour was modelled

- $P_{a}=101.325 \mathrm{kPa}$

- $R=287 \mathrm{~J} / \mathrm{kgK}$

\section{MODE 1:}

Is used to produce electric and heat loads. Mode 1 does not cycle microturbine expander exhaust through the heat exchanger network (HEN), thereby providing high temperature flow for household heating. During accumulator discharge, accumulator flow is directed through the HEN where flow temperature is increased before discharge through the secondary expander; this increases the thermal output of the IBC.

MODE 2:

Is used to produce a cooling load. Microturbine exhaust is no longer required for heating purposes, therefore it is used to pre-heat HEN combustion air before being vented to atmosphere. Mode 2 meets household thermal demands using 
the IBC alone, instead of a combination of microturbine and IBC as does mode 1. In order to meet a cooling load, secondary compressor discharge flow is cooled using \#4 $\mathrm{Hx}$ before passing into the accumulator. This ensures the air in the accumulator is at or below ambient, for use in cooling load production. During accumulator discharge, expansion through the secondary expander produces electrical power and low temperature exhaust suitable for household cooling.

As there are a number of components that require modelling, for ease of understanding this section is broken into five sub-groups: 1) the HEN 2) microturbine 3) secondary turbomachinery 4) accumulator 5) the individual generation system. 


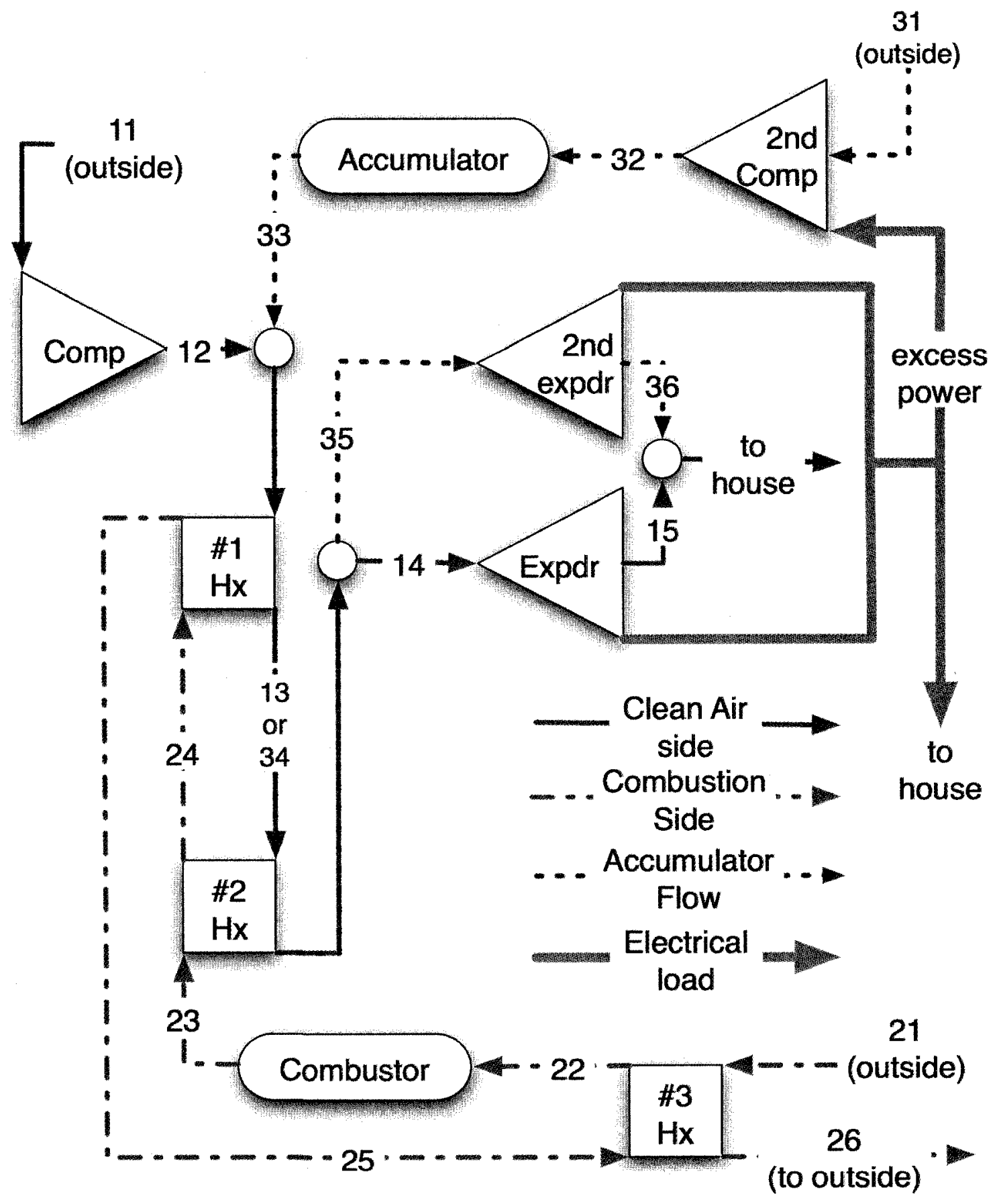

Figure 3-2: Schematic of trigeneration system in heating mode (Mode 1) 


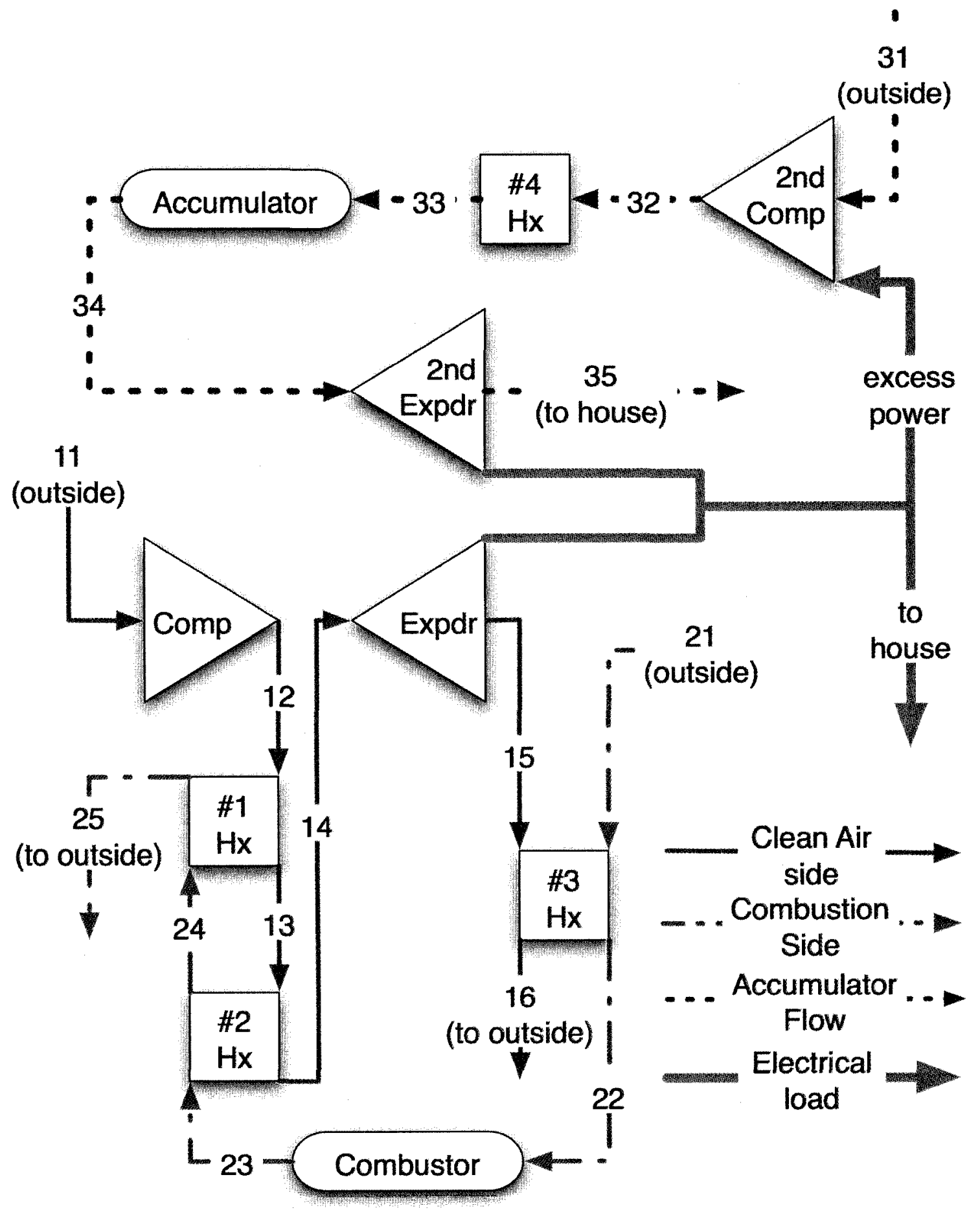

Figure 3-3: Schematic of trigeneration system in cooling mode (Mode 2) 


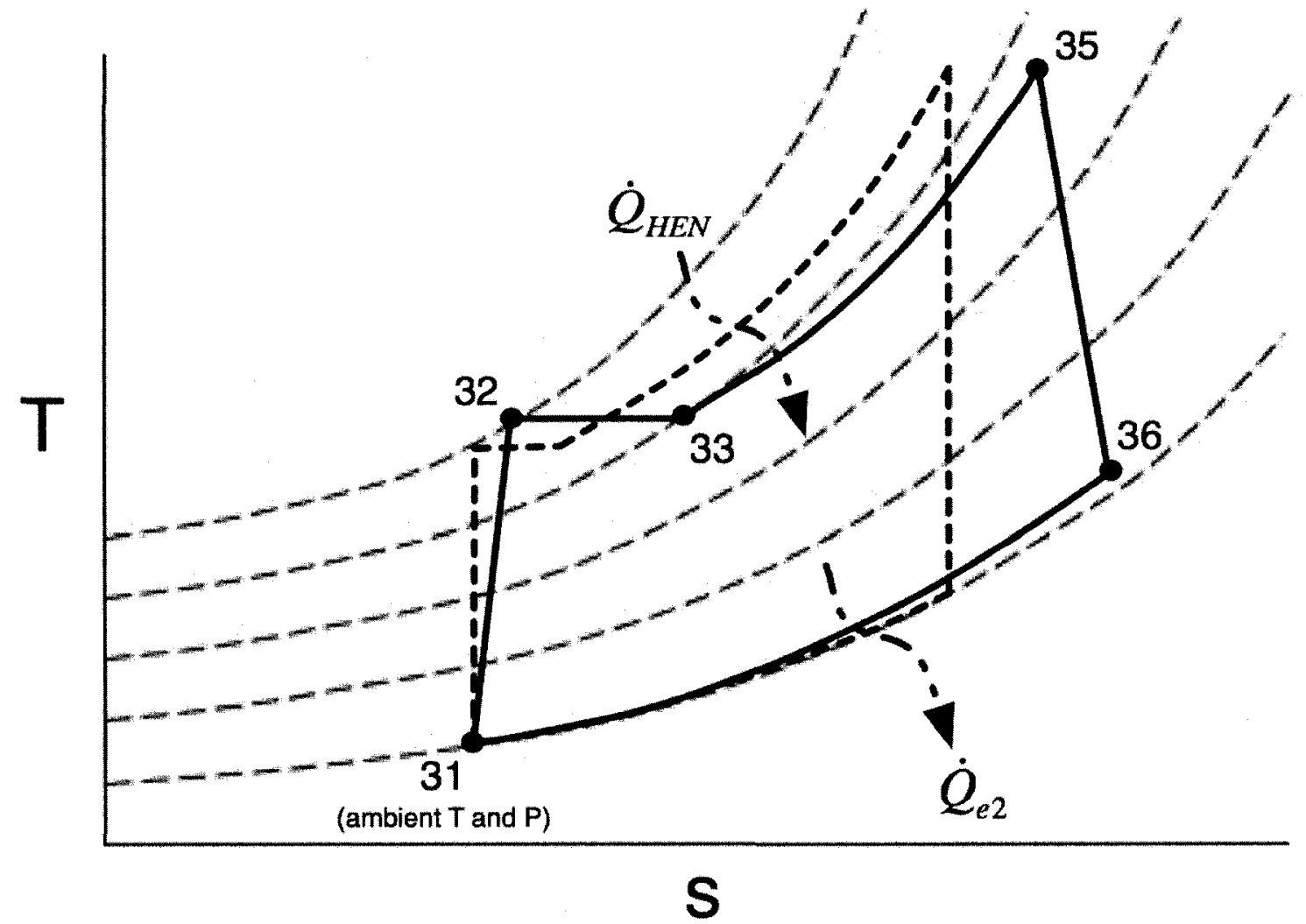

Figure 3-4: T-s diagram for the IBC in heating mode. Dashed lines represent the ideal cycle without pressure losses and isentropic expansion and compression processes. The solid line is the actual cycle which takes into pressure losses, isentropic efficiencies, and losses when discharging to the accumulator.

While the combination of the microturbine and HEN produce a standard Brayton cycle T-s diagram for both heating and cooling modes, the IBC has a slightly different diagram for each mode shown in Figure 3-4 and Figure 3-5. As secondary compressor flow is discharged to the accumulator, the flow will expand to accumulator pressure. For the ideal cycle in both heating and cooling modes, this process will generate less entropy than the actual case, as is shown 
in Figure 3-4 and Figure 3-5. The actual case also takes into account pressure losses in the HEN and exhaust ducting of the microturbine.

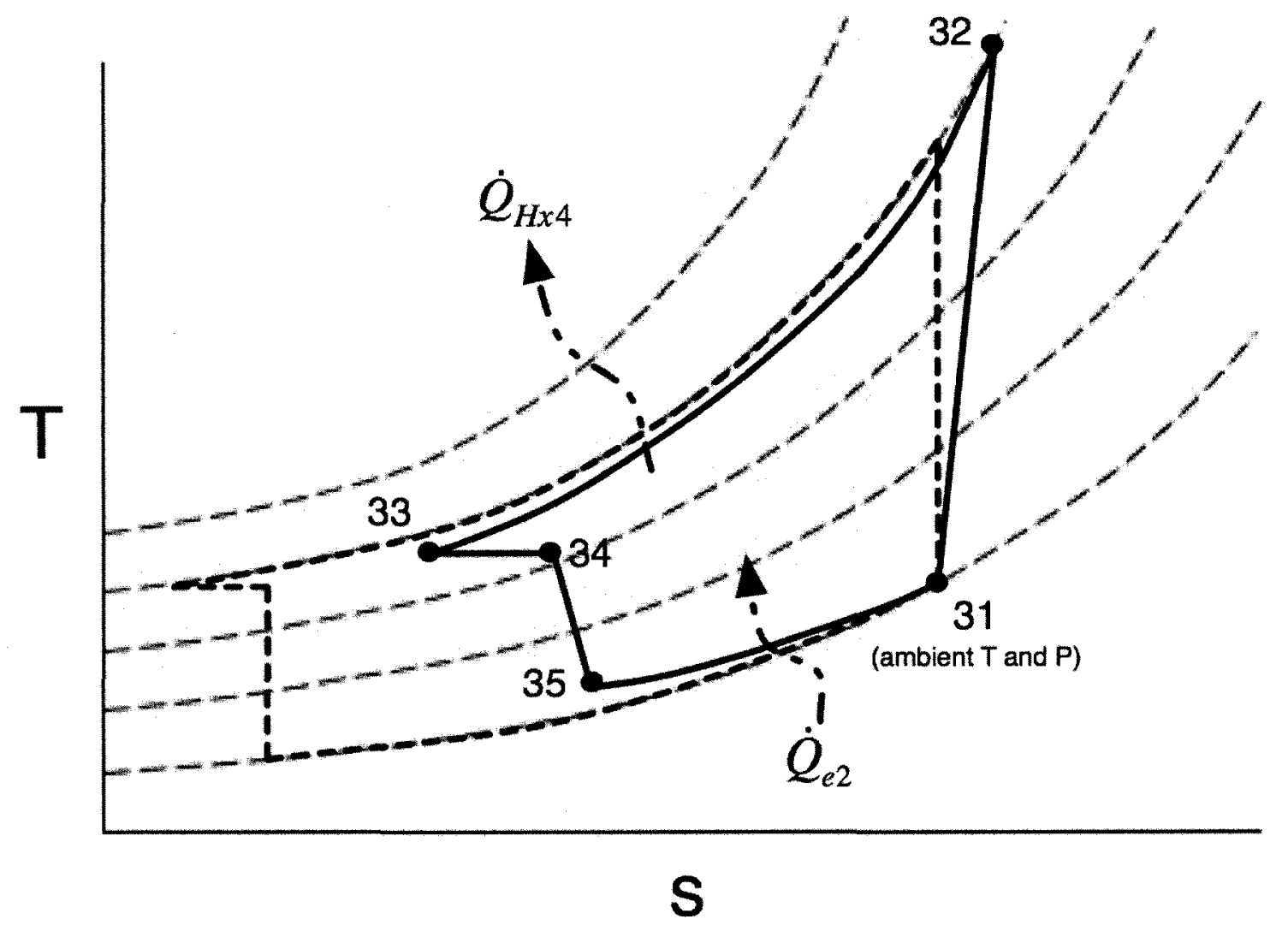

Figure 3-5: T-s diagram for the IBC in cooling mode. Dashed lines represent the ideal cycle without pressure losses and isentropic expansion and compression processes. The solid line is the actual cycle which takes into pressure losses, isentropic efficiencies, and losses when discharging to the accumulator.

While the impact of the zero moisture assumption on system performance is unknown (the presence of moisture will increase the specific work output of the microturbine, however the exact impact on thermal efficiency is unknown), 
operational impact is less ambiguous. The presence of micro droplets in the air poses a problem for turbomachinery, as impingement of these droplets will have a negative impact on efficiency and cause pitting on blade and stator surfaces. Presence of moisture in the IBC flow path will pose a problem for accumulator and valve oxidation, in addition to the impact on turbomachinery. Drying inlet air is a prudent course of action, should the theoretical model described in this chapter be practically implemented.

\subsubsection{Heat exchanger network (HEN)}

The HEN is required to indirectly fire the microturbine. A series of three heat exchangers are used to raise the temperature of compressor discharge flow before discharge to the microturbine expander. The HEN operates in two different configurations for heating and cooling loads, and are described separately. This section deals with both on-design and off-design operation of the HEN.

\subsubsection{On-design operation (maximum \#2 Hx temperature operation)} ASSUMPTIONS AND CONSTANTS:

- $\varepsilon=0.9$ for all exchangers

- Zero fouling was assumed

- $\Delta P_{h x}=2$ percent (applied across each heat exchanger) 
- $\eta_{\text {comb }}=0.99$

- Combustion side and air side mass flows are equal

- $T_{\max }=1200 \mathrm{~K}$

- Ground around \#4 Hx has an infinite heat capacity and a constant temperature of $8^{\circ} \mathrm{C}(281 \mathrm{~K})$

- Fuelled with natural gas ( $\mathrm{LHV}=50 \mathrm{MJ} / \mathrm{kg}$ )

INPUTS:

- Compressor discharge enthalpy and pressure: $h_{12}, P_{12}$

- Ambient conditions: $h_{a}, P_{a}$

\section{OUTPUTS:}

- Specific fuel flow: $\ddot{m}_{f}$

- Expander inlet enthalpy and pressure: $h_{14}, P_{14}$

\section{DECISION CHARTS:}




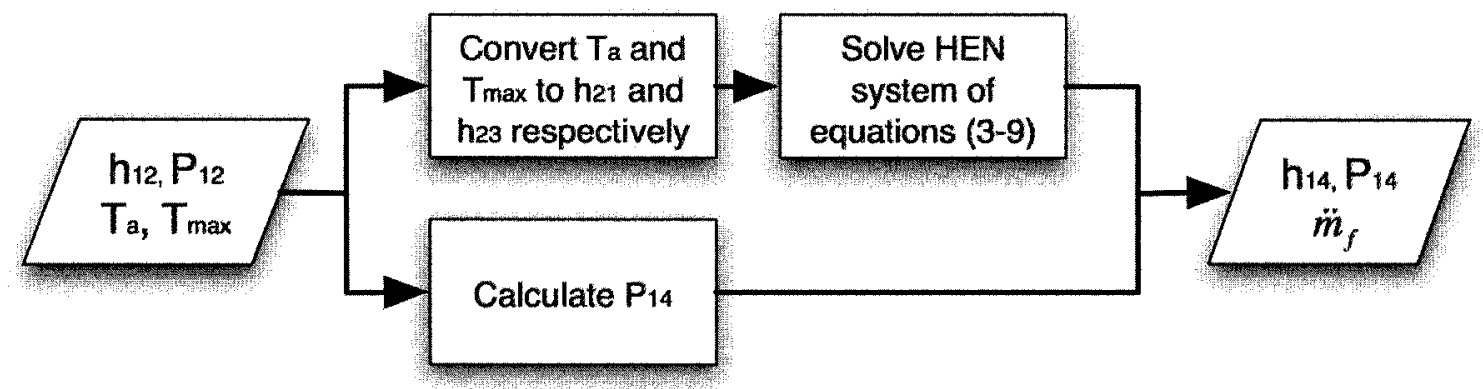

Figure 3-6: Mode 1 on-design decision chart.

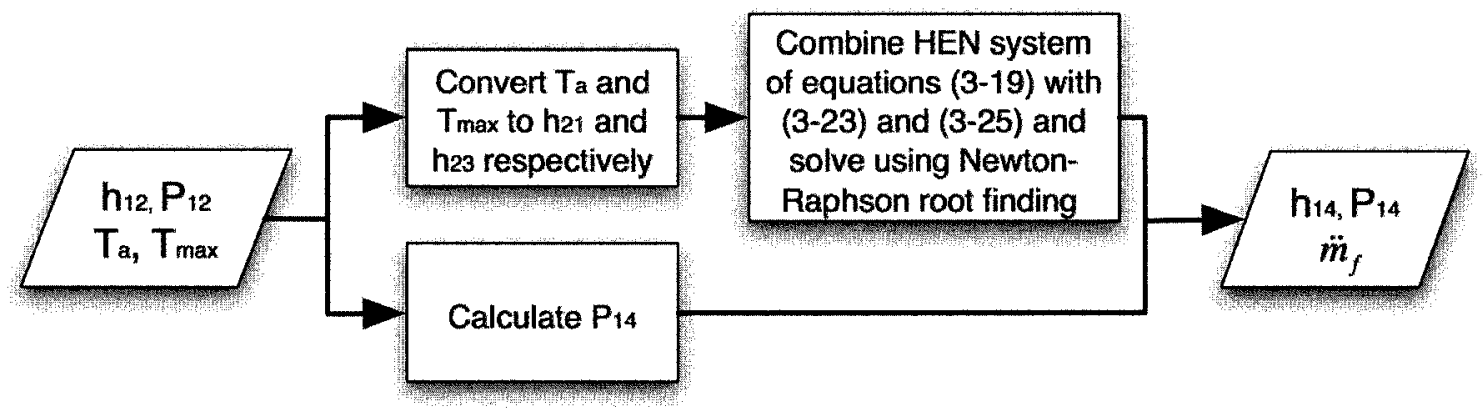

Figure 3-7: Mode 2 on-design decision chart.

\section{THEORY:}

Equations for heat exchanger effectiveness (Equation (3-1)) and the $1^{\text {st }}$ law of thermodynamics (Equation (3-2)) were applied to each exchanger in the network. With respect to Equations (3-1) and (3-2), the subscripts $C$ and $H$ stand for cold and hot streams respectively.

$$
\begin{aligned}
& \varepsilon=\frac{h_{C, \text { out }}-h_{C, \text { in }}}{h_{H, \text { in }}-h_{C, \text { in }}} \\
& \dot{m}_{C}\left(h_{C, \text { out }}-h_{C, \text { in }}\right)=\dot{m}_{H}\left(h_{H, \text { in }}-h_{H, \text { out }}\right)
\end{aligned}
$$

Using Mode 1 as an example, the following six equations result from the 
application of Equations (3-1) and (3-2) to the HEN:

$$
\begin{aligned}
& \varepsilon=\frac{h_{13}-h_{12}}{h_{24}-h_{12}} \\
& \varepsilon=\frac{h_{14}-h_{13}}{h_{23}-h_{13}} \\
& \varepsilon=\frac{h_{22}-h_{21}}{h_{25}-h_{21}} \\
& h_{13}-h_{12}=h_{24}-h_{25} \\
& h_{14}-h_{13}=h_{23}-h_{24} \\
& h_{22}-h_{21}=h_{25}-h_{26}
\end{aligned}
$$

Equations (3-3) through (3-8) are then manipulated into an $A x=b$ format by placing all unknown variables on the left hand side and all known variables on the right hand side of the equation:

$$
\left[\begin{array}{cccccc}
0 & 0 & -1 & 0 & \varepsilon & 0 \\
-1 & 0 & 0 & \varepsilon & 0 & 0 \\
1-\varepsilon & -1 & 0 & 0 & 0 & 0 \\
0 & 0 & 1 & 0 & -1 & 1 \\
1 & 0 & 0 & -1 & 1 & 0 \\
-1 & 1 & 0 & 1 & 0 & 0
\end{array}\right] \times\left[\begin{array}{c}
h_{13} \\
h_{14} \\
h_{22} \\
h_{24} \\
h_{25} \\
h_{26}
\end{array}\right]=\begin{gathered}
(\varepsilon-1) h_{21} \\
(\varepsilon-1) h_{12} \\
-\varepsilon h_{23} \\
h_{21} \\
h_{12} \\
h_{23}
\end{gathered}
$$

After solving Equation (3-9) by inverting the solution matrix, specific fuel flow can be calculated using the following: 
$\ddot{m}_{f}=\frac{h_{23}-h_{22}}{\eta_{c o m b}}$

HEN discharge pressure (expander inlet pressure) is calculated using the assumption that each heat exchanger has a 2 percent pressure loss:

$P_{14}=P_{12}\left(0.98^{2}\right)$

Heat exchanger \#4 is not included in the HEN system of equations as there is no relationship between the inlet and outlet enthalpies of the \#4 Hx and the HEN. The inlet and outlet enthalpies of the HEN are not independent of one another; they must be solved simultaneously. This is not true for \#4 Hx, which is independent of the HEN. The discharge temperature for \#4 $\mathrm{Hx}$ is simply calculated using an adaptation of Equation (3-1) where $T_{\text {out }}$ is accumulator inlet temperature and $T_{i n}$ is secondary compressor discharge temperature; an effectiveness of 0.95 was assumed for the \#4 $\mathrm{Hx}$ :

$$
T_{\text {out }}=\varepsilon_{4}\left(T_{\text {ground }}-T_{\text {in }}\right)+T_{\text {in }}
$$

The HEN solution method for Mode 2 differs from Mode 1 . This is due to the fact that as flow is directed through different paths from the heating mode, there are different unknowns. The cooling mode system of equations has one more unknown than equations. It therefore has to be implicitly solved with expander discharge temperature Equations (3-26) and (3-27). This is done by using a symbolic variable for $h_{15}$ to allow MATLAB ${ }^{\mathrm{TM}}$ to solve the system of equations 
symbolically, instead of in a closed equation format as was done for the heating mode. The system of equations for Mode 2 is as follows:

$$
\begin{aligned}
& \varepsilon_{1}=\frac{h_{13}-h_{12}}{h_{24}-h_{12}} \\
& \varepsilon_{2}=\frac{h_{14}-h_{13}}{h_{23}-h_{13}} \\
& \varepsilon_{3}=\frac{h_{22}-h_{21}}{h_{15}-h_{21}} \\
& h_{13}-h_{12}=h_{24}-h_{25} \\
& h_{14}-h_{13}=h_{23}-h_{24} \\
& h_{22}-h_{21}=h_{15}-h_{16} \\
& {\left[\begin{array}{cccccc}
1-\varepsilon & -1 & 0 & 0 & 0 & 0 \\
-1 & 0 & 0 & 0 & \varepsilon & 0 \\
0 & 0 & 0 & -1 & 0 & 0 \\
1 & 0 & 0 & 0 & -1 & 1 \\
-1 & 1 & 0 & 0 & 1 & 0 \\
0 & 0 & 1 & 1 & 0 & 0
\end{array}\right] \times\left[\begin{array}{c}
h_{13} \\
h_{14} \\
h_{16} \\
h_{22} \\
h_{24} \\
h_{25}
\end{array}\right]=\left[\begin{array}{c}
-h_{23} \varepsilon \\
h_{12}(\varepsilon-1) \\
h_{21}(\varepsilon-1)-h_{15} \varepsilon \\
h_{12} \\
h_{23} \\
h_{21}+h_{15}
\end{array}\right]}
\end{aligned}
$$

As was mentioned previously, Equation(3-19) is solved in terms of $h_{15} ; h_{14}$ is therefore as a function of the as of yet unknown $h_{15}$. Equations (3-26) and (3-27) require $h_{14}$ to be converted into $T_{14}$. However as $h_{14}$ is expressed in terms of $h_{15}$, the system of equations generated must be solved simultaneously 
and implicitly. Air-side flow passes through one more heat exchanger (\#3 $\mathrm{Hx}$ ) in Mode 2, therefore HEN discharge pressure is calculated using Equation (3-20):

$$
P_{14}=P_{12}\left(0.98^{3}\right)
$$

\subsubsection{Off-design operation (EIT specified)}

To reduce the output power of the microturbine, the EIT must be reduced. As such off-design operation needs to be taken into consideration. Equations (3-9) and (3-19) cannot be used for off-design operation, as $T_{\max }$ (and by extension $h_{23}$ ) becomes an unknown and must be removed from the solution matrix. $T_{14}$ (EIT) is specified in off-design operation, therefore has to be removed from the unknowns vector and put into the solution matrix. The inputs, assumptions, and constants remain unchanged from on-design operation and can be found in Section 3.3.1.1. Equations for HEN discharge pressure $\left(P_{14}\right)$ also remain unchanged.

\section{OUTPUTS:}

- Specific fuel flow: $\ddot{m}_{f}$

- Expander inlet pressure: $P_{14}$

- HEN maximum temperature: $T_{23}, h_{23}$ 
DECISION CHARTS:

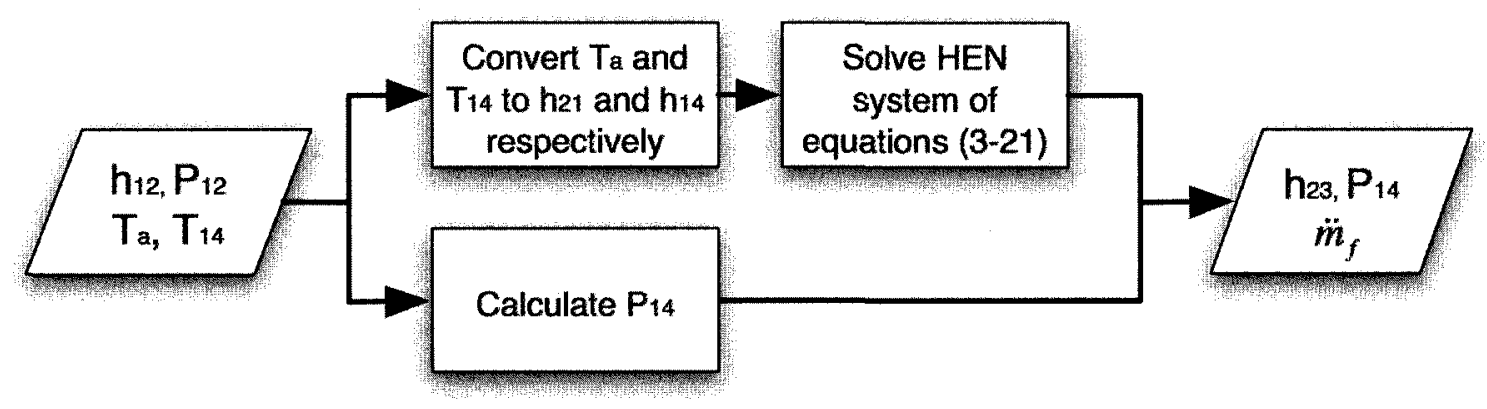

Figure 3-8: Mode 1 off-design decision chart.

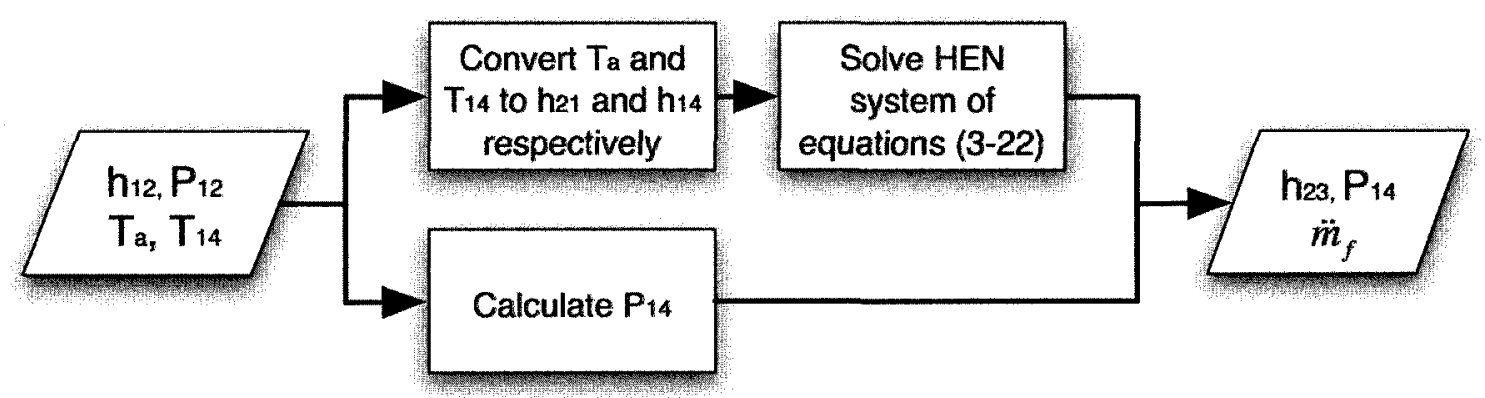

Figure 3-9: Mode 2 off-design decision chart.

\section{THEORY:}

The system of equations remains unchanged from on-design operation for both Mode 1 and 2, however the variables are separated differently to account for the change in known and unknown variables. The system of equations for Mode 1 in off-design is shown in Equation (3-21): 
$\left[\begin{array}{cccccc}0 & 0 & -1 & 0 & \varepsilon & 0 \\ -1 & 0 & 0 & \varepsilon & 0 & 0 \\ 1-\varepsilon & \varepsilon & 0 & 0 & 0 & 0 \\ 0 & 0 & 1 & 0 & -1 & 1 \\ 1 & 0 & 0 & -1 & 1 & 0 \\ 1 & 1 & 0 & -1 & 0 & 0\end{array}\right] \times\left[\begin{array}{c}h_{13} \\ h_{23} \\ h_{22} \\ h_{24} \\ h_{25} \\ h_{26}\end{array}\right]=\left[\begin{array}{c}-h_{21}(\varepsilon-1) \\ h_{12}(\varepsilon-1) \\ h_{14} \\ h_{21} \\ h_{12} \\ h_{14}\end{array}\right]$

The HEN solution matrix for Mode 2 off-design operation is slightly different from Mode 1 off-design because it includes the expander discharge enthalpy $h_{15}$. It is possible to calculate this value without first solving the HEN solution matrix, as in off-design expander inlet temperature is specified. Unlike on-design operation, the Mode 2 off-design system of equations does not need to be solved implicitly using root finding methods. The corresponding system of equations for off-design Mode 2 is found in Equation (3-22):

$\left[\begin{array}{cccccc}1-\varepsilon & \varepsilon & 0 & 0 & 0 & 0 \\ -1 & 0 & 0 & 0 & \varepsilon & 0 \\ 0 & 0 & 0 & -1 & 0 & 0 \\ 1 & 0 & 0 & 0 & -1 & 1 \\ -1 & -1 & 0 & 0 & 1 & 0 \\ 0 & 0 & 1 & 1 & 0 & 0\end{array}\right] \times\left[\begin{array}{c}h_{13} \\ h_{23} \\ h_{16} \\ h_{22} \\ h_{24} \\ h_{25}\end{array}\right]=\left[\begin{array}{c}h_{14} \\ h_{12}(\varepsilon-1) \\ h_{21}(\varepsilon-1)-h_{15} \varepsilon \\ h_{12} \\ -h_{14} \\ h_{21}+h_{15}\end{array}\right]$

The governing equation for the \#4 $\mathrm{Hx}$ does not change for on- or off-design operation, and can be found in the previous section (Equation (3-12)). 


\subsubsection{Microturbine}

The microturbine is comprised of two components: the compressor and expander. While the equations used for each component are identical in form, the station numbering is different. To avoid confusion, each component will be treated separately.

\subsubsection{Microturbine compressor} ASSUMPTIONS AND CONSTANTS:

- $\eta_{c}=0.75$ at design for ISO standard atmospheric conditions

- $\mathrm{CPR}=4$ at design for ISO standard atmospheric conditions

- No microturbine compressor overboard bleed or expander cooling flows

- No inlet pressure losses

INPUTS:

- Ambient temperature and pressure: $T_{a}, P_{a}$

OUTPUTS:

- Compressor discharge temperature and pressure: $T_{12}\left(h_{12}\right), P_{12}$ 


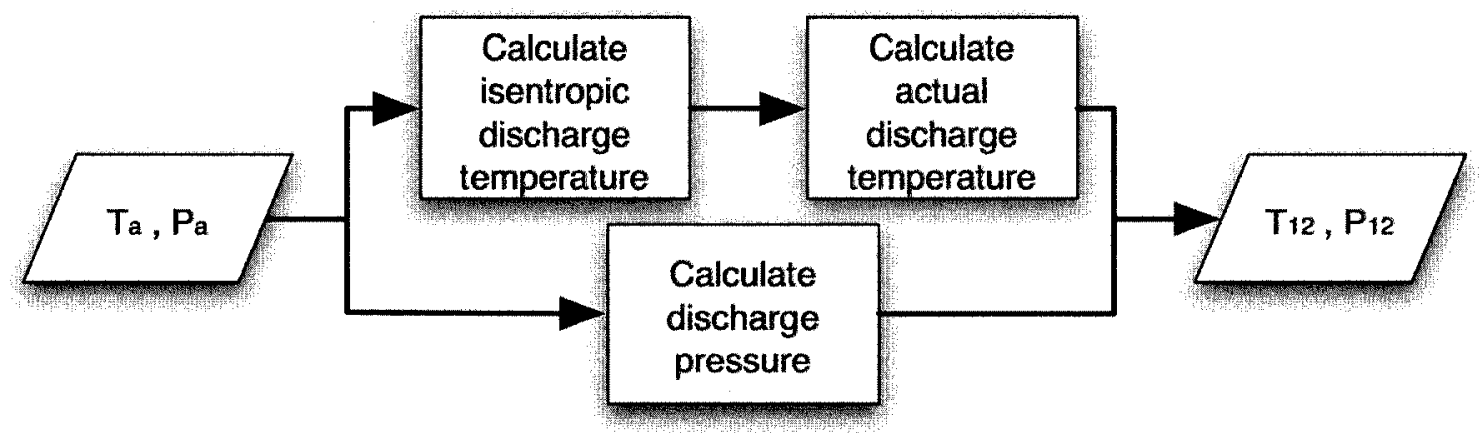

Figure 3-10: Microturbine compressor decision chart.

\section{THEORY:}

For the compression process, Equation (3-23) is used to determine the isentropic discharge temperature. Once an isentropic discharge temperature is determined, this is converted to an actual temperature using Equation (3-24) through the use of an isentropic efficiency. A curve fit for $C p_{(T)}$ is taken from [3.9] for use in Equation (3-23):

$$
\begin{aligned}
& \int_{T_{11}}^{T_{12 s}} \frac{C p_{(T)}}{T} d T-R \ln \left(\frac{P_{12}}{P_{11}}\right)=0 \\
& T_{12}=T_{11}+\frac{T_{11}}{\eta_{c}}\left(\frac{T_{12 s}}{T_{11}}-1\right)
\end{aligned}
$$

Compressor discharge pressure is calculated using the following equation:

$$
P_{12}=P_{a}(C P R)
$$




\subsubsection{Microturbine expander}

Since the expander is basically the reverse process of the compressor, the theory is similar.

\section{ASSUMPTIONS AND CONSTANTS:}

- $\eta_{e}=0.84$ at design for ISO standard atmospheric conditions

- Expander discharge pressure is 2 percent above $P_{a}$

- No cooling flows

INPUTS:

- HEN discharge temperature and pressure: $T_{14}\left(h_{14}\right), P_{14}$

- Ambient pressure: $P_{a}$

OUTPUTS:

- Expander discharge temperature and pressure: $T_{15}\left(h_{15}\right), P_{15}$ 
DECISION CHART:

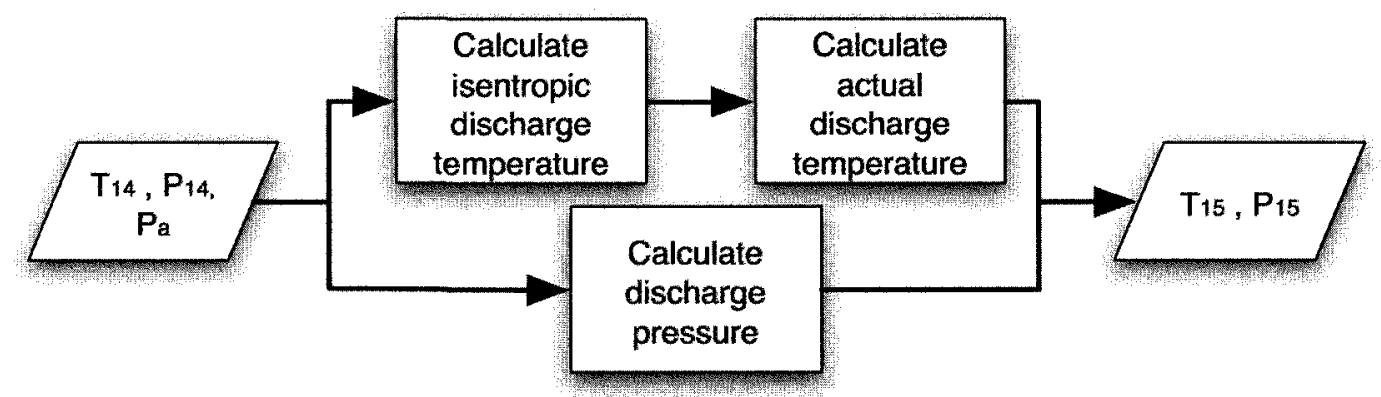

Figure 3-11: Microturbine expander decision chart.

THEORY:

For the expansion process Equation (3-26) was used to determine the isentropic expander discharge temperature. Equation (3-27) was used to convert to an actual temperature using an isentropic efficiency. A curve fit for $C p_{(T)}$ was taken from [3.9] for use in Equation (3-26).

$$
\begin{aligned}
& \int_{T_{14}}^{T_{15 s}} \frac{C p(T)}{T} d T-R \ln \left(\frac{P_{15}}{P_{14}}\right)=0 \\
& T_{15}=T_{14}+T_{14} \eta_{e}\left(\frac{T_{15 s}}{T_{14}}-1\right)
\end{aligned}
$$

Expander discharge pressure was calculated using Equation (3-28):

$$
P_{15}=1.02 P_{a}
$$

\subsubsection{Microturbine performance}

Using the outputs from the compressor, expander, and the HEN, microturbine 
performance was calculated.

\section{ASSUMPTIONS AND CONSTANTS:}

- $\dot{W}=10 \mathrm{kWe}$ at design and ISO standard atmospheric conditions

- $\eta_{m}=0.96$

- $L H V=50 \mathrm{MJ} / \mathrm{kg}$ (natural gas)

INPUTS:

- Compressor inlet and discharge enthalpy: $h_{11}, h_{12}$

- Expander inlet and discharge enthalpy: $h_{14}, h_{15}$

- Household ambient enthalpy: $h_{h}$

- HEN specific fuel flow: $\ddot{m}_{f}$

OUTPUTS:

- Microturbine mass flow, heat output, and thermal efficiency: $\dot{m}, \dot{Q}, \eta_{t h}$

- HEN fuel flow: $\dot{m}_{f}$ 
DECISION CHART:

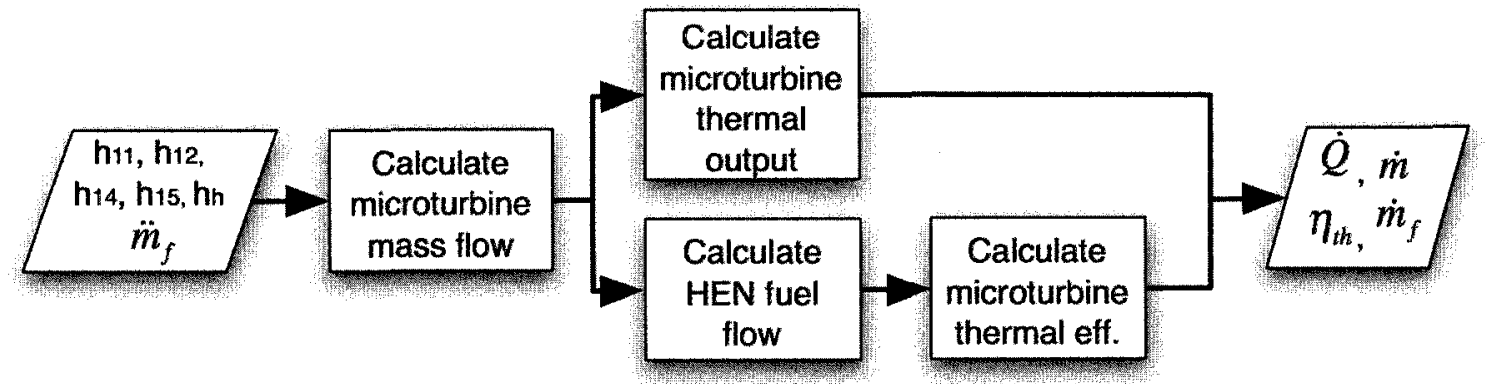

Figure 3-12: Microturbine performance decision chart.

\section{THEORY:}

For a required work output, microturbine mass flow and the HEN fuel flow are calculated:

$$
\begin{aligned}
& \dot{m}=\frac{\dot{W} \eta_{m}}{\left(h_{14}-h_{15}\right)-\left(h_{12}-h_{11}\right)} \\
& \dot{m}_{f}=\ddot{m}_{f} \dot{m}
\end{aligned}
$$

With microturbine mass flow known, the heat output of the microturbine is calculated as follows:

$$
\dot{Q}=\dot{m}\left(h_{15}-h_{h}\right)
$$

Finally, microturbine thermal efficiency is calculated:

$$
\eta_{t h}=\frac{\dot{W}}{L H V \dot{m}_{f}}
$$




\subsubsection{Off-design performance}

Off-design microturbine performance was predicted using generic compressor and expander maps incorporated into GASTURB [3.6]. These maps represent an averaging of several actual turbomachinery maps to approximate conventionally designed compressors and expanders used in gas turbines.

\section{ASSUMPTIONS AND CONSTANTS:}

- Reference temperature and pressure: $T_{r e f}=288 \mathrm{~K}, P_{r e f}=101.325 \mathrm{kPa}$

INPUTS:

- Required microturbine power output: $\dot{W}$

- Ambient temperature and pressure: $T_{a}, P_{a}$

\section{OUTPUTS:}

- Microturbine mass flow, heat output, and thermal efficiency: $\dot{m}, \dot{Q}, \eta_{t h}$

- Microturbine fuel flow: $\dot{m}_{f}$ 
DECISION CHART:

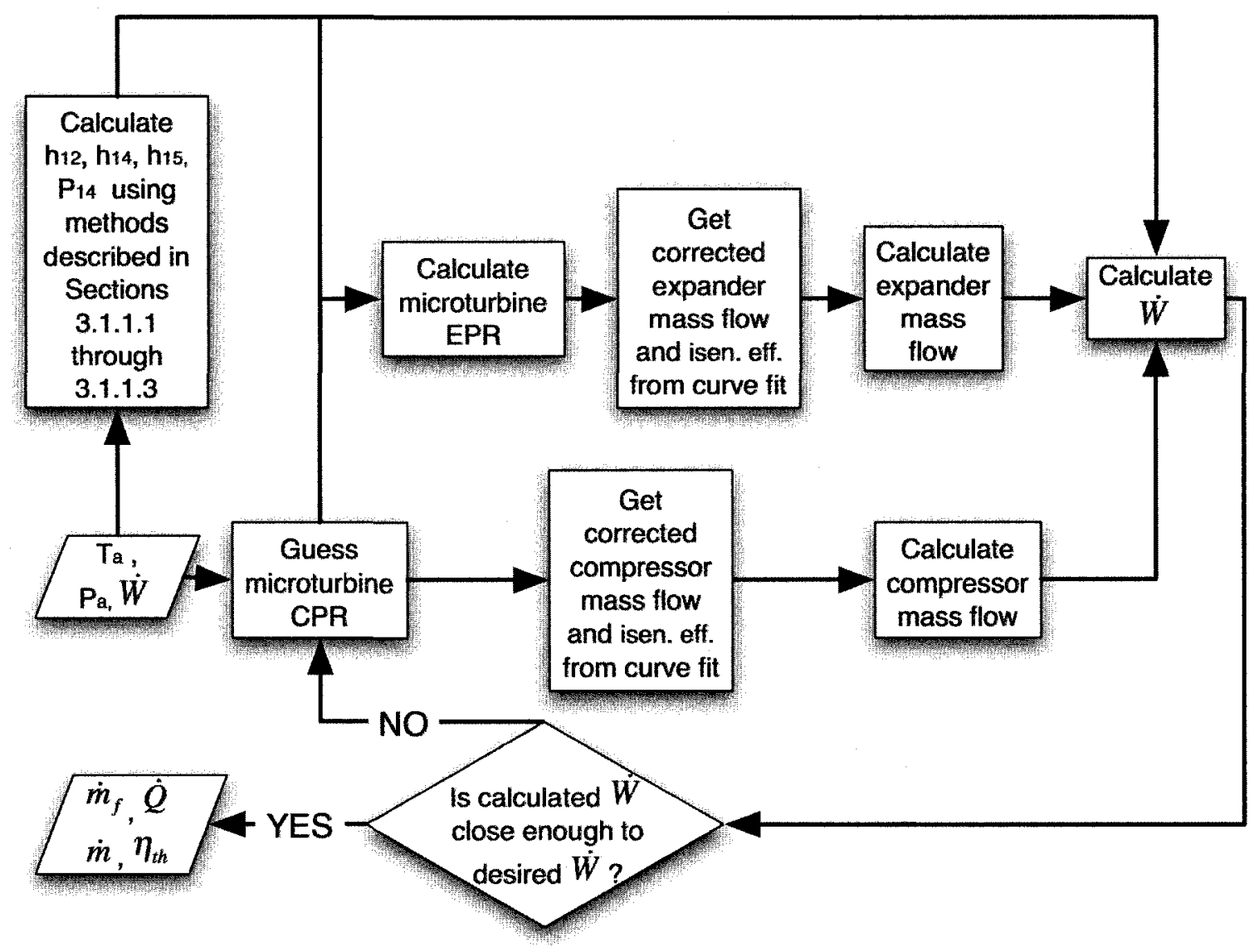

Figure 3-13: Microturbine off-design decision chart.

\section{THEORY:}

A constant speed operating line was modelled in GASTURB ${ }^{\mathrm{TM}}$ by varying the output power from design to synchronous idle. Corrected compressor mass flow, CPR, EPR, isentropic efficiencies, and corrected expander mass flow were then normalized by design point values to capture trends as shown in Figure 3-14. These normalized values were then multiplied by design point performance predictions from the in-house model to generate a constant speed off-design 
operating line.

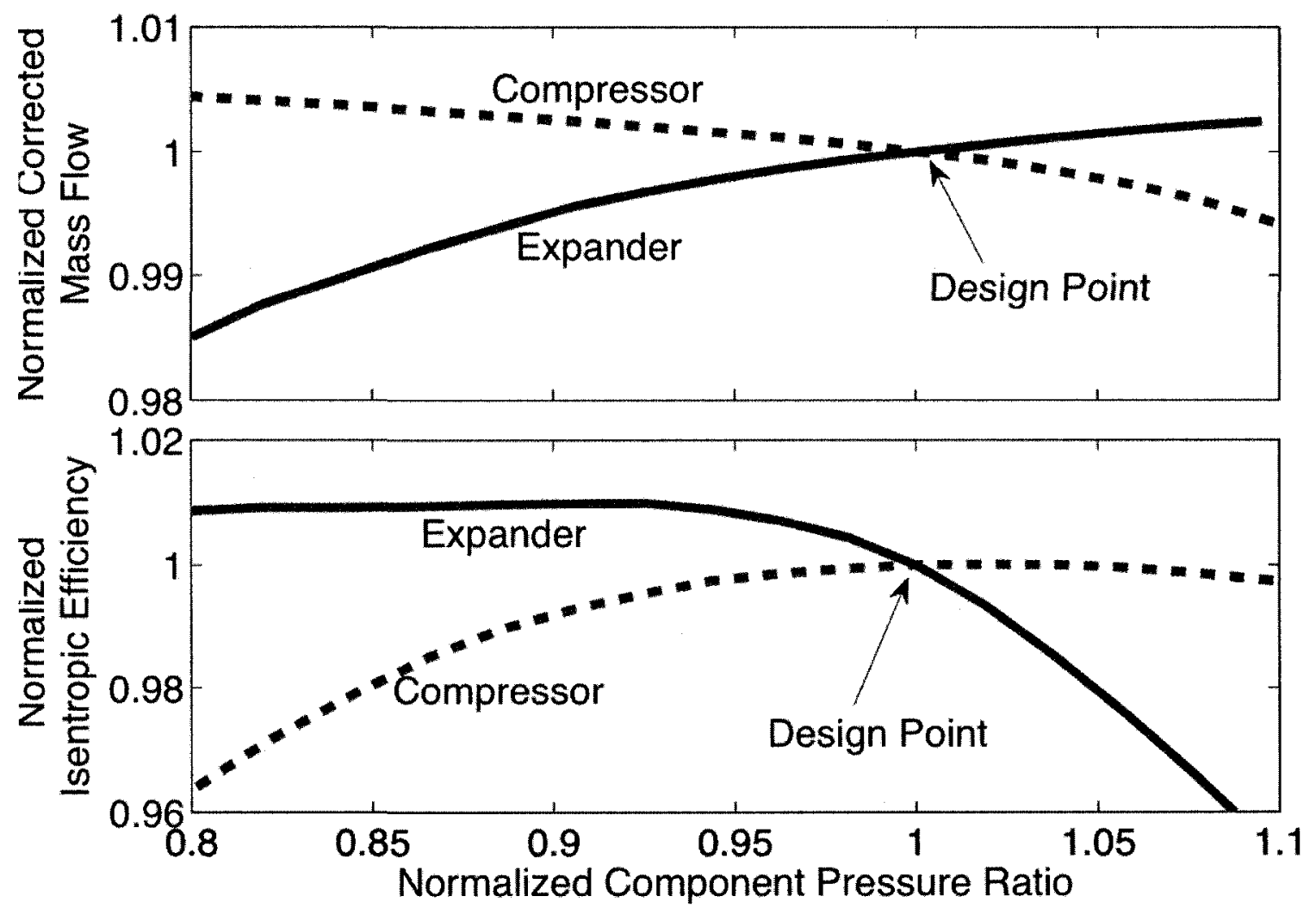

Figure 3-14: Off-design performance of the microturbine compressor and expander normalized by design point values

The operating line was expressed in the form of four curve fits:

- Corrected compressor mass flow as a function of CPR.

- Compressor isentropic efficiency as a function of CPR.

- Corrected expander mass flow as a function of EPR.

- Expander isentropic efficiency as a function of EPR. 
Calculating off-design performance was an iterative process that was broken down into the following steps:

1) For a given ambient temperature and pressure, select a desired work output.

2) Guess a CPR. Calculate corrected compressor mass flow and compressor isentropic efficiency from operating line curve fits.

3) Calculate compressor mass flow using Equation (3-33).

4) Calculate $h_{12}, h_{14}, h_{15}, P_{14}$ using methods described in Sections 3.3.2.1 and 3.3.2.2

5) Calculate EPR and then get corrected expander mass flow and expander isentropic efficiency from operating line curve fits.

6) Calculate expander mass flow using Equation (3-34).

7) Calculate microturbine power output using methods described in Section 3.3.2.3. Compare calculated output with desired output. If difference is within an acceptable tolerance, terminate calculations. If not, make another guess for CPR and continue iterations.

$$
\dot{m}^{\prime}=\frac{\dot{m} \frac{P_{a}}{P_{r e f}}}{\sqrt{\frac{T_{a}}{T_{r e f}}}}
$$




$$
\dot{m}_{e}^{\prime}=\frac{\dot{m}_{e} \frac{P_{14}}{P_{r e f}}}{\sqrt{\frac{T_{14}}{T_{r e f}}}}
$$

\subsubsection{Secondary turbomachinery}

In addition to the microturbine, there are two other turbomachinery components to model. The secondary compressor draws power from microturbine electrical output to charge the accumulator, and the secondary expander accepts discharge flow from the accumulator to provide household power and thermal loads.

\subsubsection{Secondary compressor}

The secondary compressor was modelled using performance charts from a commercially available screw compressor. Data for the compressor was digitized from which curve fits for mass flow, power input, and isentropic efficiency were calculated without the need for Equation (3-23); Equation (3-24) was used to determine discharge temperature. The second compressor operates at a constant pressure rise of 4 bar in Mode 1 and 6 bar in Mode 2. Isentropic efficiencies vary between 0.60 and 0.92 depending on the mass flow. Digitized performance graphs and isentropic efficiency curves can be found in Appendix $E$. 
ASSUMPTIONS AND CONSTANTS:

- None

INPUTS:

- Ambient temperature and pressure: $T_{a}, P_{a}$

- Microturbine power output: $\dot{W}$

- Household power demand: $\dot{W}_{h}$

OUTPUTS:

- Secondary compressor discharge enthalpy and pressure: $h_{32}, P_{32}$

- Secondary compressor mass flow: $\dot{m}_{c 2}$

DECISION CHART:

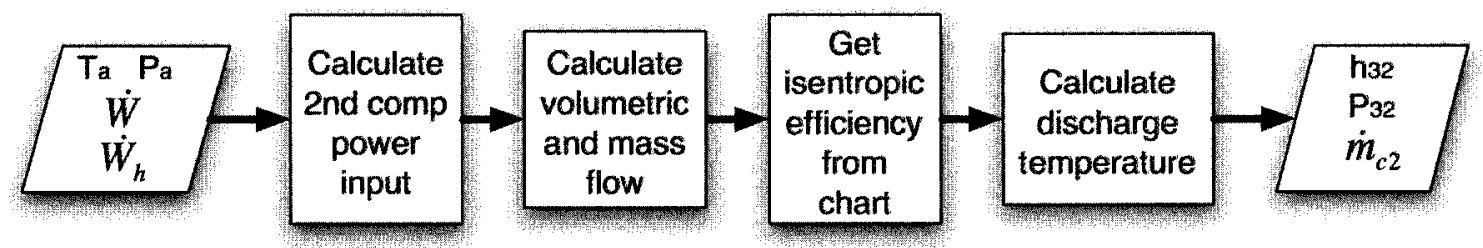

Figure 3-15: Secondary compressor decision chart. 


\section{THEORY:}

When the accumulator requires charging, the secondary compressor draws power from the excess electrical power generated by the microturbine that is not consumed by household demand:

$\dot{W}_{c 2}=\dot{W}-W_{h}$

For a given power input, volumetric flow was calculated using the digitized performance charts. This was translated into a mass flow using the following equation:

$\dot{m}_{c 2}=\frac{P_{a} \dot{V}_{c 2}}{R T_{a}}$

Isentropic efficiency is then calculated using curve fits from Figure 3-16. Secondary compressor discharge temperature is then calculated using Equation (3-37). Nomenclature is given for Mode 2:

$T_{32}=T_{31}+\frac{T_{31}}{\eta_{c 2}}\left(\frac{T_{32 s}}{T_{31}}-1\right)$ 


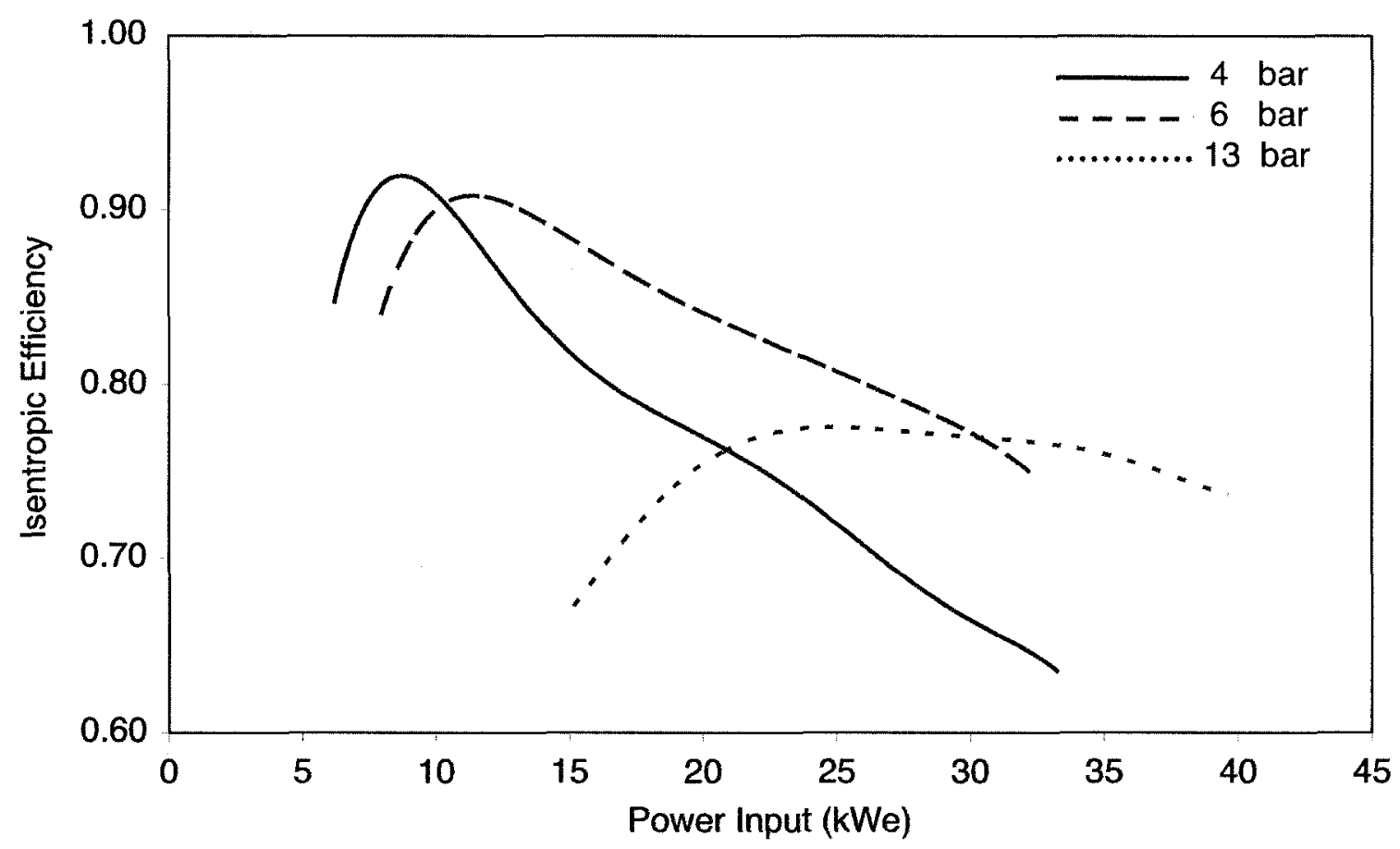

Figure 3-16: Isentropic efficiency as a function of power input for the secondary compressor

\subsubsection{Secondary expander}

The IBC has the potential to operate with pressure ratios of 1 to 7 , depending on the load demand of the household; higher electrical loads will require higher pressure ratios, while higher thermal loads will require higher mass flow rates. This range is significantly different from the pressure ratios of 3 to 3.76 experienced by the expander during microturbine operation. Hence a second expander with a design point tailored for typical mass flows and pressure ratios used in IBC operation is required to maximize efficiency. As station numbering is slightly different for Mode 1 and Mode 2, Mode 2 numbering will be used for this 
section.

\section{ASSUMPTIONS AND CONSTANTS:}

- $\eta_{e 2}=0.84$ at design for ISO standard atmospheric conditions

- Secondary expander discharge pressure is 2 percent above $P_{a}$

- No cooling flows

INPUTS:

- Ambient pressure: $P_{a}$

- Either household thermal $\left(\dot{Q}_{h}\right)$ or electrical $\left(\dot{W}_{h}\right)$ load

- Mode 1: accumulator discharge temperature: $T_{34},\left(h_{34}\right)$

Mode 2: HEN discharge temperature: $T_{36},\left(h_{36}\right)$

OUTPUTS:

- Secondary expander discharge temperature: $T_{35},\left(h_{35}\right)$

- Secondary expander electrical and thermal outputs: $\dot{W}_{e 2}, \dot{Q}_{e 2}$ 
DECISION CHART:

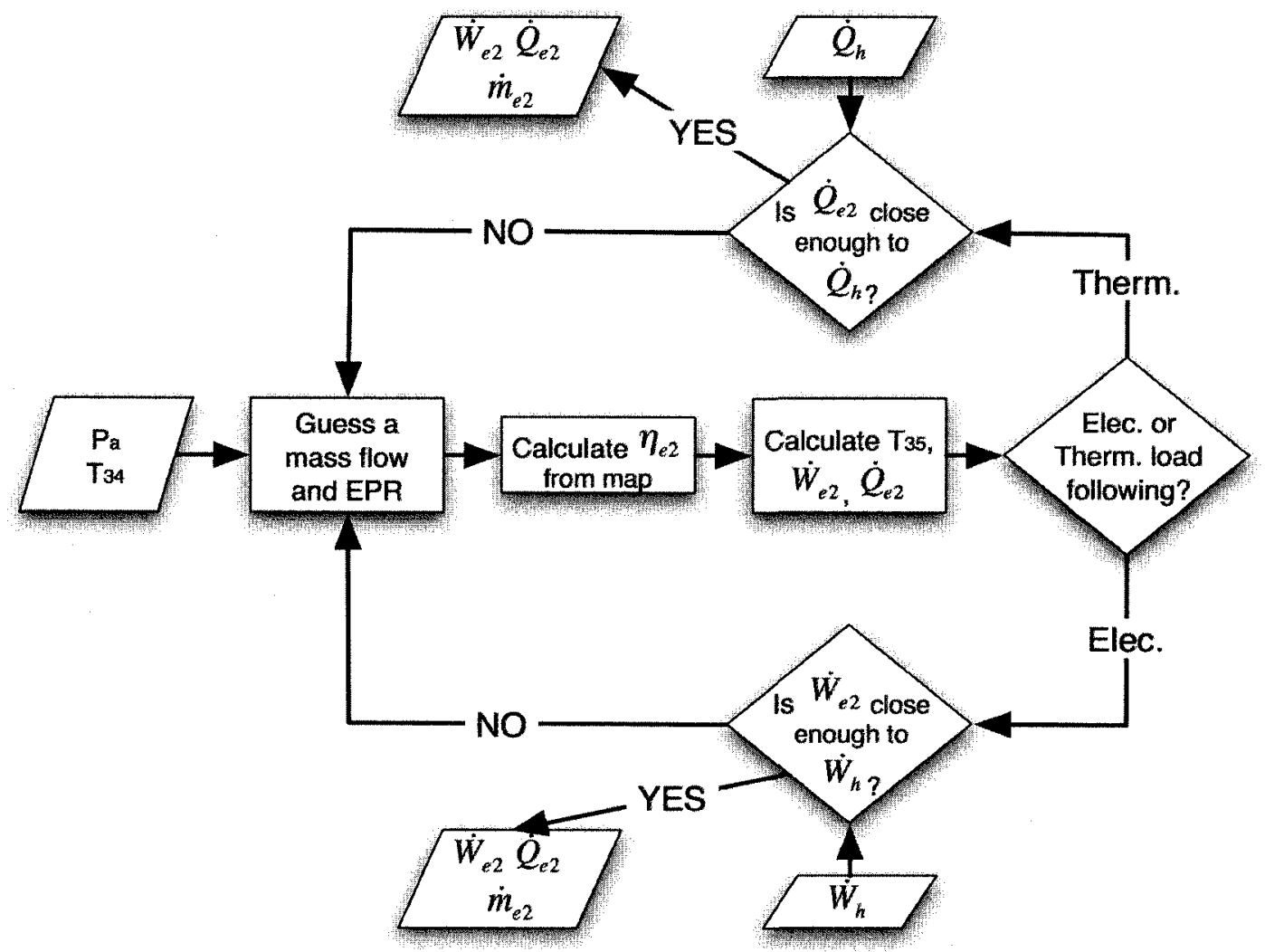

Figure 3-17: Secondary expander decision chart.

\section{THEORY:}

For a given accumulator discharge temperature, the flow pressure into the secondary expander is throttled to adjust the mass flow according to Figure 3-19. This allows either electrical or thermal load following operation, depending on what is required. For operation in Mode 1, the secondary expander always follows household electrical demand. For Mode 2, the default mode is to follow household thermal demand. If the household electrical demand cannot be met while following the thermal demand, the secondary expander switches to an 
electrical following mode to ensure all household loads are satisfied. Figure 3-18 graphically explains this process.

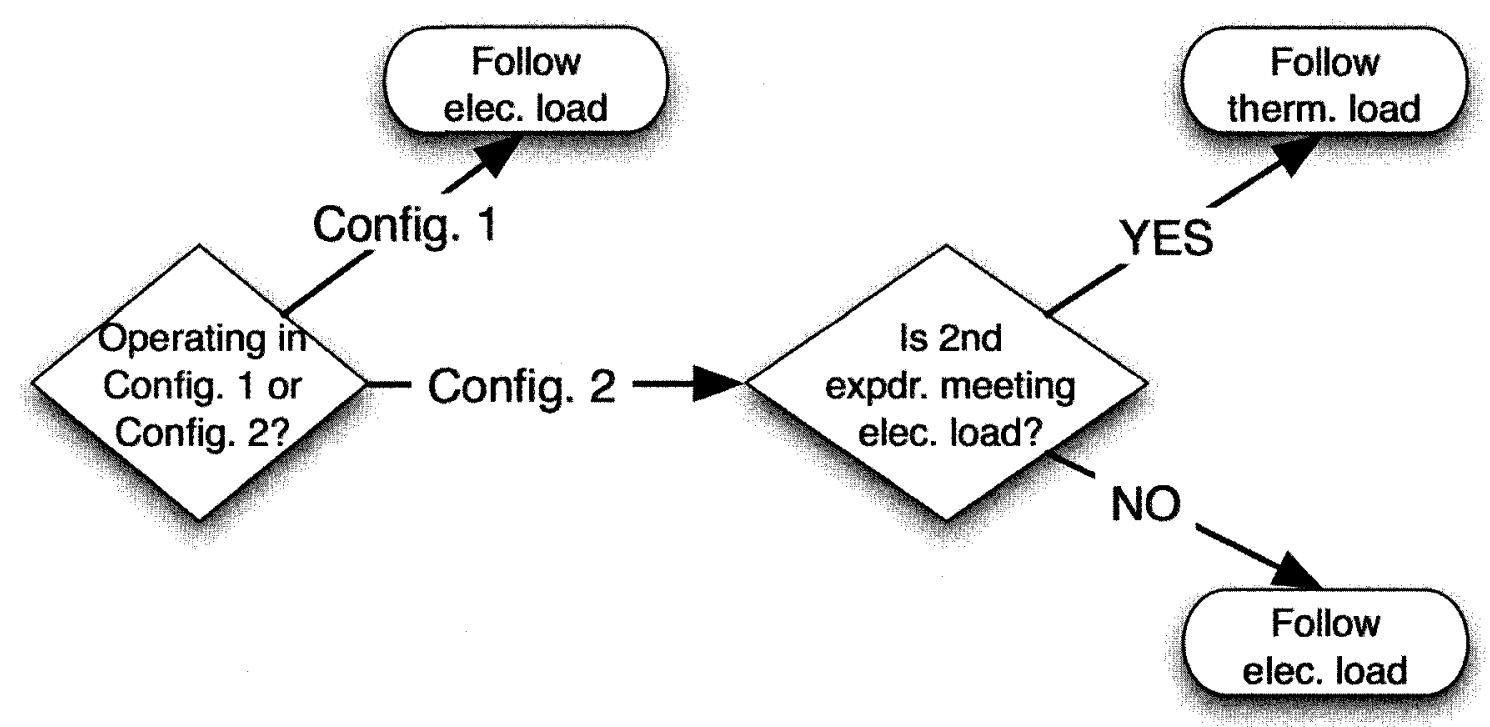

Figure 3-18: Secondary expander load following decision tree

Once it has been decided which load is to be followed, a mass flow is guessed and a corresponding EPR and $\eta_{e 2}$ is calculated using the secondary expander operating line map in Figure 3-19. Equations (3-38) and (3-39) are used to determine discharge temperature, then electrical and thermal outputs are determined using Equations (3-40) and (3-41) respectively:

$$
\int_{T_{34}}^{T_{35 s}} \frac{C p(T)}{T} d T-R \ln \left(\frac{P_{35}}{P_{34}}\right)=0
$$




$$
\begin{aligned}
& T_{35}=T_{34}+T_{34} \eta_{e}\left(\frac{T_{35 s}}{T_{34}}-1\right) \\
& \dot{W}_{e 2}=\dot{m}_{e 2}\left(h_{34}-h_{35}\right) \\
& \dot{Q}_{e 2}=\dot{m}_{e 2}\left(h_{35}-h_{h}\right)
\end{aligned}
$$

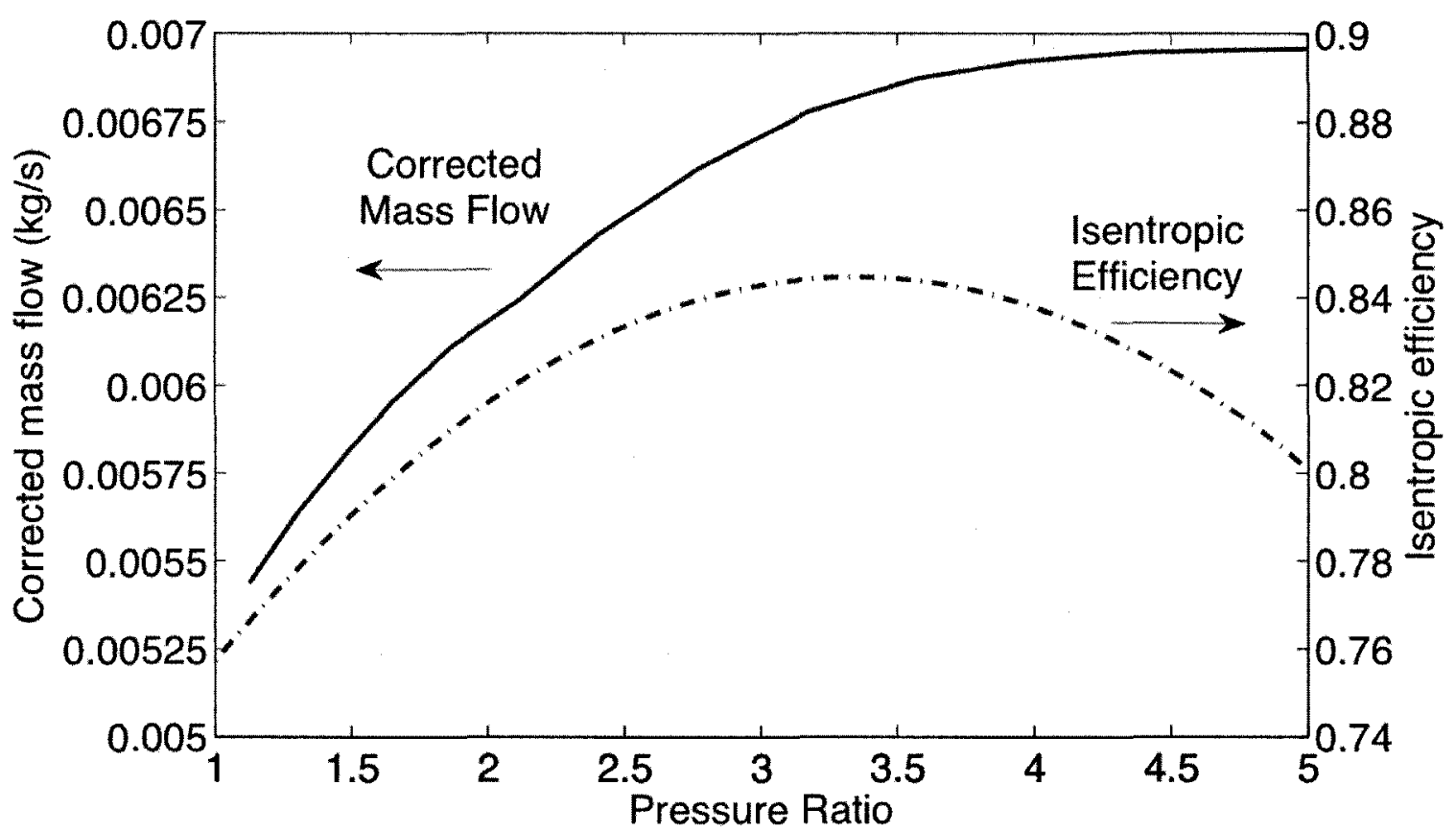

Figure 3-19: Off-design operating line for secondary expander.

\subsubsection{Accumulator}

The accumulator provides a method of storing energy when the microturbine is overproducing electrical load. It is charged with the secondary compressor and discharges to the secondary expander. The accumulator is well insulated, and is assumed to be installed inside the household. 
ASSUMPTIONS AND CONSTANTS:

- Air in the accumulator is isothermal and isobaric

- A polytropic exponent of $n=1.2$ was assumed for compression during charging and expansion during discharge (Appendix E explains the motivation behind selection of the polytropic exponent).

- Accumulator was assumed to be a horizontal cylinder with spherical end caps

- A free convection boundary condition is applied to the outer surface

- Accumulator internal surface temperature is equal to the bulk fluid temperature

- Fluid in the accumulator is quiescent

- Insulation thickness $t=0.1 \mathrm{~m}$, insulation thermal conductivity $k_{\text {ins }}=0.038$ $\mathrm{W} / \mathrm{mK}$, thermal resistance of the steel accumulator wall was treated as negligible

- Radiation heat transfer from the exterior surface of the accumulator is negligible

- Gravitational acceleration: $9.81 \mathrm{~m} / \mathrm{s}^{2}$

INPUTS:

- Household ambient enthalpy: $h_{h}$

- Discharging and charging mass flows: $\dot{m}_{\text {out }}, \dot{m}_{\text {in }}$ 
- Charging enthalpy: $h_{\text {in }}$

\section{OUTPUTS:}

- Discharging enthalpy (accumulator bulk fluid enthalpy): $h_{\text {out }}$

- Heat loss: $\dot{Q}_{a c c}^{\prime}$

- Accumulator pressure: $P_{a c c}$

\section{DECISION CHART:}

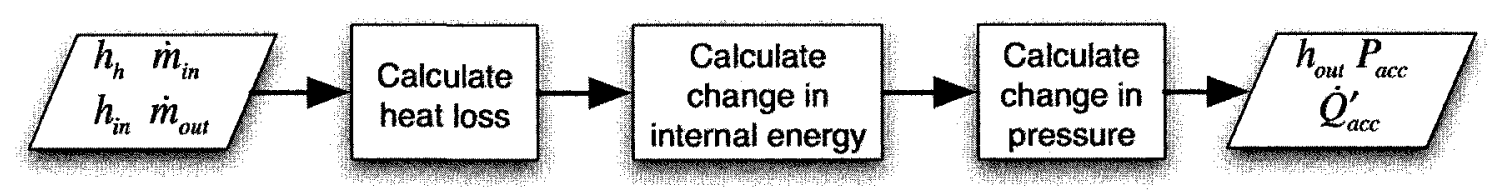

Figure 3-20: Accumulator decision chart.

\section{THEORY:}

As the model was used in a time-based simulation, a set of equations had to be used that allowed variation in inlet mass flow and enthalpy while simultaneously calculating accumulator temperature and pressure. The $1^{\text {st }}$ law of thermodynamics was applied to a control volume enclosing the accumulator where $e$ represents the specific energy of the system:

$$
\left(Q+W+\sum m h\right)_{\text {in }}-\left(Q+W+\sum m h\right)_{\text {out }}=m_{2} e_{2}-m_{1} e_{1}
$$


The flow entering the accumulator is a moving fluid and does boundary work on the quiescent fluid in the accumulator. To account for this boundary work, specific energy of the fluid in the accumulator is measured using internal energy while specific energy of the incoming (or leaving) flow is measured using enthalpy. Heat addition or loss is present only in the form of heat transfer to ambient through the accumulator wall. Using these assumptions, a discrete form of Equation (3-42) can be written as:

$$
\frac{\dot{m}_{i n} h_{\text {in }}-\dot{m}_{\text {out }} h_{\text {out }}+m_{1} u_{1}-\dot{Q}_{a c c}^{\prime}}{m_{1}+\dot{m}_{\text {in }}-\dot{m}_{\text {out }}}-u_{1}=u_{2}-u_{1}=\frac{d u}{d t}
$$

With respect to Equation (3-43), subscripts 1 and 2 correspond to the accumulator state at the previous and current timestep respectively; this convention applies to all equations in this section. Pressure was modelled using a combination of differential forms of perfect gas law and the polytropic expansion relation:

$$
\begin{aligned}
\frac{d P_{a c c}}{d t} & =\frac{R}{V}\left(T_{a c c} d m+m_{a c c} d T_{a c c}\right) \\
\frac{d T_{a c c}}{d t} & =\frac{n-1}{n} \frac{T_{a c c}}{P_{a c c}} d P_{a c c}
\end{aligned}
$$

Equations (3-44) and (3-45) are combined to form Equation (3-46):

$$
\frac{d P_{a c c}}{d t}=d m\left(\frac{n R T_{a c c}}{V}\right)
$$


An explicit discrete differential form is required to implement Equation (3-46) into a simulation marched in time:

$$
\frac{d P_{a c c}}{d t}=\left(\dot{m}_{\text {in }}-\dot{m}_{\text {out }}\right)\left(\frac{n R T_{1}}{V}\right)
$$

Finally heat loss $\left(\dot{Q}_{a c c}^{\prime}\right)$ must be estimated. Under a free convection assumption, the external convection coefficients must be estimated using empirical correlations. Equations (3-48) and (3-49) are averaged Nusselt number correlations for free convection around a horizontal cylinder [3.7] and a sphere [3.3] respectively:

$$
\begin{aligned}
& \overline{N u_{D}}=1 / 8 R a_{D}^{1 / 3} \\
& \overline{N u_{D}}=2+\frac{0.589 R a_{D}^{1 / 4}}{\left(1+[0.469 / \operatorname{Pr}]^{9 / 16}\right)^{4 / 9}}
\end{aligned}
$$

Where the Rayleigh number is calculated as:

$$
R a_{D}=\frac{g \beta\left(T_{s}-T_{\infty}\right) D^{3}}{v \alpha}
$$

Equations (3-48) through (3-50) are then combined with Equation (3-51) to produce an estimate for the averaged convective heat transfer coefficient, one for the cylindrical surface and one for the spherical end caps. 


$$
\bar{h}=\frac{\overline{N u_{D}} k}{D}
$$

Using the assumption that the heat transferred through the insulation via conduction is equal to the heat dissipated through free convection, Equation (3-52) is used to determine the external surface temperature of the accumulator where subscripts $s p$ and $c y l$ correspond to the spherical and cylindrical surfaces respectively:

$$
\frac{k_{i n s}\left(T-T_{s}\right)\left(A_{s p}+A_{c y l}\right)}{t}=\left[(\bar{h} A)_{s p}+(\bar{h} A)_{c y l}\right]\left(T_{s}-T_{\infty}\right)
$$

$\dot{Q}_{a c c}^{\prime}$ is then determined by back substituting $T_{s}$ into Equation (3-52) and calculating the heat transfer through the accumulator wall or from the external surface of the accumulator via convection:

$$
\dot{Q}_{a c c}^{\prime}=\frac{k_{i n s}\left(T-T_{s}\right)\left(A_{s p}+A_{c y l}\right)}{t}=\left[(\bar{h} A)_{s p}+(\bar{h} A)_{c y l}\right]\left(T_{s}-T_{\infty}\right)
$$

\subsubsection{Individual generation system}

Economic performance of the proposed system was compared against the performance of a natural gas furnace, vapour compression air conditioner, and purchasing grid power as is common in many North American and European households. 
ASSUMPTIONS AND CONSTANTS:

- Natural gas furnace has a $1^{\text {st }}$ law efficiency of $\eta_{f}=0.90$

- Air conditioner COP $=3$ at $T_{a}=27.8^{\circ} \mathrm{C}$ and $P_{a}=101.325 \mathrm{kPa}$

- Same energy rates used for trigeneration system were used for the individual generation system

- $L H V=50 \mathrm{MJ} / \mathrm{kg}$

INPUTS:

- Ambient temperature and pressure: $T_{a}, P_{a}$

- Household electrical and thermal loads: $\dot{W}_{h}, \dot{Q}_{h}$

\section{OUTPUTS:}

- $\left.\dot{m}_{f}\right|_{f}$

- $\dot{W}_{a c}$ 


\section{DECISION CHART:}

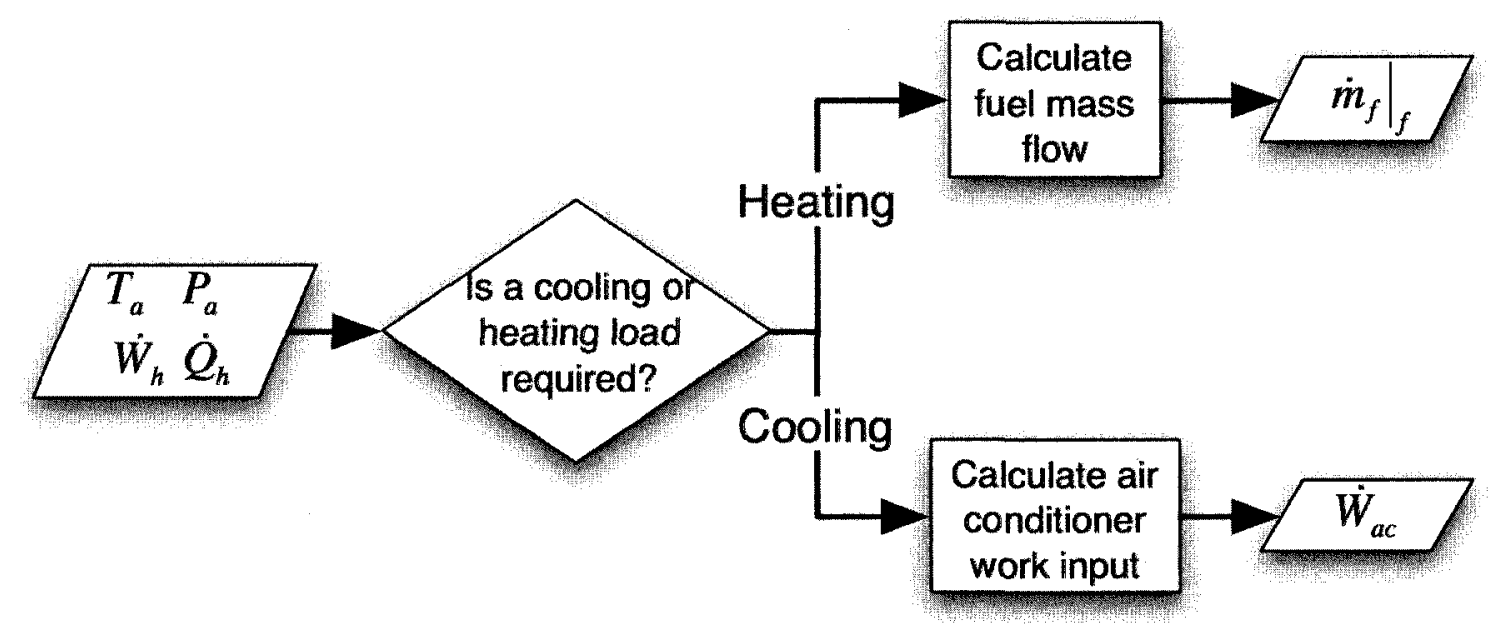

Figure 3-21: Independent generation decision chart.

\section{THEORY:}

Furnace performance was treated as invariant with changes to ambient temperature and pressure. Performance modelling was limited to calculation of furnace fuel consumption:

$$
\left.\dot{m}_{f}\right|_{f}=\frac{\dot{Q}_{h}}{\eta_{f} L H V}
$$

As the COP for most air conditioners is measured at an outside temperature of $27.8^{\circ} \mathrm{C}\left(82^{\circ} \mathrm{F}\right)$ as per Air-Conditioning and Refrigeration Institute (ARI) standard 210-240-2006 [3.1], the cooling load will be under-predicted at temperatures below $27.8^{\circ} \mathrm{C}$, and over-predicted at temperatures above if COP is not allowed to vary with temperature. As a rule of thumb, for each degree the condensing 
temperature is raised in a vapour compression cycle, the COP reduces by 2 to 4 percent (vice versa for each degree the condensing temperature is lowered) [3.2]. To mitigate the error introduced with a constant COP assumption at temperatures above the ARI nominal test conditions, a simple correction of 2.5 percent per degree Celsius [3.8] was applied to the design COP based on outside air temperature where the subscript nom indicates nominal ARI test conditions:

$$
C O P=C O P_{n o m}\left[1+0.025\left(T_{\text {nom }}-T_{a}\right)\right]
$$

Energy consumed by the air conditioner is then calculated using Equation (3-56):

$$
\dot{W}_{a c}=\frac{\dot{Q}_{h}}{C O P}
$$

\subsection{Description of simulation}

The mathematical model of the system described in the previous section was incorporated into a SIMULINK ${ }^{\mathrm{TM}}$ simulation marched in time. This simulation provided control to the mathematical model to ensure a comfortable temperature was maintained throughout the simulated dwelling while remaining within operating envelopes of each system component, in addition to ensuring the household electrical demand was met. 


\subsubsection{Solver parameters}

Household temperature profile was calculated using a bulk heat capacity calculated from Equation (3-57). The deviation of household temperature from the desired setpoint of $22^{\circ} \mathrm{C}(295 \mathrm{~K})$ is determined using Equation (3-58). Simulation control allowed household temperature to vary no more than $\pm 1.5^{\circ} \mathrm{C}$ from the nominal setpoint.

$$
\begin{aligned}
& C_{h}=\dot{m}_{h} C_{p a} \\
& \Delta T_{h}=\int \frac{\dot{Q}_{\text {load }}+\dot{Q}+\dot{Q}_{a c c}+\dot{Q}_{a c c}^{\prime}}{C_{h}}
\end{aligned}
$$

Several discretization schemes provided with SIMULINKTM were experimented with to arrive at a solver-independent solution, with the goal of optimizing solution accuracy and CPU time. With the exception of accumulator behaviour, trends in performance data were either linear or weakly non-linear in nature. As a result, higher order discretization schemes did not produce significantly different results from $1^{\text {st }}$ order schemes such as the explicit Euler method. As the control system was based on switches that turned on or shut off components abruptly, the simulation solver had to be able to deal with a high occurrence of discontinuities. The $1^{\text {st }}$ order Euler method using a fixed timestep was able to negotiate discontinuities without divergence.

It was desirable to choose as large a timestep as possible without significantly 
affecting accuracy or inducing solver instability. A timestep of one second was chosen, as larger timesteps resulted in solution instability. This instability threshold can be attributed to the high rate of change in accumulator pressure during discharge as the IBC pressure ratio approaches atmospheric. At a lower pressure ratio, less specific work is produced by the expander hence a larger mass flow is required to satisfy a given electrical or thermal load. Accumulator pressure could drop below atmospheric between timesteps larger than one second, causing rapid solution divergence.

\subsubsection{Demand scenarios}

Controlling the system poses a significant programming challenge, as each component of the complex system must be monitored while ensuring ambient household temperature remains within a desired range. This is further complicated by a rapidly changing household electrical demand. With respect to the physical system, changing between modes requires redirection of flow through the heat exchanger network in addition to using different control logic; this could be accomplished with the use of solenoid actuated computer-controlled three way valves. As the control methodology is different from cooling to heating load production, they will be treated separately. 


\subsubsection{Cooling mode (Mode 2)}

Controlling cooling operation is more difficult than controlling heating operation, as the system has greater difficulty cooling the household than heating it. This is primarily because the microturbine typically exhausts at roughly 800 to $900 \mathrm{~K}$. This high-temperature exhaust provides a 550 to $650 \mathrm{~K}$ temperature difference compared to the household setpoint of $295 \mathrm{~K}$. Conversely, the accumulator provides cooling exhaust at 200 to $294 \mathrm{~K}$, which is only a 1 to 95 degree difference when compared to the setpoint temperature. As the control logic for the system can be confusing, perhaps the best way to illustrate the methodology is through an illustration. Figure 3-22 outlines the control logic used during a cooling mode of operation. The control can be broken into three main groups: 1) temperature recharge, 2) recharge, and 3) intermediate control.

1) Temperature recharge: This mode is engaged when the maximum setpoint temperature in the dwelling is reached. The system then engages the accumulator until the minimum setpoint temperature is reached. Drawing a parallel with common HVAC terminology, the temperature recharge mode is synonymous with a building cooling cycle.

2) Recharge: This mode is engaged when the accumulator minimum pressure has been reached. It overrides the temperature recharge mode, as if no accumulator pressure is left, the accumulator has no more cooling capacity left. 
3) Intermediate control: This mode operates the microturbine or the accumulator (IBC) depending on the situation. The goal of this mode is to satisfy the electrical load, as the dwelling temperature is within the setpoint range during this mode and no recharge or temperature recharge cycle is engaged. 


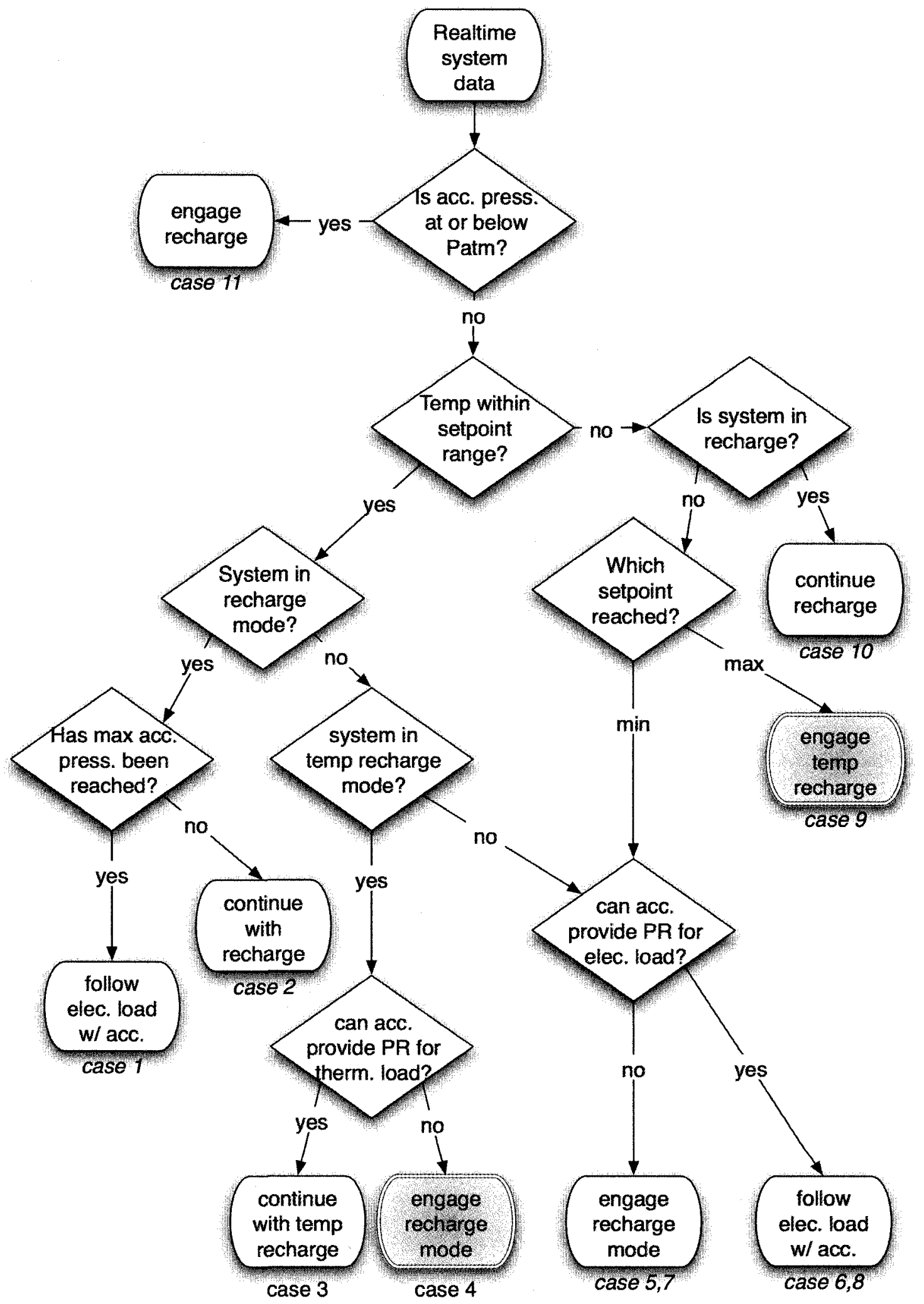

Figure 3-22: Process logic chart for cooling control 
The red warning markers in Figure 3-22 are to indicate that under these control modes, there is the potential dwelling cooling demand can exceed system cooling power. If this occurs, dwelling temperature can rise above the maximum setpoint temperature. It is possible to size a system based upon such extreme operating conditions, however the efficiency throughout the remainder of the operation envelope would suffer from a severe system to dwelling mismatch. The key parameter in determining if the system will lag behind cooling demand is the ratio of accumulator recharge time to setpoint minimum to maximum time (SMMT). The SMMT is defined as the time it takes the dwelling to increase bulk air temperature from the minimum setpoint to the maximum setpoint via heat addition from the outside. Once the accumulator is fully discharged, it must be fully recharged before the next temperature recharge mode is engaged. If the accumulator is not fully recharged, a charging deficit is created that will continue to grow at each recharge phase until no cooling output is available. To prevent this, supplementary electrical power from the grid is fed to the secondary compressor to increase charging mass flow into the accumulator. The amount of additional electrical power required is such that accumulator recharge time is equal to the SMMT. By using such a ratio, the accumulator will not be charged before the maximum dwelling setpoint temperature is reached. This is desirable as the microturbine would have to run at off-design to satisfy household electrical demand if the accumulator was prematurely charged; gas turbines experience a 
significant drop in thermal efficiency at part load, therefore part-load operation is avoided whenever possible. By using supplementary grid power, the system can be sized for an average cooling load rather than the maximum. If total energy islanding is required, household temperature will increase above the maximum setpoint limit during peak cooling load conditions as no supplementary electric power would be supplied to the secondary compressor.

\subsubsection{Heating mode}

Unlike the cooling mode of operation, there is no danger of household thermal demand exceeding system output while in a heating mode. There are however modes of operation that are extremely wasteful, and are highlighted in yellow in Figure 3-23. These modes are presented in one of two ways: the need off-design operation, or the need for heat bypass. Microturbine off-design operation is required when under a temperature recharge mode of operation and the accumulator is at maximum pressure. The heat load provided by the microturbine exhaust is still required to heat the dwelling, but the secondary compressor does not require any power as the accumulator is full. The microturbine therefore operates in an electrical load-following mode to ensure the power requirements of the dwelling are satisfied. Heat bypass is required when the inverse of the previous case is encountered. While under a recharge mode of operation, if the dwelling is at the maximum setpoint temperature, but the accumulator is not yet 
at maximum pressure, heat must be dumped to the atmosphere; during the heat bypass mode, a fraction of the microturbine heat output is directed into the dwelling such that the dwelling temperature remains at the maximum setpoint temperature. 


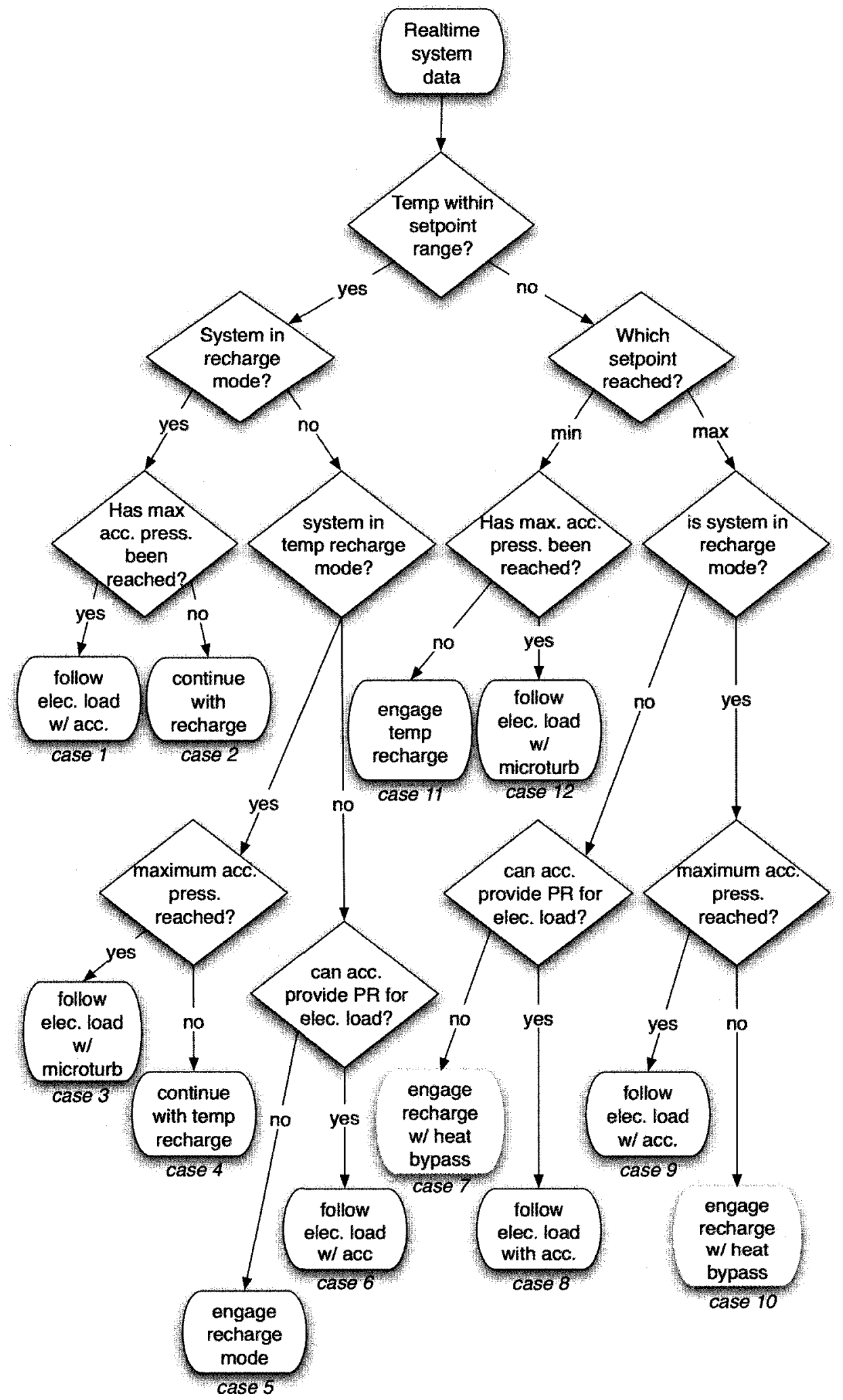

Figure 3-23: Flow chart for heating control logic 


\subsubsection{Load profiles}

To perform a detailed economic evaluation of the proposed system, a full year of operation is simulated. To accomplish this, high-resolution load data was obtained using an open source program called ESP-r [3.4]. This was developed in part by the Energy Systems Research Unit at the University of Strathclyde in the UK. After decades of development, contributions from PhD theses, and several case studies, ESP-r has the ability to predict building thermal loads with a high degree of reliability. Factors such as solar gains, solar view factors, outside air infiltration, circulation, customizable duct and vent locations, lighting thermal gains, and occupant driven gains are incorporated into the model.

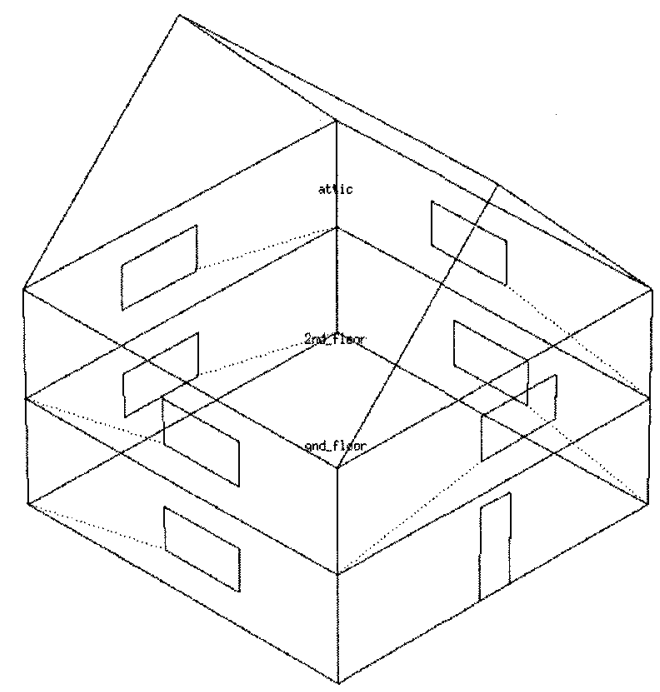

Figure 3-24: Geometry used in ESP-r to model thermal loads

Included in ESP-r is a basic CAD program that permits the user to build simple 
geometry. This geometry is then used in modelling thermal loads. Figure 3-24 shows the geometry used in estimating annual household thermal loads for this study. The parameters chosen in ESP-r were designed to reflect construction practices common to single family detached dwellings constructed between the 1950s and 1980s:

- Occupied by a four-person family

- No basement, two story, $1500 \mathrm{ft}^{2}$

- Brick exterior walls with glass fibre insulation for a total RSI value of 2.19

- Ceiling of the secondary floor is insulated with an air gap for a total RSI value of 0.39

- Solar view factors typical of a suburban environment

- Double paned windows $(2 \times 3 \mathrm{ft}$.)

- Exterior surface of ground floor subjected to an averaged ground temperature profile for Winnipeg, Canada [3.10]

- Free air exchange between $1^{\text {st }}$ and $2^{\text {nd }}$ floor

- Outside air infiltration set at 1 air change per hour

- No internal walls

- Volume of air on each floor and attic varies in an isothermal manner

- Ambient temperature, wind, sunshine, and precipitation data for Winnipeg, Canada in 2001 were used

- Separate occupancy profiles used for weekdays and weekends 
In addition, an occupancy profile was specified that included latent and sensible gains from body heat, appliances, showers/baths, and lighting. These profiles for weekdays and weekends can be found in Appendix B. Figure 3-25 is a sample of the output from the thermal simulation. While a full year was modelled in five minute increments, only data for January and July are presented to illustrate the magnitude of the largest heating and cooling loads required throughout the year.

The electrical profiles shown in Figure 3-25 were taken from a database maintained by the International Energy Agency called Annex 42 [3.5]. This program is a partnership between several governmental organizations and universities around the world. The electrical profiles used for the simulation represent the consumption of an average detached single family Canadian household, and was provided to Annex 42 by the Canadian Centre for Housing Technology based in Ottawa, Canada. The electrical profile includes consumption from air handling blowers used in furnace and air conditioning systems. Climatic data for Winnipeg, Canada was used for load simulation as this region experiences extreme cold and hot summers $\left(-40^{\circ} \mathrm{C}\right.$ to $\left.40^{\circ} \mathrm{C}\right)$. This climate requires significant heating and cooling loads, making it ideal to test the performance of the trigeneration system under study.

In an effort to keep simulation development within a prescribed timeline, hot 
water loads were not used in the simulation. As water can be heated with waste combustion exhaust, adding a hot water load will not incur any extra costs for the system under study. Conversely, providing a hot water load will increase costs for the independent generation system, making relative economic results from the simulation conservative.
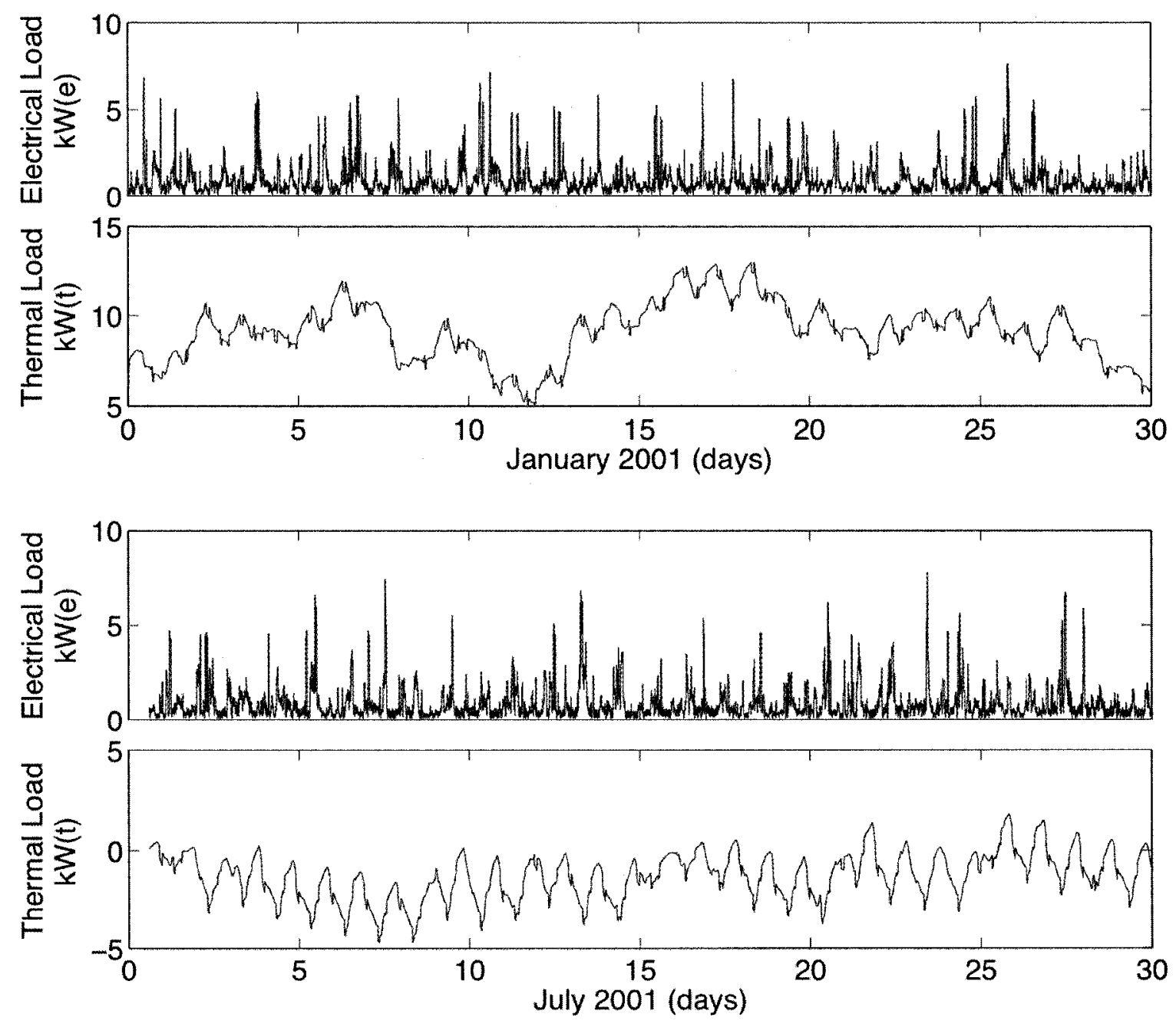

Figure 3-25: Sample of loads estimated using ESP-r 


\section{Chapter 4}

\section{Simulation Results and Sensitivity Studies}

\subsection{Introduction}

Developing the concept of hydraulic accumulation with an IFGT microturbine was an iterative process. The final system has evolved considerably from what was initially simulated. This section will describe the modifications made to the original system based on performance results.

\subsubsection{Accumulator size}

Since accumulator volume has no direct impact on turbomachinery or HEN sizing, it is easy to isolate the effect accumulator size variaion has on system performance. The effect of volume variation was studied separately for Mode 1 and Mode 2, and are presented in descending order in Figure 4-1 through Figure 4-4. It was determined that the primary effect of accumulator volume variation is to increase or decrease cycling frequency; one cycle is defined as the period between microturbine shutdown to start-up. 


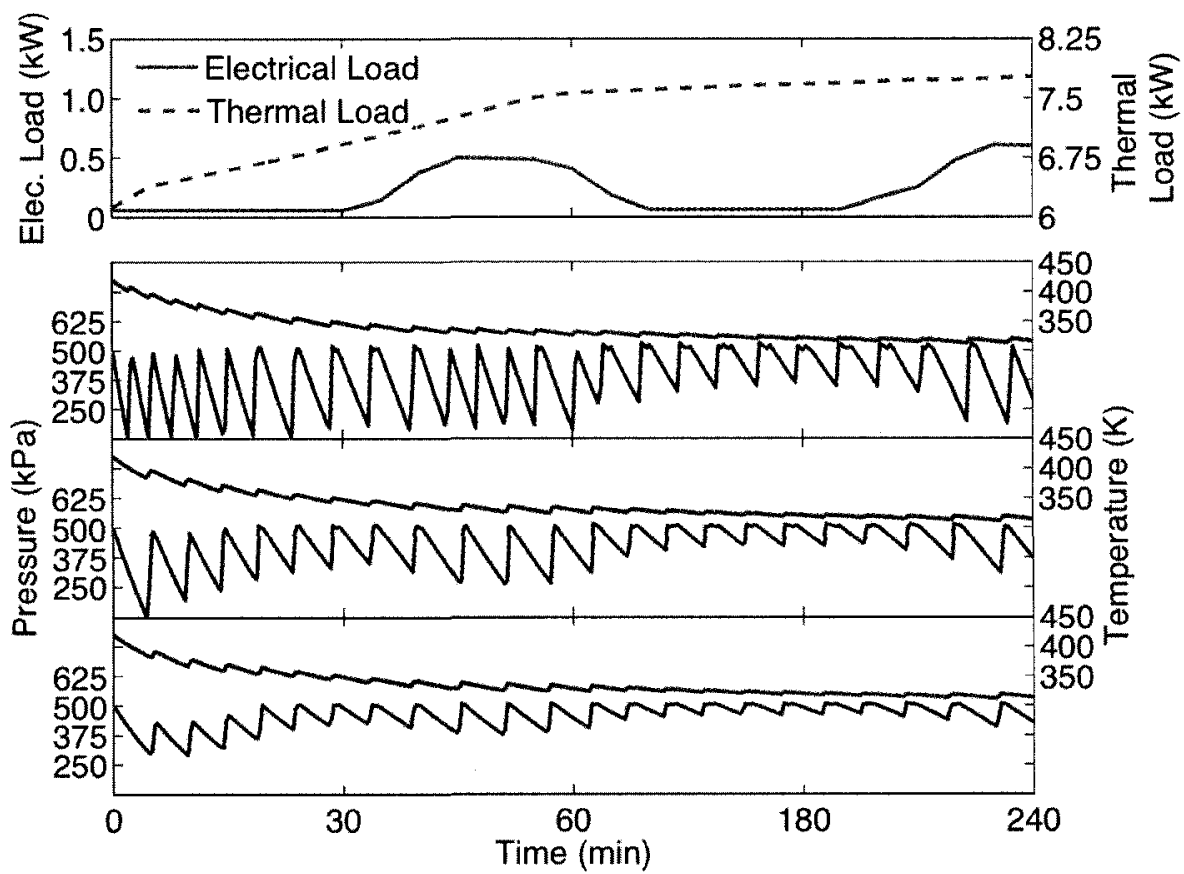

Figure 4-1: Accumulator behaviour in Mode 1 for low load conditions. Accumulator volumes of $0.5,1$, and $2 \mathrm{~m}^{3}$ are presented in descending order respectively.

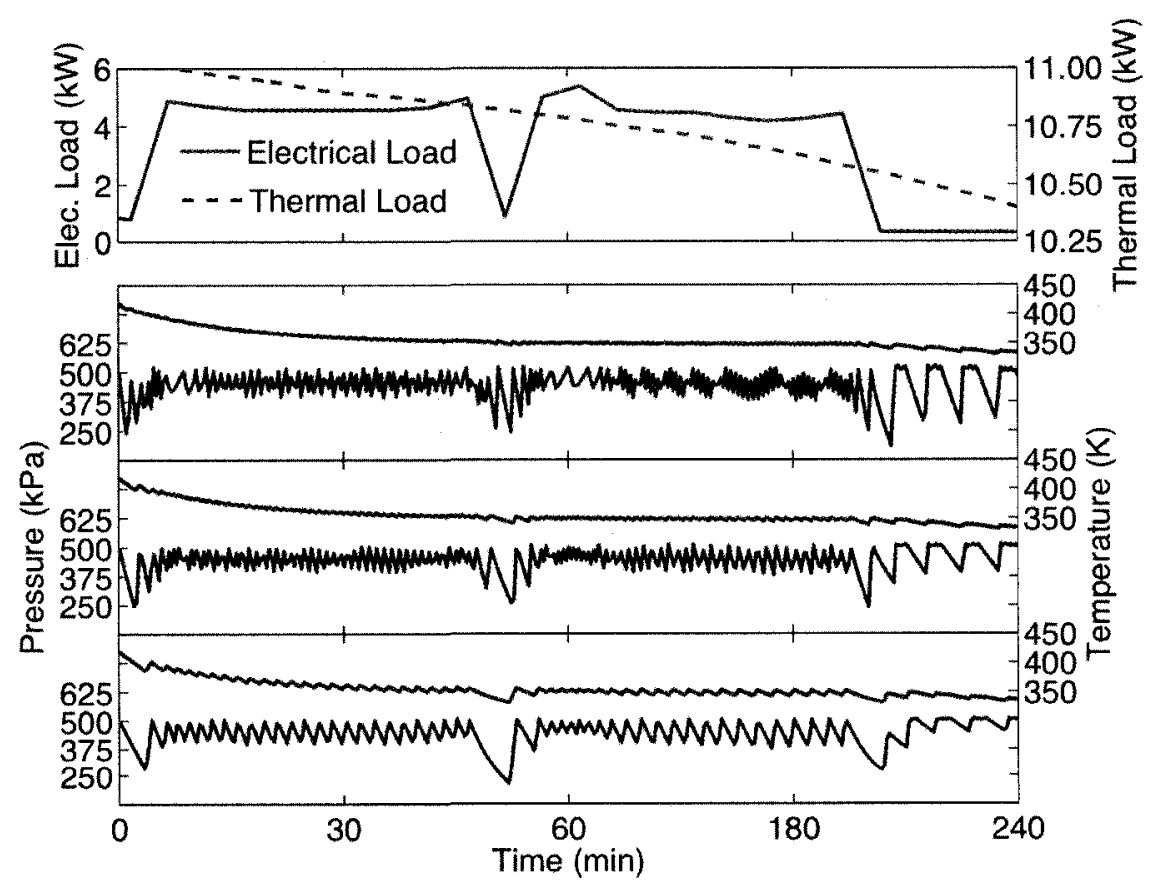

Figure 4-2: Accumulator behaviour in Mode 1 for high-load conditions. Accumulator volumes of $0.5,1$, and $2 \mathrm{~m}^{3}$ were used and are presented in descending order respectively. 
As was expected, cycle frequency increased for high-load conditions for both configurations; however, under Mode 2 high-load conditions cycle frequency was significantly higher than for Mode 1 high-load. Figure 4-2 and Figure 4-4 (highload) show a cycling frequency that would most likely be unachievable in practice for an accumulator volume of $0.5 \mathrm{~m}^{3}$.
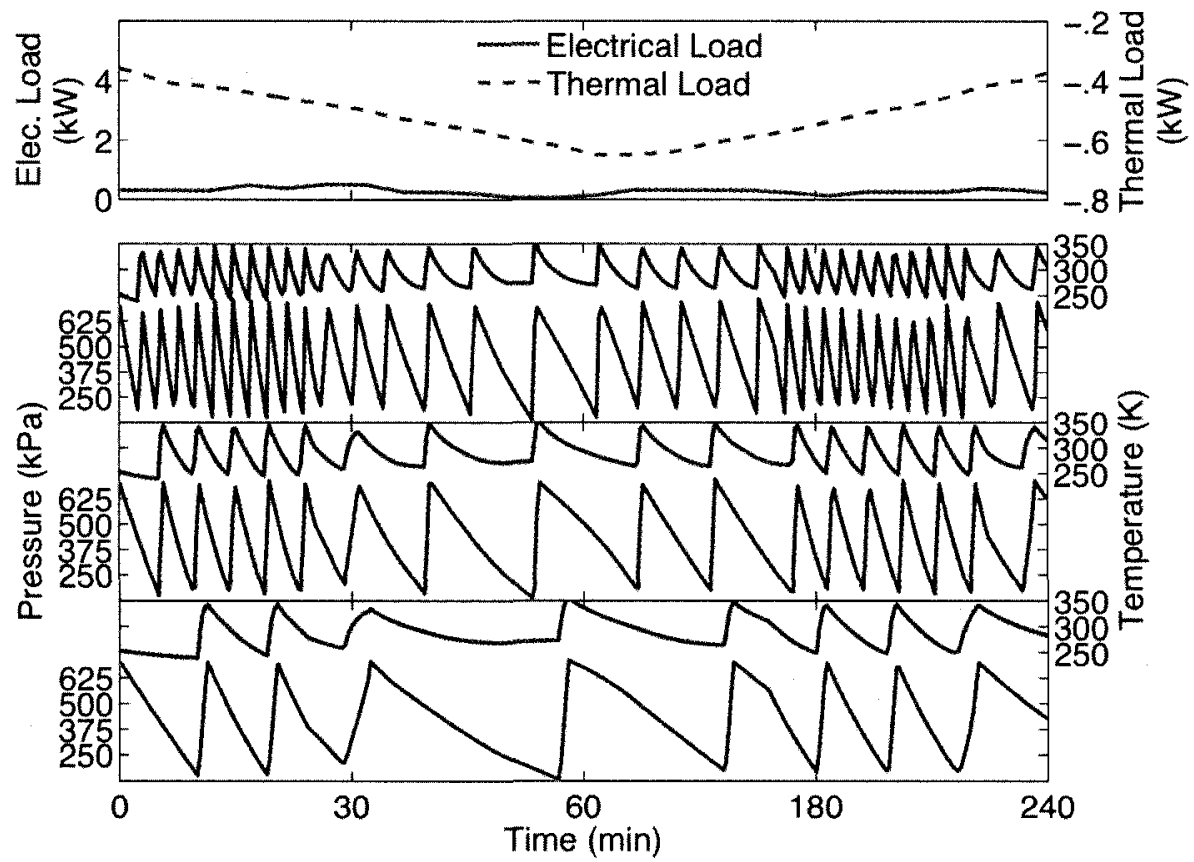

Figure 4-3: Accumulator behaviour in Mode 2 for low-load conditions. Accumulator volumes of $0.5,1$, and $2 \mathrm{~m}^{3}$ were used and are presented in descending order respectively.

As the trigeneration system is controlled with components such as solenoid flow control valves, and intake and exhaust fans, rapidly cycling these components will lead to premature component failure and degradation of system performance due to more frequent transient operation. As transient responses were not 
modelled (and the associated degradation to performance during start-up), there was no appreciable change to economic performance when accumulator size was varied.

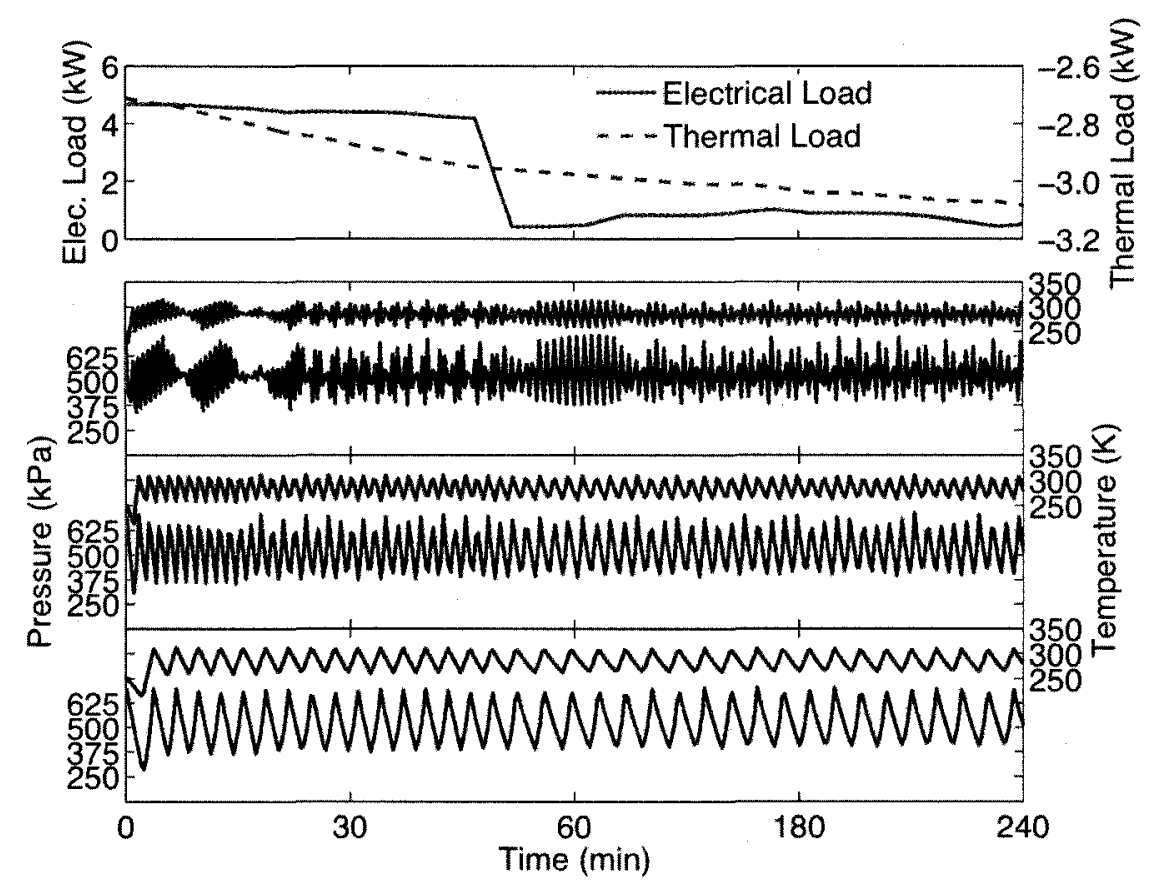

Figure 4-4: Accumulator behaviour in Mode 2 for high-load conditions. Accumulator volumes of $0.5,1$, and $2 \mathrm{~m}^{3}$ were used and are presented in descending order respectively.

Selecting an appropriate tank size can based upon three considerations:

1) Minimum accumulator volume should be selected such that an actual system can operate at the maximum cycling frequency required throughout the year without abnormal degradation to system performance or component life. The maximum cycling frequency can be expected to 
occur at peak thermal and electrical loads.

2) Larger accumulators will reduce the amount of transient operation, and by extension cycle frequency. This in turn will improve economic performance.

3) There is no recommended maximum accumulator size. Considerations to keep in mind when selecting an appropriate size are ease of installation and service, and cost.

\subsubsection{HEN configuration}

The Mode 1 schematic shown in Figure 3-2 was designed to utilize the highest system temperature as is practically possible to satisfy household heating loads. When a cooling load was required (Mode 2) high temperature expander exhaust was not required, expander exhaust was therefore dumped overboard. To improve the thermal efficiency of the HEN and microturbine system in Mode 2, different system configurations were designed for heating and cooling modes of operation,

Displayed in Figure 4-5 is electrical efficiency and SFC based upon electrical power output. Where Mode 1 lacks in electrical efficiency, it makes up for in production of thermal load. If the thermal load delivered to the household is taken into account in efficiency calculations, Mode 1 demonstrates a fairly flat total 
efficiency of 93 to 95 percent from synchronous idle to full power.
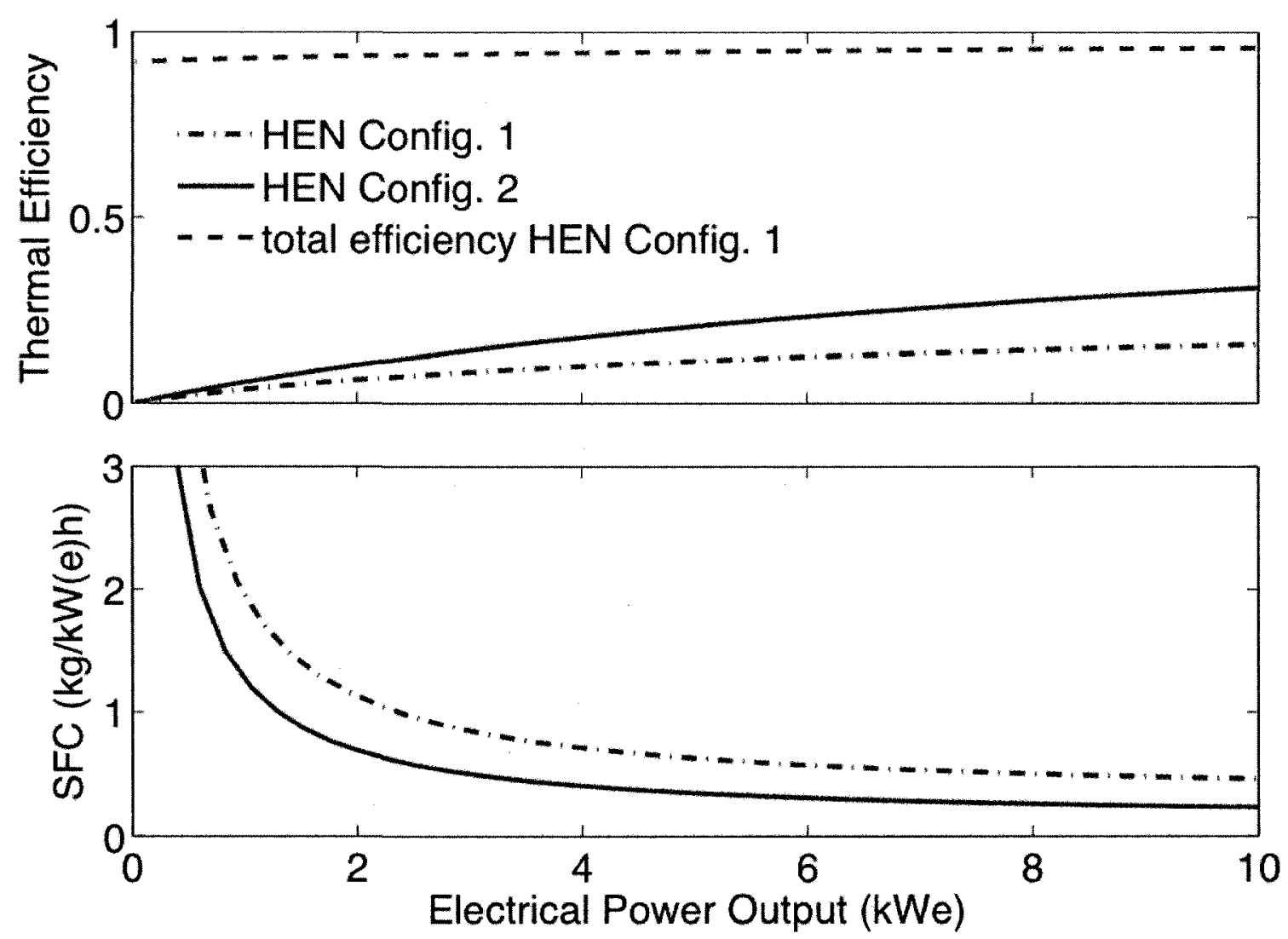

Figure 4-5: Comparison of thermal efficiency and SFC performance from full power to synchronous idle for HEN Mode 1 and Mode 2 configurations at standard ambient conditions of $101.325 \mathrm{kPa}$ and $288 \mathrm{~K}$

When the microturbine is operating in heating mode, any losses due to turbomachinery isentropic efficiencies of less than unity are translated into increased flow temperature. This increased flow energy is not utilized if exhaust energy is vented to atmosphere. In the modelled system, any turbomachinery losses are recaptured when the exhaust is delivered to the household for space 
heating purposes.

Mode 1 total efficiency losses can be attributed to pressure losses in the HEN and exhaust ducting, and due to mechanical, combustion, and electrical conversion efficiencies less than unity. This high overall efficiency is possible due to the implementation of the IFGT concept within the system, as the microturbine exhaust is free of combustion products and can be vented directly into the household. While operating in Mode 1, the microturbine and HEN are analogous to a high-efficiency natural gas furnace that produces electrical load as a byproduct.

\subsubsection{Microturbine size}

The effect of varying the electrical output of the microturbine on economic performance and system response was investigated. To size the microturbine, compressor and expander maps were adjusted by varying corrected mass flows (compressor and expander) until the desired power output was achieved. Design and off-design PR and isentropic efficiency characterisics were left unchanged. It is acknowledged that this assumption will introduce some error in the smaller sizes, as isentropic efficiencies will degrade in smaller machines when compared to larger geometrically similar machines. It is believed that this error will not be significant enough to affect the conclusions drawn from the microturbine sizing 
study. Three microturbine sizes were used for the sensitivity study: 5,10 , and 20 kWe. All component pressure temperature and power input and outputs were monitored to ensure the simulation was behaving as expected, however three key performance parameters were compared to determine the effect of microturbine size variation on system performance: fuel cost, accumulator behaviour, and household temperature. The latter two measures of performance were selected to give a measure of cycling frequency, and the corresponding effect on household temperature. While satisfying a heating load (as in Mode 1), microturbine size had a negligible effect on cost. This may seem counterintuitive given the fact that for the same accumulator pressure, larger microturbine sizes demonstrated higher accumulator temperatures as seen in Figure 4-6.

Higher accumulator temperatures translate to less fuel required to bring accumulator discharge flow up to temperature through the HEN, and therefore reduces SFC during IBC operation. The higher accumulator temperature should therefore translate to a reduction in fuel costs. A more in-depth look into how the system charges the accumulator is required to explain this phenomenon. Household electrical load varies between zero and about $6 \mathrm{kWe}$, which means with the exception of the $5 \mathrm{kWe}$ engine, the microturbine is always overproducing electrical load at full load. Excess load is fed to the secondary compressor, which then charges the accumulator. The secondary compressor was sized to ensure 
maximum isentropic efficiency was achieved for average levels of microturbine overproduction (secondary compressor input power) based on a $10 \mathrm{kWe}$ engine, shown in Figure E-11.
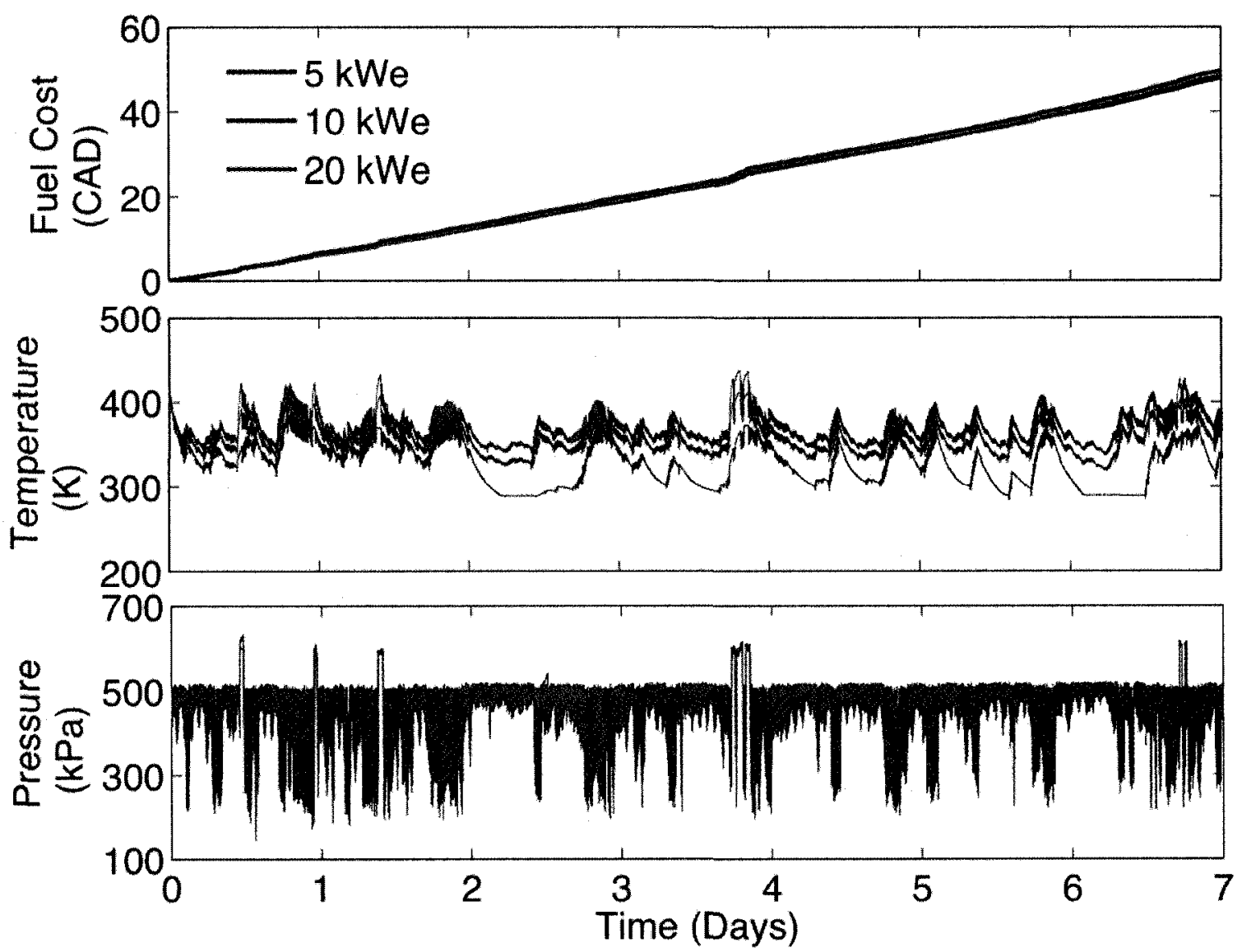

Figure 4-6: Effect of microturbine size on system behaviour. Operating costs, accumulator temperature, and pressure compared for three different microturbine sizes while satisfying a heating load (Mode 1).

The $20 \mathrm{kWe}$ engine supplies more input power to the secondary compressor than the $10 \mathrm{kWe}$ engine, and is therefore not matched for maximum isentropic efficiency. The secondary compressor sends flow to the accumulator at a higher 
temperature with larger engines due to the lower efficiencies demonstrated at higher secondary compressor mass flows.

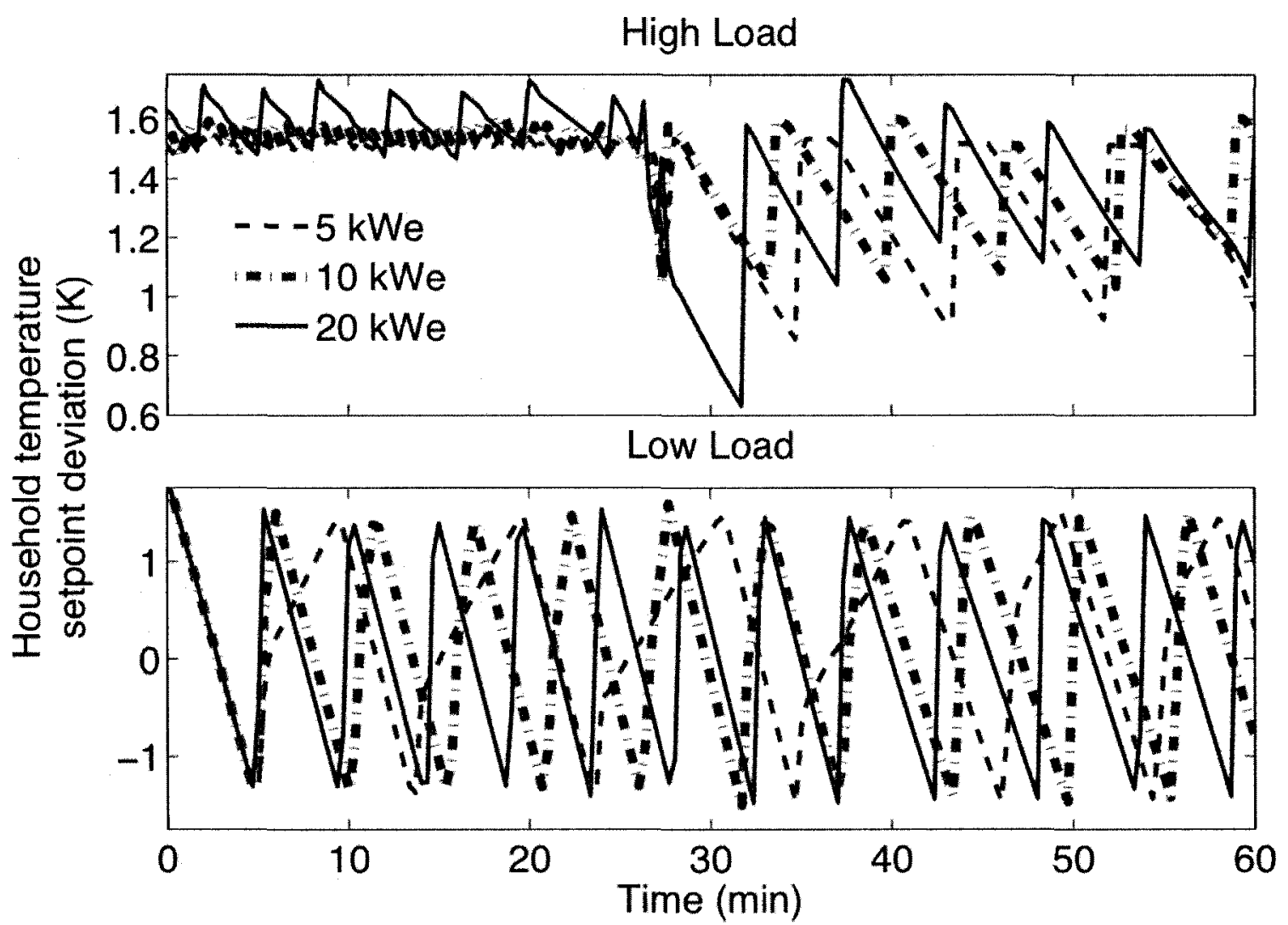

Figure 4-7: Household temperature response for three different microturbine sizes while satisfying a heating load (Mode 1).

A higher specific work is required by the secondary compressor as well, which negates the benefit of a lower HEN SFC for the $20 \mathrm{kWe}$ engine. This validates the claim made in the previous Section (4.1.1), that any losses due to turbomachinery isentropic efficiencies of less than unity are recuperated later either via reduced HEN SFC or an increase in thermal load provided to the 
household.
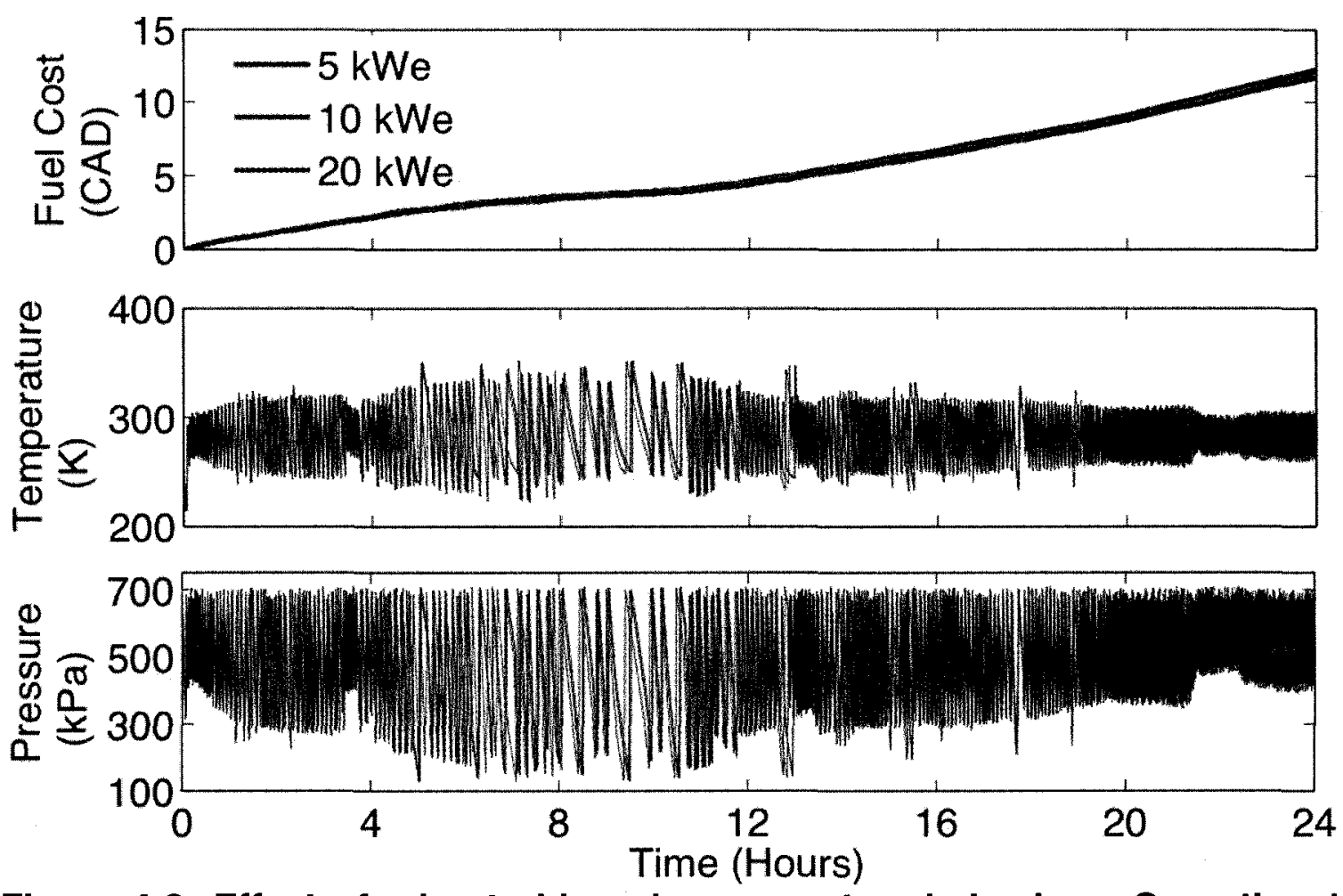

Figure 4-8: Effect of microturbine size on system behaviour. Operational costs including accumulator temperature and pressure are compared for three different microturbine sizes while satisfying a cooling load (Mode 2).

Microturbine size had very little impact on system performance while operating with Mode 2; Figure 4-8 and Figure 4-9 show negligible impact on system behaviour and household temperature response. Operating cost was not influenced by microturbine size either. All three microturbine sizes could not produce sufficient excess power to supply the secondary compressor to meet household cooling demands during peak periods (greater than $2 \mathrm{kWt}$ ). This meant that during peak periods supplementary grid power was purchased to 
increase secondary compressor mass flow; hence the accumulator was charged at the same rate despite engine size during peak cooling periods. This translates to similar accumulator temperature and pressure behaviour for all three engine sizes as shown in Figure 4-8.

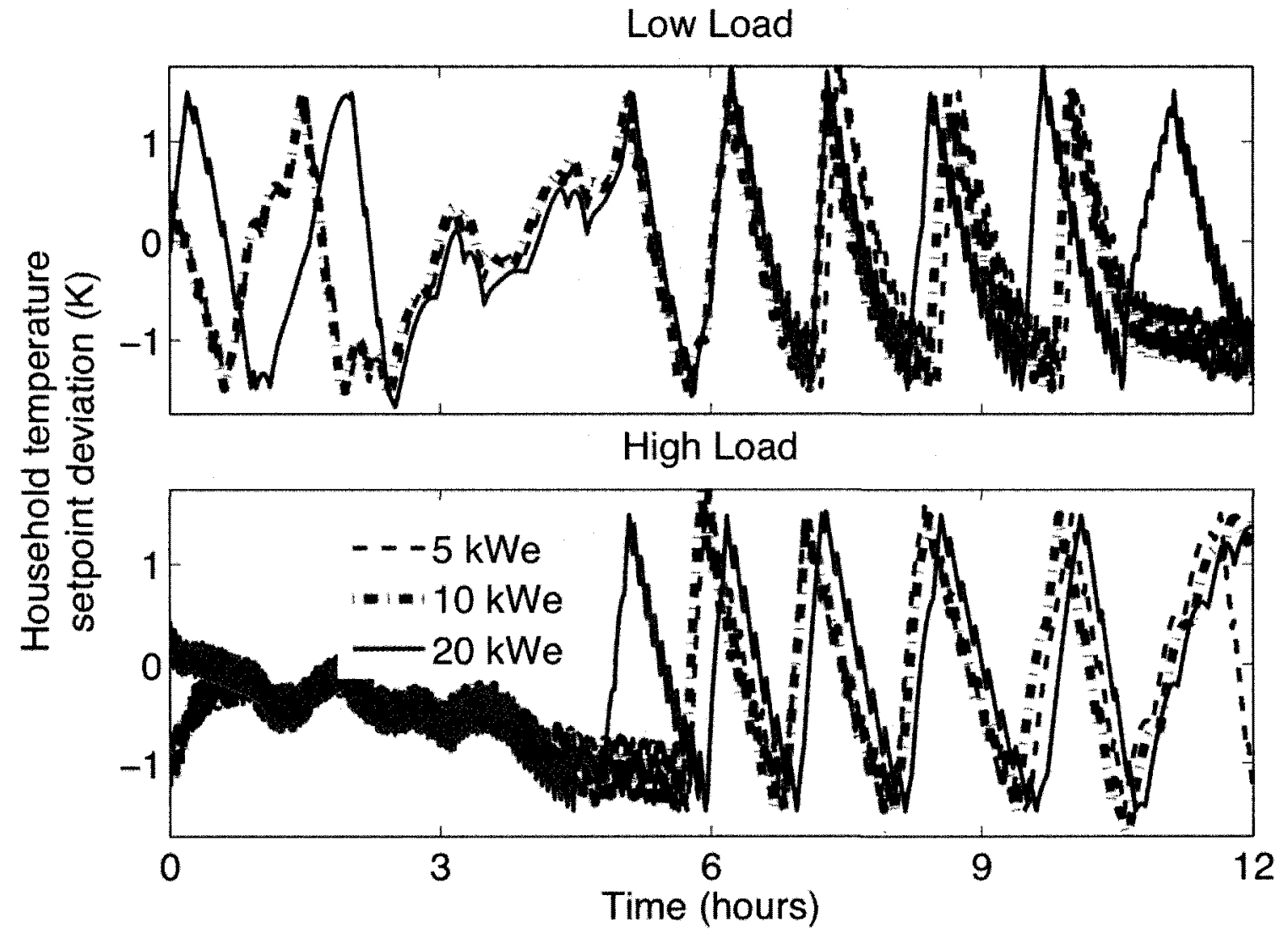

Figure 4-9: Household temperature response for three different microturbine sizes while satisfying a cooling load (Mode 2).

Based upon this study, the only consideration required when choosing a microturbine size is to ensure the engine can satisfy peak electrical loads while 
providing a power input to the secondary compressor. This will ensure total energy islanding can be attained for Mode 1, and for Mode 2 (if a higher household setpoint temperature is acceptable during peak summer temperatures). The $10 \mathrm{kWe}$ engine is therefore recommended, as the $5 \mathrm{kWe}$ engine cannot satisfy peak electrical loads, and no benefit is realized from choosing the more expensive $20 \mathrm{kWe}$ microturbine.

\subsubsection{Microturbine bleed}

In an effort to reduce system complexity and cost, initial design called for the accumulator to be charged with microturbine compressor bleed flow instead of a secondary compressor, as shown in Figure 3-1. The microturbine compressor was run at design conditions with output power controlled by throttling compressor discharge bleed flow. This allowed the microturbine to operate in an electric load following manner, while simultaneously charging the accumulator and satisfying a heating load. While satisfying a heating load, fuel costs for the system using compressor bleed flow to charge the accumulator were slightly higher than if a secondary compressor was used, as shown in Figure 4-10. The difference in cost is due to the fact that the time to increase household setpoint temperature from minimum to maximum limits was sometimes less than the time required to charge an empty accumulator. To prevent household overheating, expander exhaust was discharged to atmosphere while waiting for the 
accumulator to charge, reducing the overall efficiency of the system. This has been observed to occur during low thermal high electrical load conditions; a high electric load will reduce bleed flow into the accumulator, as the microturbine must pass more mass flow through the expander to satisfy the higher electrical demand; this translates into a longer accumulator charging period. If the thermal demand is low, expander exhaust will have to be dumped overboard due to the longer charging period if bleed flow is used to charge the accumulator.
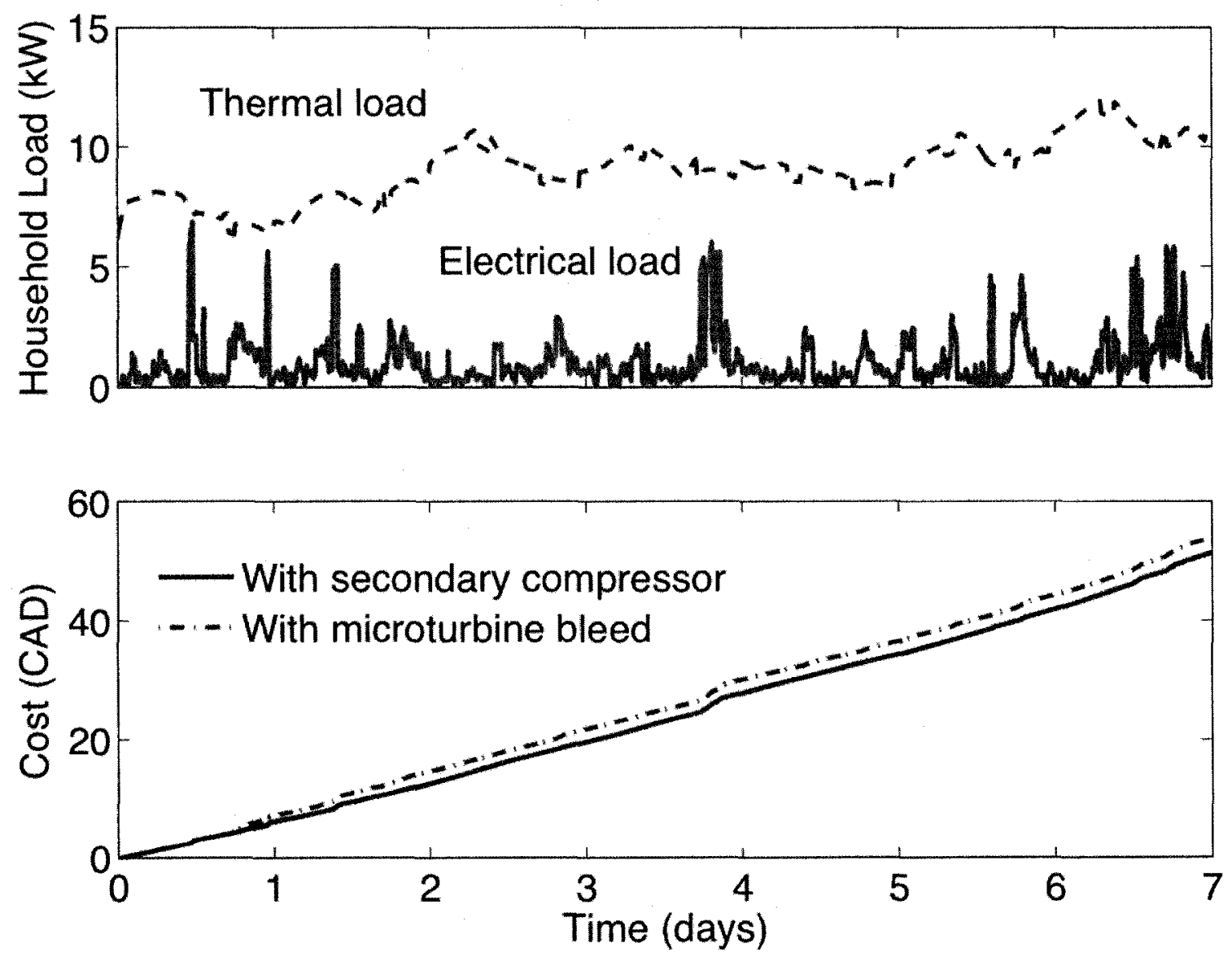

Figure 4-10: Fuel costs for Mode 1 (heating load), comparison is made between microturbine operation with compressor bleed versus using a secondary compressor. Natural gas is set at 6.2 CAD/GJ. 
Cost data for the cooling mode is not displayed as microturbine bleed flow was not able to satisfy household cooling requirements as shown in Figure 4-11; using bleed flow limits maximum cooling capacity to less than about $0.75 \mathrm{kWt}$ for a $10 \mathrm{kWe}$ engine. The trigeneration system can satisfy a cooling load as long as the accumulator charging flow is equal to the discharge flow. When the system cannot recharge the accumulator as fast as it is emptied, the household setpoint temperature exceeds the maximum setpoint limit, as is the case in Figure 4-11.

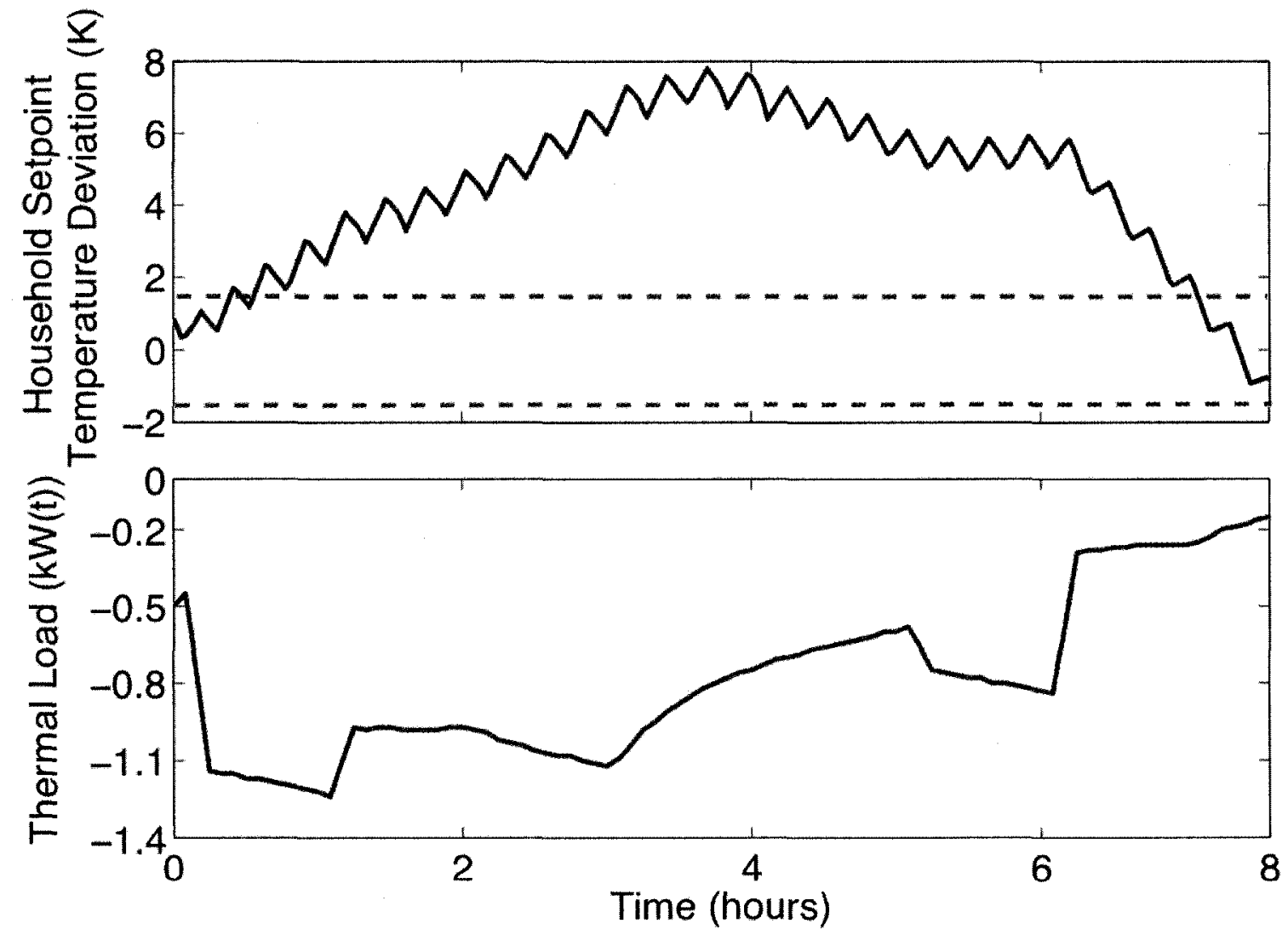

Figure 4-11: Household setpoint deviation using microturbine bleed flow to charge the accumulator while satisfying a cooling load. Red dotted lines indicate household minimum and maximum setpoint temperatures (22 \pm $\left.1.5^{\circ} \mathrm{C}\right)$ 
The microturbine compressor size is based upon a specified engine design point and has to be matched with the expander. As a result, the only way to increase microturbine maximum compressor bleed flow without changing turbomachinery isentropic efficiencies or pressure ratios is to increase the size of the engine. It is possible that a sufficiently large engine could provide the cooling load required, however it would be severely oversized for heating load production. Figure 4-12 illustrates the benefit realized by the addition of a secondary compressor. The secondary compressor does not have to be matched with another component, nor does it have to operate at a continuous speed.

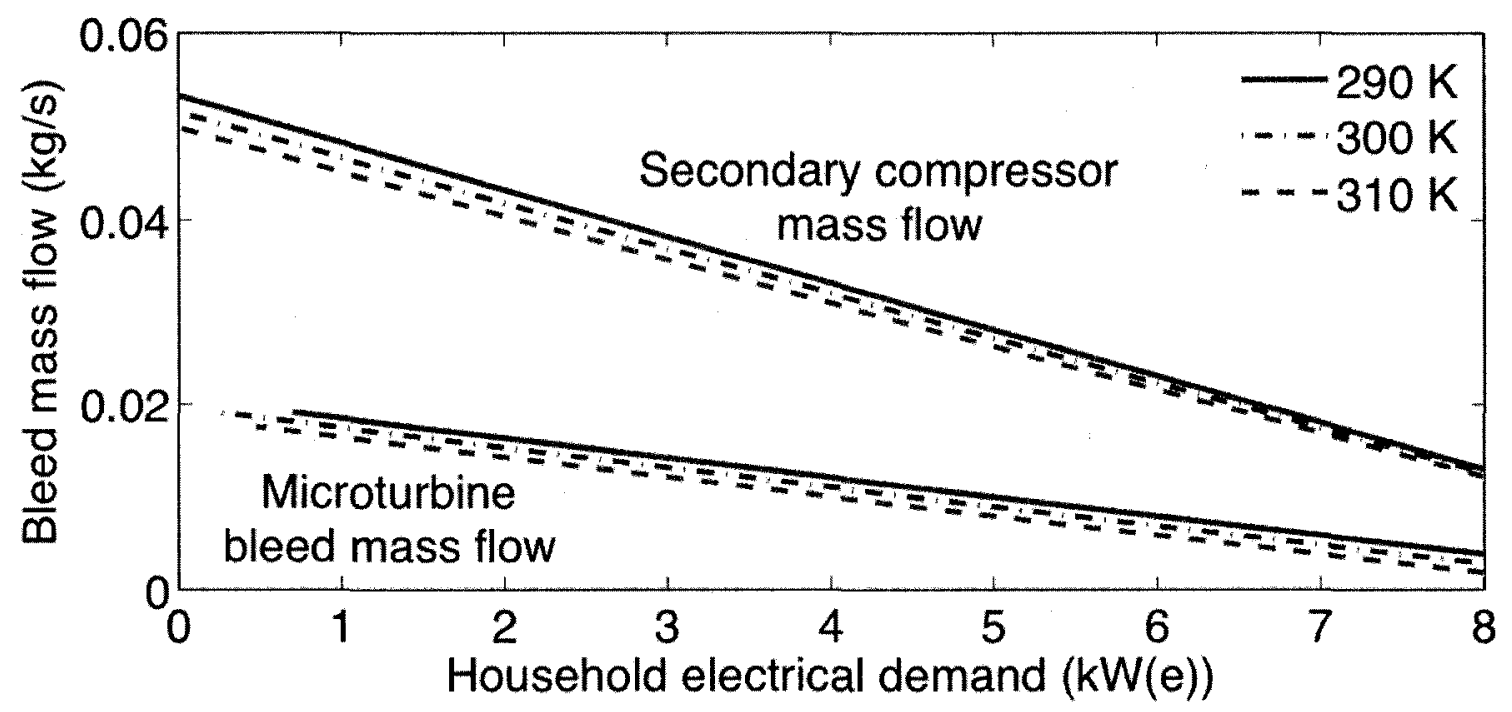

Figure 4-12: Variation in accumulator charging flows with household electrical load for various ambient temperatures. Data for microturbine bleed mass flow is for a $10 \mathrm{kWe}$ engine.

The secondary compressor used in the simulation also demonstrates significantly 
higher isentropic efficiencies (up to 0.92 ) when compared to the microturbine compressor ( 0.75 at design). When in a constant pressure mode of operation, this higher efficiency translates to higher mass flows for the same input power. The secondary compressor also has the benefit of being able to accept grid power if necessary to boost mass flow. This ensures no accumulator flow deficit exists, thereby maintaining household temperature within setpoint limits.

A typical operating line for a gas turbine in constant speed mode of operation is almost vertical on a graph of corrected compressor mass flow versus CPR; hence compressor mass flow is virtually invariant from full power to synchronous idle. If bleed flow is to be boosted without using a separate compressor or resizing the microturbine, the engine must deviate from constant speed operation. During peak loads compressor mass flow, and by extension bleed flow, could be boosted by supplying grid power to the high-speed generator; at the same time household electrical demand could be supplied by grid power as well. Supplying grid power to the high-speed generator would increase shaft power to the compressor and increase CPR; this in turn would permit a larger maximum bleed flow. This concept was not modelled or simulated, and remains a topic of further investigation. It is always desirable to reduce system complexity and maintenance costs; any concept that involves elimination of the secondary compressor is worth pursuing. 


\subsection{5. \#4 Heat exchanger}

Heat pumps and geothermal systems have benefited from the pseudo-infinite heat capacity deep in-ground installations offer for many years. A study was conducted to evaluate the effect a deep in-ground heat exchanger would have on the economic performance of the system under study. Labelled as ' $\# 4 \mathrm{Hx}$ ' in Figure 3-2 and Figure 3-3, this heat exchanger is buried in-ground such that the surrounding mass remains a constant $8^{\circ} \mathrm{C}$ year round (see Section 3.1 ). The \#4 $\mathrm{Hx}$ was used in a different manner for Mode 1 and 2:

Mode 1: Secondary compressor inlet flow is pre-heated by drawing inlet flow through \#4 Hx

Mode 2: Secondary compressor discharge flow is cooled through \#4 $\mathrm{Hx}$ before entering the accumulator.

As shown in Figure 4-13, \#4 Hx provides a significant benefit for operation in Mode 2. Without \#4 $\mathrm{Hx}$, the accumulator temperature demonstrates stagnation temperatures of up to $450 \mathrm{~K}$, as secondary compressor discharge is not allowed to cool (not shown in Figure 4-13). It is possible that even after expansion through the IBC, exhaust flow temperature is above ambient household temperature. When this happens no cooling load can be provided by the system and household temperature increases above setpoint limits. Not only does \#4 Hx provide a substantial economic benefit, it is required to satisfy the mission of the 
trigeneration system while operating in Mode 2.

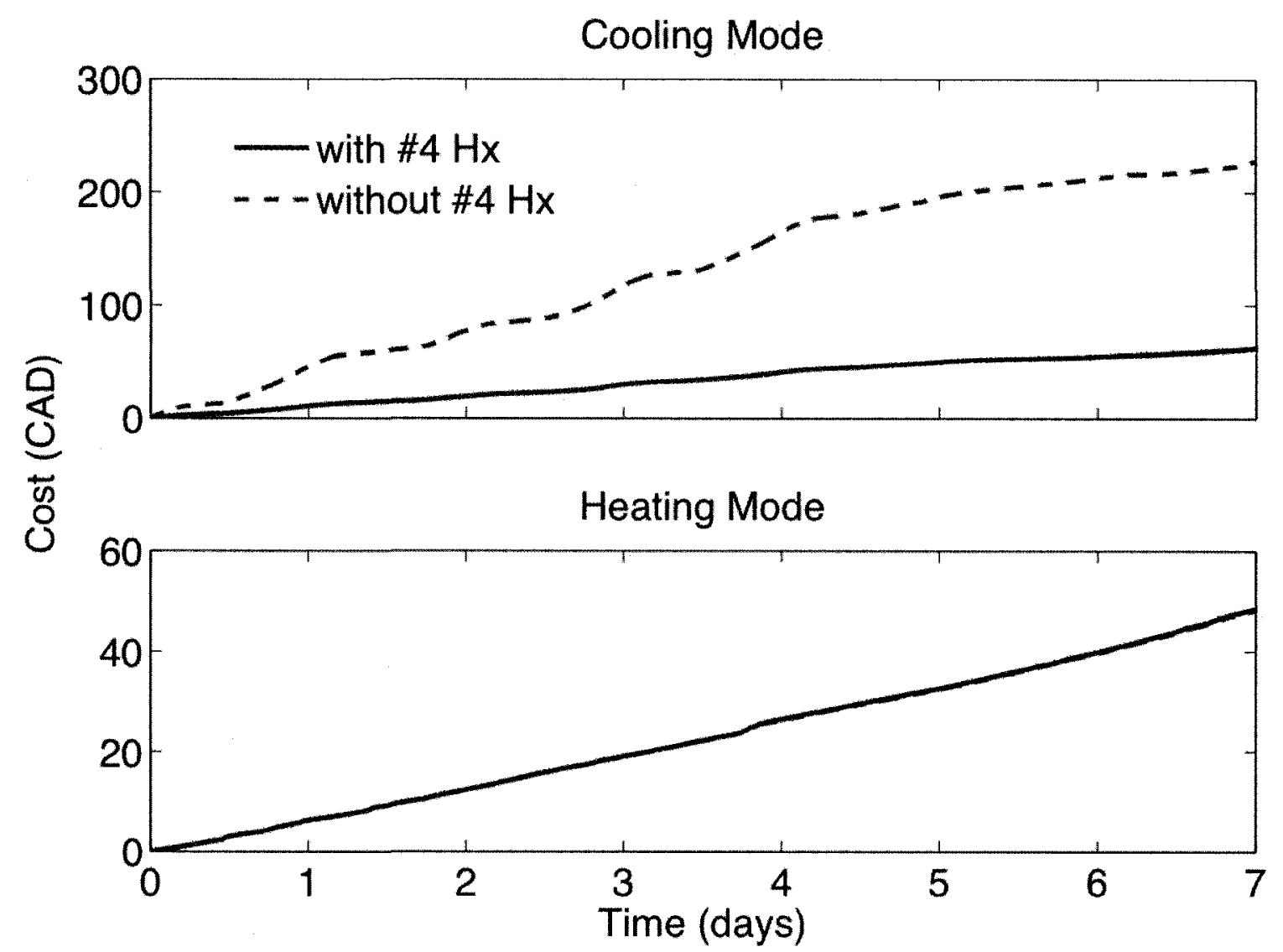

Figure 4-13: Fuel and purchased grid power costs for trigeneration operation with and without \#4 Hx in Mode 1 and Mode 2 modes of operation.

This economic benefit is not extended to operation in Mode 1, as there is negligible improvement in economic performance. It is believed that the benefit of an elevated accumulator temperature is offset by the reduced mass flow through the secondary compressor associated with less dense inlet flow. Since the system is designed to charge the accumulator until a maximum pressure has 
been reached, any reduction in mass flow into the accumulator during charging will increase the time required until fully charged. This translates into longer microturbine run times and increased fuel consumption. Of course this increase in microturbine fuel consumption is offset by a decrease in HEN fuel consumption due to higher accumulator temperature; the results shown in Figure 4-13 indicate that this offset is equal in magnitude. To reduce unnecessary wear and tear on the \#4 Hx, It is therefore recommended that the \#4 Hx be used for Mode 2 only.

\subsubsection{IBC flow treatment}

To extract more specific work from the IBC expander, the effect of increasing expander inlet temperature (EIT) was investigated. Two cases were studied: the first case did not cycle accumulator discharge flow through the HEN. As accumulator discharge flow is typically anywhere from 300 to $400 \mathrm{~K}$, secondary expander discharge flow temperature was too low to provide a useful thermal load. The second case increased accumulator discharge temperature by cycling through the HEN before entering the secondary expander. The HEN was fired at a constant maximum combustion temperature $\left(T_{23}\right)$ of $1200 \mathrm{~K}$ for all accumulator discharge pressures and flow rates. Despite consuming fuel during IBC operation, cycling accumulator discharge flow through the HEN reduced overall fuel consumption as shown in Figure 4-14. While the cost savings may seem marginal, note that the data in Figure 4-14 spans only a week. Fuel savings over 
a three to four month winter season with high thermal load are quite substantial.

Another benefit of increasing IBC cycle temperature is that HEN thermal cycling is reduced. Wear and tear placed upon heat exchanging equipment within the HEN by repeatedly heating up and cooling off is dramatically reduced, as the HEN is not allowed to cool off when operating in Mode 1.
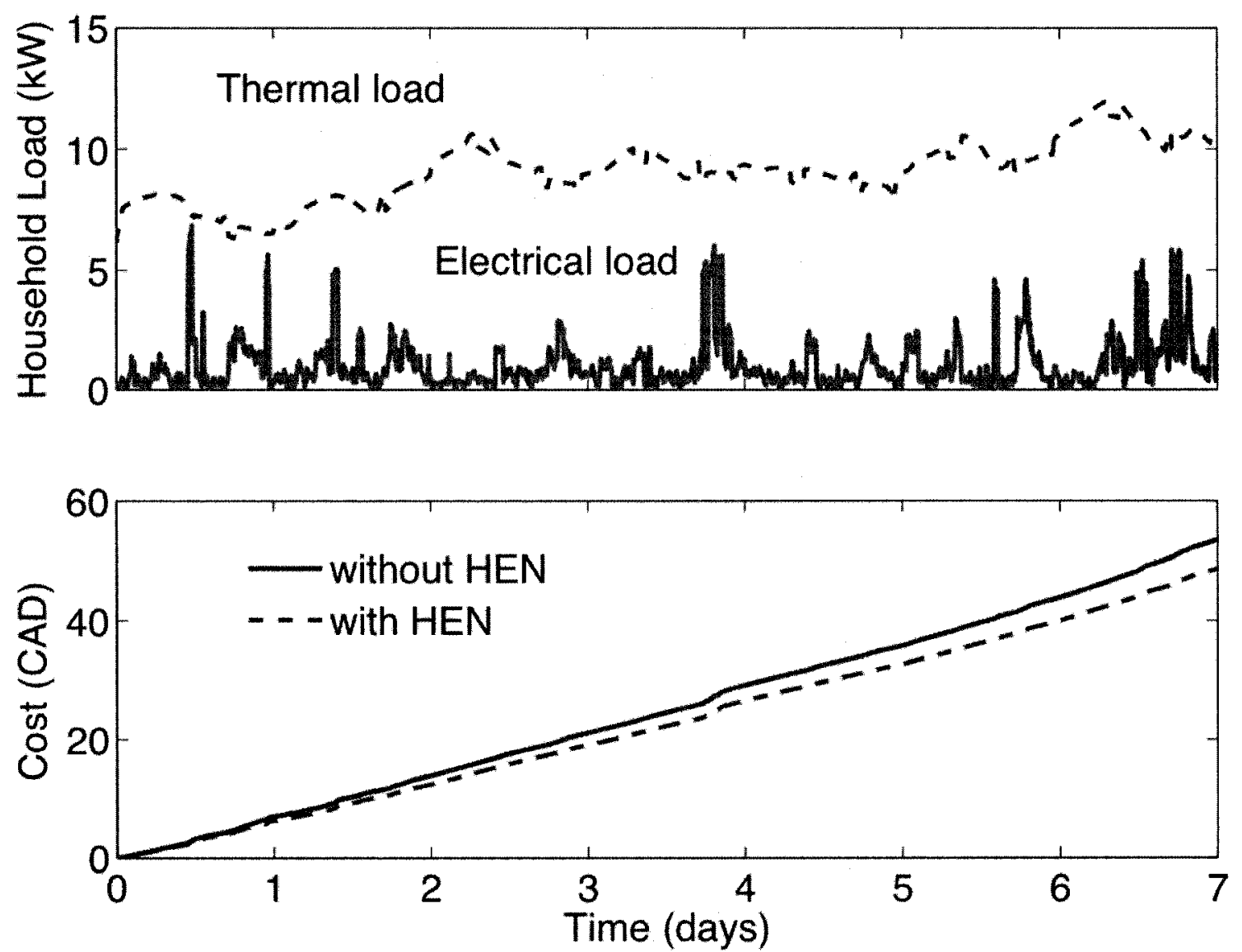

Figure 4-14: Trigeneration system economic performance with and without increasing EIT. Maximum HEN combustion temperature of $T_{23}=1200 \mathrm{~K}$ was kept constant throughout IBC operating envelope.

By continuously keeping the HEN at an elevated temperature, error introduced by 
not modelling transient heat exchanger behaviour is reduced. Maximum heat exchanger effectiveness is achieved only when energy accumulation within the components of the HEN goes to zero. If accumulator discharge is not cycled through the HEN, it will cool down. When the microturbine is started up again, there will be a brief period where the HEN is not operating at design effectiveness while internal components absorb energy from the two flows passing through. It is recommended that accumulator discharge flow be cycled through the HEN (which is to be fired at the highest possible temperature) in Mode 1, before discharge to the secondary expander. Accumulator discharge should be vented directly through the secondary expander in Mode 2.

\subsubsection{Secondary expander}

The microturbine expander must be matched with the compressor in such a manner as to produce a desired power output at design. These restrictions dictate the expander characteristic as seen in Figure 3-14. As a rule of thumb, the compressor consumes roughly two units for every one unit of shaft output in a traditional Brayton cycle [4.1]. Hence the expander characteristic is not always ideal for IBC operation given that the compressor is not consuming two out of every three units produced by the expander. It has already been determined that increasing accumulator discharge flow temperature improves economic performance (see Section 4.1.6), however this poses a challenge for maintaining 
household temperature.

If accumulator discharge was passed through the HEN while adding sufficient fuel to bring the HEN combustion side temperature to its maximum, the thermal output from the microturbine expander had the potential to exceed the household heating load. For the household temperature to remain within setpoint limits, the thermal load delivered to the household during IBC operation has to be less than the household thermal load. This controlled household cool down allows microturbine exhaust to be used for heating purposes when recharging the accumulator.

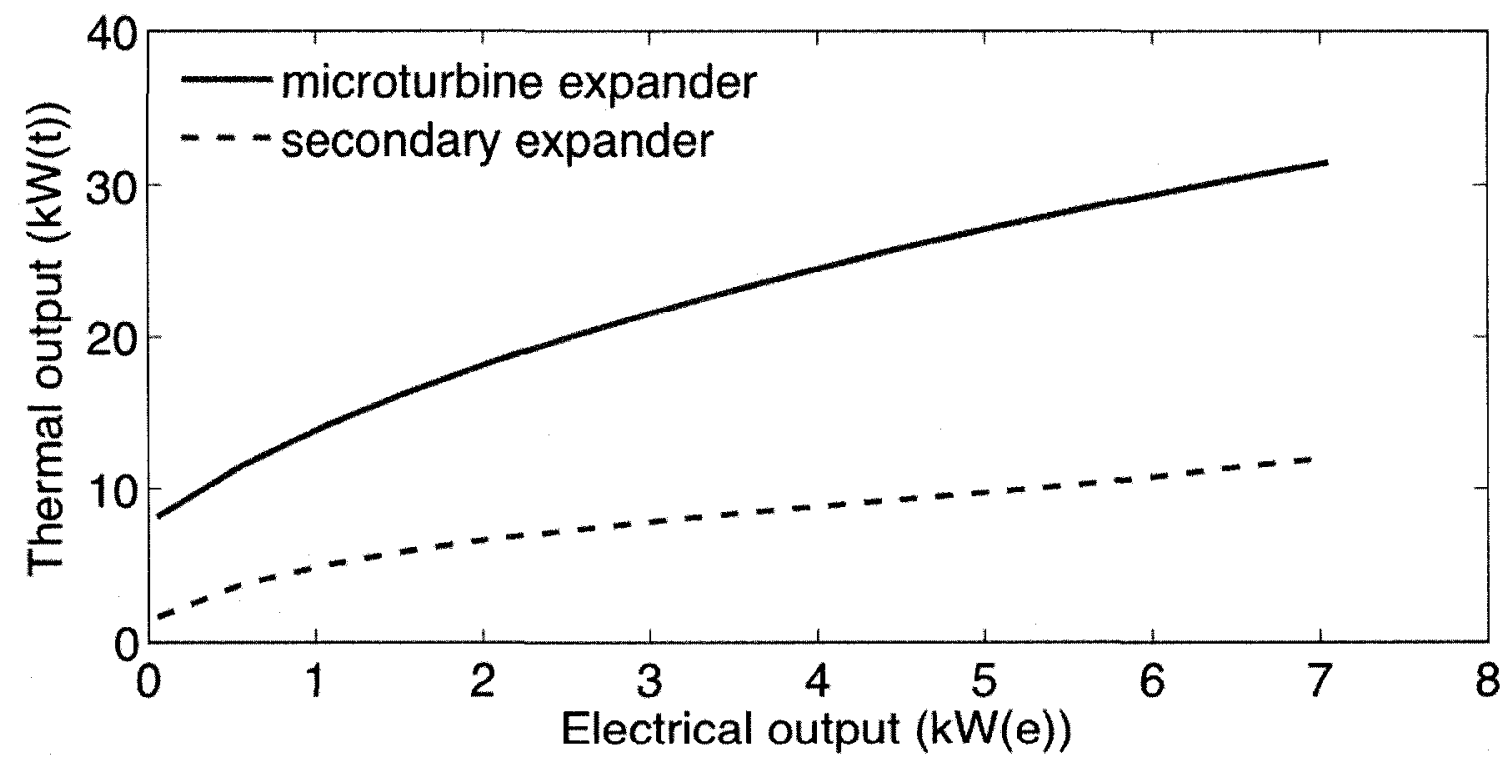

Figure 4-15: Ratio of electrical to thermal output of the IBC expander at maximum HEN firing temperature $T_{23}=1200 \mathrm{~K}(E I T=1163 \mathrm{~K})$. 
If the household temperature is too high when the microturbine engages an accumulator recharge cycle, exhaust will have to be dumped overboard to prevent household overtemp. At the same time to minimize fuel costs, IBC maximum cycle temperature $\left(T_{23}\right)$ must be kept as high as possible. Figure 4-15 shows the relationship between thermal and electrical output of the IBC using the microturbine expander, and a separate re-sized secondary expander. The secondary expander used is geometrically similar to the microturbine expander with a scaling factor applied such that the corrected mass flow is $1 / 6^{\text {th }}$ of the microturbine expander. Household heating loads during severe winter months typically vary between 8 and $15 \mathrm{kWt}$. Figure $4-15$ shows secondary expander thermal output is almost always below this demand, yet is sufficiently sized to provide for peak household electrical demand of about $7 \mathrm{kWe}$. Using the re-sized secondary expander allows the HEN to be fired at maximum temperature for improved economic performance while not exceeding household thermal demand.

\subsection{Final results}

Based upon the results from the studies described in Section 4.1, a final configuration was selected for maximum economic performance. See Figures Figure 3-2 and Figure 3-3 for schematics of the final configurations for Mode 1 and Mode 2. Key design points are summarized as follows: 
- Accumulator size was set at $2 \mathrm{~m}^{3}$. The dimensions of such an accumulator $(1.37 \times 1.37 \mathrm{~m})$ should not pose significant practical problems for installation in new and old construction alike. Larger sizes are preferred if cost permits.

- The HEN operates in heating and cooling modes (Mode 1 and Mode 2).

- Microturbine design point electrical output at ambient conditions of 101.325 $\mathrm{kPa}$ and $288 \mathrm{~K}$ is $10 \mathrm{kWe}$.

- Secondary compressor discharge is cycled through \#4 $\mathrm{Hx}$ in Mode 2. \#4 Hx is not used in Mode 1.

- IBC flow is cycled through a secondary expander which has a design corrected mass flow that is $1 / 6^{\text {th }}$ of the microturbine expander.

- IBC flow is cycled through the HEN that is fired at maximum temperature when a heating load is required.

Figure 4-16 is a comparison of yearly energy consumption for the final trigeneration system configuration and the independent generation system. A severe penalty is paid by the system during summer operation, as natural gas consumption reduces only slightly while consuming electricity at the same time. Figure 4-17 breaks down economic performance by month, better illustrating the relative performance of the two systems throughout the year. Supplemental electrical power is required for the trigeneration system during periods of high cooling load demand, accounting for half of yearly independent generation 
consumption; hence the high monthly operating cost for the trigeneration system during summer months, shown in Figure 4-17. These results show that system performance during heating load production is potentially superior to independent generation (depending on market energy prices). There is much room for improvement during cooling load production, further study is currently being conducted to improve economic performance. Eliminating supplemental electrical power consumption is one means of doing so.

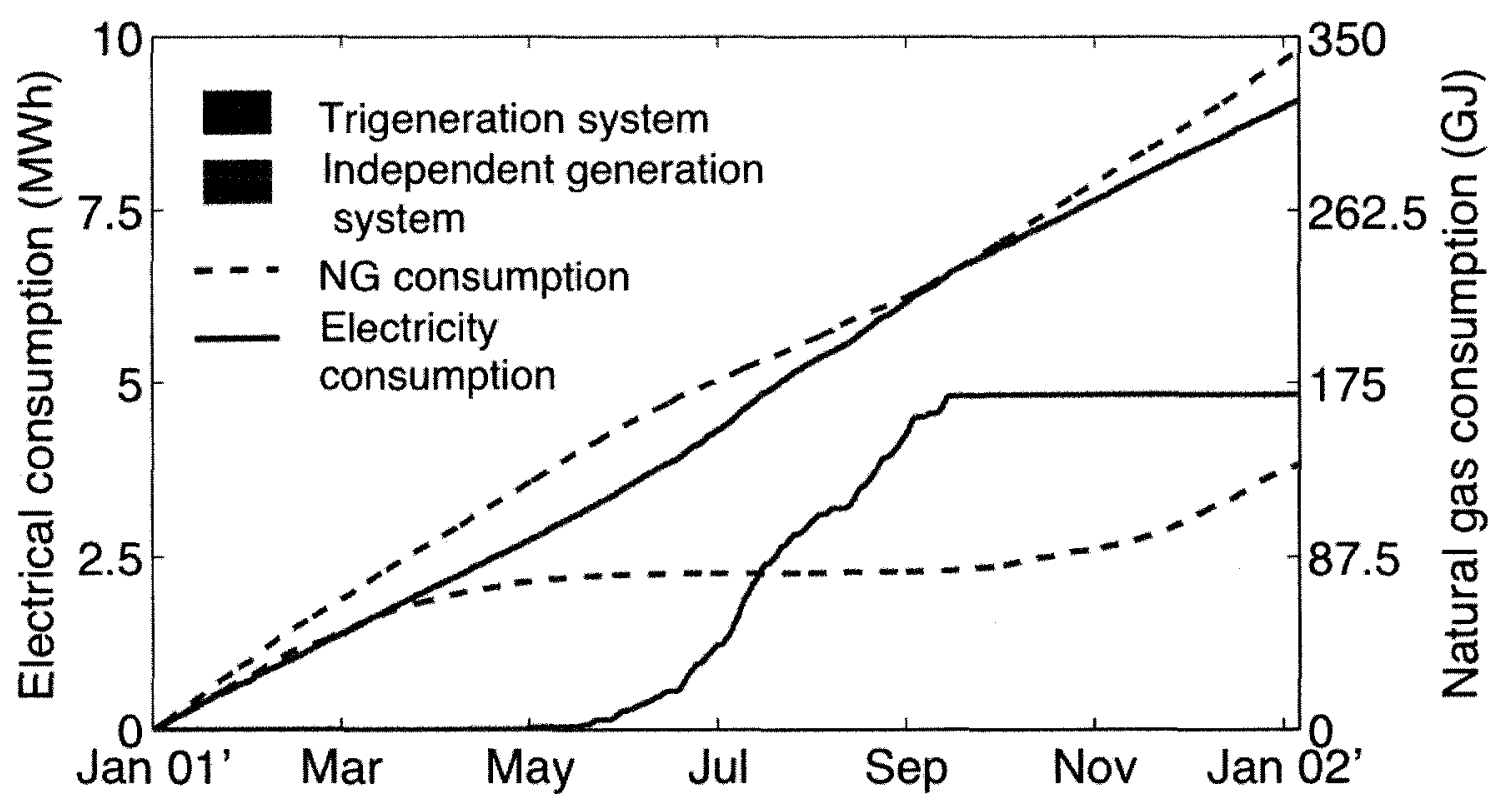

Figure 4-16: Yearly consumption of electricity and natural gas for the trigeneration and independent generation systems. 


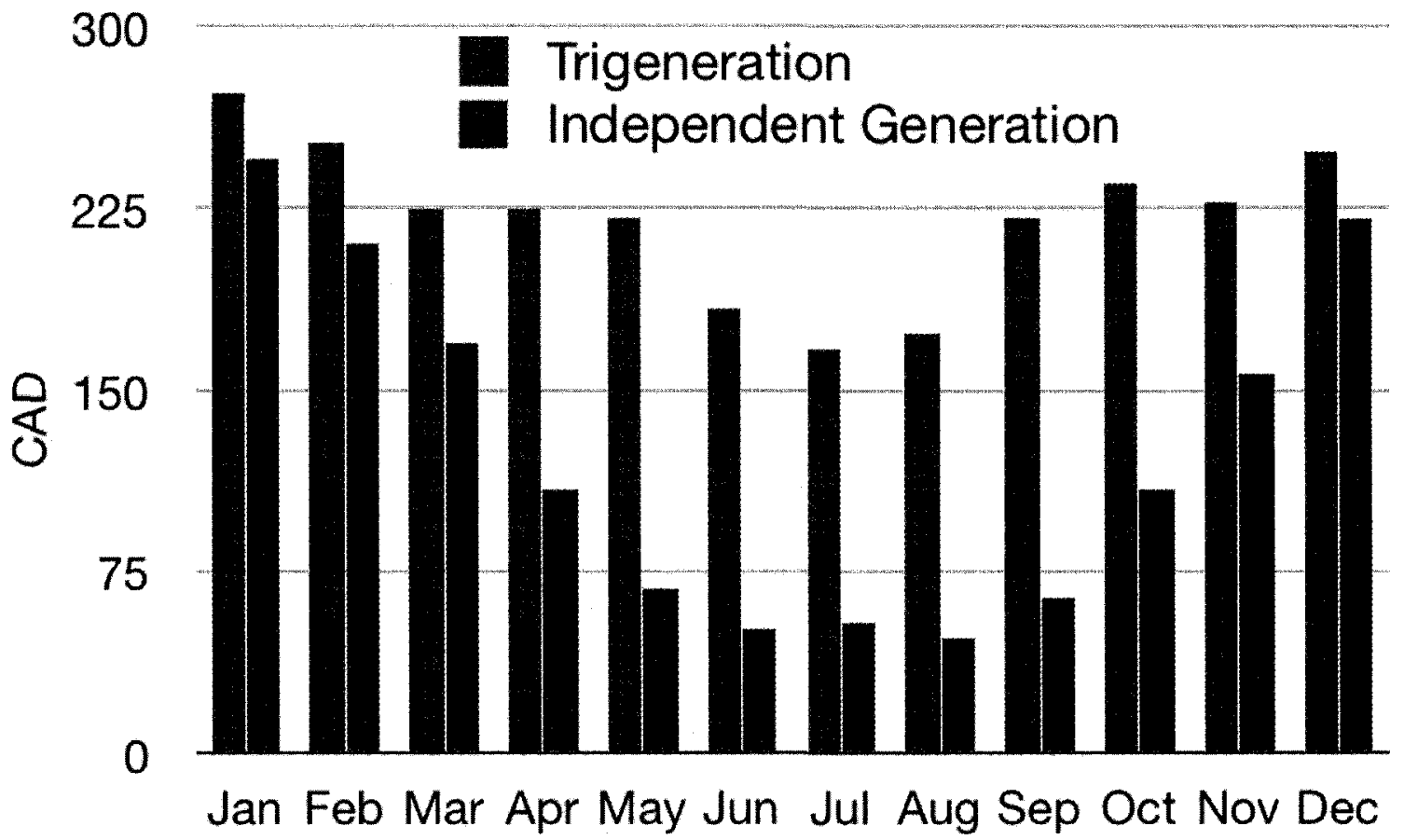

Figure 4-17: Monthly operating cost comparison between the trigeneration and independent generation systems.

Total elimination of supplemental electrical power not only brings an economic benefit, but energy islanding could be achieved for the full year. The solution lies in increasing the specific cooling output (defined as $\mathrm{kW}$ of energy input per $\mathrm{kW}$ of cooling produced). This can be accomplished in a number of ways, however it is believed that increasing the isentropic efficiency of the secondary compressor and expander would have the most impact. The primary source of thermal inefficiency within the trigeneration system during cooling load production is the heat lost through the \#4 Hx. At design, the secondary compressor has a peak isentropic efficiency of 0.92 for a volume flow rate of 0.039 to $0.043 \mathrm{~m}^{3} / \mathrm{s}$. During 
peak cooling load production, the volume flow rate increases to as much as $0.110 \mathrm{~m}^{3} / \mathrm{s}$ with a corresponding isentropic efficiency as low as 0.64 ; the secondary compressor is clearly optimized for lower flow rates. During heating load production, a low isentropic efficiency is not a penalty to economic performance as the additional heat added to the compressed air is recovered later as a heat load. Low isentropic efficiencies are a penalty during cooling load production, as any excess heat added to secondary compressor flow is removed through the \#4 $\mathrm{Hx}$. If a compressor is optimized for operation close to its maximum flow rate, it is believed that specific cooling output would increase. A similar argument is made for the secondary expander. With a higher isentropic efficiency, expander discharge temperatures will be lower. The secondary expander typically operates at pressure ratios between 1.05 and 2.5 with a corresponding variation in isentropic efficiency of about 0.76 to 0.83 (see Figure 3-19). Modern aerodynamic design has allowed radial turbines to achieve isentropic efficiencies in excess of 0.92 [4.7]; hence there is much room for improvement in the current design.

Electrical efficiency is not a concern when satisfying a heat load, as a reduction in electrical output translates to a proportional increase in heat load output. Electrical efficiency is a concern when satisfying a cooling load, as any reduction in electrical output due to a decrease in electrical efficiency mean less power is 
provided to the secondary compressor; hence the accumulator takes longer to charge. While the HEN is effective in extracting energy from microturbine expander exhaust, combustion flow from the HEN is still discharged at about 510 $\mathrm{K}$ and microturbine exhaust is discharged at about $350 \mathrm{~K}$ in Mode 2. Future iterations of the simulation will use these flows to provide a hot water load without an increase in fuel consumption. As the independent generation system would require additional fuel or electricity to satisfy a hot water load, the difference between the economic performance of the trigeneration and independent systems would decrease.

In an effort to ensure results were not unrealistically optimistic, microturbine parameters such as PR, maximum cycle temperature, and component isentropic efficiencies were selected to be conservative. An upper limit for microturbine compressor and expander efficiencies of 0.85 and 0.90 respectively could be used, however the economic performance was not investigated. Perhaps the largest potential gain to system electrical efficiency can be achieved by uprating the HEN. 
Table 4-1: Effect of increasing maximum \#2 $\mathrm{Hx}$ temperature $\left(\mathrm{T}_{23}\right)$ on microturbine electrical efficiency in Mode 2. Values are for ambient conditions of $288 \mathrm{~K} 101.325 \mathrm{kPa}$.

\begin{tabular}{|c|c|}
\hline Max HEN Temp (K) & Electrical Efficiency \\
\hline 1200 & 30.6 \\
\hline 1300 & 34.3 \\
\hline 1400 & 35.7 \\
\hline 1500 & 37.4 \\
\hline
\end{tabular}

A conservative value for maximum HEN temperature was selected $\left(T_{23}=1200\right.$ $\mathrm{K})$, to ensure a reasonable service life for $\mathrm{Hx} \# 2$. Use of high temperature materials and special design would permit an increase to the maximum cycle temperature. Table 4-1 shows the efficiencies possible with a temperature uprate. Note that these results were obtained without modifying compressor or turbine characteristics. For temperatures other than the design maximum temperature of $1200 \mathrm{~K}$, the compressor and expander selected for this study will be operating in off-design at 100 percent power with an associated penalty on isentropic efficiency. The values in Table 4-1 are therefore lower than what would be achieved with turbomachinery that has been sized specifically for the new maximum temperature.

\subsubsection{Market variation study}

Using 2007 market energy prices for Winnipeg, Canada, household thermal loads were estimated. Results from Figure 4-16 were used to arrive at a yearly economic performance comparison between the modelled and independent generation systems shown in Figure 4-18. Two key conclusions can be made 
based upon Figure 4-18: 1) The trigeneration system is superior to individual generation while producing a heat load. 2) The independent generation is superior while producing a cooling load. With electricity charged at 5.7 CAD/MWh and natural gas at $8.2 \mathrm{CAD} / \mathrm{GJ}$, the independent generation system was 48 percent less expensive to run for one year when compared to the trigeneration system. The effect of market price variation on economic performance was investigate. Figure 4-19 is a plot of projected natural gas and electrical prices for Winnipeg, Canada (the same city used to predict thermal loads in ESP-r). The projections in Figure 4-19 are averages of the results from four independent studies commissioned by Natural Resources Canada [4.6].

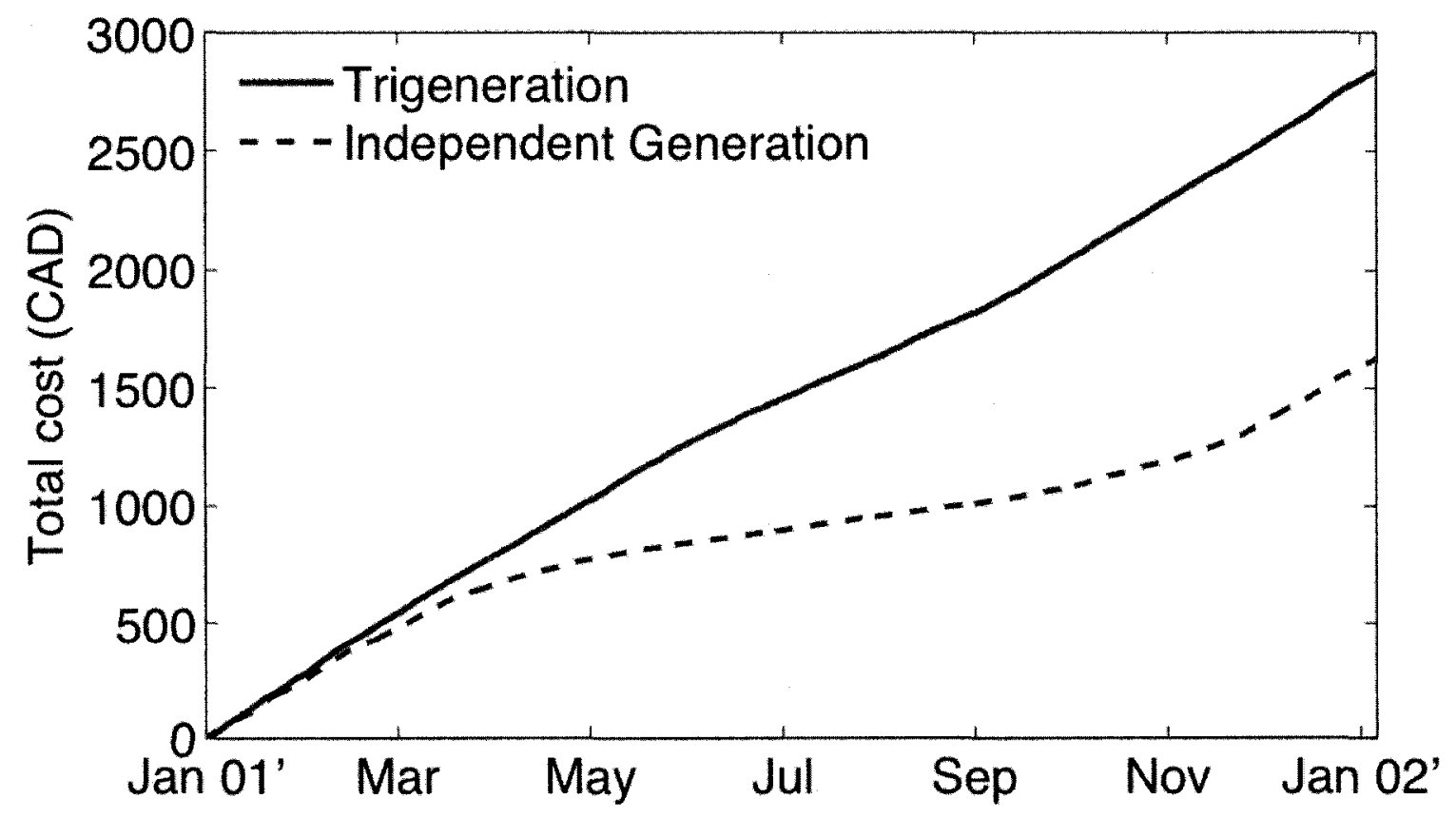

Figure 4-18: Yearly cost comparison between the trigeneration and independent generation systems using 2007 market data from Figure 4-19. 


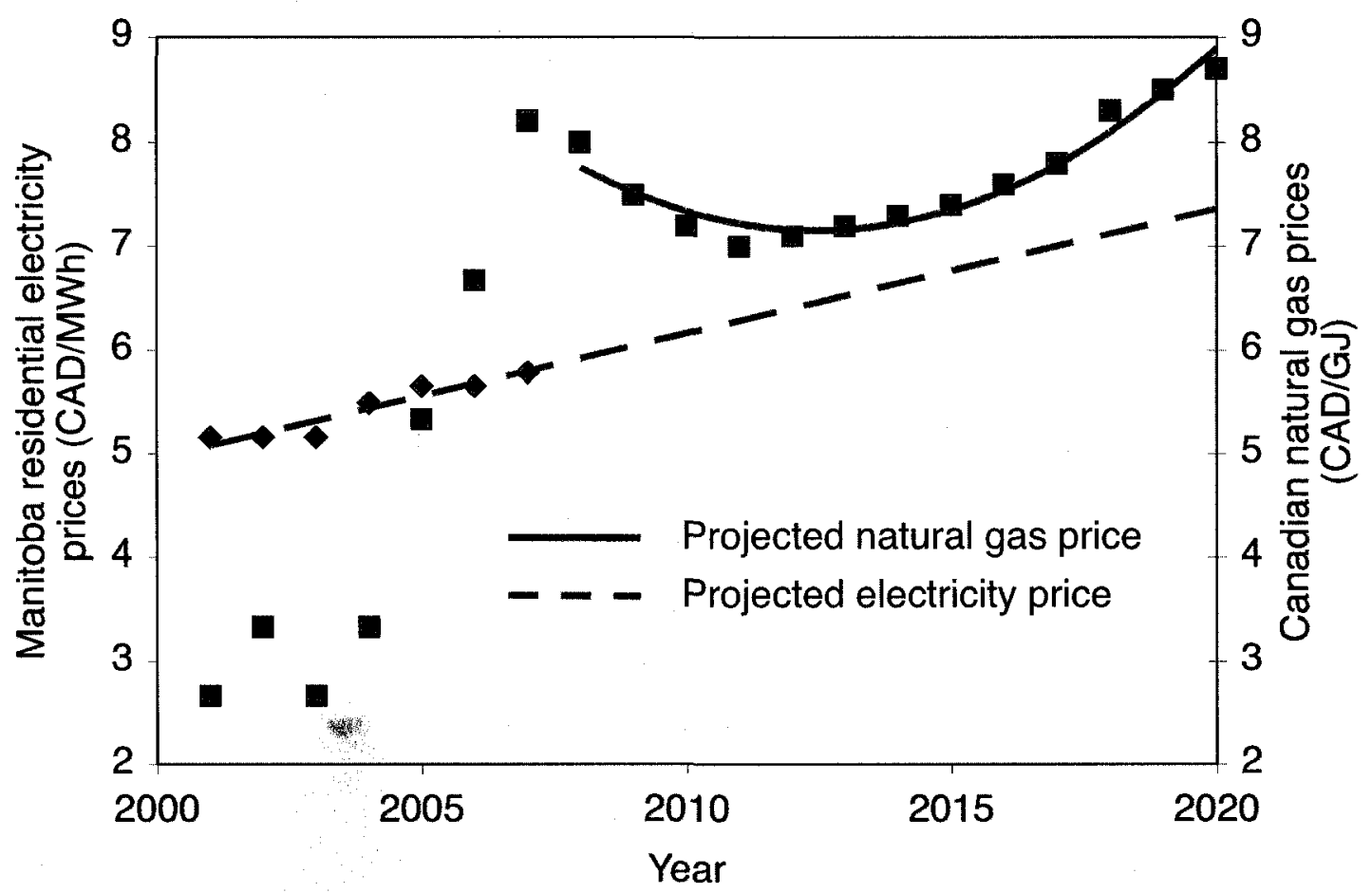

Figure 4-19: Historical and projected household natural gas and electricity prices. [4.1]

Table 4-2: Projected economic performance of the trigeneration and independent generation systems. Market prices are based on projections from Figure 4-19.

\begin{tabular}{|c|c|c|c|c|c|c|c|c|c|}
\hline & Market Prices & \multicolumn{3}{c|}{ Trigen System } & \multicolumn{3}{c|}{ Ind. Gen. System } \\
\hline Year & CAD/GJ & CAD/MWh & $\begin{array}{c}\text { NG } \\
\text { cost }\end{array}$ & $\begin{array}{c}\text { Elec. } \\
\text { cost }\end{array}$ & $\begin{array}{c}\text { Total } \\
\text { cost }\end{array}$ & $\begin{array}{c}\text { NG } \\
\text { cost }\end{array}$ & $\begin{array}{c}\text { Elec. } \\
\text { cost }\end{array}$ & $\begin{array}{c}\text { Total } \\
\text { cost }\end{array}$ & $\begin{array}{c}\% \\
\text { less }\end{array}$ \\
\hline 2007 & 8.2 & 5.7428 & 2805 & 277 & 3082 & 1096 & 521 & 1618 & $\mathbf{4 8}$ \\
\hline 2011 & 7 & 6.2244 & 2394 & 300 & 2695 & 936 & 565 & 1501 & $\mathbf{4 4}$ \\
\hline 2015 & 7.4 & 6.7060 & 2531 & 324 & 2855 & 989 & 609 & 1598 & $\mathbf{4 4}$ \\
\hline 2019 & 8.5 & 7.1876 & 2908 & 347 & 3254 & 1136 & 653 & 1789 & $\mathbf{4 5}$ \\
\hline
\end{tabular}

Economic performance was then evaluated based upon projected market data. Unfortunately, projected economic performance does not change appreciably as 
shown in Table 4-2. To favourably change economic performance for the trigeneration system based on market price alone, natural gas prices must fall while electricity prices remain constant or increase. This has not been the trend in Canadian markets, and is not expected to change in the future [4.1].

Energy prices from international markets that have regions of similar climate to Winnipeg, Canada were compared in Table 4-3 to see if a different energy market has an impact on economic performance. All regions studied still predicted the independent generation system would outperform the trigeneration system economically, however there was some degree of variation. Western European countries and the United States demonstrated similar results showing the economic performance of independent generation is about 35 to 47 percent better than the trigeneration system; similar to the results obtained for Winnipeg, Canada.

It is particularly interesting to note the difference in economic performance between the western world and the former Soviet Union. Russia's Gazprom is the primary supplier of natural gas to Europe, and has flooded the Russian market with cheap natural gas. The dramatically lower natural gas prices in Russia create a favourable economic climate for the trigeneration system. In addition, peak cooling loads are less for the more populated regions of Russia, as summer temperatures are lower than the Canadian prairies. Due to a pre-World War two 
electricity-generating infrastructure, reluctant international, and heavy public utility regulation, Russia is facing a shortage in capacity.

Table 4-3: Yearly economic performance of the trigeneration and independent generation systems for international markets. Market prices are for 2006 [4.5][4.6][4.3][4.2].

\begin{tabular}{|c|c|c|c|c|c|}
\hline \multirow{2}{*}{ Country } & \multicolumn{2}{|c|}{ Market Prices } & \multirow{2}{*}{$\begin{array}{c}\text { Trigeneration } \\
\text { Cost }\end{array}$} & \multicolumn{2}{|c|}{$\begin{array}{l}\text { Independent } \\
\text { Generation }\end{array}$} \\
\hline & CAD/GJ & CAD/MWh & & Cost & $\begin{array}{c}\text { percent } \\
\text { less }\end{array}$ \\
\hline US & 13.02 & 10.4 & 4956 & 2685 & 46 \\
\hline Finland & 8.42 & 12.8 & 3498 & 2288 & 35 \\
\hline Switzerland & 18.3 & 13.3 & 6902 & 3654 & 47 \\
\hline Czech Rep. & 12.99 & 12.2 & 5032 & 2844 & 43 \\
\hline Romania* & 4.3 & 11.6 & 2031 & 1628 & 20 \\
\hline Russia* & 0.54 & 4.92 & 422 & 519 & -23 \\
\hline
\end{tabular}

* market prices are for 2004,2006 prices were unavailable

In an effort to fund modernization, Russia's electrical tariffs have already jumped

15 percent in 2007, with another 10 percent increase planned next year [4.3].

This dramatic increase in electricity rates is not expected to affect natural gas prices, which are expected to increase at the nominal rate of inflation. This trend will serve to make the trigeneration system more attractive from the standpoint of the consumer and investors. International investment firms or companies interested in capitalizing on the lack of capacity in Russia's electricity grid would be much more interested in selling stand alone units to consumers, rather than invest in large infrastructure and then have to deal with tariff regulation. 


\subsection{Validation}

Modules contained within the in-house model and simulation were externally verified to provide a measure of confidence in conclusions made. A description of the methodology used, and results from the validation studies performed can be found in Appendix E. 


\section{Chapter 5}

Component Selection and Conceptual Design

\subsection{Introduction}

Simulating and modelling physical systems gives valuable information about system behaviour, economic performance, and parameter sensitivity without the need of costly prototyping processes. A simulation may produce favourable results that lead to promising conclusions, but practical considerations prevent prototyping. The conclusions drawn in Chapter 4 are invalid if the modelled system has significant practical challenges. These challenges can present themselves in high component purchase costs, high design costs for specialized equipment, and unfavourable market conditions to name a few. The following chapter will investigate if any such challenges are foreseen for the trigeneration system, and suggest solutions.

\subsection{Microturbine}

One of the strengths of the trigeneration system under study is the fact that the majority of the components used employ proven industry tested technologies; the microturbine is a good example of such a component. While there are several companies that produce commercial microturbine packages, none produce an 
engine with an output of less than $30 \mathrm{~kW}$. The mathematical model assumes a microturbine output at design of $10 \mathrm{kWe}$, which does not exist as an off-the-shelf purchase. While there are other microturbines available for purchase than those listed in Table 5-1, the units listed therein span the full range of microturbine power sizes offered.

Table 5-1: Summary of specifications for commercially available microturbines [5.18]

\begin{tabular}{|c|c|c|c|c|c|c|c|}
\hline & Capstone $\mathrm{C} 30$ & Capatone $\mathrm{C60}$ & $\begin{array}{l}\text { Ingersoll-Rand's } \\
\text { Power Works } \\
250\end{array}$ & $\begin{array}{l}\text { TOYOTA } \\
\text { Turbine Bystoms } \\
\text { TPCSORA }\end{array}$ & $\begin{array}{c}\text { TOyoTA } \\
\text { Tumbine \& Systems } \\
\text { TPC300A }\end{array}$ & $\begin{array}{l}\text { General } \\
\text { Electric }\end{array}$ & $\begin{array}{l}\text { Bowman } \\
\text { Turbogen }^{\text {ma }} \\
\text { TG80RC } G\end{array}$ \\
\hline Electrical efficient $(\%)$ & 26 & 28 & 32 (Target) & 26 & 18 & 35 (Target) & 28 \\
\hline Output power (kWe) & 30 & 60 & 250 & 50 & 295 & 175 & go \\
\hline Mass flow tate $(\mathrm{kg} / \mathrm{s})$ & 0.31 & 0.49 & 1.84 & 0.48 & 2.0 & & \\
\hline Pressure ratio & 3.5 & & 4.1 & 3.5 & 6.7 & & 4 \\
\hline Axial speed (rpan) & 96,000 & 96,000 & 45,6000 & 80,000 & $49,000 / 35,000$ & & 68,000 \\
\hline $\operatorname{TrT}\left({ }^{\circ} \mathrm{C}\right)$ & 840 & & 927 & 940 & 940 & & \\
\hline Exhausst temp. $\left({ }^{\circ} \mathrm{C}\right)$ & 275 & 370 & & 271 & 580 & & 238 \\
\hline Exhaust energy ( $\mathrm{kW}$ ) & 85 & 150 & & lol (Hot water) & 1074 (Steam) & & 136 \\
\hline NOx (pprov) & $\begin{array}{l}<9\left(15 \% \mathrm{O}_{3}\right) \\
\text { (Natural gas) }\end{array}$ & $\begin{array}{c}<9\left(15 \% 0_{7}\right) \\
\text { (Natural gas) }\end{array}$ & $\begin{array}{c}<9\left(15 \% \mathrm{O}_{2}\right) \\
\text { Natural gas }\end{array}$ & $\begin{array}{r}<15\left(16 \% \mathrm{O}_{7}\right) \\
\text { (Towa gas 13A) } \\
\end{array}$ & $\begin{array}{r}<19\left(16 \% 0_{2}\right) \\
\text { (Town gas 13A) } \\
\end{array}$ & $\leq 10\left(15 \% 0_{2}\right)$ & $<25\left(15 \% \mathrm{O}_{2}\right)$ \\
\hline Fuel & $\begin{array}{c}\text { Gaseous propane } \\
\text { or } \\
\text { Natural gass }\end{array}$ & Natural gas & Natural gas & $\begin{array}{l}\text { Town gas 13A, } \\
\text { LPG, Kerosene }\end{array}$ & $\begin{array}{l}\text { Town gas } 13 A_{\text {, }} \\
\text { LPG, Kerosene }\end{array}$ & Natural gas & $\begin{array}{l}\text { Natural gas, } \\
\text { LPG, Propane, } \\
\text { Butane }\end{array}$ \\
\hline Maintenance interwal (h) & 8,000 & & & 12,000 & 12,0000 & 11,000 & \\
\hline Life time $(\mathrm{h})$ & & & & $43_{n}(000)$ & 48000 & 45,000 & \\
\hline Sound level (Package) & $65 \mathrm{dBA} @ 10 \mathrm{~m}$ & 70 dBA@10 m & $72 \mathrm{dBA} @ \mathrm{~lm}$ & 65 aBA@1 & $70 \mathrm{dBA} 1 \mathrm{~m}$ & & $704 B A @ \mathrm{~m}$ \\
\hline Unit cost (\$KW) & & & & & & $\begin{array}{c}\text { s } \$ 500 / k W \\
\text { (Target) }\end{array}$ & \\
\hline
\end{tabular}

Despite the lack of microturbine packages in the required size, small-scale compressor and expander technology is widely available in a different form. Turbochargers have been used for decades to increase specific power output from spark and compression ignition engines. Turbochargers do not produce a useful work output, as all work generated by the turbine goes into compressing engine inlet air, however radial turbomachinery and housings could be adapted to 
function as a microturbine. The Garrett GT22 series turbocharger, with a compressor input power of 15 to $25 \mathrm{~kW}$ offers a good basis from which to build a suitable microturbine, see Appendix C for component maps for the GT22 series turbocharger.

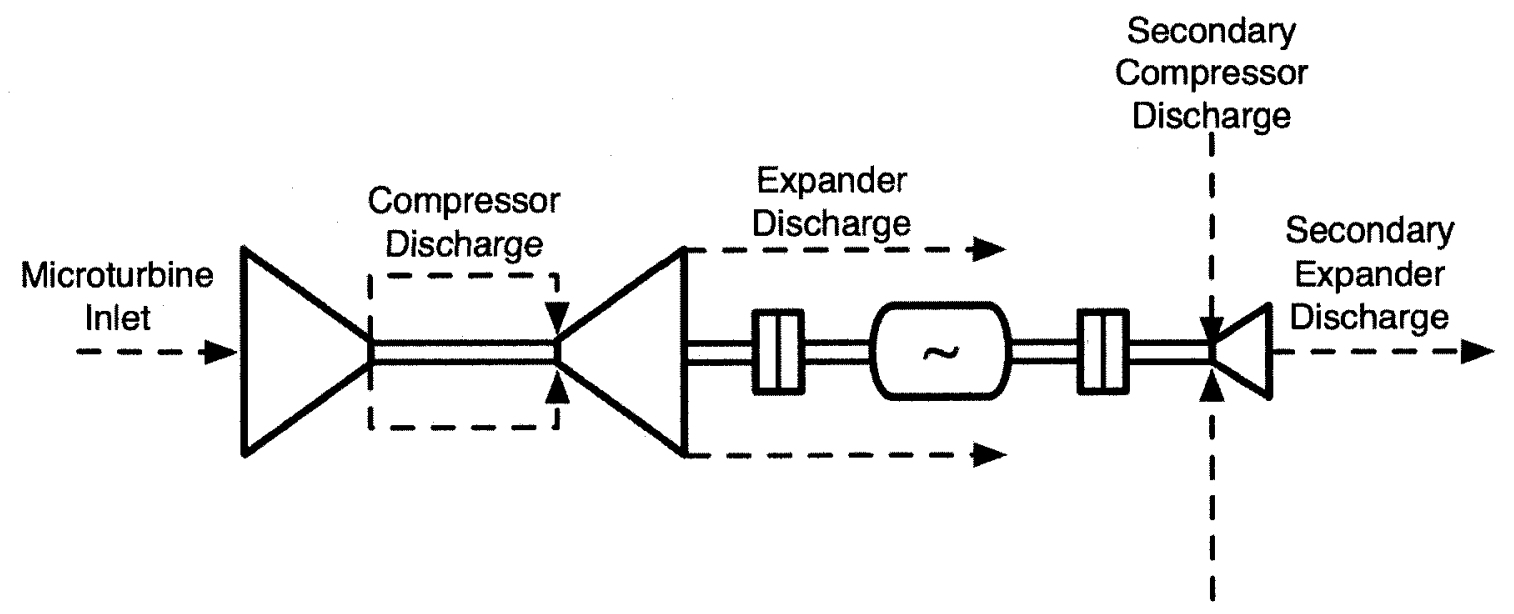

Figure 5-1: Special design for microturbine powertrain

As seen in Figure 5-1, the trigeneration system requires a special microturbine powertrain design that incorporates clutches to allow each component to operate independently of another. The modular construction of this drive train makes for easy fabrication and modification of an existing microturbine design, without significant alterations to the microturbine casing or exhaust manifold.

\subsection{Heat exchangers}

\subsubsection{High-temperature heat exchanger $(\# 2 \mathrm{Hx})$}


The fired heat exchanger $(\# 2 \mathrm{Hx})$ is similar in appearance to a common household natural gas furnace, however the operating pressure and temperature is significantly higher. This requires alternate materials and design to ensure an adequate service life is achieved. As the exchanger will be subject to a high rate of thermal cycling, reducing cracking and fatigue due to thermal expansion is of paramount importance in a successful design. Exchanger designs using plates and thin metal membranes such as plate fin, plate, and spiral constructions would most likely not be able to withstand burner operating temperatures (1200K) without some degree of warp and/or cracking. Ceramic heat exchangers show signs they may be able to be adapted for use in a fired exchanger with high thermal cycles. Exchangers fabricated from SiC exhibit very low thermal expansion coefficients, have good strength at elevated temperatures and have very low heat capacities [1.44]. SiC would be ideally suited for systems that are frequently cycled due to the very high thermal conduction coefficient (which exceeds copper and almost doubles aluminium). This would allow the exchanger to be brought up to temperature rapidly. Although ceramic heat exchangers have been in use for some time, their application to compact heat exchangers is still in the experimental phase. As they are unproven in both performance and cost, ceramic heat exchangers will not be considered for use in the fired heat exchanger module for this study. Directly fired heat exchangers are typically built to order, hence the few companies that do make them do not have a standard 
product line from which to choose. Fired exchangers are typically seen in the oil and gas or mining industries as process re-heaters to keep process fluids up to temperature. Such an application generally requires a very large unit, an example is shown in Figure 5-2, making the unit required for this study a special order. As design and procurement of the fired exchanger is outside the scope of this thesis, companies were not pursued to obtain quotes.
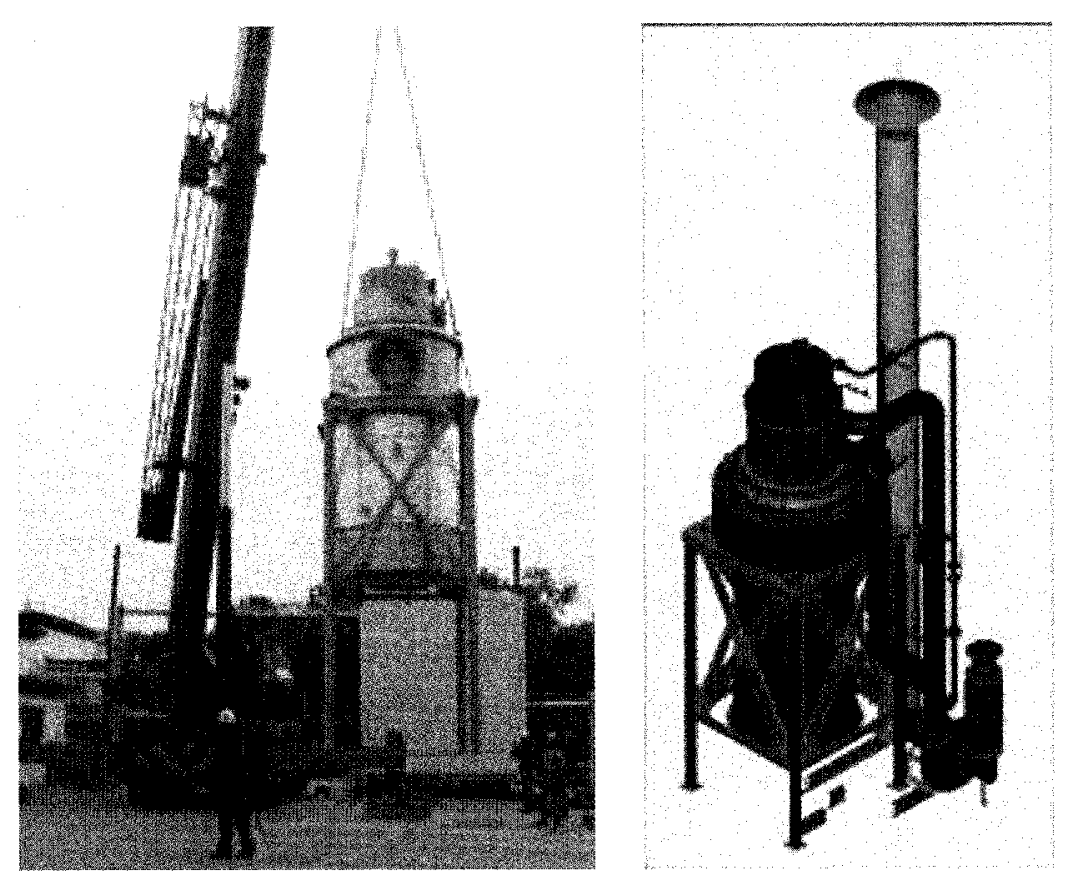

Figure 5-2: Directly fired heat exchanger fabricated by Selas Fluid for the oil and gas industry [5.9]

\subsubsection{Low-temperature heat exchangers (\#1 and \#3 Hxs)}

Unlike exchanger \#2, the two non-fired exchangers used in the system (\#1 and \#3) can be purchased off-the-shelf due to lower operating temperatures, and due 
to the fact that they operate with a common gas-to-gas exchange process. Table 5-2 lists the operating temperatures of the heat exchangers in the HEN; Figure 3-2 and Figure 3-3 show the locations of the heat exchangers within the modelled system. Evaluation and selection of heat exchanger construction was subject to the following design constraints for exchangers \#1 and \#3:

- Must be able to withstand sustained maximum operating temperatures as listed in Table 5-2.

- Must demonstrate a service life of 10 to 15 years of normal operation.

- Must be resistant to degradation due to high thermal cycling during operation.

- Must demonstrate an effectiveness of 85 percent or higher, 90 percent is preferred.

- Unit cost must be realistic for purchase by a household consumer.

This evaluation process identified the following heat exchanger classifications as potential candidates for use as non-fired exchangers in the subject system: brazed plate, shell and tube, plate fin, and regenerators.

Table 5-2: Heat exchanger operating temperatures for an OAT of $288 \mathrm{~K}$

\begin{tabular}{|l|c|c|c|c|c|c|}
\hline & \multicolumn{2}{c}{ Hx \#1 } & \multicolumn{2}{c|}{ Hx \#2 } & \multicolumn{2}{c|}{ Hx \#3 } \\
\cline { 2 - 8 } & In & Out & In & Out & In & Out \\
\hline Air Side (K) & 452 & 830 & 830 & 1164 & 513 & 839 \\
\hline Comb. Side (K) & 868 & 513 & 1200 & 868 & 897 & 491 \\
\hline
\end{tabular}




\subsubsection{Brazed plate heat exchanger}

The brazed plate heat exchanger (BPHE) typically uses a series of corrugated plates stacked together to deliver compact and effective heat transfer. Unlike a gasketed plate heat exchanger, these plates are brazed together in a vacuum furnace. This permits higher temperature operation due to the presence of high temperature nickel alloy braze in lieu of elastomer gaskets. As one fluid passes through every other gap provided by adjacent plates, large amounts of heat transfer surface are provided in a small package, shown in Figure 5-3.

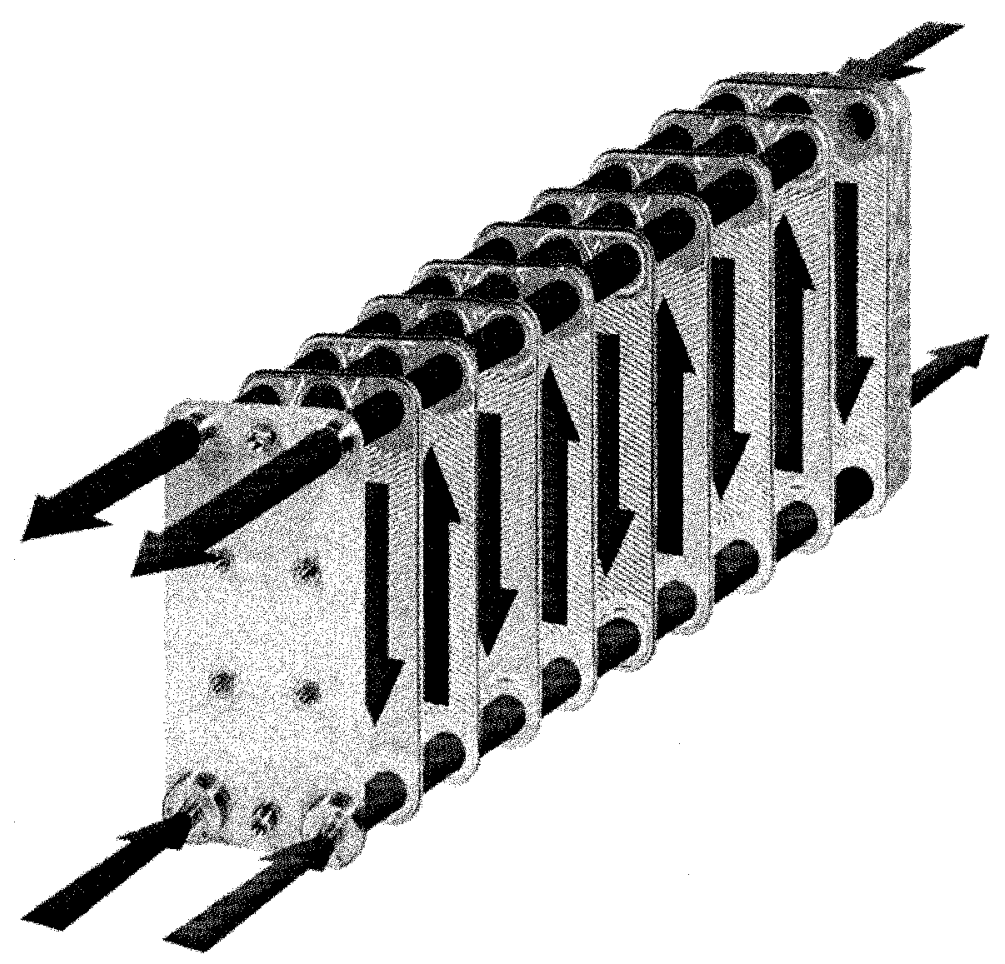

Figure 5-3: Illustration of alternating fluid pattern for a three fluid BPHE [5.25] 
BPHEs offer very high heat transfer performance due to low velocities and high turbulence induced by rapidly changing flow directions; high turbulence also contributes to reducing fouling, effectively increasing service life [5.22]. When combined with a large heat transfer surface area, plate exchangers can achieve fluid exit temperature differentials of 0.5 to $1 \mathrm{~K}$ [5.13]. Due to the simple modular construction of the BPHE, capital costs are very low compared to equivalent shell and tube exchangers. Although brazing plates together raises the allowable operating temperature, the thin plate construction is susceptible to warping due to thermal cycling at temperatures well below the softening points of the braze and plate materials. As the plates are constrained at the outside perimeter with braze material, any warp will break the brazed joint and vent fluid to atmosphere. Brazing the plates together also limits de-fouling maintenance to chemical cleaning only, which is not always effective. Despite the very attractive low cost and high effectiveness demonstrated by BPHE units, they are not suitable for use in the subject system due to operating temperatures that would severely limit service life.

\subsubsection{Shell and tube heat exchanger}

The shell and tube heat exchanger (STHE) is the most common variety of heat exchanger, accounting for 80 percent of all industrially installed exchangers in the European market [5.22]. This can be partially attributed to the versatility of the 
design and due to a high degree of standardization. Such standardization allows fabrication of the STHE without requiring a costly design process. The standard most commonly used around the world is the Tubular Exchanger Manufacturers Association (TEMA); this standard is meant to augment the ASME boiler and pressure codes [5.22]. A STHE can be built by choosing from the various standardized components available under the specification, a summary of the specification is shown in Figure 5-4. STHE units are typically larger and heavier than plate fin or BPHE units, but benefit from a more robust design. For processes that require high pressure (greater than 30 bar) or high temperature (greater than $800^{\circ} \mathrm{C}$ ), non-tubular exchangers are generally not suitable. For mobile applications such as powerplant recuperation, the prohibitively large size and weight of the STHE force designers to consider lighter and smaller alternatives. The STHE consists of a shell which determines the flow pattern within the exchanger. Different shell constructions can be used to achieve different overall heat transfer coefficients. Depending on internal baffle construction and where inlet and output ports are placed flow can be made to travel in a cross, counter, parallel, or split-flow manner. 


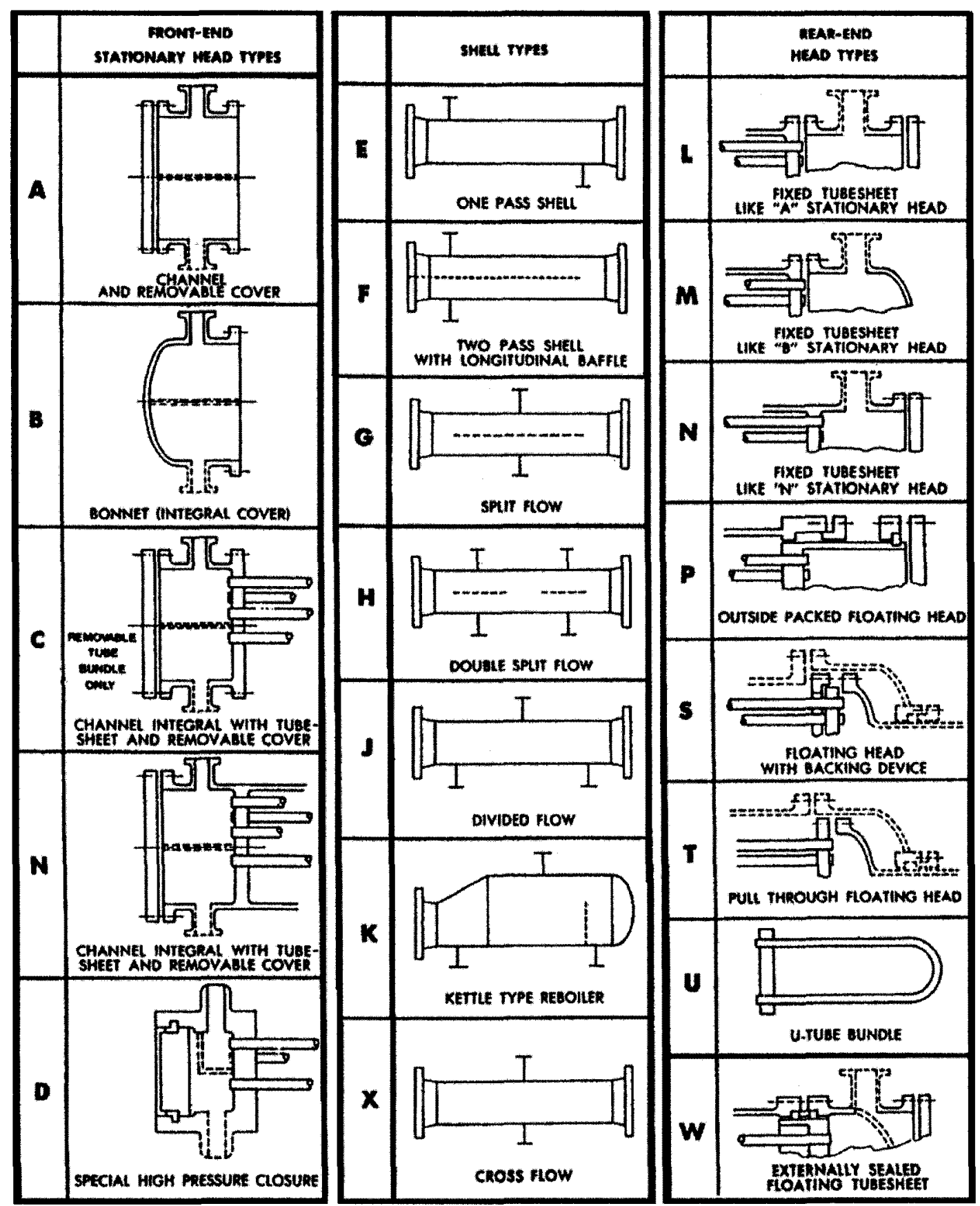

Figure 5-4: Graphical summary of TEMA fabrication specifications [5.23]

To some extent the tube geometry is dictated by the shell geometry, however two 
main variations exist: straight tube, and U-tube. While increasing the overall heat transfer coefficient is always a priority, ease of maintenance is also significant. Utube construction offers a lighter and simpler design as only one tubesheet is required, see Figure 5-5; U-tube bundles are also easily removed for cleaning*. Compared to the straight tube, which requires two tube sheets and two removable heads, the U-tube saves on weight and cost. A penalty is paid in that the flow in a U-tube installed in a shell without a longitudinal baffle varies between parallel-, counter-, and cross-flow with a deleterious effect on overall heat transfer. Straight tube versions can choose and tightly control what method of flow arrangement is desired.

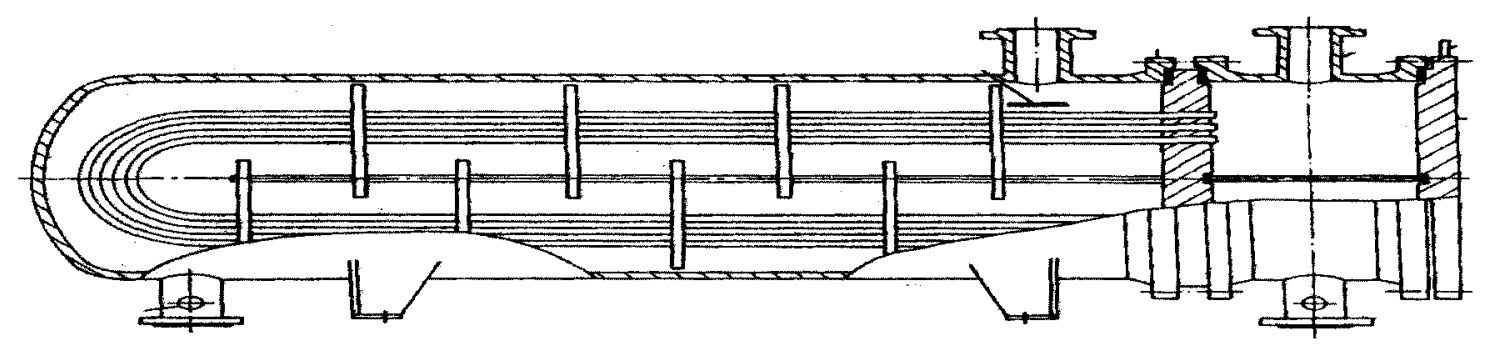

Figure 5-5: Cross section cutaway of a straight tube and U-tube STHE [5.22]

For the purposes of this thesis heat exchanger selection criterion consisted primarily of cost, ease of maintenance, and service life. The STHE has the

\footnotetext{
"Note that U-tube bundles can only be removed if no longitudinal baffle is present in shell construction.
} 
potential to meet or exceed the maximum operating temperatures and pressures found in the modelled system, and has decades of successful industry use. Quotes from suppliers for dual pass cross-flow STHE units sized for the trigeneration system under study were obtained at an average specific cost of 60.5 CAD per kW of heat transfer [5.11]. This cost was quoted for two units, it is anticipated this price would be significantly lower for bulk orders. As the price for a suitable STHE unit is sufficiently low for small-scale applications, and the operating characteristics permit high temperature and pressure operation the STHE is ideal for use as a low temperature heat exchanger in the subject system.

\subsubsection{Plate fin heat exchanger}

The plate fin heat exchanger (PFHE) consists of a stack of alternating plates and folded fin spacers as shown in Figure 5-6. Flow is directed into the spaces between the plates provided by the fins in an alternating manner. This flow can be cross- or counter-flow. PFHE have very high area densities (heat transfer surface area per volume), which makes them ideal for compact applications [1.46][2.36][5.13]. Due to the thin wall construction of the PFHE, a differential pressure of less than $1000 \mathrm{kPa}$ must be maintained; however high service temperatures upwards of $800^{\circ} \mathrm{C}$ can be achieved [5.13]. Because construction involves numerous brazing operations, cost can be high. Due to extensive use of 
PFHE technology in the automotive industry, automation and high volume demand has significantly reduced the cost for standardized PFHE designs.
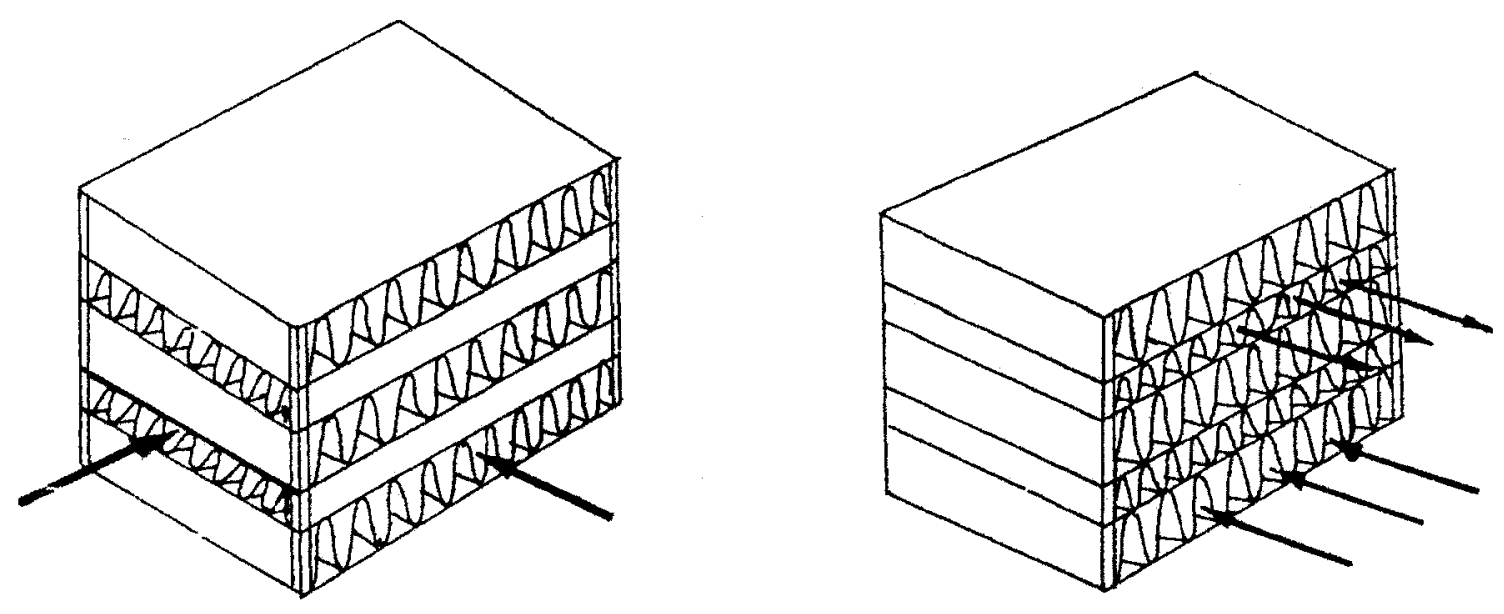

Figure 5-6: Cutaway view of a PFHE in cross-flow and counter-flow [5.13]

Of particular interest is the low heat capacity of PFHE units. One of the simplifications made for the model was that no transient behaviour was incorporated. With respect to a heat exchanger the lower the heat capacity, the less error introduced during load changes given that transient behaviour is not being modelled. Any energy required to warm up the exchanger results in reduced efficiency during the warm up period. Since the system being studied cycles on and off roughly every 20 minutes, such warm up periods will temporarily decrease the electrical efficiency of the microturbine. Use of PFHE designs for \#1 and \#3 $\mathrm{Hx}$ would help in reducing the required warm up time, and reach design electrical efficiency faster. 
No price quotes or estimates could be obtained for a high-temperature PFHE unit sized appropriately for the subject system, therefore it is not possible to determine if PFHE designs are cost competitive with STHE designs. For lower HEN firing temperatures ( $1200 \mathrm{~K}$ or less), the PFHE is considered superior to the STHE however STHE designs have the potential to operate at much higher temperatures than the PFHE. Fabrication of PFHE units with ceramic materials invalidates this claim, however the cost of such a unit would most likely be prohibitively high for a small-scale user. As the option of increasing maximum cycle must be left open, the PFHE is not considered a suitable candidate to fulfil the role of low-temperature heat exchanger.

\subsubsection{Regenerators}

Regenerators are one of the most unique heat exchanger designs available today. Even though they demonstrate effectiveness in excess of 98 percent [5.26], and are compact and lightweight, cross-contamination is a problem. Figure 5-7 illustrates the challenge that exists to keep the cold and hot streams separated across a rotating component. \#1 and \#3 $\mathrm{Hx}$ exchange heat between clean air from the microturbine and combustion gases from \#2 $\mathrm{Hx}$. The clean air is then exhausted into the dwelling after expansion through the microturbine, therefore any cross-contamination with combustion gases is unacceptable. For 
this reason regenerators cannot be used in this application.

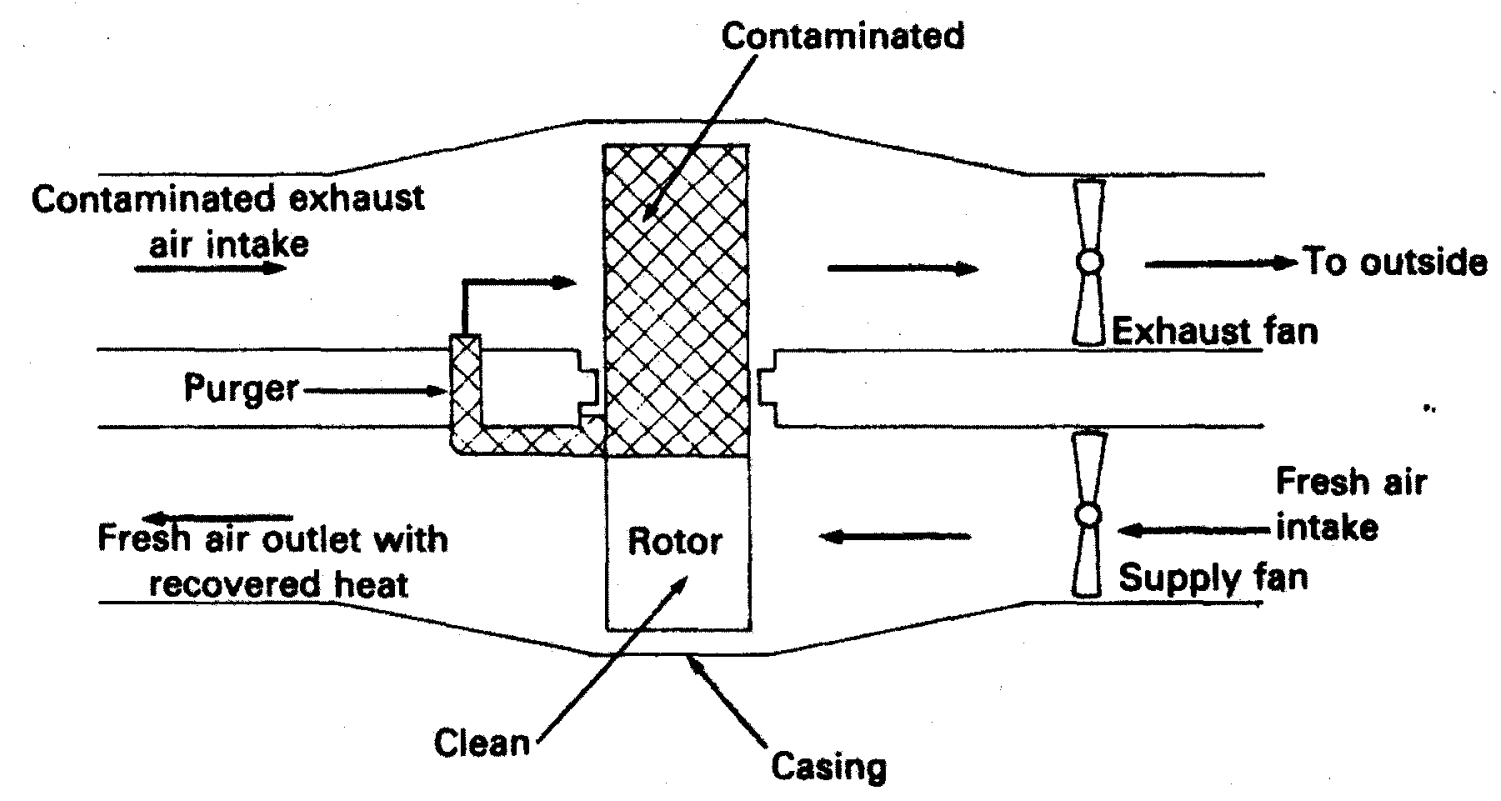

Figure 5-7: A rotating matrix regenerator [5.22]

\subsection{Secondary compressor}

Several compressor designs were considered to fulfil the role of secondary compressor. As the secondary compressor operates with a highly variable power input, it is important to select a machine that demonstrates good off-design isentropic efficiency performance. A suitable machine also has to be able to produce reasonably high flow rates to facilitate rapid accumulator charging. Three compressor styles were considered and will be compared: radial, reciprocating, and screw compressors. 


\subsubsection{Radial compressors}

Most small gas turbines and almost all microturbines make use of radial compressors, an example of a radial compressor wheel from a turbocharger is shown in Figure 5-8. Radial machines offer high flow rates in a compact and cost-effective design, making them ideal for aerospace applications. Designed for applications with small to medium flow rates that require high RPM operation, radial machines are capable of continuous operation above 250,000 RPM is due to robust design.

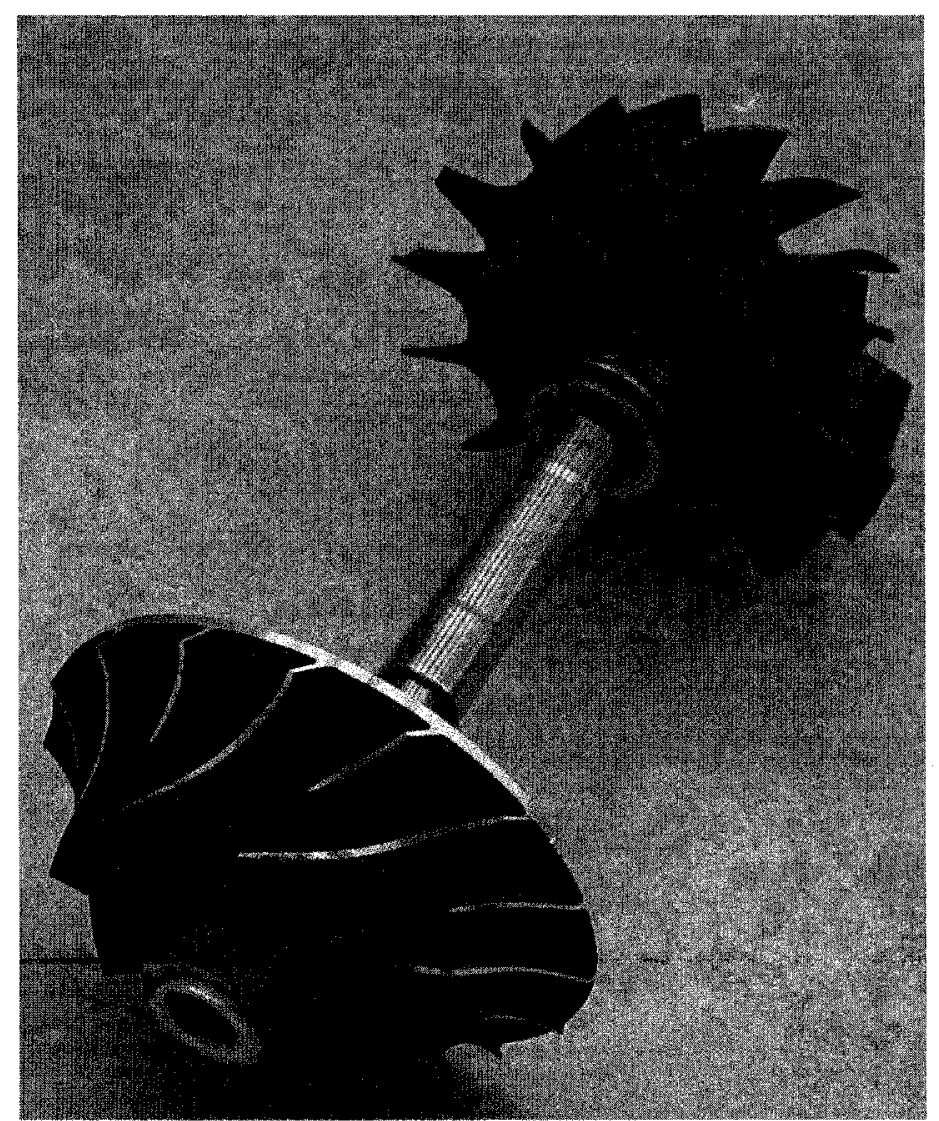

Figure 5-8: Radial compressor (foreground) and axial turbine from a turbocharger [5.19]. 
Radial machines have traditionally demonstrated design point isentropic efficiencies of 0.75 to 0.80 at a PR of up to 4 , however high-performance machines can operate at a PR up to 8 [5.19] with efficiencies in excess of 0.90 [5.20]. Unfortunately to enjoy the benefit of high compression with high efficiency a premium must be paid to achieve efficiencies in excess of 0.85 . Radial machinery is therefore not considered an economical candidate for the secondary compressor.

\subsubsection{Reciprocating compressors}

Gas-compression applications for reciprocating compressors range from provision of shop air for air tools to providing natural gas pipeline compression. The pros and cons of reciprocating technology have been discussed in Sections 1.4.1 and 1.4.3. With respect to a small-scale application, some concerns with regard to the use of reciprocating equipment include: high operational noise, high maintenance cost, inclusion of expensive auxiliary systems. A suitable secondary compressor must not reduce the life cycle of the system as a whole; hence maintenance intervals and service life of the secondary compressor must be equal to or greater than that of the microturbine. Reciprocating compressor technology cannot meet this requirement, therefore is not considered a suitable candidate for the secondary compressor. 


\subsubsection{Screw compressors}

Screw compressors offer a unique combination of high flow and high efficiency without special design, as shown in Figure E-9 through Figure E-11. Commercially available units, such as the model used in the simulation, demonstrated isentropic efficiencies in excess of 0.90 with single stage pressure ratios of up to 13 [5.2]. The combination of low RPM and only two moving parts (compressor rotors) allows for an expected service life in excess of 20,000 hours operating at maximum load [5.1]. While screw compressors are more expensive than reciprocating compressors, the combination of low operating noise, low maintenance costs, and availability of packaged small-scale commercial units makes the screw compressor a superior choice for small-scale users. Screw compressors also deliver high-quality discharge air with very low oil intrusion. This is particularly important as secondary compressor discharge is eventually vented into the house. As a screw compressor delivers high efficiencies, with low maintenance, low operational noise, and a long service life, it makes an ideal candidate to fill the role of secondary compressor for this study. 


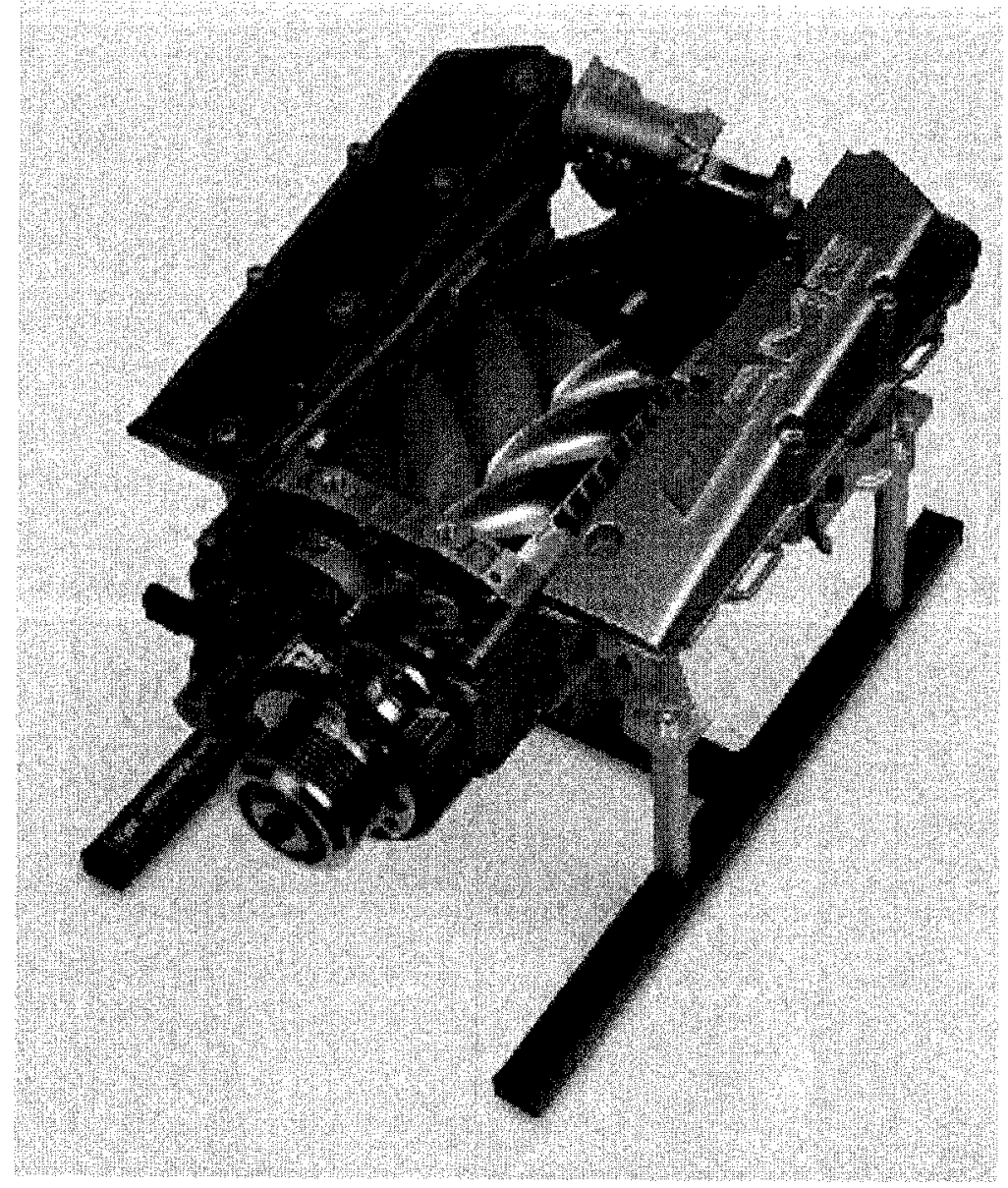

Figure 5-9: Cutaway view of a screw compressor used in a highperformance supercharger [5.6]. 


\section{Chapter 6} Conclusion

\subsection{Summary}

Severe weather, greenhouse gases, and energy tariff fluctuations have typically not been primary concerns of individual consumers when making decisions regarding energy needs in the $20^{\text {th }}$ century; this will not be the case in the $21^{\text {st }}$ century. With the dawn of rolling blackouts due to insufficient power grid capacity, communities becoming isolated due to inclement weather, and rising energy prices new solutions for small-scale users are becoming increasingly important to meet future energy needs. Several ingenious small-scale solutions that reduce energy consumption and decrease dependence on grid power have been in use for many years. Heat pumps, geothermal heating and cooling, and thermal storage systems have proven to be effective at providing thermal control for residential and small commercial customers alike. These solutions are still at the mercy of disruptions in grid power service. Each system has problems that prevent widespread acceptance; for example, heat pumps do not work well in extreme cold and geothermal heating cannot be installed in northern communities where disruption of the permafrost layer results in geological instability. No system currently exists in practice that can provide the option of complete energy islanding for the small-scale user. To meet these challenges, this study was initiated to design and model a trigeneration system capable of on- 
site production of heating cooling and power.

Large trigeneration systems have been successfully implemented for industrial purposes; they work well and are thoroughly documented. These systems have not filtered down to small-scale users in part due to the use of chilling equipment with very high specific capital cost. A successful small-scale trigeneration system must compete with the most efficient form of individually providing heating cooling and electric power via a natural gas furnace, vapour compression air conditioner, and grid power. A successful small-scale trigeneration system will demonstrate the following qualities: a long service life with minimal maintenance requirements, autonomous operation, low capital costs to compete with individual generation systems, and operating costs competitive with individual generation.

A new trigeneration system was proposed to satisfy these requirements for a small-scale application. An indirectly fired microturbine was combined with energy storage in the form of a hydraulic accumulator. The accumulator was used in an inverse Brayton cycle in combination with a microturbine to provide for all heating cooling and peak power needs for a typical detached single-family dwelling. To ensure capital costs stay as low as possible, state-of-the-art turbomachinery and heat exchangers were not used in modelling and simulations. This produced conservative results that provide for additional studies. Performance data for the proposed system was mathematically modelled using MATLAB ${ }^{\mathrm{TM}}$. This model was then incorporated into a time-based 
SIMULINK ${ }^{\mathrm{TM}}$ simulation, using modelled energy load profiles for a typical household located in central Canada. The simulation provided control to ensure a comfortable household temperature was maintained, and electrical demands were satisfied. The simulation was used to measure economic performance and to identify areas of future improvement in the system. Microturbine design and off-design performance data was validated against performance data from GASTURB $^{\mathrm{TM}}$, commercially available microturbines, and simulated systems discussed in open literature, and were found to be in good agreement. The accumulator model was verified against experimental data for both charging and discharging. As pressure and temperature of the experimental and modelled accumulators were in agreement once fully charged or discharged, the model maintained conservation of mass.

After experimenting with various system modifications in an effort to improve economic performance, a final configuration was arrived at which operates in two modes; one for heating and one for cooling load production. This configuration uses a secondary compressor and expander in addition to the indirectly fired microturbine and accumulator. An additional heat exchanger $(\# 4 \mathrm{Hx})$ was used in addition to the heat exchangers installed as part of the indirectly fired microturbine assembly. The \#4 $\mathrm{Hx}$ is buried in-ground to take advantage of the year round pseudo-infinite heat capacity offered by deep ground installation. 


\subsection{Summary of results}

The effect of varying accumulator size on system performance was investigated. It was determined that accumulator size has negligible impact on economic performance. Size variation did have an effect on cycle frequency, with smaller sizes decreasing the period between successive microturbine starts. Accumulator size was therefore determined to only have an impact on system life and durability. Larger sizes were found to reduce system cycling; this is expected to increase component life and reduce maintenance costs. Selection of an appropriate size should also be based upon practical considerations such as ease of installation, cost, and microturbine cycling limitations.

Different HEN modes were used for heating and cooling load production. Mode 1 was designed to ensure a high microturbine exhaust temperature of 860 to $880 \mathrm{~K}$ (depending on ambient temperature) was delivered for household heating purposes. A thermal efficiency of 15.7 percent and total efficiency of 95 percent was achieved at ISO standard atmospheric conditions for Mode 1. Mode 2 was designed to maximize the thermal efficiency of the microturbine while producing a cooling load. Since high-temperature exhaust was not required, a thermal efficiency of 29.3 percent was achieved at ISO standard atmospheric conditions. Microturbine size had a negligible effect on economic performance. Microturbine size determined how fast household temperature was recharged during heating mode, and how fast the accumulator was recharged during cooling mode. In combination with accumulator size, microturbine size determined the period 
between successive starts. To achieve energy islanding during heating mode, a minimum engine size was required to satisfy peak household electrical demand. An oversized engine should be avoided as well to avoid excessive household heating mass flows and increased capital costs. Factors influencing microturbine selection therefore include capital cost, household electrical load, and household thermal load. A microturbine with $10 \mathrm{kWe}$ output at standard conditions was selected.

Two different methods to charge the accumulator were investigated. The first method attempted to use the microturbine to simultaneously provide electrical load and charge the accumulator. By extracting varying levels of compressor bleed flow, the microturbine could be operated in an electrical load following manner. The second method used a separate compressor to charge the accumulator. Electrical input was fed to the secondary compressor from a microturbine that operated at full power. Using bleed flow consumed 4 percent more fuel when compared to use of a secondary compressor when operating in Mode 1. If bleed flow is used in Mode 2, the system could not provide a cooling load greater than $0.75 \mathrm{kWt}$, while a cooling load of up to $2 \mathrm{kWt}$ was provided with a secondary compressor without supplemental electrical power. The addition of a secondary compressor also provided the option of using grid power to increase the cooling capacity of the system. A secondary compressor was incorporated into the final configuration to benefit from the reduced fuel costs, and to provide 
sufficient cooling load during peak summer months.

The effect of using an in-ground heat exchanger $(\# 4 \mathrm{Hx})$ to increase the thermal output of the accumulator was studied. Cooling secondary compressor flow in an in-ground heat exchanger before discharge to the accumulator reduced system operation costs by up to 72 percent for high cooling load conditions. This reduction in cost can be attributed to a significant increase in specific cooling capacity of expander discharge flow with cooler accumulator temperatures. Preheating secondary compressor inlet flow in the in-ground heat exchanger had a negligible effect on system operational costs; therefore the in-ground heat exchanger was used for Mode 2 only.

To increase specific work output from the expander when operating as part of the inverse Brayton cycle in Mode 1, accumulator discharge was cycled through the heat exchanger network to raise expander inlet temperature to design point levels. Fuel costs were reduced by 9 percent when firing the HEN at a constant design temperature of $1200 \mathrm{~K}$.

It was found that if the microturbine expander was used as part of the inverse Brayton cycle in Mode 1, thermal output often exceeded household demand. If household temperature was not allowed to cool down during inverse Brayton cycle operation, microturbine exhaust had to be dumped overboard to prevent 
household temperature from exceeding setpoint limits; which reduced system economic performance. A second expander $1 / 6^{\text {th }}$ the size of the microturbine expander was added to modify the thermal output of the inverse Brayton cycle. This ensured household thermal demand was not exceeded. The smaller second expander permitted the HEN to be operated at maximum temperature during IBC operation for maximum economic performance, without exceeding the household thermal load.

The independent generation system was found to be 48 percent cheaper to operate based on one year of operation in Winnipeg, Canada when compared to the trigeneration system. Economic performance was compared for regions around the world with similar climates to central Canada. As the ratio of electricity tariffs to natural gas prices were relatively constant throughout the regions investigated, economic performance demonstrate minor variation; independent generation was found to be between 35 and 47 percent cheaper to operate when compared to the trigeneration system. This was not the case for countries in the former Soviet Union, where the combination of extremely low natural gas prices and relatively high electricity prices result in the trigeneration system being 20 percent cheaper to operate when compared to the independent system, based on one year of operation. 


\subsection{Conclusions}

The preliminary design and simulation of a small-scale trigeneration system was successfully completed with promising results and provided direction for future studies. Preliminary designs indicate that the system can be built using a combination of modifying existing technology, and off-the-shelf components such as shell and tube heat exchangers. Despite the lower than expected economic performance of the system in Mode 2, there is much room for optimization and improvement. The results obtained represent a conservative prediction of performance, and can be improved upon with future system designs. Economic performance while providing a heating load was predicted to be marginally higher than an independent generation system.

It was a goal of this project to create a system that offered total energy islanding to small-scale consumers. The results show that if peak summer thermal loads are to be satisfied, connection to a grid is required. The trigeneration system is capable of supplying continuous cooling loads of about $2 \mathrm{kWt}$ or less. For the climate in the geographical region used for load prediction (central Canada), cooling loads exceeded $2 \mathrm{kWt}$ only 5 percent of the year. This means total energy islanding was achieved for 95 percent of the year. Energy islanding for the full year is possible if any of the following criteria are satisfied: 1) the region has mild cooling demands, 2) the household setpoint temperature is raised during summer months, 3) improvements to the trigeneration system increases cooling capacity. 
Perhaps what is most promising about the trigeneration system is that there is no other product being simulated, tested, or made available for purchase that can satisfy the same load demands. Trigeneration has not yet been brought to the small-scale consumer in an economical manner that permits energy islanding, leaving no current solution for a growing niche market. Energy islanding is an attractive option for mobile and remote users, and provides a solution for those dissatisfied with frequent power outages. It is difficult to place an economic value on the intrinsic benefit of energy islanding, as this value will change from user to user. For some users, operating a household free from grid power may justify the increased fuel costs associated with the subject trigeneration system. Despite demonstrating inferior economic performance when compared to the independent generation system, the subject trigeneration system still has much to offer.

\subsection{Future work}

A sensitivity study should be performed to investigate the effect component isentropic efficiencies have on economic performance. Such a study has the most impact on cooling load production, which requires as much energy to be extracted from microturbine flow as possible to increase electrical efficiency.

Increasing HEN maximum temperature was found to increase microturbine electrical efficiency, however as no suitable high-temperature heat exchanger with integrated burner exists in the size required, a realistic maximum 
temperature is unknown. Research and testing are required to be able to estimate maximum HEN temperatures with accuracy.

Further work is required to increase the accuracy of the accumulator model. As estimates of heat transfer coefficients are highly empirical, the heat transfer coefficients used in the simulation are not calibrated for the application. Removing isothermal and isobaric assumptions will also improve accumulator behaviour prediction.

There is potential for improvement to system economic and thermodynamic performance with the incorporation of water injection. This system could also be used to maintain household humidity levels year round. Simulation is required to investigate if such a system would justify the increased capital cost.

The simulated trigeneration system must be prototyped to confirm simulation predictions with confidence. The simulation could then be modified and used to predict system performance due to subsequent modifications with a higher degree of confidence. 


\section{References}

\section{ChAPTER 1}

[1.1] Bassols, J. Kuckelkorn, B., Langreck, J., Schneider, R., Veelken, H., "Trigeneration in the food industry," Applied Thermal Engineering 22: 595-602, 2002.

[1.2] Campanari, S., Boncompagni, L., Macchi, E., "Microturbines and Trigeneration: Optimization Strategies and Multiple Engine Configuration Effects", ASME Turbo Expo proceedings: GT2002-30417, Amsterdam, Netherlands, 2002.

[1.3] Canadian Centre for Occupational Health and Safety, "Noise Occupational Exposure Limits in Canada", accessed June 11, 2007. www.ccohs.ca/oshanswers/phys_agents/exposure_can .

[1.4] Cardona, E., Piacentino, A., "Cogeneration: a Regulatory Framework Toward Growth," Energy Policy 33: 2100-2111, Reno-Tahoe, USA, 2005.

[1.5] Chiradeja, P., "An approach to Quantify the Technical Benefits of Distributed Generation," IEEE Transactions on Energy Conversion vol.19 no.4: 764-773, 2004.

[1.6] Consumer search: Furnace reviews, accessed June 10, 2007. www.consumersearch.com/ww/house_and_home/furnaces/index.html

[1.7] EDUCOGEN, "The European Educational tool on Cogeneration". accessed June 12, 2007. www.cogen.org/projects/educogen.htm .

[1.8] EPA Climate Protection Partnership Division, "Technology Characterization: Reciprocating Engines", prepared by Energy Nexus Group, Feb 2002.

[1.9] EPA Climate Protection Partnership Division, "Technology Characterization: Microturbines", prepared by Energy Nexus Group, March 2002.

[1.10] EPA Climate Protection Partnership Division, "Technology Characterization: Fuel Cells", prepared by Energy Nexus Group, March 2002.

[1.11] FC+Cogen-Sim, Annex 42, International Energy Association. accessed 
Oct 2007. http://cogen-sim.net .

[1.12] Galdo, J., "Distributed Energy Resources - A National Perspective", Distributed Energy Resources: Policy options for Virginia, May 2002.

[1.13] Grillo, O., Magistri, L., Massardo, A.F., "Hybrid Systems for Distributed Power Generation Based on Pressurization and Heat Recovering of an Existing 100 kW Molten Carbonate Fuel Cell," Journal of Power Sources 115: 252-267, 2003.

[1.14] Hasnain, S. M., Alabbadi, N. M., "Need for Thermal-Storage AirConditioning in Saudi Arabia", Applied Energy 65: 153-164, 2000.

[1.15] Hirotaka, K., Hirohiko, M., "Development of Portable Gas Turbine Generator 'Dynajet 2.6',' IHI Engineering Review 37-3: 113-114, 2004.

[1.16] Huang, J., Feng, Z., Yue, C., Liu, L., "Operation Modes and Economic Performance Study of $100 \mathrm{~kW}$ Microturbine Building Cooling, Heating and Power Systems," ASME Turbo Expo Proceedings: GT2005-68277, Reno-Tahoe, USA, 2005.

[1.17] Jackson, G.M., Leventhall, H.G., "Household Appliance Noise", Applied Acoustics, 8: 101-118, 1975.

[1.18] Kataoka, T., Nakajima, T., Sakata, S., Kishikawa, T., "A Microturbine Cogeneration Package for Japanese Market", ASME Turbo Expo proceedings: GT2007-27697, Montréal, Canada, 2007.

[1.19] Kong, X.Q., Wang, R.Z., Huang, X.H., "Energy Efficiency and Economic Feasibility of CCHP Driven by Stirling Engine,", Energy Conversion and Management 45: 1433-1442, 2004.

[1.20] Kong, X.Q., Wang, R.Z., Wu, J.Y., Huang, X.H., Huangfu, D.W., Wu, D.W., $\mathrm{Xu}, \mathrm{Y} . \mathrm{X}$., "Experimental Investigation of a Micro-Combined Cooling, Heating and Power System Driven by a Gas Engine," International Journal of Refrigeration 28: 977-987, 2005.

[1.21] Mackie, E. I., "Inlet Air Cooling for a Combustion Turbine Using Thermal Storage", ASHRAE Transactions 100-1: 572-582, 1994.

[1.22] Maidment, G.G., Zhao, X., Riffat, S.B., "Combined Cooling and Heating Using a Gas Engine in a Supermarket," Applied Energy 68: 321-335, 2001.

[1.23] Manning, M., "Reference House Load Data" ,Canadian Centre for Housing Technologies. Obtained via email communication, June 2007. 
[1.24] Mastronarde, T.P., "Shipboard Cogeneration - A Second Generation Design Approach", Naval Engineers Journal, 97: 306-314, May 1985.

[1.25] Míguez, J.L., Murillo, S., Porteiro, J., López, L.M., "Feasibility of a New Domestic CHP Trigeneration With Heat Pump: I. Design and Development," Applied Thermal Engineering 24: 1409-1419, 2004.

[1.26] Míguez, J.L., Murillo, S., Porteiro, J., López, L.M., "Feasibility of a New Domestic CHP Trigeneration With Heat Pump: II. Availability Analysis," Applied Thermal Engineering 24: 1421-1429, 2004.

[1.27] Natural Resources Canada, "Energy use data handbook", 2006.

[1.28] Otto, N.A., 1887, "Gas motor engine", United States patent, 365,701

[1.29] Personal files from experience at Air Canada Technical Services, 2006.

[1.30] Personal files from experience at Standard Aero Energy Limited, 2003.

[1.31] Rawson, M., Sugar, J., "Distributed Generation and Cogeneration Policy Roadmap for California", California Energy Commission Staff Report, CEC-5002007-021, March 2007.

[1.32] Samuelsen, S., "Fuel Cell/Gas Turbine Hybrid Systems", National Fuel Cell Research Centre. ASME International Gas Turbine Institute, 2004.

[1.33] Smith, D.J., "Cogeneration, Distributed Generation and Peak Shaving Drive the Market for Small Gas Turbines", Power Engineering, pgs. 70-72, Oct 2000.

[1.34] Smugeresky, C.S, "An Integrated Combined Heat and Power Distributed Energy Resource for Modular Applications," ASME Turbo Expo proceedings: GT2007-28294, Montréal, Canada, 2007.

[1.35] Stirling, R., 1816, "Economiser", British patent, 4081.

[1.36] STM Power, accessed June 11, 2007, www.stmpower.com/Technology/Technology.asp

[1.37] Synchrony, www.synchrony.com/images/indmb.jpg, downloaded January 18, 2007.

[1.38] Turbec Inc., "On site turbine power", sales brochure, accessed June 7, 2007, http://www.turbec.com/pdf/Turbec\%20brochure\%202005... \%20engEmail\%20version.pdf

[1.39] U.S. Dept. of Energy Information Administration, "The Market and 
Technical Potential for Combined Heat and Power in the Commercial/Institutional Sector", prepared by Onsite Sycom Energy Corp., Jan. 2000.

[1.40] United States Department of Energy, "Advanced Microturbine System: Market Assessment", prepared by Energy and Environmental Analysis Inc. May 2003.

[1.41] Veyo, S., "Westinghouse Fuel Cell Combined Cycle Systems", Fuel Cells Review Meeting: DOE/MC/28055-97/C0772, Morgantown, West Virginia. August 1996.

[1.42] Weaver, H. F., "NASA PS304 Lubricant Tested in World's First Commercial Oil-Free Gas Turbine", NASA Glenn Research and Technology Report accessed Jan 2008, http://www.grc.nasa.gov/WWW/RT2002/5000/5960weaver.html.

[1.43] WhisperGen Limited, "WhisperGen product brochure" accessed June 11, 2007, www.whispergen.com/main/acwhispergen .

[1.44] Wilson, M.A., Recknagle, K., Brooks, K., "Design and Development of a Low-Cost High Temperature Silicon Carbide Micro-Channel Recuperator," ASME Turbo Expo proceedings: GT2005-69143, Reno-Tahoe, USA, 2005.

[1.45] Zhang, H.F., Ge, X.S., Ye, H., "Modelling of a Space Heating and Cooling System With Seasonal Energy Storage", Energy 32: 51-58, 2007.

[1.46] Ziher, D., Poredos, A., "Economics of a Trigeneration System in a Hospital," Applied Thermal Engineering 26: 680-687, 2006.

\section{ChAPTER 2}

[2.1] "Barajas T4 Trigeneration Plant", InfoPower: Trigeneration, October 2006.

[2.2] "New Contract for Dalkia in Chongquing, China", Dalkia corp., press release July $31,2006$.

[2.3] "TPGS Green Energy PTE LTD Develops and Constructs Singapore's First Trigeneration Facility", TPGS Green Energy, press release November 7, 2006.

[2.4] AMTUIR Musée des Transports Urbains, "Automotrice Mekarski a Air Comprimé no. 22 (1879)", accessed Dec. 5, 07, http://www.amtuir.org/01_musee/collection/fiches_tv_tm/fiche_nantes_tramway_ mekarski_22.htm

[2.5] Bassols, J. Kuckelkorn, B., Langreck, J., Schneider, R., Veelken, H., 
"Trigeneration in the Food Industry," Applied Thermal Engineering 22: 595-602, 2002.

[2.6] Bolatturk, A., "Thermodyanamic Evaluation of First and Second Law Performance of Evaporative Cooling Scheme for Regenerative Gas Turbines", Energy Exploration and Exploitation, 25-3:. 227-246, June 2007.

[2.7] Building Research Consultants, "Air Cycle Project", accessed Dec. 6, 07. http://projects.bre.co.uk/aircycle/aircycleproject.htm

[2.8] Colonna, P., Gabrielli, S., "Industrial Trigeneration Using Ammonia-Water Absorption Refrigeration Systems (AAR)", Applied Thermal Engineering, 23: 381396, 2003.

[2.9] Dewis, Dave., "Absorption Chiller Integration System Development", Micro-CHP Technologies Workshop Proceedings, U.S. Department of Energy. Greenbelt, Maryland, June 11-12, 2003.

[2.10] Engle, D., " The New Trigeneration Player: Integrated Cooling, Heating, and Power Systems are Here", Distributed Energy, May/June, 2004.

[2.11] Firestone, R., "Distributed Energy Resources Customer Adoption Model Technology Data", Ernest Orlando Lawrence Berkeley National Laboratory, January 2004.

[2.12] Godefroy, J., Boukhanouf, S.R., "Design, Testing and Mathematical Modelling of a Small-Scale CHP and Cooling System (Small CHP-Ejector Trigeneration)", Applied Thermal Engineering 27: 68-77, 2007.

[2.13] Hernández-Santoyo, J., Sánches-Cifuentes, A., "Trigeneration: An Alternative for Energy Savings", Applied Energy 76: 219-227, 2003.

[2.14] Kong, X.Q., Wang, R.Z., Huang, X.H., "Energy Efficiency and Economic Feasibility of CCHP Driven by Stirling Engine,", Energy Conversion and Management 45: 1433-1442, 2004.

[2.15] Kong, X.Q., Wang, R.Z., Wu, J.Y., Huang, X.H., Huangfu, D.W., Wu, D.W., Xu, Y.X., "Experimental Investigation of a Micro-Combined Cooling, Heating and Power System Driven by a Gas Engine," International Journal of Refrigeration 28: 977-987, 2005.

[2.16] Lennox home comfort systems, accessed Dec. 4, 2007, www.lennox.com/residential .

[2.17] Liang, H.X., Wnag, Q.W., "Evaluation of Energy Efficiency for a CCHP System With Available Microturbine", ASME Turbo Expo proceedings: GT2007- 
27883, Montréal, Canada, 2007.

[2.18] Lin, L., Yaodong, W., et. al., "An Experimental Investigation of a Household Size Trigeneration", Applied Thermal Engineering, 27: 576-585, 2007.

[2.19] Lynn, A., Smid, E., Eshraghi, M., Caldwell, N., Woody, D., "Modelling Hydraulic Regenerative Hybrid Vehicles Using AMESim and MATLAB/SIMULINK", Proceedings of SPIE 5805: 24-40. Bellingham, USA, 2005.

[2.20] Mackie, E. I., "Inlet Air Cooling for a Combustion Turbine Using Thermal Storage", ASHRAE Transactions 100-1: 572-582, 1994.

[2.21] Maidment, G.G., Zhao, X., Riffat, S.B., "Combine Cooling and Heating Using a Gas Engine in a Supermarket," Applied Energy 68: 321-335, 2001.

[2.22] Meunier, F., "Co- and Tri-Generation Contribution to Climate Change Control", Applied Thermal Engineering, 22: 703-718, 2002.

[2.23] Midwest CHP Application Centre, "Financial Institutions - Economics", accessed Dec. 6, 07, www.chpcentermw.org/08-043_economics.html

[2.24] Míguez, J.L., Murillo, S., Porteiro, J., López, L.M., "Feasibility of a New Domestic CHP Trigeneration With Heat Pump: I. Design and Development," Applied Thermal Engineering 24: 1409-1419, 2004.

[2.25] Míguez, J.L., Murillo, S., Porteiro, J., López, L.M., "Feasibility of a New Domestic CHP Trigeneration With Heat Pump: II. Availability Analysis," Applied Thermal Engineering 24: 1421-1429, 2004.

[2.26] Najjar, Y.S.H, Jubeh, N.M., "Comparison of Performance of CompressedAir Energy Storage Plant with Compressed-Air Storage with Humidification", Proceedings of I MECH E Part A Journal of Power and Energy, 220-6: 581-588, 2006.

[2.27] Oztop, H.F., Hepbasli, A., "Cogeneration and Trigeneration Applications", Energy Sources, Part A 28: 743-750, 2006.

[2.28] "Pure Comfort ${ }^{\mathrm{TM}}$ Cooling, Heating and Power Solutions". UTC Power South Windsor, USA, 2005.

[2.29] Rufer, A., Lemofouet, S., "Energetic Performance of a Hybrid Energy Storage System Based on Compressed Air and Super Capacitors", International Symposium on Power Electronics Electrical Drives Automation and Motion, 2006.

[2.30] Sears, J.R., "Thermal and Compressed-Air Storage (TACAS): The Next 
Generation of Energy Storage Technology", Proceedings of the International Stationary Battery Conference, Miami Beach, USA, 2005. Downloaded Dec. 5, 07. www.battcon.com/PapersFinal2005/SearsPaper2005.pdf .

[2.31] "Social Responsibility Report 2006", pgs. 14-15. Athens, Greece: CocaCola HBC, 2006.

[2.32] Spence, S.W.T., Doran, W.J., Artt, D.W., McCullough, G., "Performance Analysis of a Feasible Air-Cycle Refrigeration System for Road Transport", International Journal of Refrigeration 28: 381-388 2005.

[2.33] Vosburgh, K.G., "Compressed Air Energy Storage", Proceedings of AIAA/EEI/IEEE Conference on New Options in Energy Technology: 77-1008. San Fransisco, USA, August 2-4, 1977.

[2.34] Zaki, G.M., Jassim, R.K., Alhazmy, M.M., "Brayton Refrigeration Cycle for Gas Turbine Inlet Air Cooling", International Journal of Energy Research 31: 1292-1306, 2007.

[2.35] Zaugg, P., "Brown Boveri Air-Storage Gas Turbines", Brown Boveri Review 64-1: 34-39, January 1977.

[2.36] Ziher, D., Poredos, A., "Economics of a Trigeneration System in a Hospital," Applied Thermal Engineering 26: 680-687, 2006.

\section{Chapter 3}

[3.1] Air-Conditioning Refrigeration Institute, "Performance Rating of Unitary AirConditioning and Air-Source Heat Pump Equipment", ARI 210-240-2006, (c) 2006. accessed Sept. 2007, www.ari.org .

[3.2] Cengle, Y.A., Boles, M.A., "Thermodynamics an Engineering Approach",pg. 568, McGraw Hill, New York, 2002.

[3.3] Churchill, S.W., "Free Convection Around Immersed Bodies", Heat Exchange Design Handbook, hemisphere publishing, New York, 1983.

[3.4] Energy Systems Research Unit, University of Strathclyde, accessed Sept. 2007, www.esru.strath.ac.uk/programs/ESP-r.htm .

[3.5] FC+Cogen-Sim, Annex 42, International Energy Association accessed Oct. 2007, http://cogen-sim.net .

[3.6] Kurzke, J., GASTURB ${ }^{\mathrm{TM}} 11$, available from www.gasturb.de .

[3.7] Morgan, V.T., "The Overall Convective Heat Transfer from Smooth 
Circular Cylinders," Advances in Heat Transfer, 11: 199-264, 1974.

[3.8] Neal, L., O'Neal, D., "The Impact of Residential Air Conditioner Charging and Sizing on Peak Electrical Demand," Proceedings of the Summer Study on Energy Efficiency in Buildings, Vol. 2: 189, American Council for an Energy Efficient Economy, Washington D.C., USA 1993.

[3.9] Turns, S.R., "An Introduction to Combustion, Concepts and Applications", Second ed., McGraw Hill, Singapore, 2000.

[3.10] Williams, G.P., Gold, L.W., "Ground Temperatures", NRC Digest CBD180, National Research Council. Ottawa, Canada 2007.

\section{Chapter 4}

[4.1] Manitoba Hydro, "Historical Electricity Rate Changes", accessed Dec. 12 2007, www.hydro.mb.ca/regulatory_affairs/energy_rates/electricity/historical.shtml

[4.2] Natural Resources Canada, "Canadian Natural Gas Review of 2005 and outlook to 2020", Dec 2006.

[4.3] Pogrebnyak, E., "Russian Electricity Sector: Reform Overview and Modelling Issues", Modelling and Managing Competitive Electricity Markets Conference. London Business School, Sept. 2007.

[4.4] Saravanamuttoo, H.I.H, Rogers, G.F.C., Cohen, H., "Gas Turbine Theory", $5^{\text {th }}$ ed., Pearson Education Ltd., Essex, UK. 2001.

[4.5] US Energy Information Administration, "International Electricity Price and Fuel Cost Tables", accessed Dec. $12 \quad 2007$. www.eia.doe.gov/emeu/international/elecprih.html

[4.6] US Energy Information Administration, "International and United States Natural Gas Price Tables”, accessed Dec. $12 \quad 2007$. www.eia.doe.gov/emeu/international/ngasprih.html

[4.7] Yin, J., Li, M.S., Huang, W.M., "Performance Analysis and Diagnostics of a Small Gas Turbine", Proceedings of the International Gas Turbine Congress, Tokyo, Japan, Nov. 2-7 2003.

\section{Chapter 5}

[5.1] Aerzen USA Corporation, VMX0a37R screw compressor operator's manual, obtained via email with sales representative Pierre Noack, Nov 72007.

[5.2] Aerzen USA Corporation, VMX0a37R screw compressor performance 
maps, obtained via email with sales representative Pierre Noack, Oct 242007.

[5.3] Canadian Centre for Housing Technologies, "Twin Houses Project", Ottawa, Canada, accessed Sept. 2007, www.ccht-cctr.gc.ca/twinhouses_e.html .

[5.4] Carlyle Compressors, accessed Dec. 12, 07, www.carlylecompressor.com

[5.5] Churchill, S.W., "Free Convection Around Immersed Bodies", Heat Exchange Design Handbook, Hemisphere Publishing, New York, 1983.

[5.6] "Cut-Away Model Screw Compressor with Charge Air Cooling", accessed on Dec. 13, 07, www.technolab.org.

[5.7] Energy Systems Research Unit, University of Strathclyde, www.esru.strath.ac.uk/programs/ESP-r.htm, 2007.

[5.8] FC+Cogen-Sim, Annex 42, International Energy Association, http://cogen-sim.net, 2007.

[5.9] Fired Heat Exchangers, Selas Fluid, accessed Oct. 26 2007, www.selasfluid.com/international/web/le/us/likelesfus.nsf/docbyalias/fired_heat... exch, 2007.

[5.10] Gauther, J.E.D., "Analysis of Indirectly Fired Gas Turbine Power Systems", ASME Turbo Expo Proceedings: GT2007-27226, Montréal, Canada 2007.

[5.11] Heat Exchangers, Belfast, PEl. Price quote obtained from Peter Metaxas via personal email on Oct. 162007.

[5.12] Incropera, F.P., DeWitt, D.P., "Fundamentals of Heat and Mass Transfer", $4^{\text {th }}$ ed., John Wiley \& Sons, New York, 1996.

[5.13] Kirloskar Copeland Ltd., "Scroll Compressors ... The Technology for the $3^{\text {rd }}$ Millennium", National Conference on Refrigeration and Air Conditioning, Chennai, India, Aug 29-30 2002.

[5.14] Kuppan, T., "Heat Exchanger Design Handbook", Marcel Dekker Inc., New York, 2000.

[5.15] Kurzke, J., GASTURB ${ }^{\text {TM }} 11$, available from www.gasturb.de .

[5.16] The Mathworks Inc., "MATLAB 7.1.0.21 R14 Service Pack 3 Student Edition Help Files”, (c) 2005.

[5.17] Morgan, V.T., "The Overall Convective Heat Transfer from Smooth Circular Cylinders," Advances in Heat Transfer, 11: 199-264, 1974. 
[5.18] Ohkubo, Y., "Outlook on Gas Turbine", R\&D Review of Toyota CRDL 41-1, 2005.

[5.19] Robby foundation, accessed Dec. 12, 07, www.robbyfoundation.com

[5.20] Rolls Royce Energy Division, Pipeline centrifugal compressors, accessed Dec. 12, 07, http://energy.rolls-royce.com/oil-and-gas-industry-compressors/.

[5.21] Saravanamuttoo, H.I.H, Rogers, G.F.C, Cohen, H., "Gas Turbine Theory", $5^{\text {th }}$ ed., Pearson Education Ltd., Essex, UK. 2001.

[5.22] Saunders, E.A.D, "Heat Exchangers: Selection, Design \& Construction", Longman Scientific \& Technical, Essex, UK, 1988.

[5.23] Tubular Exchanger Manufacturers Association, Section N-1, 1978.

[5.24] Turns, S.R., "An Introduction to Combustion, Concepts and Applications", $2^{\text {nd }}$ ed., McGraw Hill, Singapore, 2000.

[5.25] WCR heat exchangers, accessed Jan 22 2007. www.wcrregasketing.com/bhe/lmages/2circuitgraphicll.gif

[5.26] Wilson, D.G., Ballou, J., "Design and Performance of a High-Temperature Regenerator Having Very High Effectiveness, Low Leakage and Negligible Seal Wear", ASME Turbo Expo Proceedings: GT2006-90095, Barcelona, Spain, 2006.

\section{Appendix E}

[E.1] Aerzen USA Corporation, VMX0a37R screw compressor performance maps, obtained via email with sales representative Pierre Noack, Oct 242007.

[E.2] Aerzen USA Corporation, quotation for a VMX0a37R screw compressor, obtained via email with sales representative Pierre Noack, Nov 62007.

[E.3] Gauthier, J.E.D., "Analysis of Indirectly Fired Gas Turbine Power Systems", ASME Turbo Expo Proceedings: GT2007-27226, Montréal, Canada, 2007.

[E.4] Kaikko, J., Backman, J.L.H, Koskelainen, L., Larjola, J., "Optimum Operation of Externally-Fired Microturbine in Combined Heat and Power Generation", ASME Turbo Expo Proceedings: GT2007-28264, Montréal, Canada, 2007.

[E.5] Ohkubo, Y., "Outlook on Gas Turbine", R\&D Review of Toyota CRDL 41-1, 2005. 


\section{Appendix A \\ Experimental small-scale CHCP apparatuses}

The following are some photographs of experimental small-scale trigeneration apparatuses discussed in open literature.

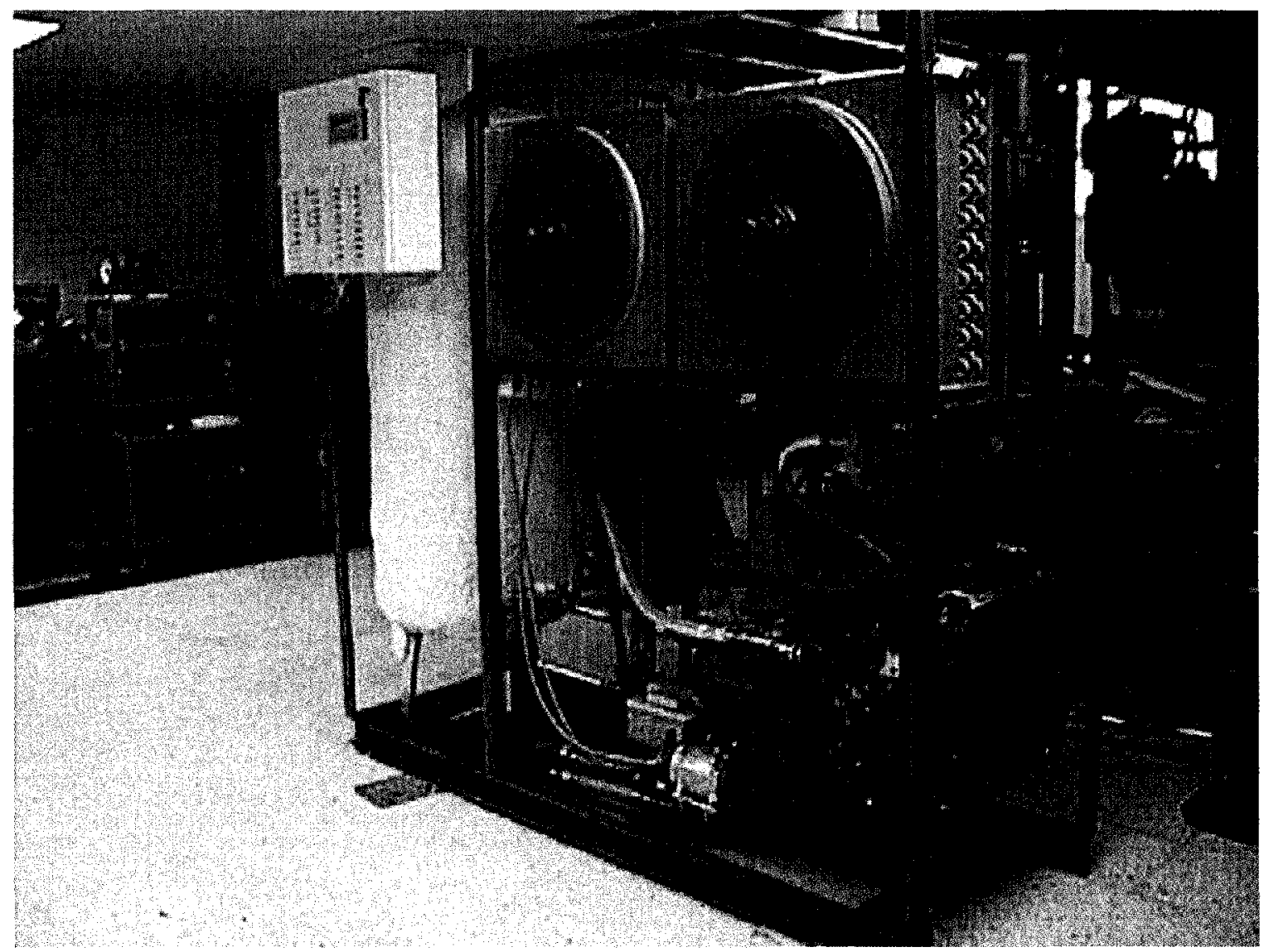

Figure A-1: Experimental CHCP using a VCR unit [1.26] 


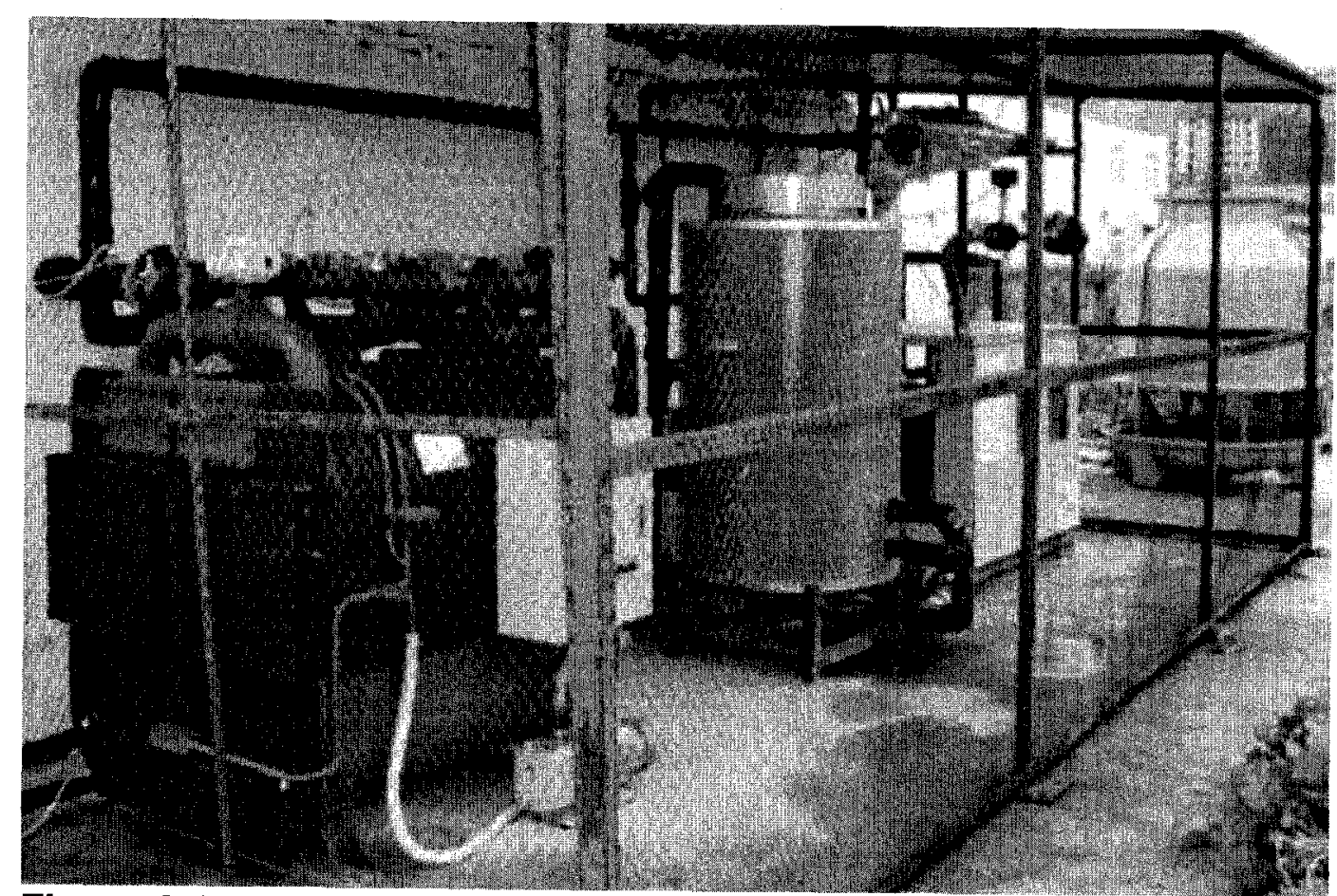

Figure A-2: Experimental CHCP using an ACR unit [1.20]

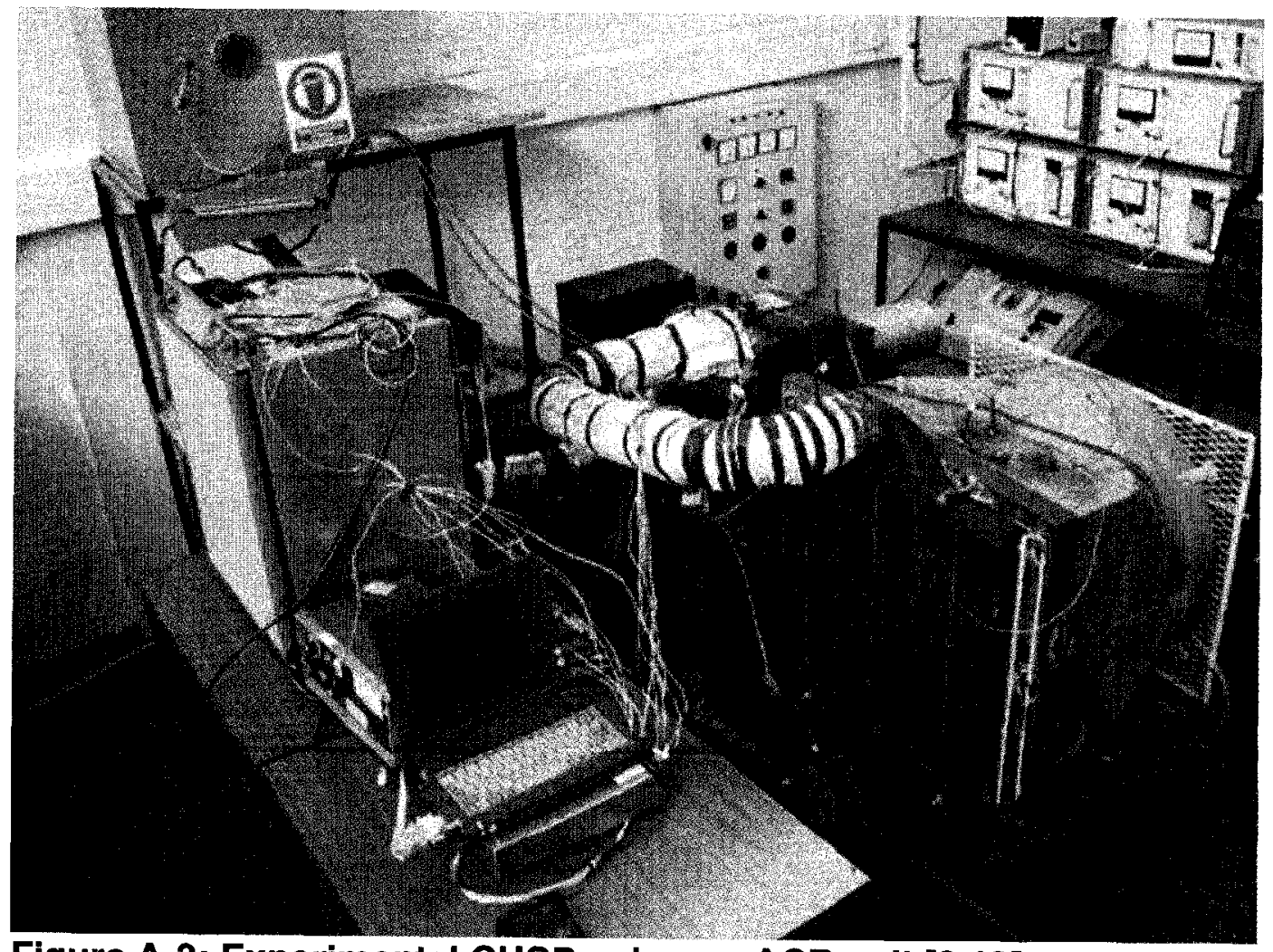

Figure A-3: Experimental CHCP using an ACR unit [2.18] 


\section{Appendix B ESP-r profiles}

Lighting and occupant gains were automatically calculated by the ESP-r program based upon typical habits of a four-person family. Equipment gains included heat output from a refrigerator, latent heat gains from showers and baths, latent and sensible heat gains from cooking on a stove or oven, and sensible heat output from computer equipment.

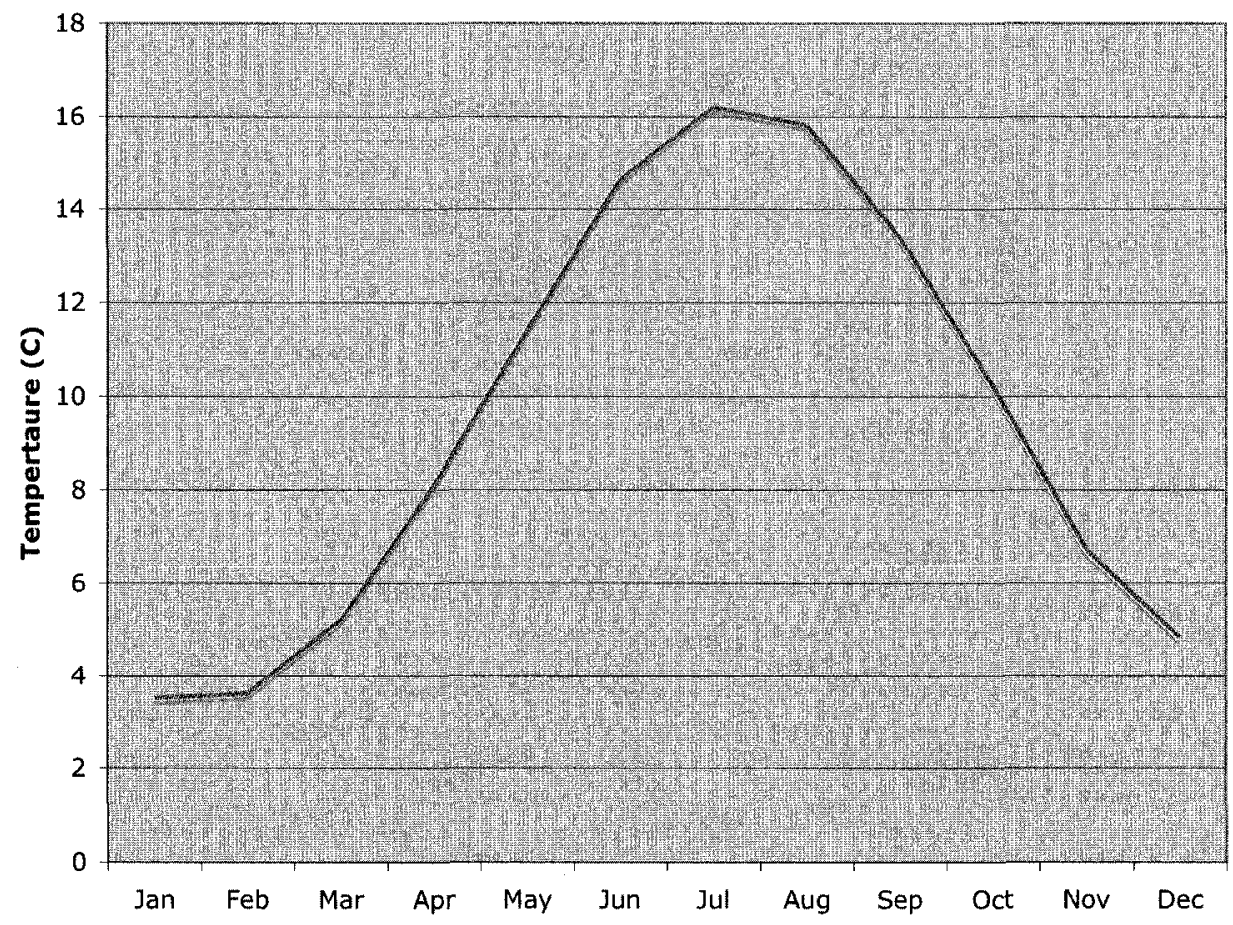

Figure B-1: Typical Canadian ground temperature profile imposed on exterior of ground surface of 1st floor. Data taken from standard proflles included in ESP-r 


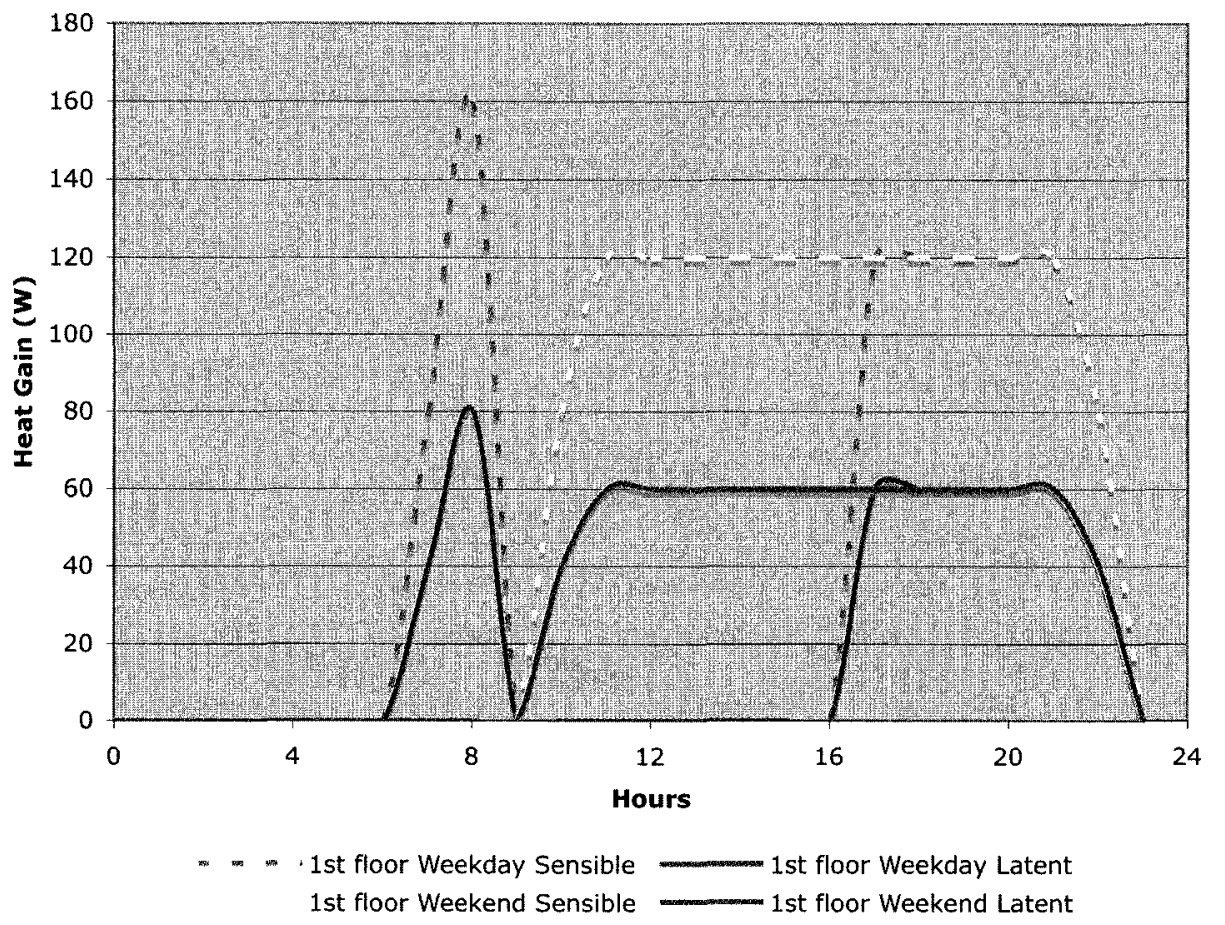

Figure B-2: Occupant driven gains for 1st floor of ESP-r model

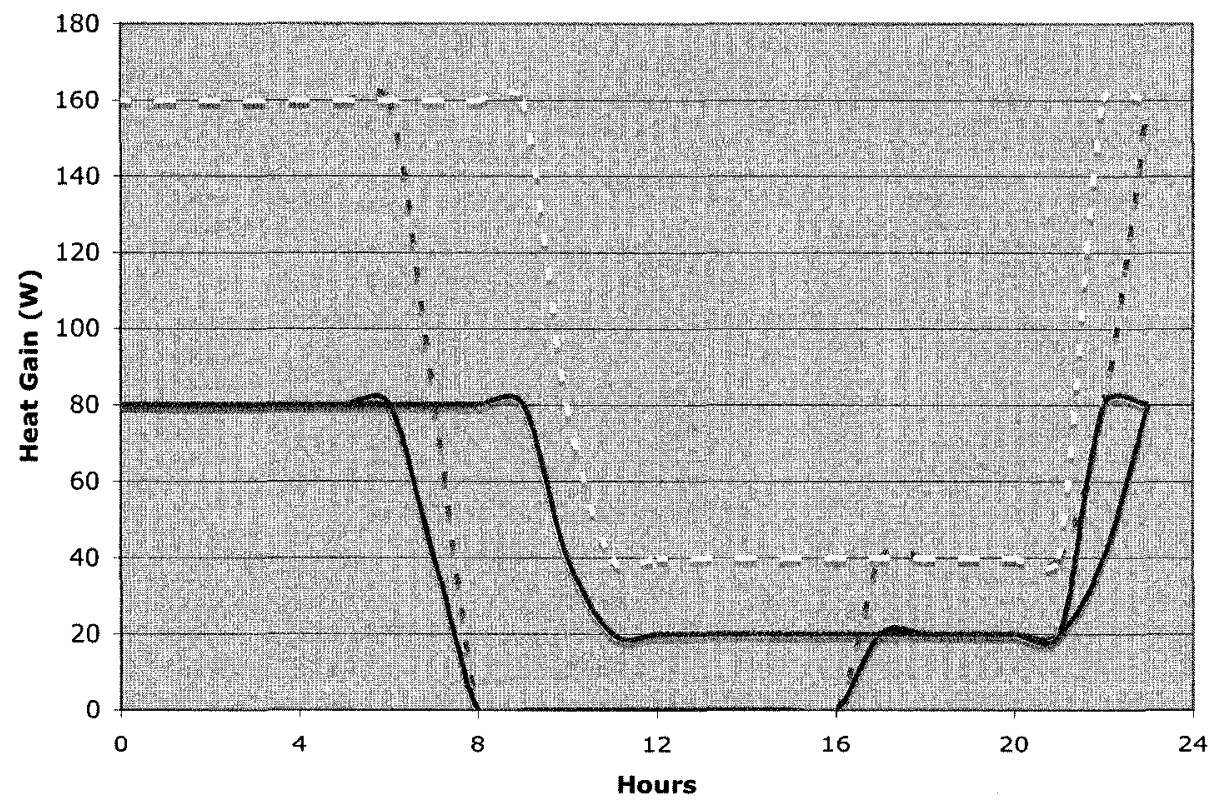

$\approx \ldots-2$ 2nd floor Weekday Sensible $\quad$ 2nd floor Weekday Latent 2nd floor Weekend Sensible — 2 nd floor Weekend Latent

Figure B-3: Occupant driven gains for 2nd floor of ESP-r model 


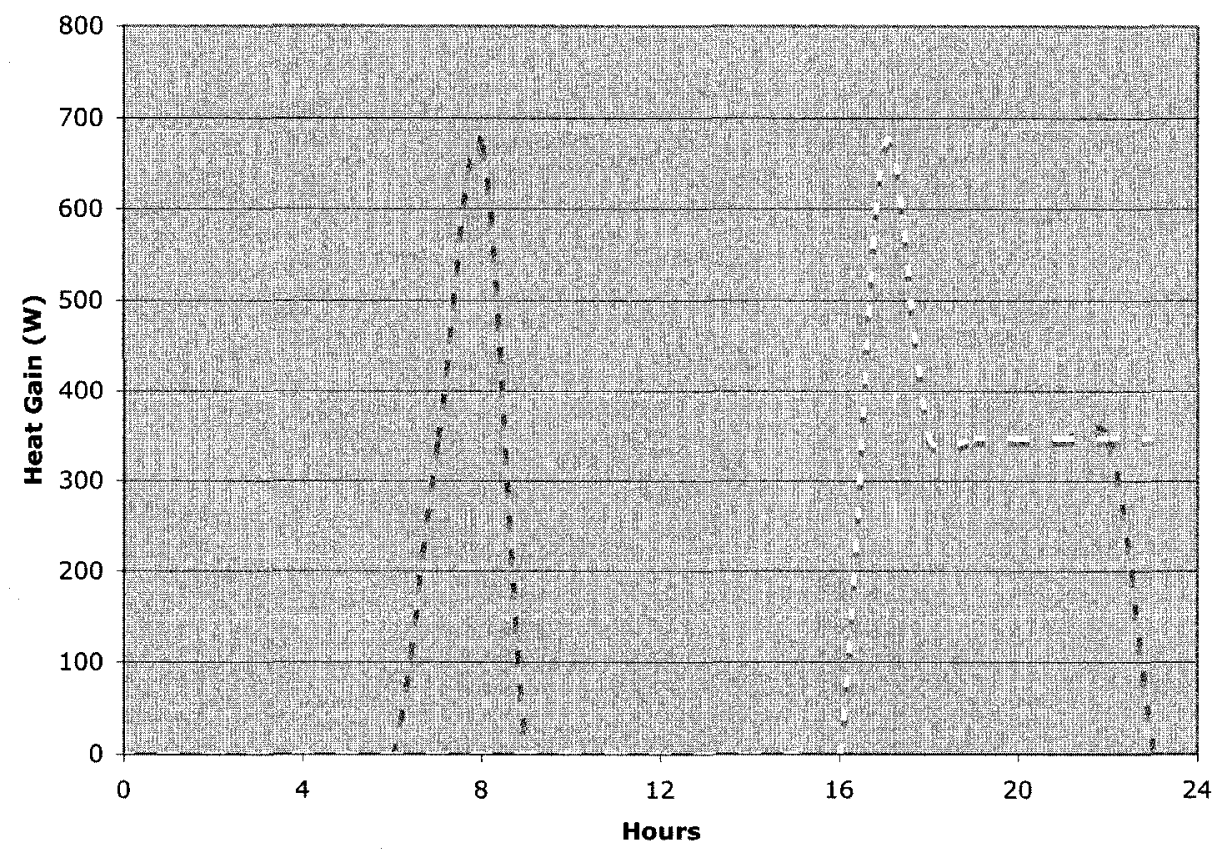

Figure B-4: Lighting gains for 1st floor of ESP-r model

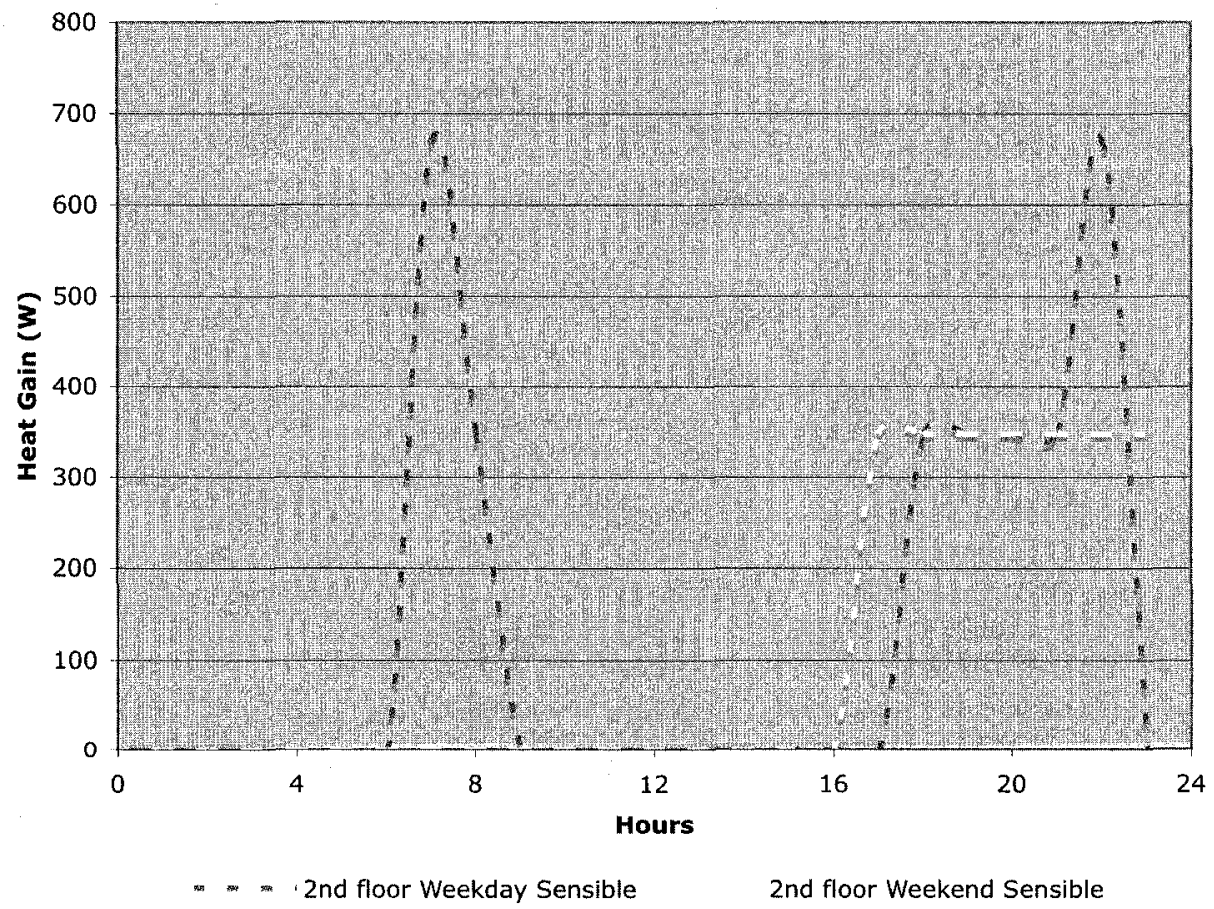

Figure B-5: Lighting gains for 2nd floor of ESP-r model 


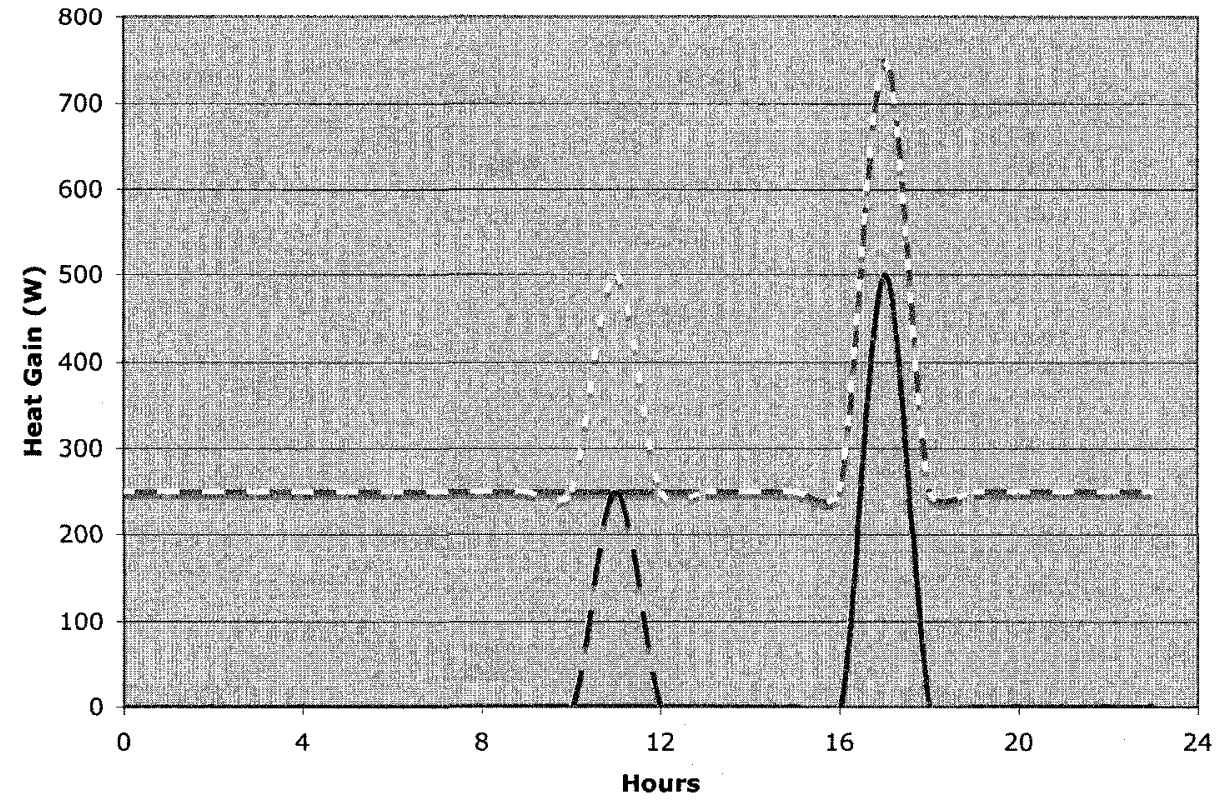

1st floor Weekday Sensible

Figure B-6: Equipment gains for 1st floor of ESP-r model

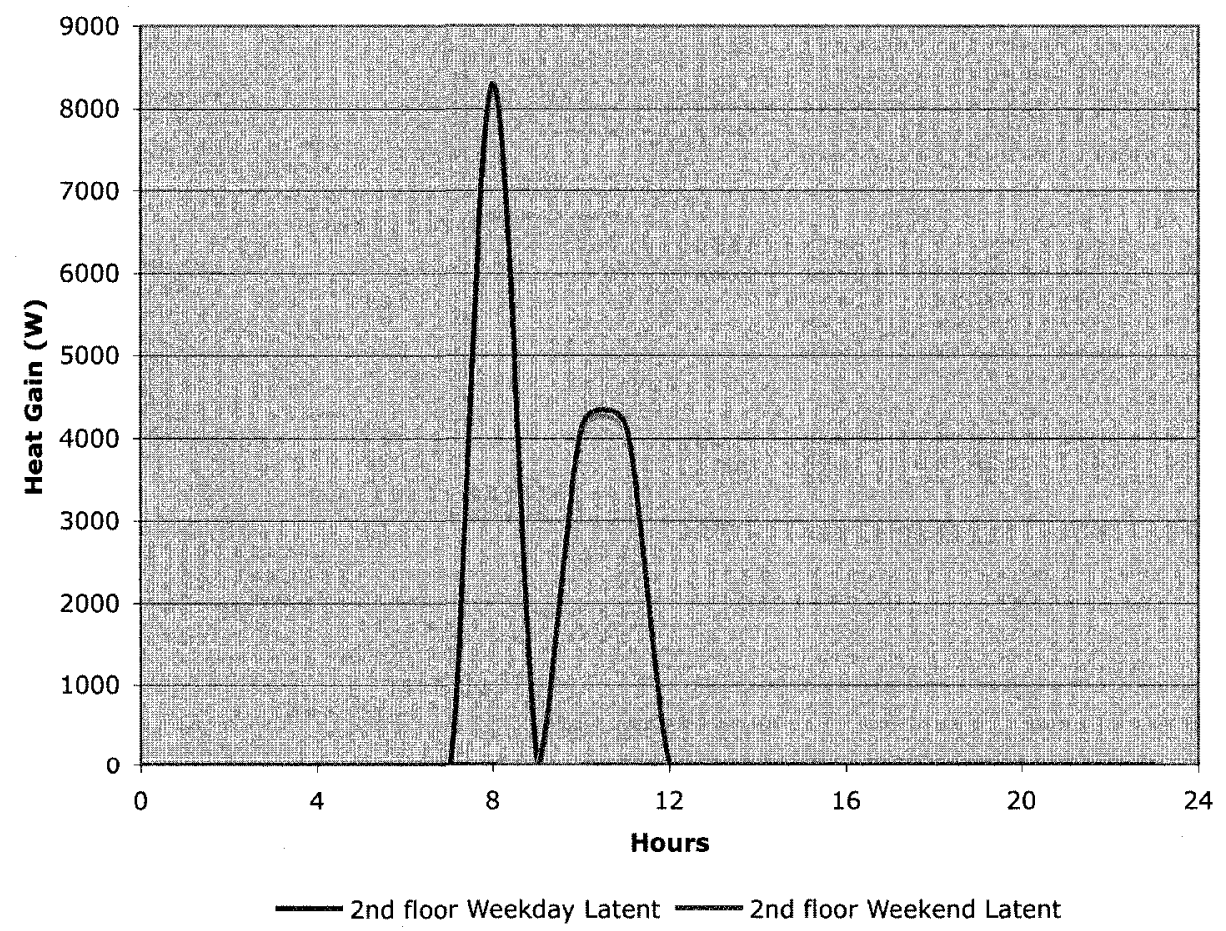

Figure B-7: Lighting gains for 2nd floor of ESP-r model 


\section{Appendix C \\ Garrett GT22 performance maps}

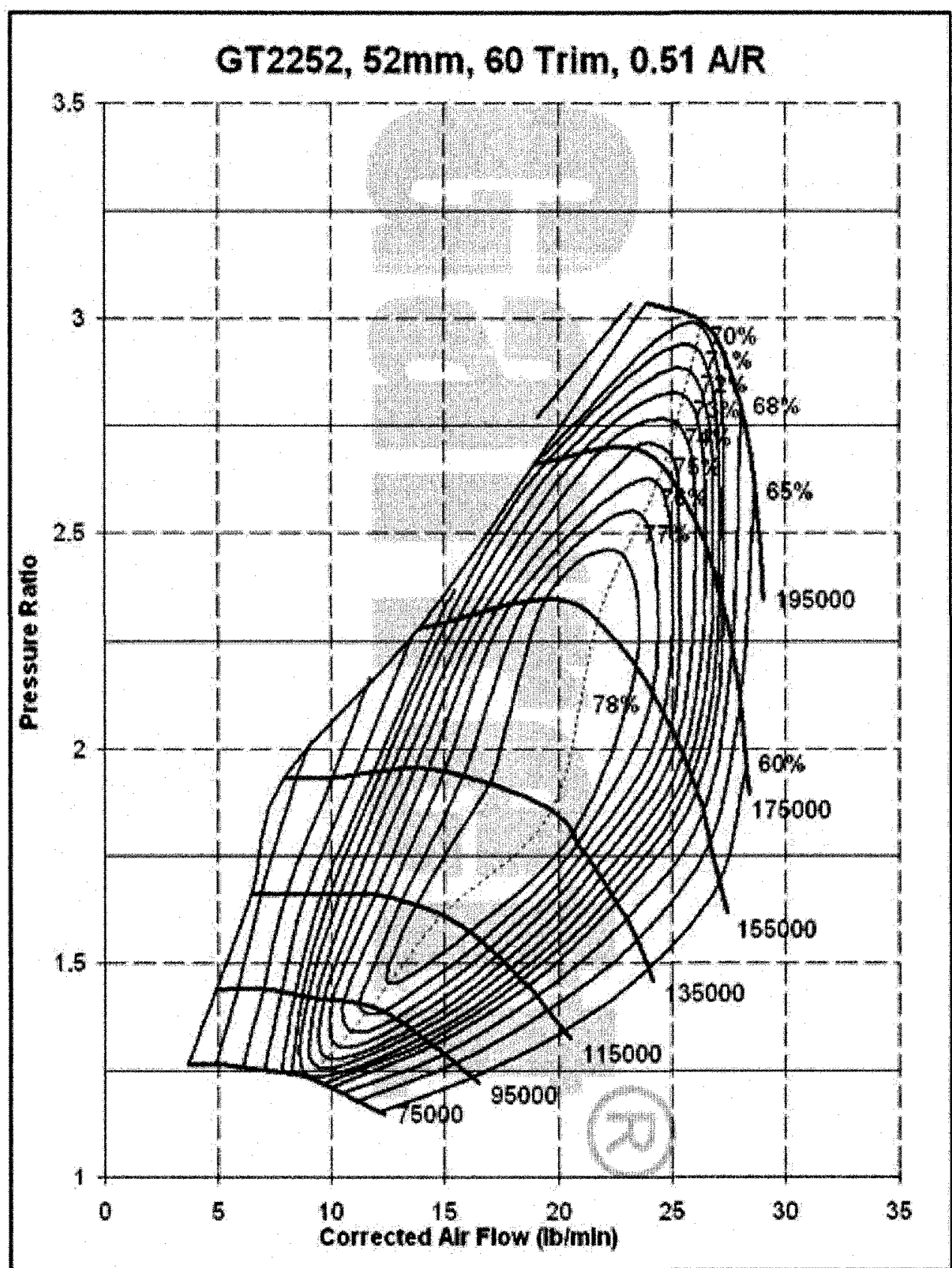

Figure C-1: Compressor map for the Garrett GT22 series turbocharger Downloaded from www.turbobygarrett.com on Dec. 22007 


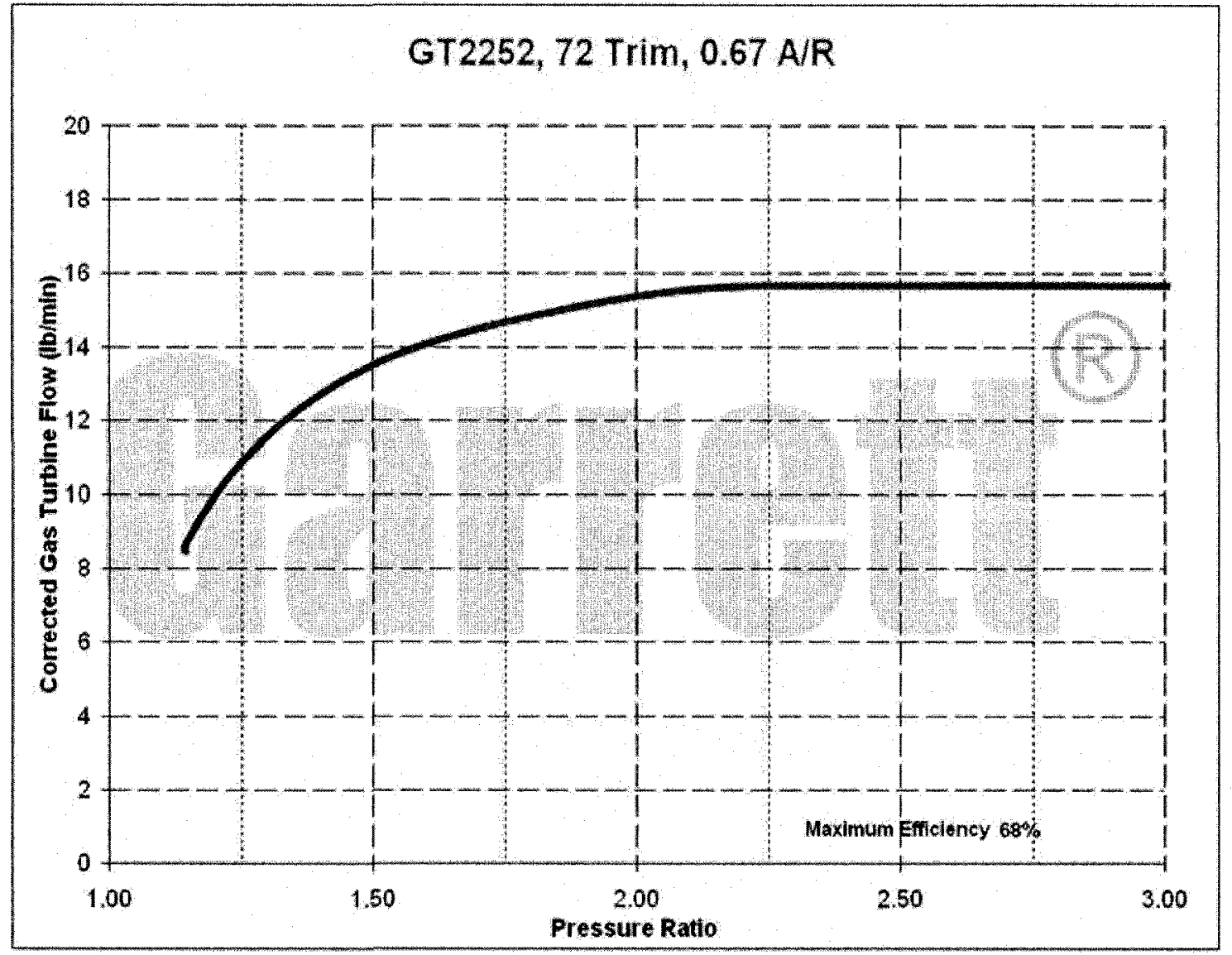

Figure C-2: Expander map for the Garrett GT22 series turbocharger Downloaded from www.turbobygarrett.com on Dec. 22007 


\section{Appendix D}

\section{Capstone microturbine standard maintenance schedule}

\section{C60 and C65 Gaseous Fuel Systems Scheduled Maintenance}

C60 and C65 gaseous fuel systems scheduled maintenance intervals apply to Model C60, C65, and ICHP High Pressure Natural Gas systems. Maintenance items and intervals for the various components of these systems are highlighted in the following table.

\begin{tabular}{|c|c|c|c|}
\hline $\begin{array}{l}\text { Maintenance } \\
\text { Interval }\end{array}$ & Component & $\begin{array}{l}\text { Maintenance } \\
\text { Action }\end{array}$ & Comments \\
\hline 24 months & UCB Battery & Replace & See Note 1 \\
\hline \multirow[t]{4}{*}{4,000 hours } & Engine Air Filter & Inspect & Replace if application requires - see Note 2 \\
\hline & Electronics Air Filter & Inspect & Clean if necessary - see Note 2 \\
\hline & $\begin{array}{l}\text { Fuel Filter Element } \\
\text { (External) }\end{array}$ & Inspect & $\begin{array}{l}\text { Replace if application requires - see Note } 2 \\
\text { (Not required for Gas Pack) }\end{array}$ \\
\hline & Fuel System & Leak Check & $\begin{array}{l}\text { Refer to "Gaseous Fuel Fittings and } \\
\text { Components" section below for } \\
\text { recommended procedure }\end{array}$ \\
\hline \multirow[t]{5}{*}{8,000 hours } & Engine Air Filter & Replace & \\
\hline & Electronics Air Filter & Clean & \\
\hline & $\begin{array}{l}\text { Fuel Filter Element } \\
\text { (External) }\end{array}$ & Replace & Not required for Gas Pack \\
\hline & Igniter & Replace & See Note 3 \\
\hline & ICHP Actuator & Replace & \\
\hline $\begin{array}{c}20,000 \text { hours } \\
\text { or } 3 \text { years }\end{array}$ & Battery Pack & Replace & $\begin{array}{l}\text { Refer to Battery Tech Ref }(410044) \text { for } \\
\text { expected life vs duty cycle, and "Battery } \\
\text { Maintenance During Storage" section below } \\
\text { for recharge intervals }\end{array}$ \\
\hline \multirow[t]{3}{*}{20,000 hours } & Injector Assemblies & Replace & \\
\hline & TET Thermocouple & Replace & \\
\hline & SPV & Replace & Replace with Woodward Valve Upgrade Kit \\
\hline \multirow[t]{2}{*}{40,000 hours } & $\begin{array}{c}\text { Electronic } \\
\text { Components: ECM, } \\
\text { LCM \& BCM Power } \\
\text { Boards, BCM \& ECM } \\
\text { Fan Filters, Fans, EMI } \\
\text { Filter, Frame PM } \\
\end{array}$ & Replace & Kits available for each major configuration \\
\hline & Engine & Replace & Use Reman or New Engine Replacement \\
\hline
\end{tabular}

Figure D-1: Excerpt from Capstone Turbines scheduled maintenance work instructions for the $60 \mathrm{kWe} \mathrm{C60}$ and $\mathrm{C65}$ models. Obtained via personal communication with Dan Lubell, chief turbomachinery engineer with Capstone Turbines 


\section{Appendix E Component Performance Validation}

\section{Accumulator}

To verify the results obtained from the accumulator model, experimental data was gathered from a simple accumulator apparatus illustrated in Figure E-1. The accumulator was charged from shop pressure at $90 \mathrm{psi}$, and then discharged to ambient through a $1 / 4$ " orifice.

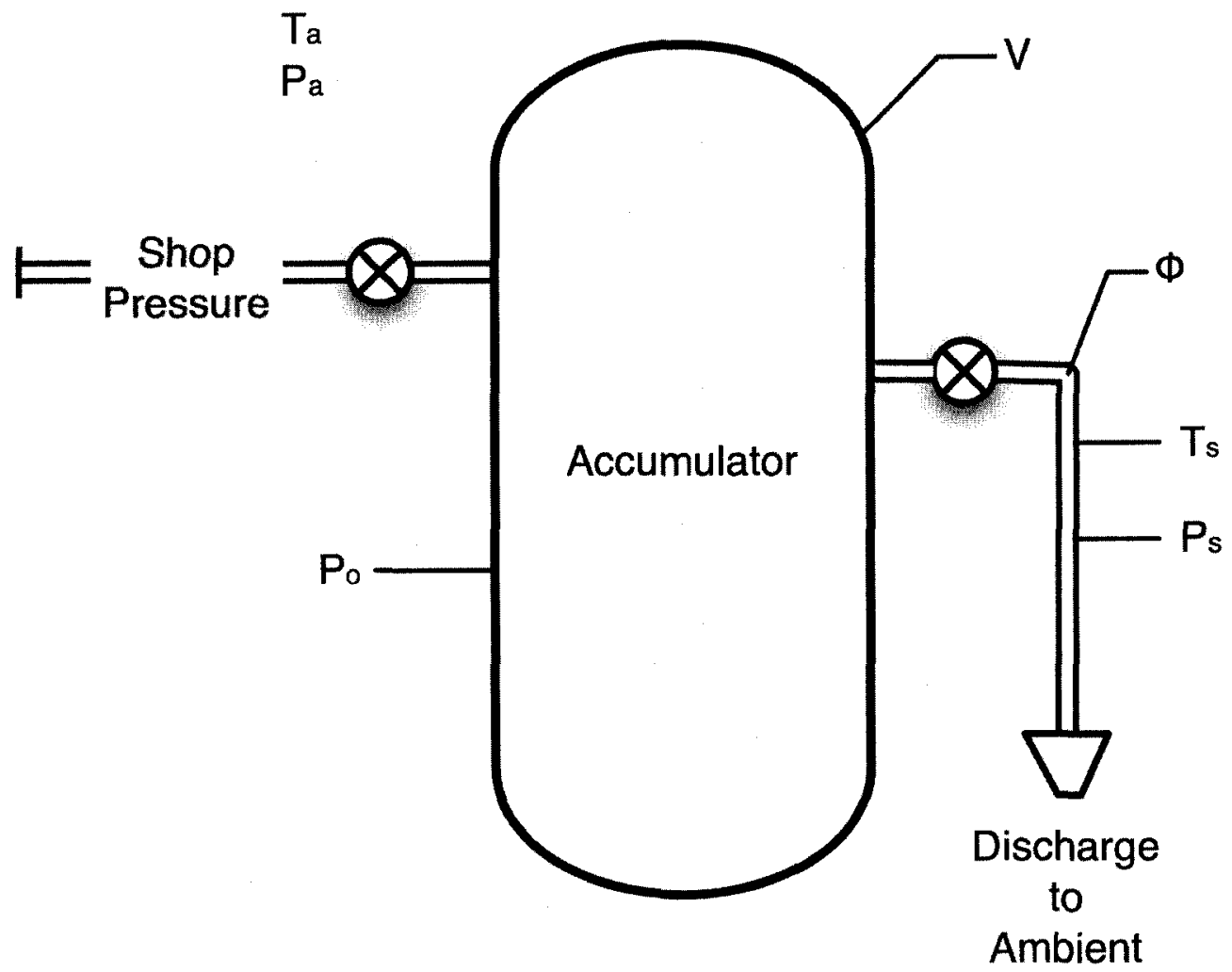

Figure E-1: Experimental accumulator apparatus

The accumulator model was modified to mirror the test apparatus: 
- no insulation was used

- ambient temperature was set at a constant $18^{\circ} \mathrm{C}$

- mass flow during discharge and charging of the test apparatus was calculated from temperature and pressure readings and then used as a mass flow vs. time profile for the accumulator model
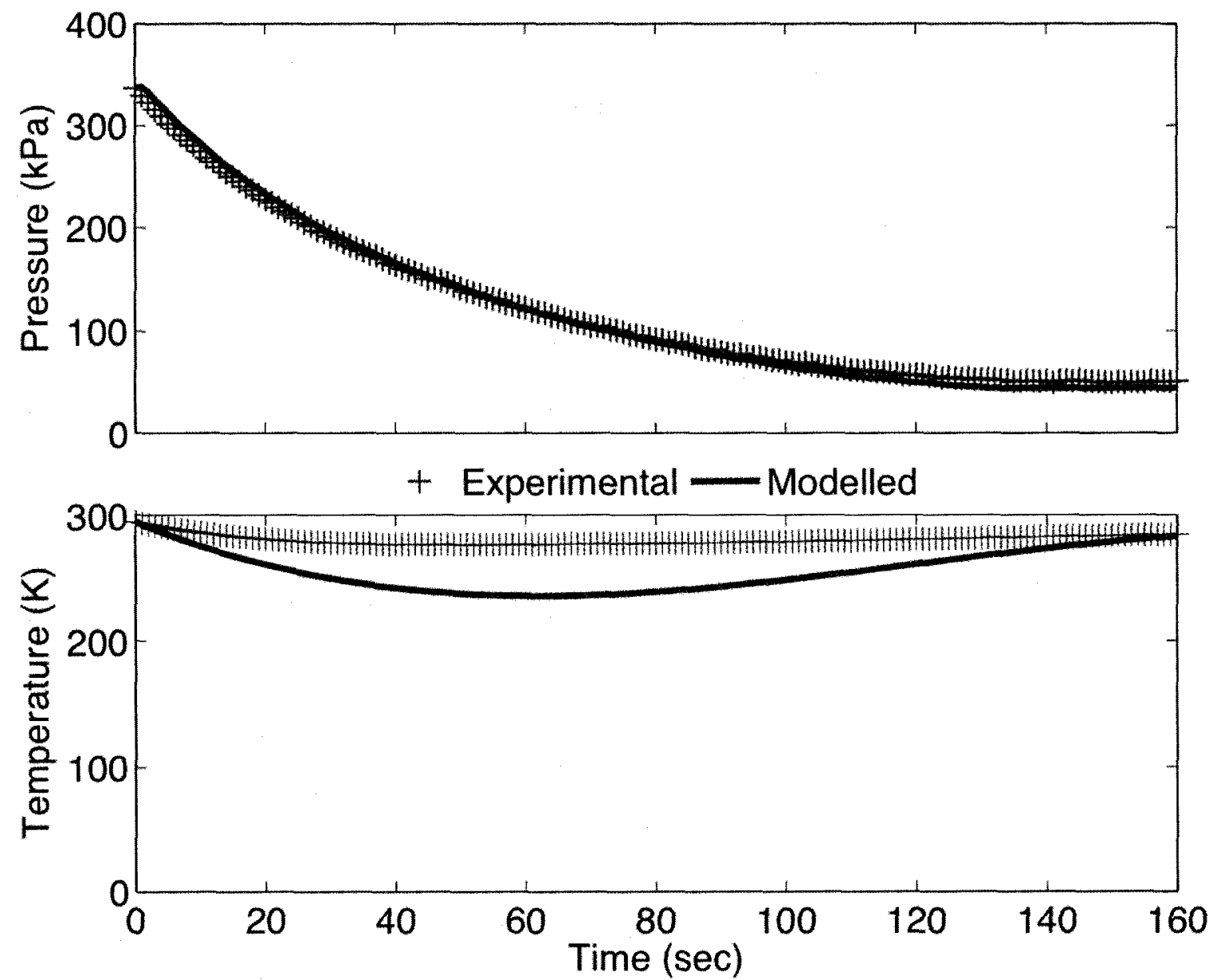

Figure E-2: Comparison of modelled accumulator $(n=1.2)$ and experimental results during discharge

Figure E-2 and Figure E-3 show good agreement for pressure. Note the different values of the polytropic coefficient $n$ used for discharging and charging. It was 
found that assuming isothermal $(n=1)$ compression for the charging example was valid as the process was completed over a long time. This assumption was not valid for discharging, as the time for complete discharge was about half of the charging period.
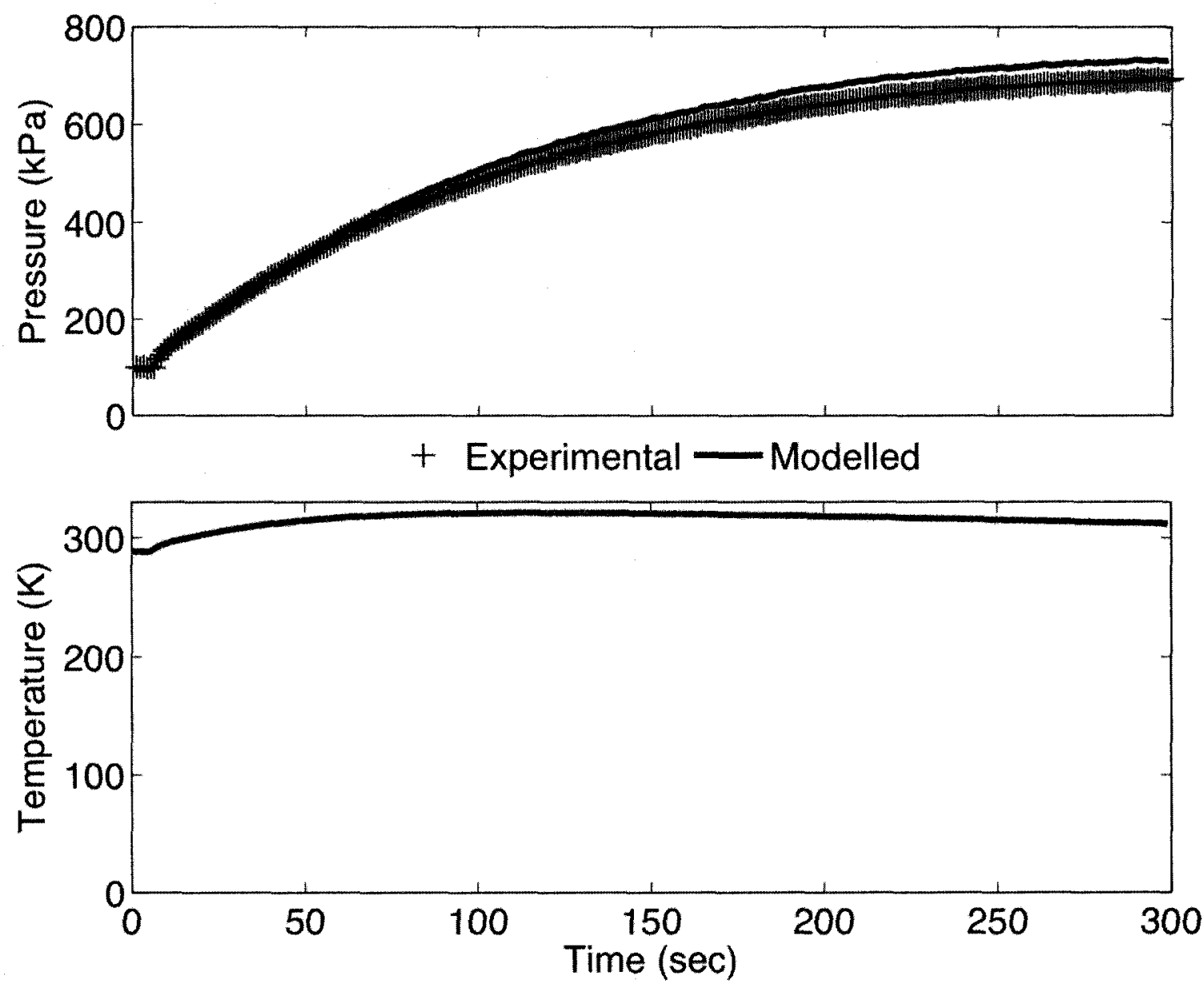

Figure E-3: Comparison of modelled accumulator $(n=1)$ and experimental results while charging.

Conversely, assuming a completely isentropic process $(n=1.4)$ did not produce 
good agreement either. These results illustrate the need to tailor the polytropic coefficient depending on rate of discharge or charging. The simulation uses a polytropic exponent of 1.4 as the charging and discharge period is most often less than 100 seconds; at peak electrical demand the accumulator can discharge in less than 30 seconds.
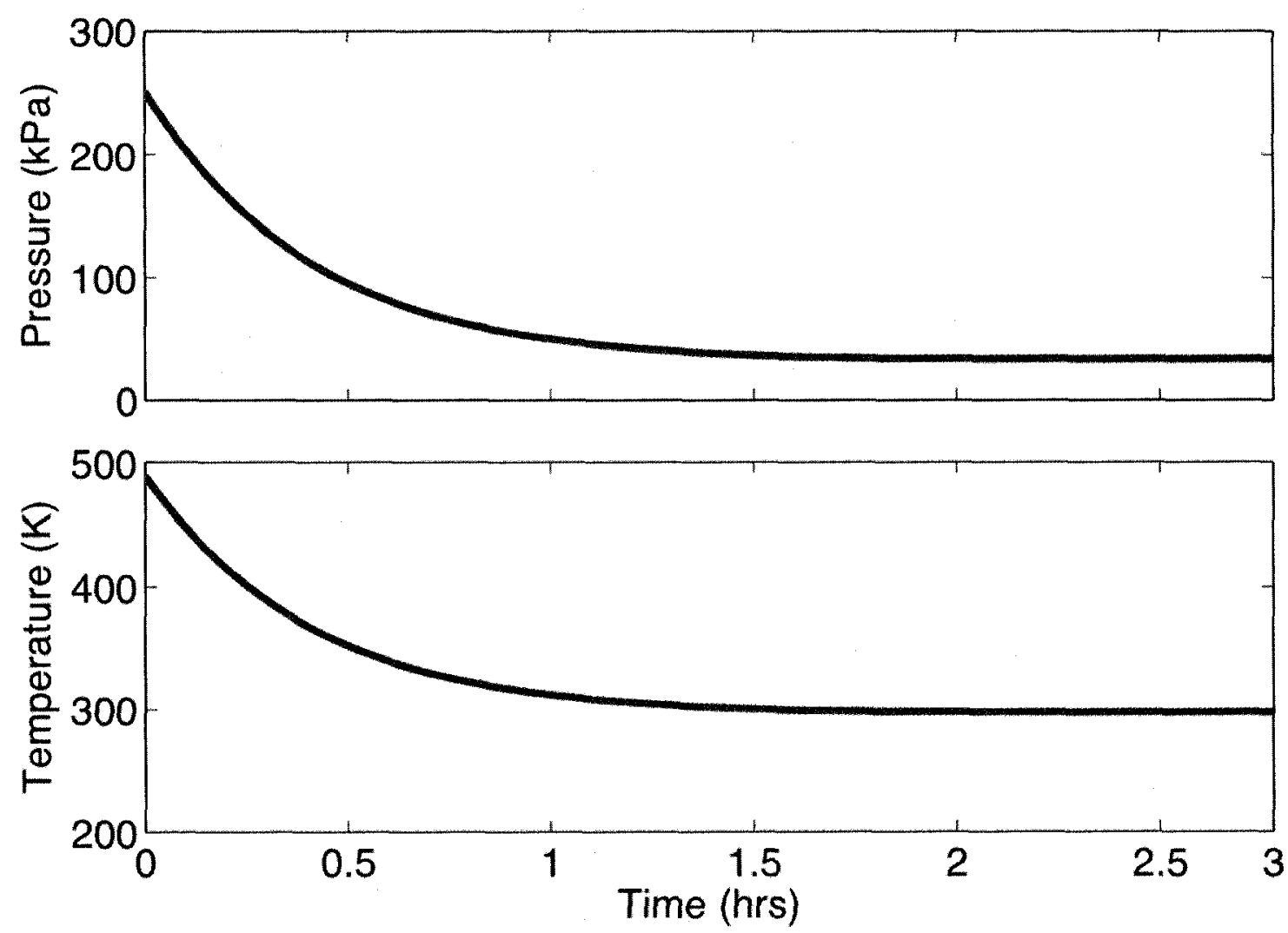

Figure E-4: The effect of heat transfer on modelled accumulator behaviour with zero flow. Exterior insulation is glass fibre $(0.038 \mathrm{~W} / \mathrm{mK})$ and is $10 \mathrm{~cm}$ thick

Good agreement was not achieved for temperature. This is believed to be a 
combination of two factors. Heat transfer calculations for the model are for a horizontal cylinder and are based upon empirical correlations for convection coefficients that are a best guess; actual convection coefficients are most likely much higher. Flow temperature is also recorded at the end of a $1 \mathrm{~m}$ long, 0.0508 $m$ (2 in.) diameter pipe rather than in the accumulator (as seen in Figure $E-1)$. Residence time for flow in the pipe was on average about 1 second for the blowdown period. Combined with a large wetted area, this makes for a high rate of heat transfer between the accumulator and the temperature measuring point.

As the disagreement in temperature is believed to be a result of heat transfer to ambient not accounted for in the model, it is anticipated that if the test apparatus was well insulated this discrepancy would be negligible. Mass is conserved during discharge, as the final temperature and pressure readings agree. Temperature data was not measured during charging, as there was no provision to measure the accumulator temperature; measuring pipe flow temperature did not provide any information as there was no flow in the pipe during charging. Therefore there is no comparison available for accumulator temperature during charging.

Figure E-4 is an example of the effect of heat transfer on the accumulator with zero flow. The accumulator was charged at a high temperature and then allowed 
to remain static, with no discharge or charging flows to observe the temperature and pressure drop over time. Ambient air was set at $22^{\circ} \mathrm{C}$. The accumulator took roughly an hour to equalize its temperature with ambient. This result shows that heat transfer has a negligible effect on IBC performance if the accumulator is discharged and charged frequently. During low load periods, there is greater potential for heat loss or gain to occur.

\section{Microturbine}

The trigeneration system under study is complex, involving off-design component matching, over a wide range of operating conditions. To have a measure of confidence in the results obtained from the simulation, verification of the model is required. A good place to start is by looking at IFGT performance at design.

\section{Design point performance}

As the trigeneration model is based upon component maps generated from GASTURB $^{\text {TM }}$, external validation is required in addition to using GASTURB $^{\text {TM }}$ to validate in-house model performance. A team from the Lappeenranta University of Technology has designed an IFGT CHP microturbine system fueled by biomass (wood, corn, etc..) for a medium sized commercial application as shown in Figure E-5; this system will be referred to as the bio-IFGT system. The bioIFGT system differs in how the heat load is provided and in the fuel used, however the heat exchanger configuration is similar to what is used for Mode 1. 


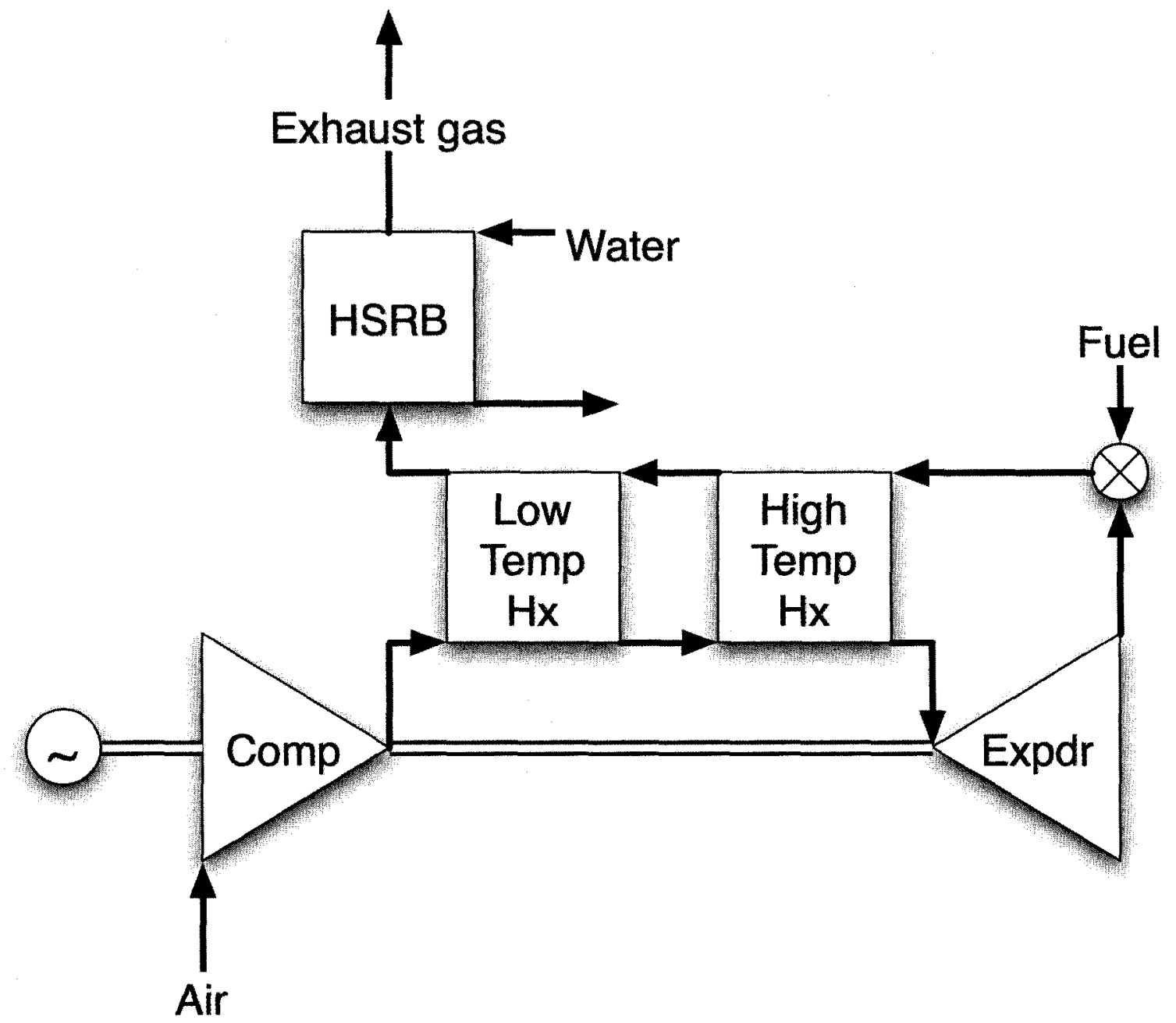

Figure E-5: Schematic of the bio-IFGT system fuelled by low heating value bio-fuels [E.4]

The presence of a HSRB and use of bio-fuels does not allow a fair comparison of total efficiency between the two systems, however these differences have negligible impact on power output given the similar heat exchanger configuration. Table E-1 compares design performance of the trigeneration model with the output from GASTURB ${ }^{\mathrm{TM}}$ and the performance of the bio-IFGT configuration. In order to make a fair comparison, parameters in the GASTURB ${ }^{\mathrm{TM}}$ and 
trigeneration models were modified to match those used in the bio-IFGT simulation. They are as follows:

- $\eta_{c}=0.84$

- $\eta_{\mathrm{e}}=0.83$

- $\Delta \mathrm{P}_{\text {exhaust }}=9$ percent

- $\Delta \mathrm{P}_{\mathrm{hx}}=4$ percent

- $E I T=1223 \mathrm{~K}$

- $\mathrm{LHV}=10.459 \mathrm{MJ} / \mathrm{kg}$

- $\eta_{\mathrm{m}}=0.98$

- $\dot{W}=80 \mathrm{kWe}$

The results, tabulated in Table E-1, show good agreement for all three simulations. GASTURB ${ }^{\text {TM }}$ does not have an option to model the burner section of a gas turbine as a series of heat exchangers. The effect is similar to specifying heat exchangers with 100 percent effectiveness. As a result, the GASTURB ${ }^{\text {TM }}$ simulation predicted a high thermal efficiency. Even though the thermal efficiencies do not match, it is expected the trigen system should have a lower predicted value. With an HEN effectiveness of unity, the thermal efficiency of the trigen system increases, shown in Table E-1. The bio-IFGT model used an inhouse heat exchanger heat transfer model that made use of the log mean 
temperature difference method to more accurately predict HEN performance. Use of effectiveness parameters by the in-house model and the GASTURB ${ }^{\text {TM }}$ simulation is a simplification that introduces error. The discrepancy in thermal efficiency between the bio-IFGT system and the trigen system is inferred to be due to the different methods of modelling heat exchanger heat transfer.

Table E-1: Comparison of design point performance of Mode 1 at standard atmospheric conditions for several similar microturbine IFGT cycles

\begin{tabular}{|c|c|c|c|c|}
\hline & $\begin{array}{c}\text { Specific } \\
\text { Power Output } \\
(\mathrm{kJ} / \mathrm{kg})\end{array}$ & $\begin{array}{l}\text { Thermal } \\
\text { Efficiency } \\
\text { (percent) }\end{array}$ & PR & TIT (K) \\
\hline $\begin{array}{c}\text { Trigen } \\
\text { system }\end{array}$ & 143.4 & 19.5 & 4 & 1223 \\
\hline $\begin{array}{c}\text { Trigen } \\
\text { system } \\
\varepsilon=1\end{array}$ & 143.2 & 19.9 & 4 & 1223 \\
\hline $\begin{array}{l}\text { GASTURB' } \\
\text { single spool }\end{array}$ & 146.8 & 21.3 & 4 & 1223 \\
\hline $\begin{array}{c}\text { Bio-IFGT } \\
\text { [E.4] }\end{array}$ & 145.0 & 17.8 & 4 & 1223 \\
\hline
\end{tabular}

Modelling Mode 2 in GASTURB ${ }^{\text {TM }}$ differed from Mode 1 in that combustion flow is pre-heated by expander exhaust. This effect is approximated in GASTURB ${ }^{\mathrm{TM}}$ with the use of a recuperator that exchanges heat between expander exhaust and compressor discharge flow. \#1 and \#2 Hxs are treated as 'black boxes' in the same manner as was done for Mode 1 . This is accomplished by specifying a TIT and combustor pressure loss that is equal to what the HEN delivers in the 
mathematical model. Again the CHCP system and GASTURB ${ }^{\mathrm{TM}}$ simulations were in agreement to within about 2 percent on key performance parameters as shown in Table E-2. The IFGT-Rec-Rec (IFGT double recuperated) system, shown in Figure E-6, shares the same HEN design as the trigen system but operates at a lower TIT and PR.

Table E-2: Comparison of design point performance of Mode 2 at standard atmospheric conditions for several similar microturbine IFGT cycles

\begin{tabular}{|c|c|c|c|c|}
\hline & $\begin{array}{c}\text { Specific } \\
\text { Power Output } \\
(\mathrm{kJ} / \mathrm{kg})\end{array}$ & $\begin{array}{l}\text { Electric } \\
\text { Efficiency } \\
\text { (percent) }\end{array}$ & PR & TIT (K) \\
\hline Trigen system & 113.0 & 30.6 & 4 & 1163.4 \\
\hline $\begin{array}{l}\text { GASTURB } \\
\text { Single spool } \\
\text { recuperated }\end{array}$ & 111.6 & 29.9 & 4 & 1163.9 \\
\hline $\begin{array}{c}\text { IFGT-Rec-Rec } \\
\text { [E.1] }\end{array}$ & 94.3 & 22.0 & 3 & 1150 \\
\hline $\begin{array}{c}\text { Ingersoll-Rand } \\
\text { PowerWorks } \\
250 \text { [E.5] }\end{array}$ & 135.9 & 32 & 4.1 & 1200 \\
\hline $\begin{array}{c}\text { Capstone C30 } \\
\text { [E.5] }\end{array}$ & 96.8 & 26 & 3.5 & 1113 \\
\hline
\end{tabular}

It is therefore expected that the efficiency and specific power is lower than the trigen system. The two other systems included in Table E-2 are commercially available microturbine CHP units. While no system described in Table E-2 matches CHCP system performance (except for GASTURB'M), the trend of low PR and low TIT corresponding to lower efficiency and specific power output (or 
vice versa) is consistent with the results obtained from the CHCP system model. For example, the Ingersoll-Rand package has a slightly higher TIT and PR when compared to the CHCP system, and has a corresponding slight increase in specific power and efficiency.

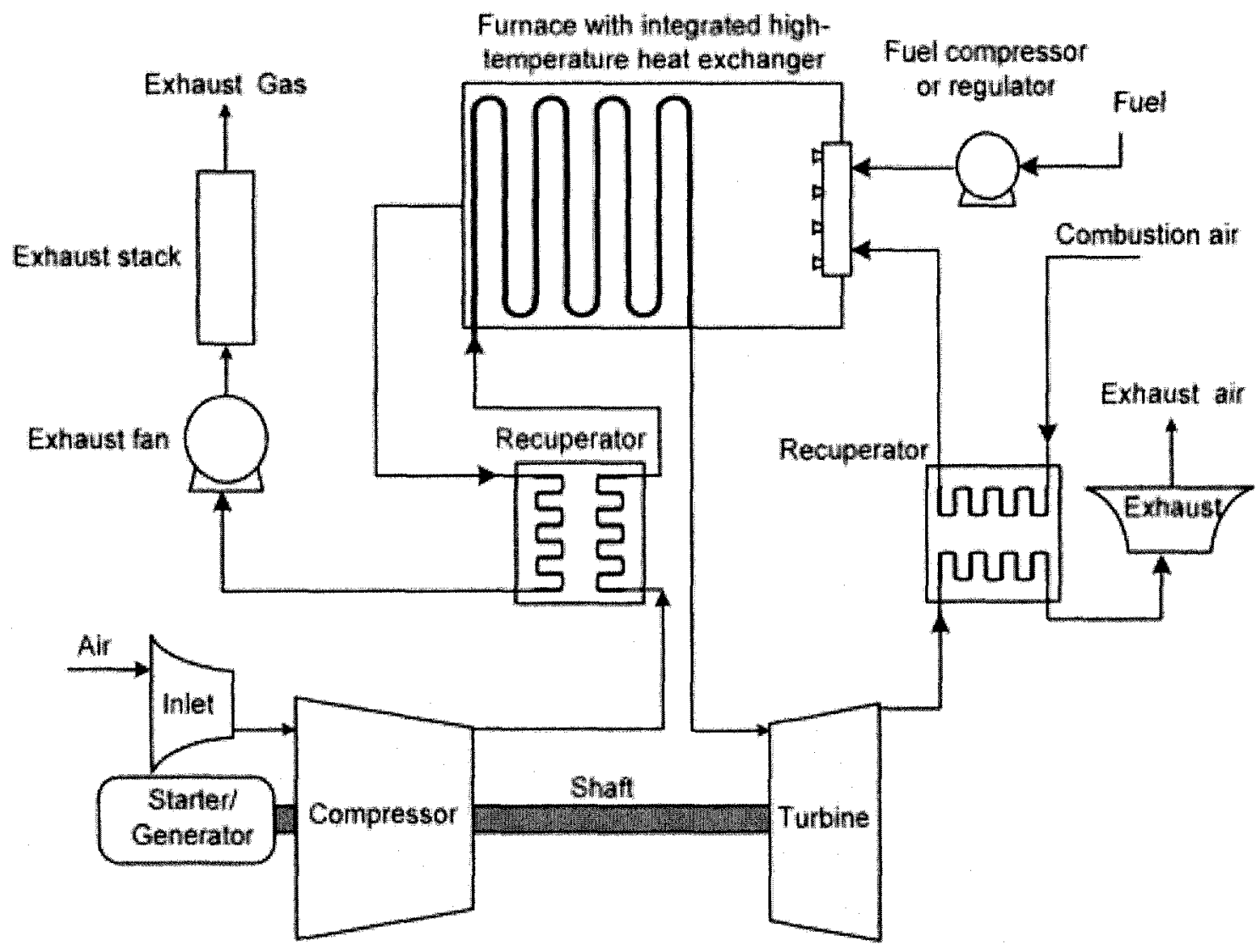

Figure E-6: Schematic of the IFGT-Rec-Rec system

\section{Off-design performance}

Microturbine performance was compared against output from GASTURB ${ }^{\mathrm{TM}}$ for all 
possible outside air temperatures, and for power settings that were varied from maximum HEN temperature (maximum power) to synchronous idle along a line of constant speed. Good agreement was obtained throughout the operating envelopes for both Mode 1 and 2, as shown in Figure E-7 and Figure E-8.
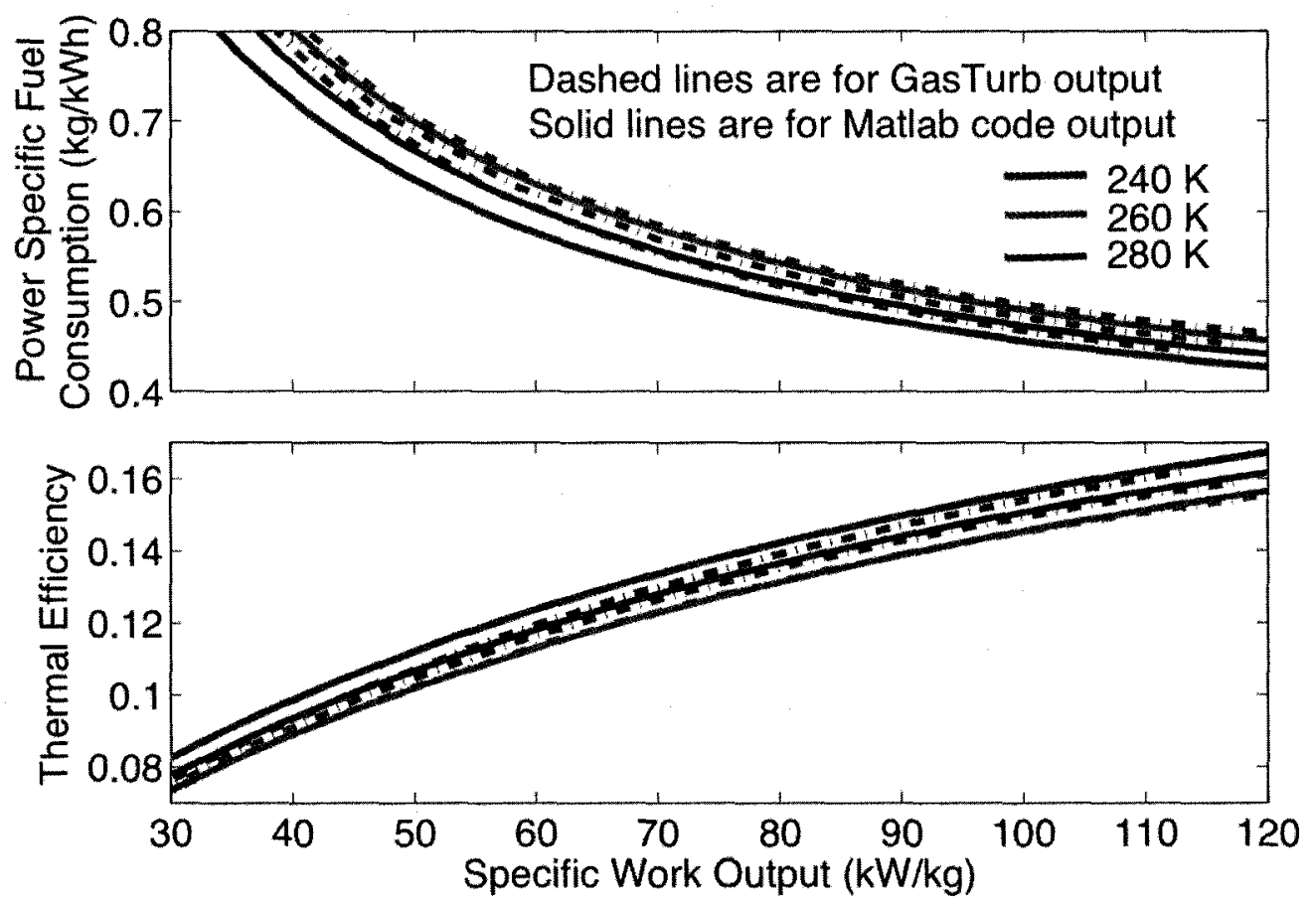

Figure E-7: Comparison of output from GASTURB ${ }^{\text {TM }}$ and the in-house model for Mode 1 for various ambient temperatures 


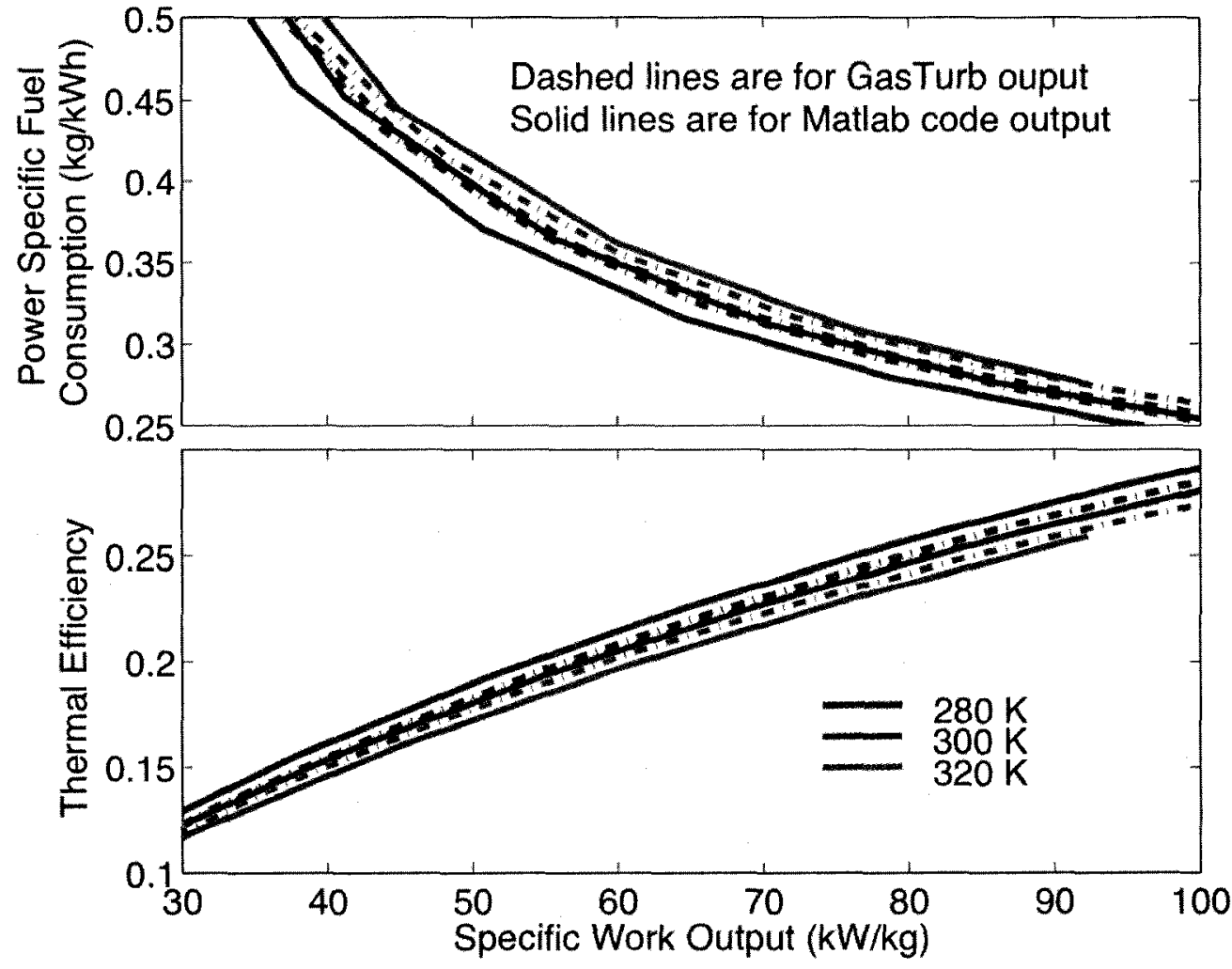

Figure E-8: Comparison of output from GASTURB ${ }^{\text {TM }}$ and the in-house model in Mode 2 for various ambient temperatures

\section{Secondary compressor}

Performance throughout the full range of possible flow rates and delivery pressures for the secondary compressor was modelled using actual performance data from a commercially available compressor. Flow and power versus RPM charts from the Aerzen Maschinenfabrik corporation's VMXa037R screw compressor, shown in Figure E-9 and Figure E-10, were digitized then used to create functions relating mass flow and pressure rise to isentropic efficiency. 


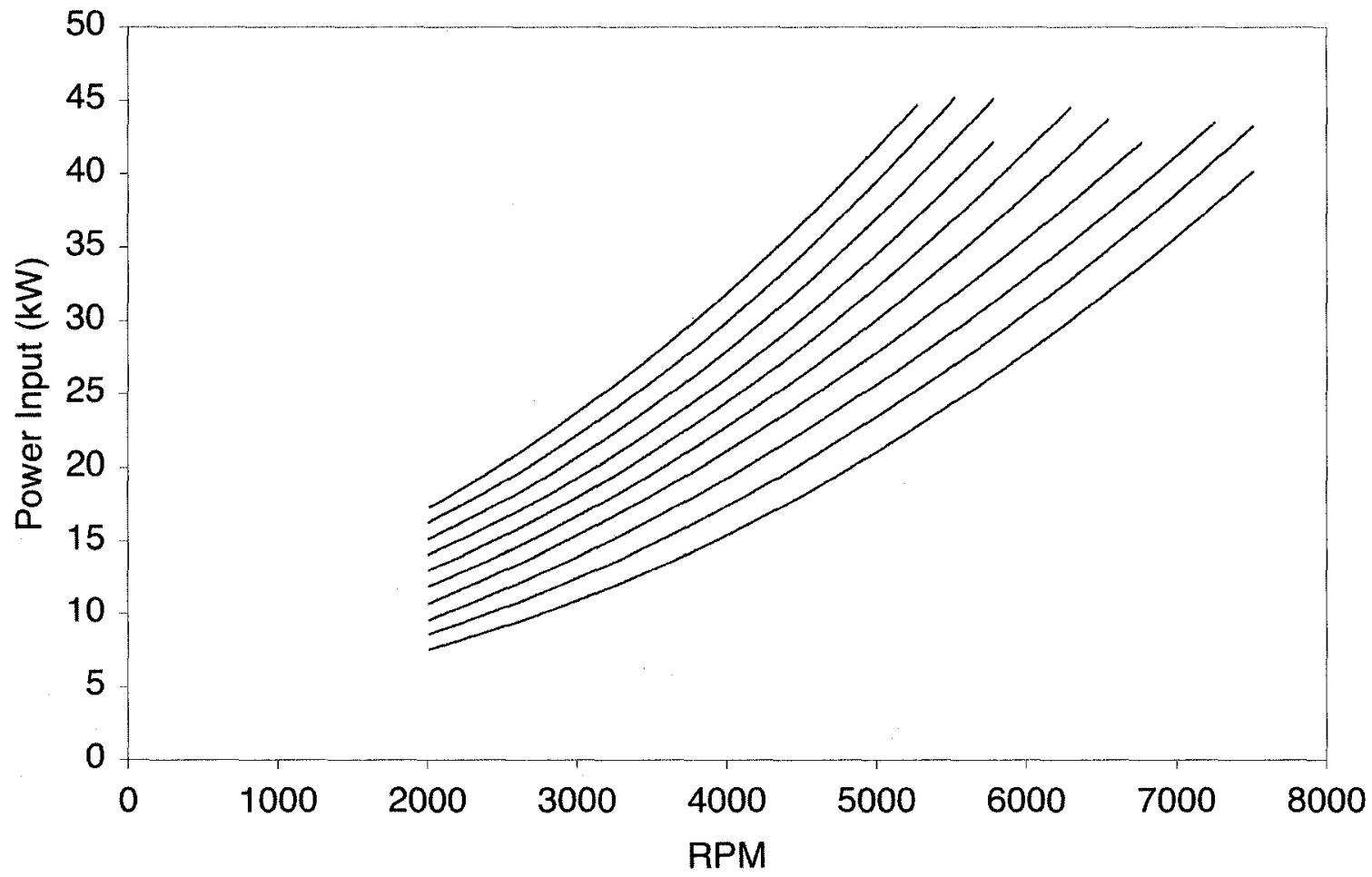

Figure E-9: Power as a function of RPM for the VMXa037R screw compressor at ISO standard atmosphere, digitized from sample maps [E.1].

The power consumption shown in Figure E-9 takes into account the efficiency of the driving electric motor and any mechanical efficiency associated with the compressor drivetrain. The efficiency calculated from the charts is therefore not a true isentropic efficiency, as it incorporates the motor efficiency as well. This is actually preferable for ease of integration with the simulation, as the actual power consumption of the compressor motor is required rather than the power input to the compressor. 


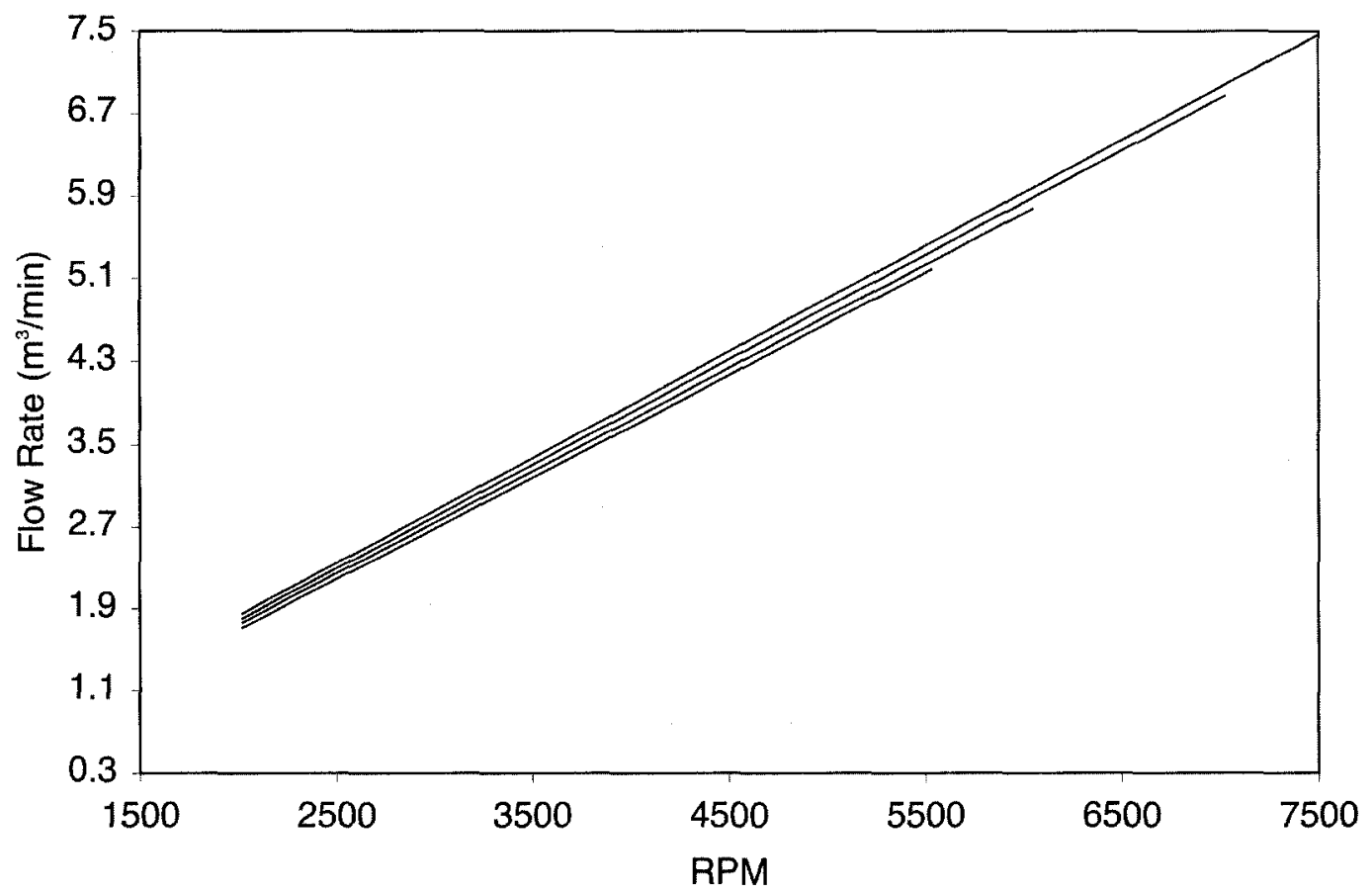

Figure E-10: Flow rate as a function of RPM for the VMXa037R screw compressor at ISO standard atmosphere, digitized from sample maps [E.1].

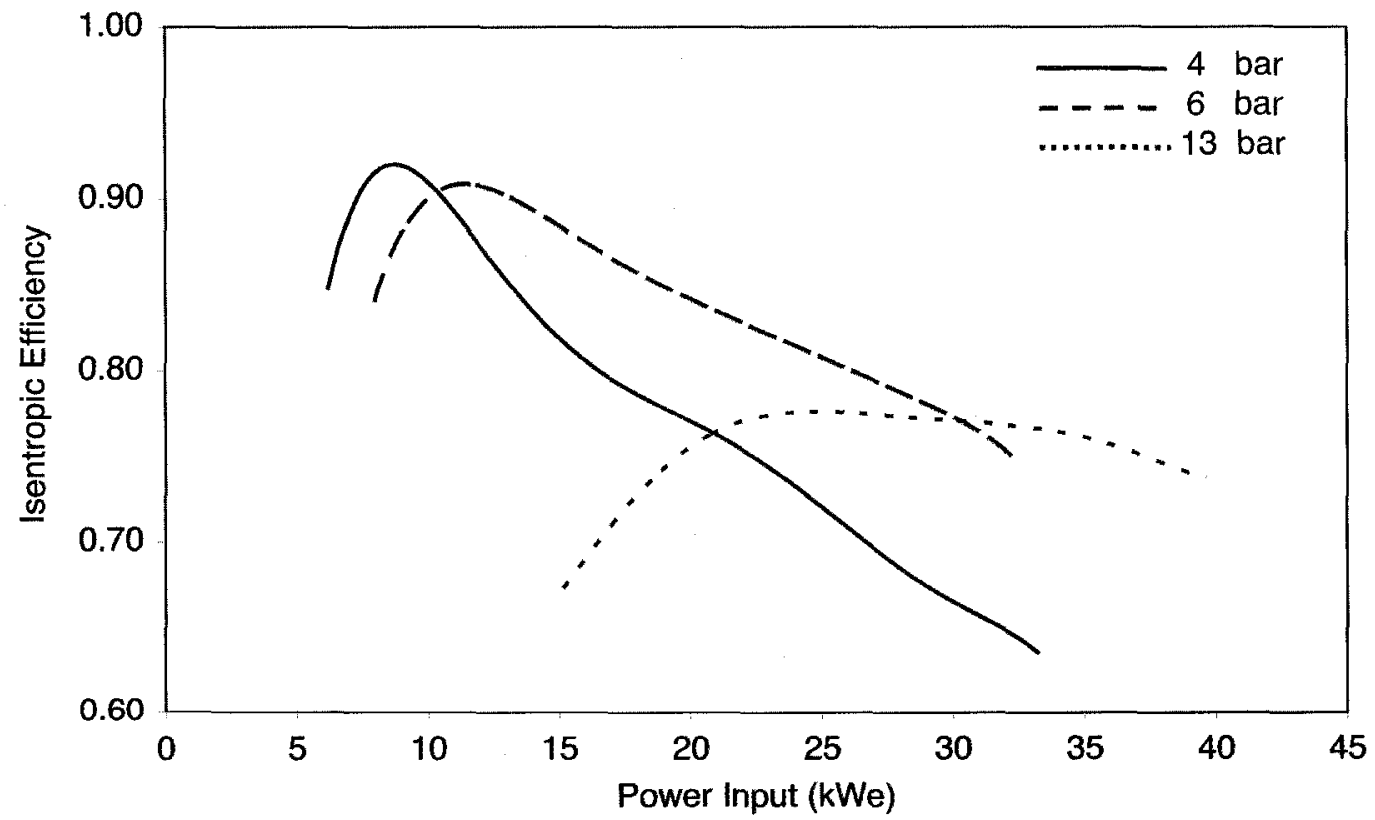

Figure E-11: Isentropic efficiency curves for lines of constant pressure rise for the VMXa037R compressor, calculated from Figure E-9 and Figure E-10. 


\section{Appendix F Ejector cooling}

In an ejector cooling system, as shown in Figure F-1, refrigerant pressure and temperature is increased through heat addition provided by waste exhaust from the CHP cycle. The vapourized refrigerant then flows into a convergent-divergent ejector where liquid refrigerant is entrained into the suction area through the secondary entrance, shown in Figure F-2.

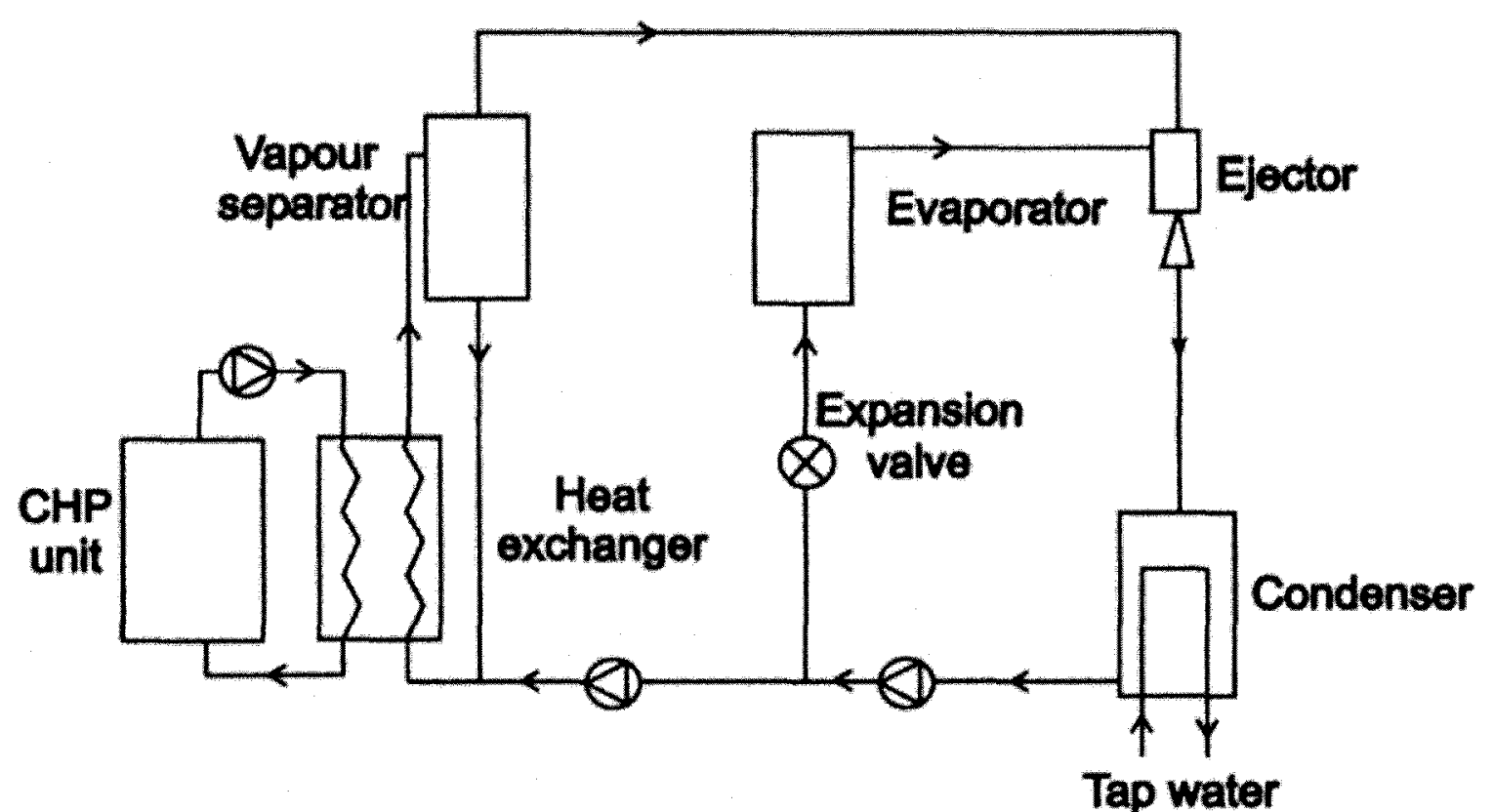

Figure F-1: Schematic of an ejector cooling cycle as part of a $\mathrm{CHCP}$ system [2.12].

The vapour and liquid refrigerant mix in the constant-area throat section, and 
then experience an increase in pressure and reduction in temperature associated with transition through a shock as the flow passes into the diffuser. The refrigerant then enters the condenser where it is returned to a liquid state. Cooling load is provided by high-pressure refrigerant passing through the evaporator.

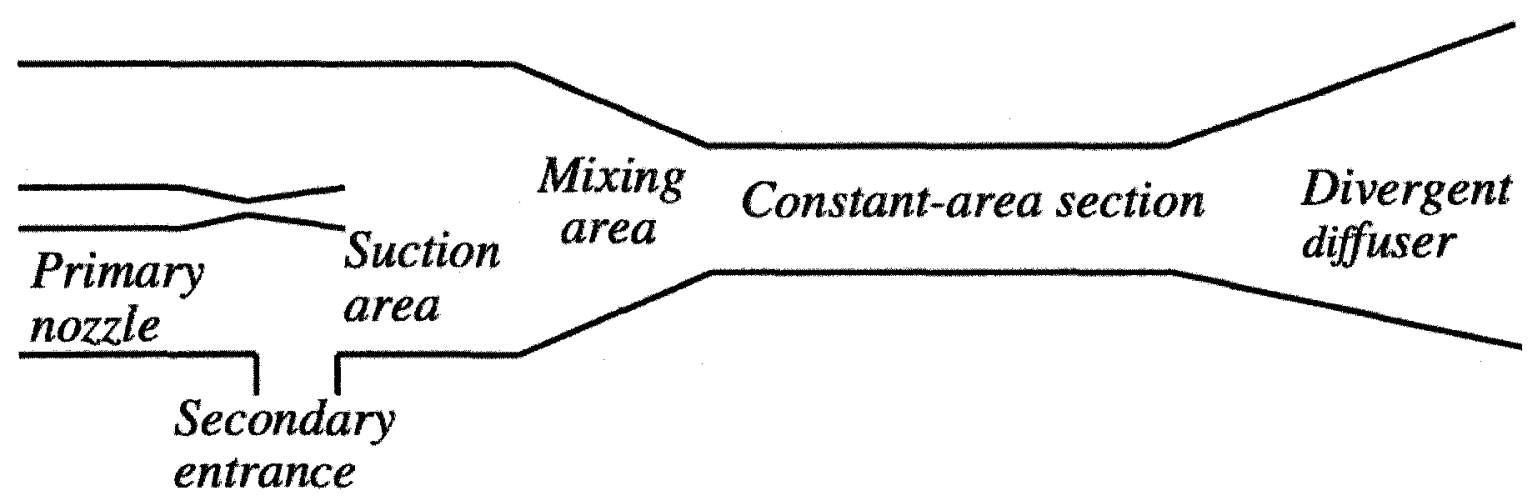

Figure F-2: Cross-section of an ejector [2.12]. 